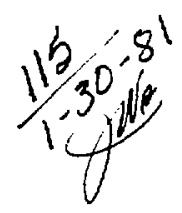

(1)

$$
\begin{aligned}
& D .2243 \\
& R-1563
\end{aligned}
$$

\title{
Mirror Fusion Test Facility magnet system- Final design report
}

C. D. Henning

A. J. Hodges

J. H. VanSant

E. N. Dalder

R. E. Hinkle
J. A. Horvath

R. M. Scanlan

D. W. Shimer

R. W. Baldi

R. E. Tatro

September 3, 1980

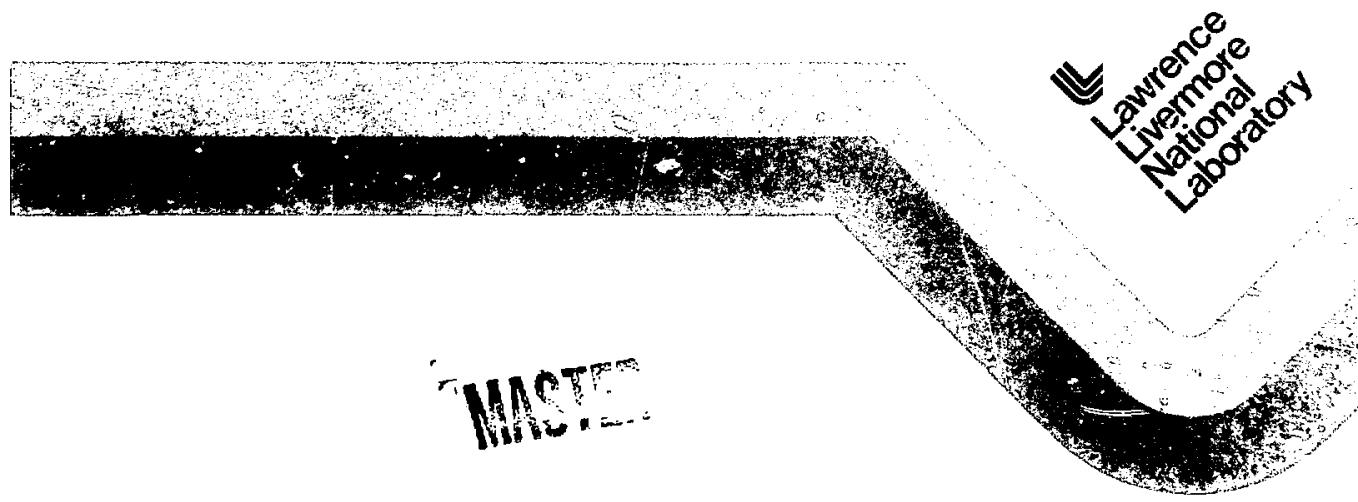




\section{Mirror Fusion Test Facility magnet system- Final design report}

C. D. Henning

A. J. Hodges

J. H. VanSant

E. N. Dalder

R. E. Hinkle
J. A. Horvath

R. M. Scanlan

D. W. Shimer

R. W. Baldi

R. E. Tatro

Manuscript date: September 3, 1980

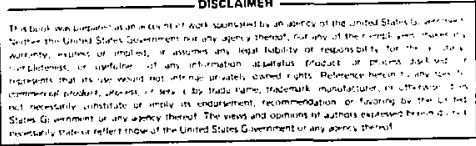

\section{LAWRENCE LIVERMORE LABORATORY} University of California $\bullet$ Livermore, California 94550 


\section{ACKNOWLEDGMENTS}

The authors wish to acknowledge the many contributions of all those who worked on the magnet design. Special eredit is given to the following persons:

Andersen. A.

Berkey, J.

Bulmer, R.

Chang, $Y$.

Cornish. D. N.

Depue, $\mathbf{D}$.

Johnson. G. L.

Karpenko, V. N.

Koeman. T. A.

Lathrop, G.

Lictske. J.

MacDonald, J.
Martinek, R.

Montoyis. $C$.

Peterson, R.

Podesti. D.

Ross. W, N.

Shouk, W. R.

Thomassen, K. J.

witherell, $C$.

Zimmerman. B.

Jones, R. G.-General Dynamics, Convair

O'Neil, R. F.-General Dynamics/Convair

Roy, C. E.-General Dynamics : Convair 


\section{TABLE OF CONTENTS}

1. Magnet Description ......................... 1

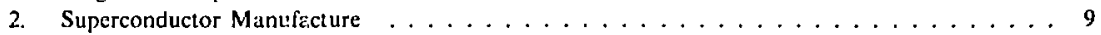

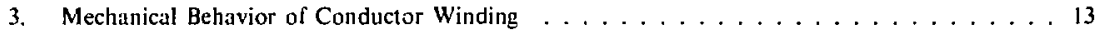

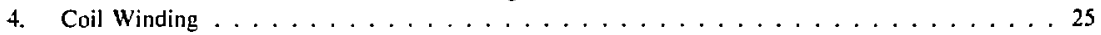

5. Thermal Analysis . . . . . . . . . . . . . . . . . . . 41

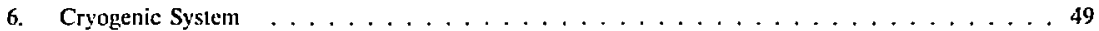

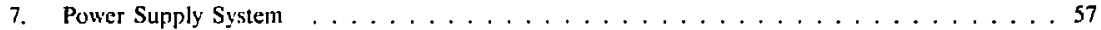

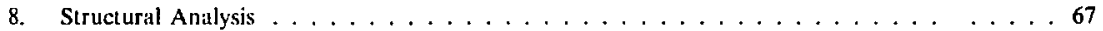

9. Structural Finite Element Anilysis Relinement . . . . . . . . . . . . . . 79

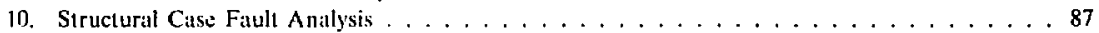

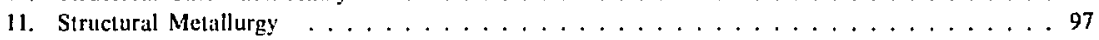

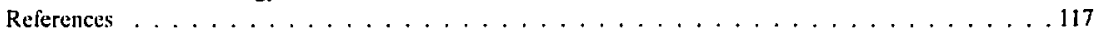




\section{Mirror Fusion Test Facility \\ magnet system- \\ Final design report}

\section{SECTION 1 \\ MAGNET DESCRIPTION}

The Mirror Fusion Test Facility (MFTF) is the largest of the mirror program experiments for magnetic fusion encrgy It sceks to combine and extend the near-classical plasma confinement achieved in $2 \times 1 / B^{1}$ with the most advanced ncutral beam and magnet technologies available. The product of ion density and confinement time will be improved while the superconducting magnet weight will be cxtrapolated from 15 tons in Basebal! $]^{2}$ to 375 tons in MFTF. Other project parameters listed in Table 1 show that the MFTF will traverse much of the distance in magnet technology towards the reactor regime. ${ }^{3}$

Authorized to start construction in FY 1978. the MFTF project is close to its schedule for completion in October 1981. Following a change in geometry at the end of the preliminary design stage. detailed design was commenced in May 1978. By August of 1979 the design was complete and the first coil constructed. The second coil was finishcd in March 1980. Final assembly, inciuding the case structure. will be completed and ready for test in early 1981. An extension of the project called MFTFB has been authorized and will delay project comrtstion three years.

\section{MAGNET DESIGN}

Figure 1 is a computer graphics display of the MFTF magnet with neutral-beam injection acess. The magnet is a yin-yang pair with an average major radius of $2.5 \mathrm{~m}$ and an average minor radius of $0.75 \mathrm{~m}$. The geometrical centers of the pair are overlapped by $0.7 \mathrm{~m}$ to produce a net outside dimension of about $8 \mathrm{~m}$ and a plasma length between mirrors of $3.6 \mathrm{~m}$. A peak magnetic field of $7.68 \mathrm{~T}$ occurs at the windings in the minor radius. Becaluse the field is a cusped magnetic well, it drops rapidly to $4.2 \mathrm{~T}$ at the mirrors and $2.0 \mathrm{~T}$ in the center.
A current-versus-field curve is shown in Fig. 2. with superconductor stability limits determined from test coil results reported by Cornish, et al. ${ }^{4}$ The conductor exhib:ts cold-end recovery, and the stability limit appears to extrapolate in accordance with the copper magnet resistance and a modest surface heat flux of $0.19 \mathrm{~W} \cdot \mathrm{cm}^{-2}$. This experimental observation can be explained by averaging heat nluxes of $0.4 \mathrm{~W} \cdot \mathrm{cm}^{-2}$ and $0.1 \mathrm{~W} \cdot \mathrm{cm}^{-2}$ over the open external and restricted internal cooling stirfaces, in accordance with usual heat transfer experiments.

The MFTF conductor is the result of at twoyear development effort. ${ }^{5}$ Listed in Table 2 are the

TABLE 1. MFTF parameters.

\begin{tabular}{|c|c|}
\hline Parameter & Value \\
\hline \multicolumn{2}{|l|}{ Plasntu: } \\
\hline Ion density $\times$ containment time, s $\cdot \mathrm{cm}^{-3}$ & $10^{12}$ \\
\hline Ion teriperature, keV & 50 \\
\hline Flectron tempirature, keV' & 1 \\
\hline Plasma/magnetic nressuru & 4.5 \\
\hline Startup heamis, A. keV & 1010. 20 \\
\hline Sustaining beams. A. liev & 750.80 \\
\hline \multicolumn{2}{|l|}{ Magnet: } \\
\hline Masimum field, $\mathrm{T}$ & 7.68 \\
\hline Central ficld, $T$ & 2.0 \\
\hline Mirnor ratio & 2.1:1 \\
\hline Mirrar-to-mirror length, m & 3.6 \\
\hline Mlajor radius (mean), in & 2.5 \\
\hline Mfinor radius (mean I. nr & 0.75 \\
\hline Current. 4 & 5775 \\
\hline Turns & 1392 \\
\hline Slored energy, .11.I & $4(0)$ \\
\hline Conductor current density, $\mathrm{A} \cdot \mathrm{cm}^{-2}$ & 3729 \\
\hline Coil current density, $A \cdot \mathrm{em}^{-2}$ & 2525 \\
\hline Surface beat $\Pi u x, W \cdot \mathrm{cm}^{-2}$ & 0.19 \\
\hline Conductor length, $\mathbf{k m}$ & si) \\
\hline Total Height, kg. & $.141,000$ \\
\hline
\end{tabular}




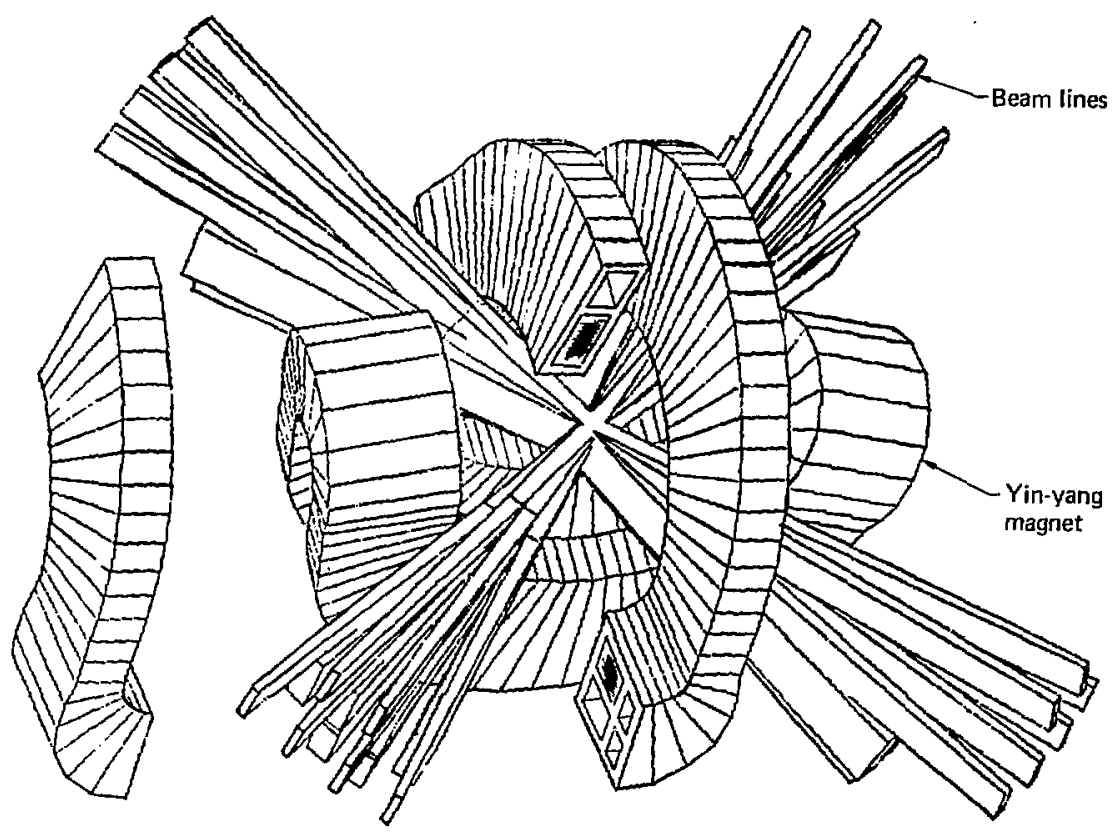

FIG. 1. Computer graphic display of MFTF magnet with neutral beam injection access.

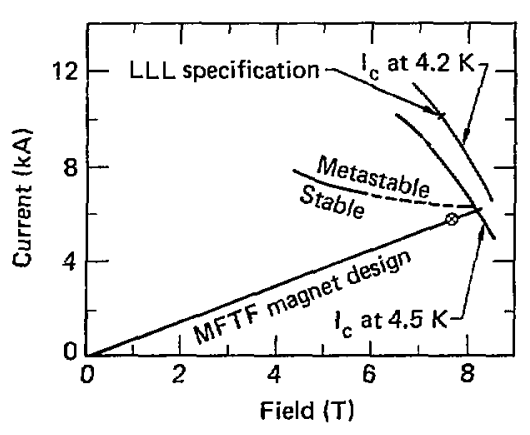

FIG. 2. MFTF magnet load line. primary specifications of both the core and stabilized conductor. It consists of a $6.5-\mathrm{mm}$ square, copper-stubilized, niobium-titanium composite wrapped in an embossed and perforated sheath of high-purity copper. The core-1o-sheath bond had to be improved by replacing the original 90/10 Pb-Sn solder with 50/50 Pb-Sn solder for improved wetability at lower bonding temperature. Once initial manufacturing difficulties were resolved, both quality and production efficiency were good.

A typical cross section of the coil is shown in Fig. 3. An inner coil form of $316 \mathrm{~L}$ stainless steel is leveled with epoxy and glass fibers. Then five overlapping layers of Kapton film are installed as a ground-plane insulation. Ferforated NEMA G-11 epoxy-glass laminate is placed on top of the Kapton for helium circulation before the 58 layers ( 24 turns 
TABI.E. 2. MFIF conductor specifications.

\begin{tabular}{|c|c|}
\hline Conductor paraneters & Value \\
\hline \multicolumn{2}{|l|}{ Superconductor : } \\
\hline Critical curren1, $\mathrm{kn}$ at $7.5 \mathrm{~T}, 4.2 \mathrm{k}$ & 10 \\
\hline Copper to superconductor & $1.7: 1$ \\
\hline Vumber of rilaments & 480 \\
\hline Filument diameter, mm & 0.20 \\
\hline Iwist pitch, mm & 180 \\
\hline Conductor-resistance ratio & 150:1 \\
\hline Core size, $\mathrm{mm}$ & $6.5 \times 6.5$ \\
\hline \multicolumn{2}{|l|}{ Stabilized condwetor: } \\
\hline Waximum conductor field, $\mathbf{T}$ & 7.68 \\
\hline Maximum conductor current, A & 5775 \\
\hline Conductor operating temperature, $k$ & 4.5 \\
\hline Grerall: copper to superconductor ratio & $6.7: 1$ \\
\hline Stabilizer copper-resistunce ratio & $220: 1$ \\
\hline $\begin{array}{l}\text { Copper resistance } \\
\text { (at } 7.68 \text { T. } 4.5 \mathrm{~K} \text { ), } \mathrm{n} 9 \cdot \mathrm{cm}\end{array}$ & 46 \\
\hline $\begin{array}{l}\text { Ilclium-couled surfece area, } \\
\mathrm{cm}^{2} \cdot \mathrm{cm}^{-1}\end{array}$ & 8.17 \\
\hline Required heut transfer rate, $\mathrm{W} \cdot \mathrm{cm}^{-2}$ & 0.19 \\
\hline Therall size, mm & $12.4 \times 12.4$ \\
\hline
\end{tabular}

each) of conductor are wound. After closing the Kaplon ground-plane insulation around the coil, two sheets of Mylar are installed as a sip plane.

In the small-radius area, an additional crushable Dacron-felt layer is applied for controlled spacing. All other spaces are filled with $\mathrm{G}-11$ blocks and fiber-filled epoxy before the outer coil jacket is welded in place.

A stainless-steel bladder is installed around the encased coil so a urethane shim can be injected between the coil jacket and structure. Disks welded to the inner structure surface preserve conductance through the guard-vacuum space for differential pumping. This arrangement greatly relaxes the helium-leakage requirements for both the coil jacket and structure.

The coil-winding operation is shown in Fig. 4. A tension of $600 \mathrm{lb}$ is maintained on the conductor to control the accumulation of winding tolerances below 0.005 in. $(0.12 \mathrm{~mm})$ per turr. Compaction tests on conductor stacks and computer modeling of the winding motion confirmed that such tolerances were compatible with the allowable conductor strain. On initial energizing the conductor strain is $0.3 \%$. but is reduced to $0.1 \%$ for repeated stress cy- cles. No degradation has been observed for niobium-titanium conductors at these strain levels.

Conductor joints are made by cold weiding the central core and soldering the conductor in to a copper tray. The joint exceeds the strength and stability of the core and is redundant. so that some quality control problems experienced with the cold welding were alleviated.

Figure 5 shows the coil-winding rate. Much of the rate improvement was associaled with the efficiency in joint making. Once mastered. joints vere routinely made in less than four hours. Figure 6 shows the first completed coil being removed from the winder for placement on the shim-bladder assembly stand before the structure is wiaed around the coil.

\section{THERMAL AND QUENCH PROTECTION}

Thermal conditions for the magnet are summarized in Table 3. More than 8,000 liters of liquid helium will circulate by natural convection between the magnet and a storage Dewar locited on the fourth floor of the building. The convection is the result of heat input to the magnet. $A$ computer model of the helium loop was developed from the Blasius friction equation, Darcy's porous media equation, and a three-dimersional orifice model. ${ }^{7}$ Estimates of effective hydraulic diumeter. flow tortuosity, porosity, permeability, friction factor, and effective orifice dimensions were made for the magnet and connection piping. The eflects of twophase flow were included by using the LockhartMartenelli correlation. ${ }^{8}$ Helium flow rates were estumated by an iterative method corresponding to an

T.III.1: 3. Therma! conditions in the magnet.

\begin{tabular}{|c|c|c|}
\hline P'arameter & Location & Vialue \\
\hline Helium temperature. $\mathrm{K}$ & Magne1 inlet & 4.36 \\
\hline Pressure, $k P_{2}$ at $1.28 \mathrm{gtm}$ & Magnet hottom & 130 \\
\hline Saturation temperature, $K$ & Vlagnet hottom & 4.52 \\
\hline $\begin{array}{l}\text { Helium rate } \\
\text { (nutural circulation), g/s }\end{array}$ & & $=700$ \\
\hline Heat loud, II & Ylagnet & $\simeq 350$ \\
\hline Nlean quality of helium, $\%$ & Mlagnet outlet & $<5$ \\
\hline $\begin{array}{l}\text { Ilinimum transition } \\
\text { tcmperature, } K\end{array}$ & C onductor & 4.98 \\
\hline
\end{tabular}




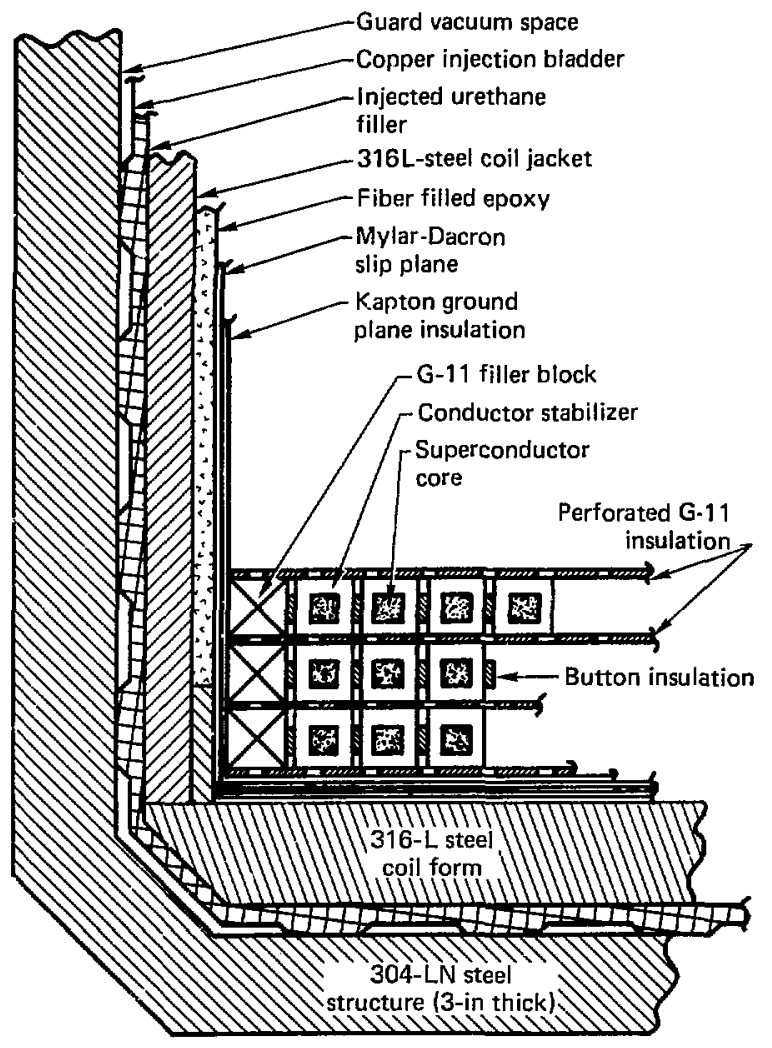

FIG. 3. Coil assembly detail.

assigned heat load for eich model element. It was found that, with a magnet heat load of $350 \mathrm{~W}$, the circulating helium flow is $700 \mathrm{~g} / \mathrm{s}$ with less than $5 \%$ vapor volume at the top of the magnet.

Quench protection for the magnet is accomplished by conventional means using an external dump resistor and a 1,000- $\mathrm{V}$ discharge. The magnet time constant (sec Table 4 ) is $69 \mathrm{~s}$ and an adiabatic conductor temperature rise of $200 \mathrm{~K}$ is calculated assuming a 10-s delay for the quench detection circuit to sense the quench condition and activate the circuit breakers to the power supply.
T.ABI.E. 4. Quench characteristics.

\begin{tabular}{ll}
\hline \multicolumn{1}{c}{ Characteristic } & Value \\
\hline Coil inductance, $H$ & 11.0 \\
Mutual inductance, H & 1.2 \\
Peak volinge, V & 1000 \\
Quench time constant, s & 69 \\
Peak conductor temperature & \\
after 100 s, K & $<200$ \\
Detay time, s & 10 \\
Jropagation velocity, $\mathrm{m} \cdot \mathrm{s}^{-1}$ & 1.2 \\
Quench resistor, $\Omega$ & 0.17 \\
\hline
\end{tabular}




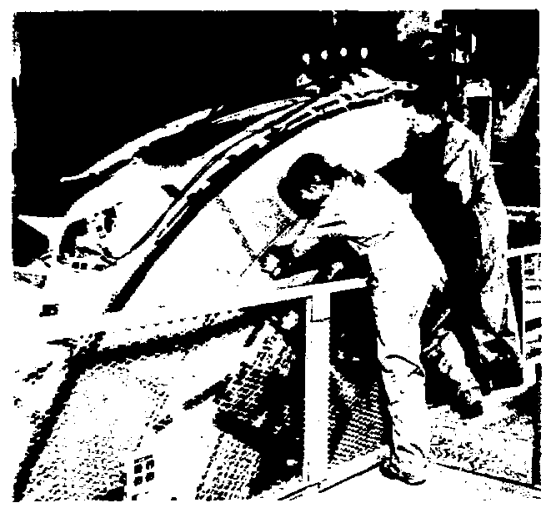

FIG. 4. Coil winding operation.

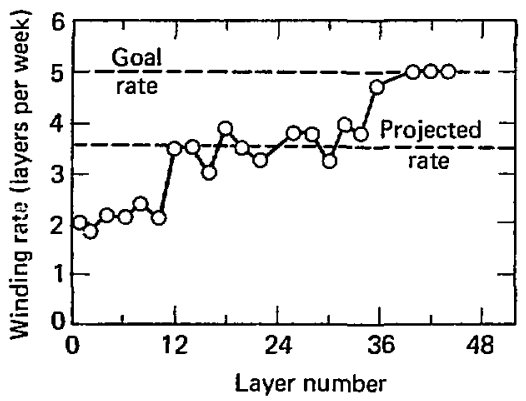

FIG. 5. Magnet winding rate. Rate does not include out-of-conductor time, but does include turnaround time and side glue blocks.

\section{MAGNET STRUCTURE}

No code or standard guidanee exists for the design of magnet siructures. Instead, referenet was made to Sections III and VIII of the ASME Unfired Pressure Vessel Code. However, blind obedience to existing codes can result in either excessively heavy or dangerously fracture-prone structures. For example, paragraph UA-500 of the ASME Code recommends that $1 / 4$ of the tensile strength or $5 / 8$ of the yield strength be used for design stress,

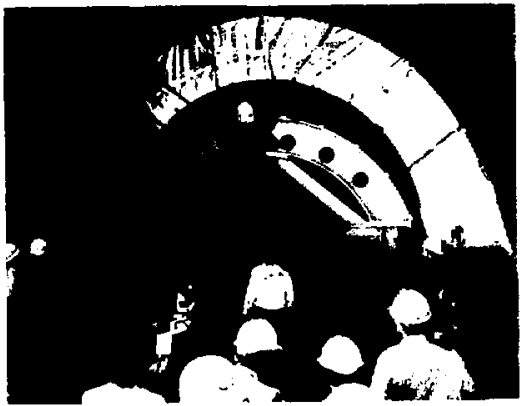

FIG. 6. First completed coil being removed from the wiader for placement on the shim-bladder-assembly stand.

whichever is lower. For some stainless steels like 304 , the design would be limited by yield strength and be excessively conservative. considering the very high tensile strength and toughness at low temperature. Also. Charpy impact iests at $77 \mathrm{~K}$ are not at all representative of the fracture toughness and crack-growth properties at $4 \mathrm{~K}$. so that insufficient fracture resistance might result. Figurc 7 show's a better relationship to compare fracture toughness and yield strength of several stainless steels.

Our criterial for the design of the MFTF magnet are summarized in Table 5. Note that the percents of yield and tensile strength are higher than those recommended in UA-500 for two reasons: sophisticated electromagnetic computer codes accurately resolved the forces on the magnetic structurs. and the environment is benign and noncorrosive. Becituse of the tendency of materials to embrittle at low lemperatures. the design stress dependence upon fracture mechanics at $4.2 \mathrm{~K}$ was more restrictive. The plane-strain fracture toughness, $K_{I C}$, had to be compatible with the detectible naw size. a. Equaliy important was the crack growth rate, da/dn. during cyclic loading conditions. MFTF was designed for a life of 2,000 stress cycles corresponding to a sufety factor of four during the expected 10-yeur service life.

When the aforementioned general design criteria were applied to MFTF and materials properties evaluated. the specific structure-design criteria in Table 6 were adopted for the detailed 


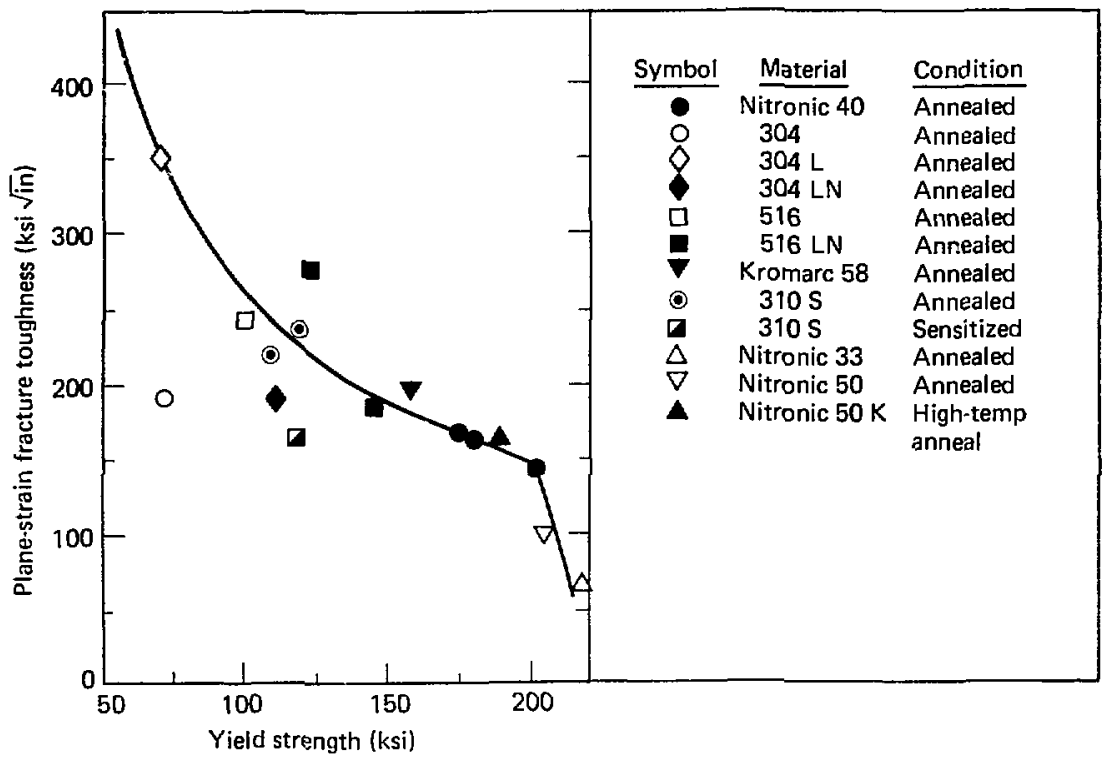

FIG. 7. Decline of fracture toughness with increasing yield strength.

stress analysis to be performed by General Dynamics. Convair Division. ${ }^{10} \mathrm{~A}$ finite-element SAP IV computer analysis was performed and supported by various detailed calculations. In the peak stress region of the structure, three-dimensional elements in the NASTRAN code were used to refine the anulysis, so that no calculated stress cxceeded the $80 \mathrm{ksi}$ criteria.

TA13I.F: 5. Design stress criteria for magnetic structure."

\begin{tabular}{ll}
\hline Stress & \multicolumn{1}{c}{ Criteria } \\
\hline Design & $2 / 3$ yield strength \\
Design & $100 \%$ yield strength \\
Design & $1 / 2$ tensile strength \\
Design & $1 / 2 \mathrm{~K} / \mathrm{c} / \sqrt{\pi \mathrm{a}}$ \\
Design, cycles & 4 Hifetimes \\
\hline
\end{tabular}

"The lowest stress criterion is chosen from ameng those listed.

Prianarily tension and combined siresses.

Eprimarily bending.
After a review of avisilable material properties. $304 \mathrm{LN}$ stainless stet was chosen for the structure.

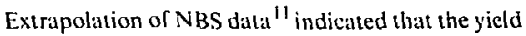
strength of $304 \mathrm{LN}$ would equal $120 \mathrm{ksi}$. if $0.14 \%$ nitrogen could be added. while the fracture toughness. KIC. was expected to remain about 200 $\mathrm{ksi} \sqrt{\mathrm{in}}$. Production of $800,000 \mathrm{lb}$ of $304 \mathrm{LN}$ steel was successfull; completed with the material passing all

T IBI.I: 6. N1inimum structural materials properties.

\begin{tabular}{|c|c|}
\hline Property & Yalue \\
\hline Design stress, ksi & BO \\
\hline l'ield stress, ksi & 120 \\
\hline Litimate stress, ksi & 160 \\
\hline Elongation, & 20 \\
\hline \multicolumn{2}{|l|}{ Churpy impact at $77 \mathrm{~K}$} \\
\hline Absorbed energs, fe-lh & +0 \\
\hline I.alcral expansíon, in. & 0.030 \\
\hline Toughness ( $\left.k_{l(}\right)$, ksi $\sqrt{\text { in }}$. & 120 \\
\hline
\end{tabular}


chemistry, microstructural, and ultrasonic inspections, and the steel was supplied for the coil struclure fabrication shown in Fig. 8.

An extensive development program was necessary to achieve weld properties that would match those of the balse metal. Because 316L weld metal promised to have good yield and ultinate strength. it was selected for development. Steel toughness was known to be infleneed by ferrite contemt $^{12}$ (see Fig. 9), so very low ferrite content was necessury. However, below $3 \%$ ferrite, mierofissuring of this weld netal becones a problem. Several welding methods were attempted. but only shielded metal-are welding produced an adequate combination of loughness, sufficient welding speed. and versatility. ${ }^{13}$ Table 7 summarizes a few of the weld and base ntetal properties which qualified the coil siructure r.anufacturing. Careful control of purity. ferrite ievel, and welding methods aclicved the demanding requirements.

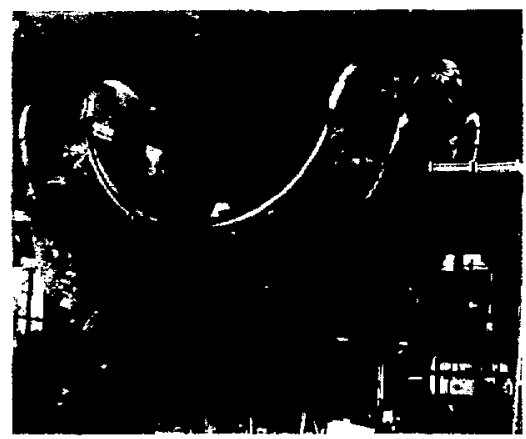

FIG. 8. Coil structure fabrication.
TABLE 7. MFTF structural material properties.

\begin{tabular}{|c|c|c|c|c|}
\hline & $\underset{k s i \sqrt{t n} .}{K_{i}}$ & $\begin{array}{l}\text { Yicld } \\
\text { strength, } \\
\text { ksi }\end{array}$ & $\begin{array}{c}\text { Ultimate } \\
\text { strength. } \\
\text { ksi }\end{array}$ & $\begin{array}{l}\text { Reduction } \\
\text { area-\% }\end{array}$ \\
\hline $\begin{array}{l}3161,-15 \\
\text { Weld }\end{array}$ & 183 & 112.0 & 183.2 & 28.1 \\
\hline $\begin{array}{l}\text { M(4L) } \\
\text { Puse material }\end{array}$ & 2112 & 111.6 & 2.37 .4 & 36.0 \\
\hline
\end{tabular}

a All measurements made at $\mathrm{A} h$.

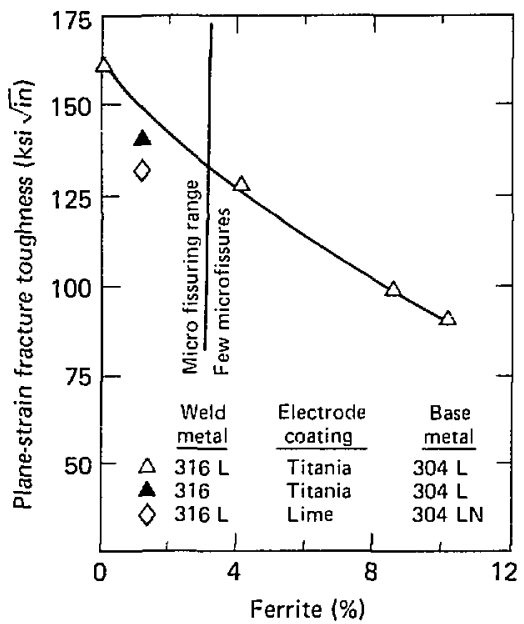

FIG. 9. Effect of ferrite content on weld toughness. 


\section{SECTION 2 \\ SUPERCONDUCTOR MANUFACTURE}

The MIT Th conductor design was developed as part of the generat magnet development work at I.I.NI." lath l.S. manufacturer produced one billet of prototy pe core material and, based on the resules of this work. a specification (MEl_770 or 373.31 was prepared. Nfter selecting a manufacturer (Intermagnetics (ienteral Corporation), the detisils of that manulacturer's design were incorporaled into a modified specification (MEL.77. if113736 which was used als a basis for the producliun urder.

1 copper theath. shown in 17ig. 10, was soldered to the core to provide addizional conling for e1:ostatic stability. This process was contracted (1). vires. ${ }^{14}$

In this wraparound technique, the supercondueting core is passed through a continuous electroplating process prior to applying the stabilizer. the latter is prepared from an oxygen-free high-

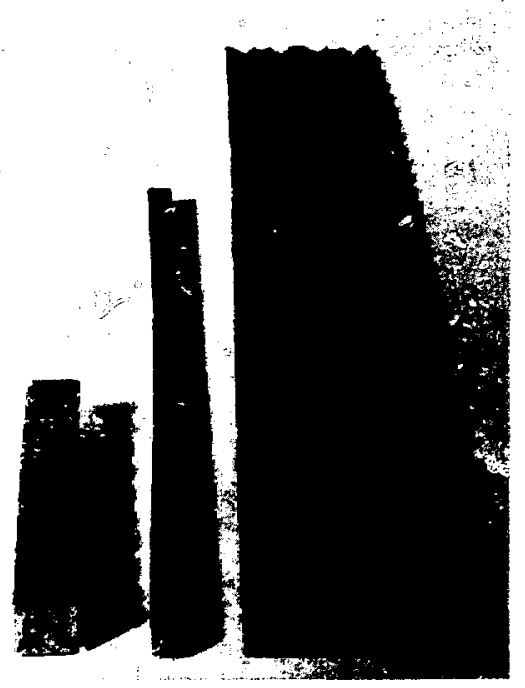

FIG. 10. MFTF superconducting core and copper sheath. conducting (OFHC) copper by first slitting and rolling a strip, followed by punching helium access holes. On a roll-forming line, the stabilizer is wrupped around the core, and the conductor is then sized by a Turk's-head. The completed eonductor then passes through the soldering furnace, a quenchirig system, and a cleaning process before being wound onto the supply drum.

The choice of a monolith conductor presents several manufacturing and quality assurance problems not encountered with a cable or braid. In order to achieve optimum critical current in $\mathrm{Nb}-\mathrm{Ti}$, a large amount of cold work is required. ${ }^{15}$ This cold-work requirement can be met for a cable or braid by starting with a billet of $150-$ to $200-\mathrm{mm}$ diameter, because the braid strand size is typically 0.5 to $2.0 \mathrm{~mm}$ in diameter. The final size of the MFTF core is $6.5 \mathrm{~mm}$ by $6.5 \mathrm{~mm}$; consequently, a large-diameter billet must be used, and the manufacturing risks are greater. In addition, the MFTF magnet requires rentinuous lengths of greater than $380 \mathrm{~m}$; large-diameter billets are necessary to produce these lengths in an economical manner, and breakage during manufacture must be minimized.

The absence of redundancy in a monolith such as the MFTF superconductor requires that the quality assurance tests be especially rigorous. Consequently, samples from each end of each length are checked for critical current $\left(I_{c}\right)$, matrix-resistivity ratio $\left(\mathrm{R}_{293 \mathrm{~K}} / \mathrm{R}_{10 \mathrm{~K}}\right)$, copper-to-supersonductor ratio, $t$ wist pitch, filament size, and filament integrity. $A$ basic premise for the quality assurance of the MFTF superconductor is that samf,es from both ends of each length are sufficient to guarantee the quality of each lengih. $\mathrm{Nb}-\mathrm{Ti}$ alloy in the composition range $46 \pm 1.5 \mathrm{wt} \% \mathrm{Ti}$, balance $\mathrm{Nb}$, was specified. The $\mathrm{Nb}-\mathrm{Ti}$ alloy presented few problems and rejections were under $1 \%$. Defects were mainly associated with surface quality, size, and straightness. Many of the surface quality rejections were discovered by the manufacturer to come from "fretting" (self-abrasion) of the material during transit. The solution was simply to pack such that relative motion between the rods was minimal. Ingot and product chemistry were always within specification. All copper used in the billets was either phosphorous-deoxidized oxygen-free 
(PDOF) or OFHC brand with a guaranteed resistivity ratio of greater than 180:1.

Conductor fabrication followed a relatively standard sequence for all $\mathrm{Nb}-\mathrm{T} i$ superconducling composites. ${ }^{16}$ The billets were assembled using hexagonal copper tubes in which cylindrical Nb-Ti rods were inserted. All elements were chemicilly cleaned and stored under dry nitrogen prior to assembly. The array was stacked to in within a copper extrusion can which became the shell of the conductor. The billet was then eapped with a nose and lid. evacuated. and sealed by electron-beam welding. Electron-beam welding was used to ensure reproducible welds.

The extrusion operation reduced the billet to a much smaller rod and metallurgically bonded the interfaces together to yield a true composite. The press capacity of 5000 tonne was almost fully utilized in the extrusion of the billet. An initial problem of tooling failure resulted in the misextrusion of several billets. The problem was remedied by the design of special tooling to fully utilize the press capacity.

The ends of the extruded rod were cropped and the rod was cut into two lengths. These rods were drawn through a series of dies using scveral draw benches.

After the rods were reduced to $20-\mathrm{mm}$ diam. drawing was done on conventional bull blocks specially modified to handle the high tensile strengths of these conductors. An internediate heat treatment was introduced during the drawing process to obtain the maximum superconductor properties. Few problems were noted in the drawing for sizes below $20 \mathrm{~mm}$. The conductor was twisted and Turk's-headed by a special machine designed to rotate the pay-off spool. The final conductor sizing to a tolerance $\pm 0.05 \mathrm{~mm}$ was done with a lungsten carbide die. A final annealing step was performed to restore high conductivity to the copper matrix.

\section{QUALITY ASSURANCE}

The various steps in the manufacture of the MFTF superconductor were reviewed from the standpoint of quality assurance, and a comprehensive plan was prepared. This plan specified the documentation required for each length of conductor and the method for verifying that each manufacturing step had been performed. A written discrepancy report was required for any condition or procedure which differeo lrom the guality absurance plan. When manufacture wals complete. samples from each end of each length were tested to see that the specifications were met. These results. ogether with any discrepancy reports filed during manulacture, were reported to a Miarials Review Board which made the linal decision on any out-ofspecification material.

\section{CRITICAL-CURRENT TESTS}

A total of $350-$ to 400 -criticil-current measurenents were anticipated and a test facility cuapable of handling this large number of samples was construcled. A superconducting solenoiu with it $25-m m$ by $50-\mathrm{mm}$ access produces a maximum transverse field of $8.5 \mathrm{~T}$. and al regulated $12.000 \mathrm{~A}(\mathrm{de})$ porat supply provides current to the sample. The sample holder with helium-vapor-cooled keads wan be changed while the solenoid is maintained at cryogenic temperatures. Three of these sample holders werc constructed so that four samples ean be tested in one day. Voliage taps spaced 25 -mm apart were attached 10 , !c sample in the uniform field region. and a criterion of $i 0^{-11}$ ! - $\mathrm{cm}$ resistivity (for the Nb-Ti area) is used to detine eritical current.

One problem encountered in testing large highcurrent specizens is that the self-field generated by the currer $\mathrm{i}$ in the specimen becomes significant. Fur the cast of untwisted filaments, calculation : dicated that the influence of self-field on the measured critical current would be small. due to this effect enhancing the field on one side of the sample but reducing the field on the other side. However. when the twist pitch $(190 \mathrm{~mm})$ of the filaments in the MFTF conductor is taken into account. the selffield acts to teduce the measured critical current by about $7 \%$. Measurements of critical currents on identical samples in the twisted and untwisted condition verified this effect. However, $I_{\text {s }}$ for the MFTF samples were typically 15 to 20 , above the specification of $10.000 \wedge$ all $7.5 \mathrm{~T}$, so selfifield ef fects have not crealed a problem in acceptance of samples. Another consideration for testing highcurrent samples is the current-transfer length: both the length necessary to transfer current from the sample holder to the sample and the kength for redistribution of the current from the vuter lititments to the inner liliments as the satmple passes 
from the low-field to the uniform high-field en. vironment are important. Insuflicient area for current transfer from sample holder to sample can result in heiting. Insuflicient length in the uniform field region on either side of the voltage taps can result in a voltage signal due to eurrent trinsfer. rather than due to exceeding the eritical current. The length in the first cilse can be obtuined from Refs. 16 and 17. The second case is more difficult to calculate. so we determined it experinentally by placing voliage laps spaced $25-\mathrm{mm}$ and $50-\mathrm{mm}$ apart. As a result, we found that using a $610-\mathrm{mm}-$ long sample with $100-$ mm-lones solder joints at the ends and rollige taps spaced $25-\mathrm{mm}$ apart would prevent current-transfer problems from occurring.

\section{COPPER-TO-SUPERCONDUCTOR RATIO}

The copper-to-superconductor ratio (Cu:S.C.) 1 required to be belween 1.63 and 1.77 . The chotec of this ratnge was batsed on considerations of stability. strength, and quality of cold-welded foints. " This parameler is determined by weighing it 100-mm length of corc. dissolving the Cu matrix. and weighing the Nb-Ti filaments. The major variable affecting the Cu:S.C. ratio (assuming the curcent ratio is used in billet construction) is the umount of cropping done at the nose and end of the extruded rod. Initially. a number of lengths were found to be oulside this specification. However, a master curve of ratio versus distance along the conductor length at final size has been developed. so that the anoum of cropping neessary can be determined from the Cu:S.C. ratio at any point along the longth.

\section{MATRIX RESISTIVITY RATIO}

The matrix resistivity ratio is specitied to exceed a value of 150 . This ratio is determined by measuring the resistance at $293 \mathrm{~K}$ and at $10 \mathrm{~K}$ : the $10 \mathrm{~K}$ value is obtained by lowering the sample and its thermometry through the temperature gradient above liquid helium. We mount up to six samples in a horizontal plane and connect them in series, so that six measurements can be made in each experiment. Only one lengtin of MFTF core failed to meet the resistivity ratio specilication. A review of the records indicated that this length has missed the final annealing step: after annealing, it met specification.

\section{FILAMENT TWIST PITCH}

The twist pitch requirement for mirror fusion magnets such as MFTF are not as stringent as for Tokamak magnets, since the mirror magnets are not exposed to rapidly varying lields. The twist pitch for the MFTF superconductor is dictated by the proposed charging rate and should be less than $100 \mathrm{~cm}$. $\Lambda$ specification for twist pitch was chosen as between $16.5 \mathrm{~cm}$ and $19.0 \mathrm{~cm}$; this range is easily achieved in a conductor the size of MFTF without danger of the twisting operation causing filament breakage.

Simples were found with out-of-specification twist pitch at the early stiages of conductor delivery. This problem was traced to a mathod of starting the twisting operation. The manufacturing procedure wals changed to avoid this froblem by performing the end-cropping operation after the twisting operalion.

The only other problem involving twist pitch resulted from a malfunction in the twisting-squaring operation when a pin sheared in the twist machine drive. This resulted in a $12-\mathrm{m}$ length having no twist and required that the entire length be rejected. This experience is one case in which sampling each end of curh length was inadequate to guarantee the quality of the length: it was necessary to rely on manufacturing quality control to note the problem and to lïle a discrepancy report.

\section{FILAMENT SIZE AND INTEGRITY}

Since MFTF is a cryostable, steady-state magnet. filament size does not plity an important role. However, fliament uniformity and filament integrity are an important indication of good manufacturing practice. A specification of filament size between $0.18 \mathrm{~mm}$ and $0.23 \mathrm{~mm}$ was established for this conductor. Metallographic examination of sample cross sections indicated that lengths from billets prepared in the early stages of this program contained nonuniform filaments. A typical case eneountered contains several filaments measuring $\mathbf{0 . 4}$ $\mathrm{nm}$ in diameter (the worst case identified showed 
one filament measuring $0.8 \mathrm{~mm}$ by $0.4 \mathrm{~mm}$ ). This condition can arise if a billet is not packed densely enough and can occur anywhere along a given length. This is the other instance in which we found a problem that can remain undetected in samples taken from each end of each length.

Subsequently, improved billet assembly procedures were introduced and these extreme ranges in filament sizes were reduced. This experience suggests that applicitions needing a close tolerance on flament size. e.g. those requiring intrinsic stability or low ac losses, should specify close tolerances on billet density.

Filament integrity was not anticipated to be at problem for the Nb-Ti core, since the filament size $(0.2 \mathrm{~mm})$ is ather large and the amount of cold work is moderate for $\mathrm{Nb}-\mathrm{Ti}$. However, routine examination after removal of the matrix revealed slip lines on the filaments and occasional breaks. The density of breaks. i.e., approximately one in it $2-\mathrm{cm}$ length, suggestec that broken filaments should not affect the short sample critical current. and the experimental measurements bore this out. The other concern was that broken filaments might affect the strength of the core. so a series of tensile measure- ments were made at $4.2 \mathrm{~K}$. Again, there was no difference between samples with and without broken filaments. Consequently, lengths with up to $1 \%$ broken filaments in a $2-\mathrm{cm}$ length have been accepted.

Analysis of the problem indicates that filament breakage occurs in the final sizing steps; filament breakage occurs only in the outer filaments where the deformation due to converting from a round to a square cross section is greatest. This problem can most probably be eliminated by the addition of an annealing step prior to final sizing or by changing the filament distribution. However, these corrective actions are not being attempted at this time. since the properties of the MFTF core still exceed specification and the manufacturing changes would result in considerable delays in conductor manufacuture.

$A$ benefit of this quality assurance program has been significant improvements in manufacturing techniques: (1) better billet assembly procedures, (2) less reliance on outside rod drawing capabilities. (3) controlled rod-cropping procedures, and (4) careful monitoring of the manufacturing steps to ensure that each step is performed to all specifications. 


\section{SECTION 3 \\ MECHANICAL BEHAVIOR OF CONDUCTOR WINDING}

\section{INTRODUCTION}

The following is : Immary of analytical and experimental studies into the mechanical behavior of the Mirror fusion Test Facility (MFTF) magnet superconductor pack. The superconductor pack is here defined as the 24-turn by 58-layer coil with its interturn and interlayer insulation and any filles material between the superconductors and the coil jacket. Tine relative shapes and sizes of the MFTF conductor. structural case, and plasma fan are shown in Fig. 11. Mechanical behavior is delined as the stress and strain that the superconductor pack components experience during magnet winding and normal 2-T central ficld operation, as well as any anticipated conductor motion that impacts the internal design of the coil.

Mechanical properties of the coil components at $4 \mathrm{~K}$ are reviewed. This is followed by a description of the electromagnetic loads that the coil will experience, their method of calculation, and the redistribution of these loads due to structural compliance. Investigations of the possible buckling offects of superconductor pretension on the jacketed coil are also discussed.

Superconductor stress and strain analysis. performed by using a selected range of coil mechanical properties, are summarized, as are tine possible effects of static and cyclical strain on the niobiuntitanium superconductor and its copper stabilizer. Finally, an analytical prediction of superconductor motion is detailed. including a diagram of the expected superconductor pack displacement with respect to the coil jacket.

\section{MECHANICAL PROPERTIES}

The first step in modeling the mechanical behavior of the MFTF coil was to determine the physical properties of its components at $4 \mathrm{~K}$. The MFTF superconductor pack mily be thought of as a modified orthatropic composite that can carry only compressive loads in two directions and only tensilc loads in the third direction. In addition, the properties in each direction are nonlinear and exhibit hysteresis in their stress-strain responses.
The MFTF superconductor core is a 0.25 -in.square conper-stabilized niobium-titunium composite consisting of 480 superconducting filaments in a copper matrix with a copper-to-superconductor ratio of $1.7 .^{19}$ An embossed and perforated copper wrap ${ }^{20}$ is soldered around the core to provide heat transfer and mechanical support to the core. The final assembled conductor is 0.490 -in. square. ${ }^{2 i}$

Tensile tests of the MFTF superconductor were performed in liquid helium to establish both the stress-strain response curves and the tensilc failure loads. ${ }^{22}$ Strain-gauged samples were used to oblain the stress-strain curves up to an elongation of $1 \%$ using foil gatuges designed for use in liquid helium. ${ }^{23}$ Figure 12 shows the stress-strain response of the wrapped superconductor at liquid helium temperature. Unload/relond cycles always folloved hysteresis loops while loadings beyond the previous peak always followed the envelope curve until being unloaded.

The bare MFTF superconductor core was found to fail in tension at about $8200 \mathrm{lb}$, while the wrapped superconductor assembly was pulled to beyond $10,600 \mathrm{lb}$ without tensile failure. The adaition of a cold weld joint to the superconductor core reduced the failure load to $7100 \mathrm{lb}$, showing very littie sensitivity to the number or length of cold welder strokes. The technique chosen for MFTF joints was live cold welder strokes at $1 / 2$ in. per stroke. Annealing oi the cold weld due ta soldering of the copper stabilizer further reduced its strength to $5700 \mathrm{lb}$.

The cold-weld tensile tests showed a large spread in tensile failure values. The design requirement of high reliability placed on the magnet system meant that adequate joint strength must be guaranteed. This milter was resolved by the addition of a monolithic copper joint-reinforcement bar. Joint assembly verification tests showed that the copperreinforced cold-weld joints can withstand three times the maximum anticipated axial load of $3000 \mathrm{lb}$ and are stronger than the parent superconductor even when no cold weld is applied, thereby providing $100 \%$ joint strength redundancy. ${ }^{2+}$

The coil pack is made up of the above superconductor in 58 layers of 24 turns each. ${ }^{25}$ Interturn 


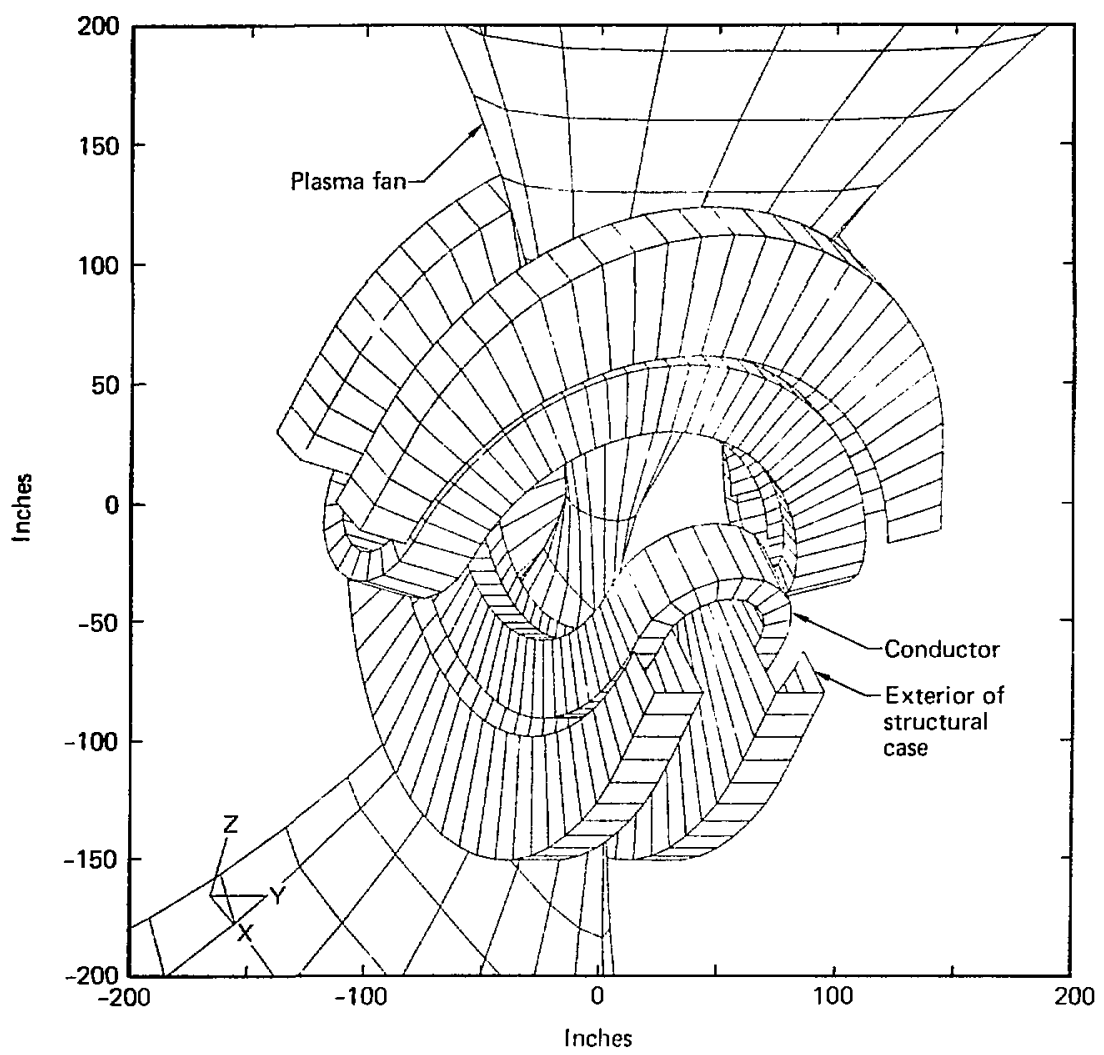

FIG. 11. Relative size and shape of MFTF conductor, structural case, and plasma fan.

insulation is composed of 0.045-in.-thick NEMA G-11 buttons glued to a woven string. ${ }^{26}$ Interlayer insulation is 0.0625 -in.-1hick slotted NEMA G-11 sheets. ${ }^{27}$

The compressive response of the superconductor coil pack was measured at liquid nitrogen and room temperature using a coil pack mock-up. ${ }^{28}$ This series of tests revealed a linear compressive modulus of $2.0 \times 10^{6} \mathrm{psi}$ in the interturn (button) direction and $3.0 \times 10^{6} \mathrm{psi}$ in the interlayer (slotled sheet) direction. Both response curves exhibited an early soft region followed by a stiff linear modulus. Figure 13 shows compression test data in the in- terliger direction which illustrates this phenomenon. The initial nonlinear coil pack behavior is associated with the uneven surfaces of the pick components. If ideally "flat" mating surfaces are assumed. the carly softness can be interpreted as a 0.005 -in. gap per layer of superconductor.

Accumulated stack height measurements performed on the coil winder showed actual winding gaps to be less than 0.005 in. per layer per turn at all monitored stations on the cuil. ${ }^{29}$ Coil winding procedures such as tensioning at $600 \mathrm{lb}$. clamping. and coil-height ineasurements place an emphasis on obtaining a tight winding. This reduces the 


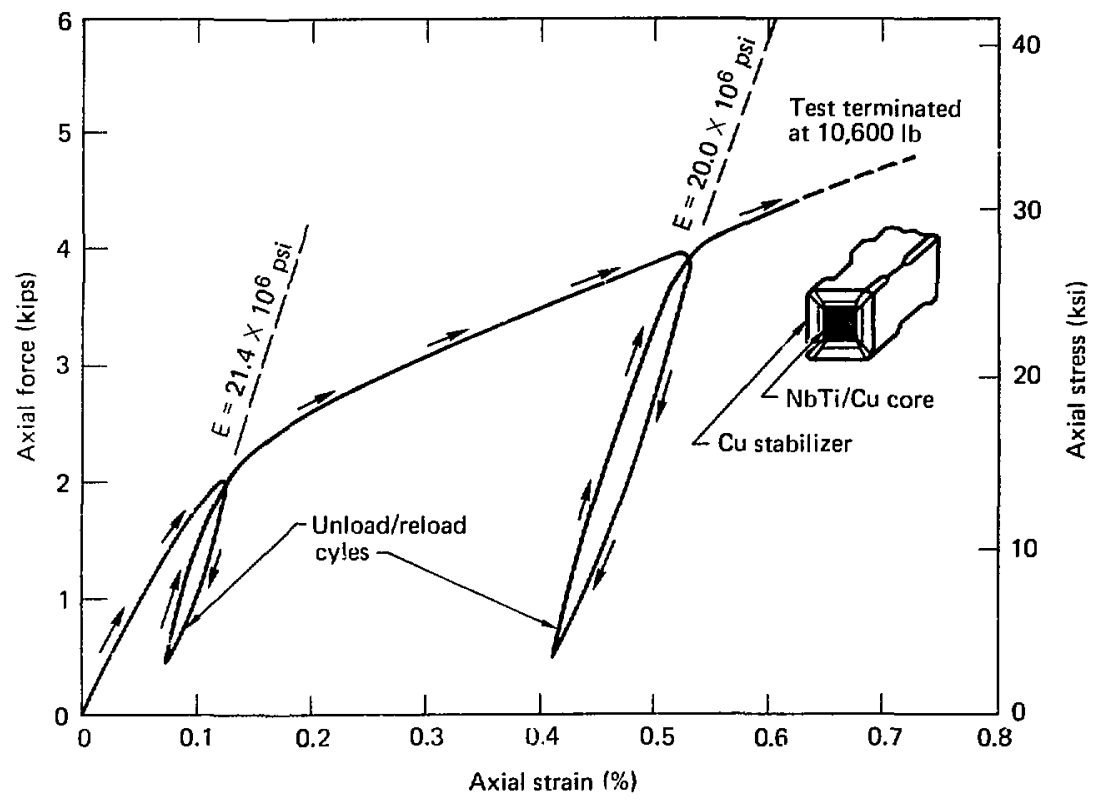

FIG. 12. MFTF superconductor tensile test done in liquid helium.

nagnilude of coil pack motion during magnel energizing and de-energizing.

A pienum region is provided between the top of the 58th layer and the inside surface of the coil jacket for the collection of helium bubbles outside of the superconductor itsclf. The plenum filler material is composed of laminated sheets of slotted NEMA G-11. The laminated assembly was compression tested and found to be structurally sound to beyond $4000 \mathrm{psi}^{22}$ Compressive strength was needed only during coil closure since the bubble plenum region experiences very small compressive loads during magnet operation.

The outside face of the 58-layer coil pack bears against a slip plane on the large radius of both magnets as shown in Fig. 14. The slip plane, consisting of two sheets of 0.007 -in.-thick Mylar, allows relative motion between the superconduclor pack and the surrounding coil jacket to occur without damaging the Kapton or NEMA G-1I insulation. Analysis of the slip-plane requirements found a coefficient of friction of 0.9 or less to be

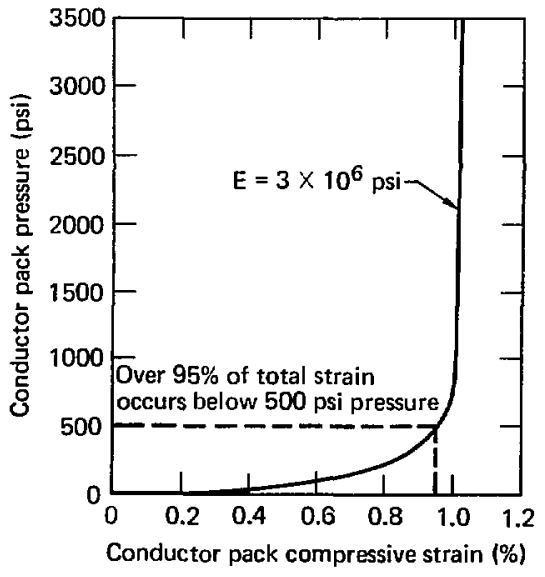

FIG. 13. Compaction of MFTF conductor pack interlayer (slotted G-11) direction at LN temperature. 


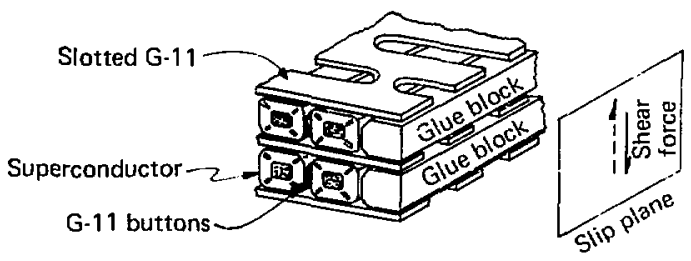

FIG. 14. Bearing lace of MFTF superconductor pack.

satisfactory. ${ }^{30}$ Laboratory tests on a slip-plane mockup showed a friction coefficient of 0.17 for the Mylar-on-Mylar configuration. 31,32

Tests were also performed to verify the compressive strength of the filled epoxy used to yrout the completed coil prior to applying the jacket. ${ }^{33}$ This investigation included a thermal shock test using an embedded steel wusher. No damaging effects due to differential thermal contraction were found.

The compressive load, at which the soft copper wrap on the superconductor begins to be permanently indented by interturn insulation, was found by testing to be $4500 \mathrm{psi}^{34}$ The coining load in the interlayer direction is 5400 psi due to the larger effeclive contact area of the NEMA $\mathrm{G}-11$ sheets, These compare favorably with the anticipated 3400 . psi interturn and interlayer compaction pressures exerted during magnet operation at full field. ${ }^{35}$

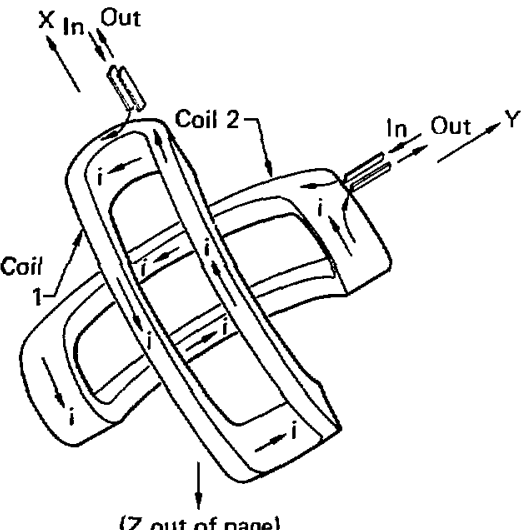

FIG. 15. MFTF magnet current direction.

\section{ELECTROMAGNETIC LOADING}

The MFTF yin-yang magnet geometry and the direction of current flow in each coil is illustrated in Fig. 15. As the diagram suggests, the large and small radii of the two eoils behave somewhat like segments of solenoids. The peak magnetic ficld value of $7.68 \mathrm{~T}$ occurs on the inside surface of the coil pack in the small radius region, as seen in Fig. 16. The similarity to a solenoid diminishes. however, when the transition from large to small radius is considered (as shown in Fig. 17) where the transition region displuys high gradients of electromagnetic forces.

Most of the electromagnetic load calculatinns for the MFTF yin-yang magnet wire performed using the Electromagnetic Fields. Forces and Inductance (EFFI) computer program. ${ }^{36-3 k}$ E.FI is capable of modeling an arbitrary system of coik made from circular are and/or straight segments of reclangular cross-section conductors, and was used extensively in the analysis of the MFTF magnet.

The internal pressure exerted on the side walls of the coil jacket by the superconductors has been

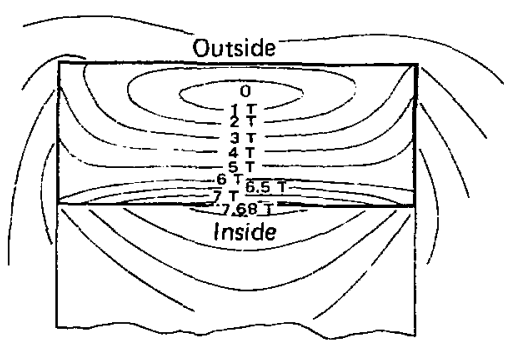

FIG. 16. MFTF magnet field distribution-minor radius symmetry plane. 


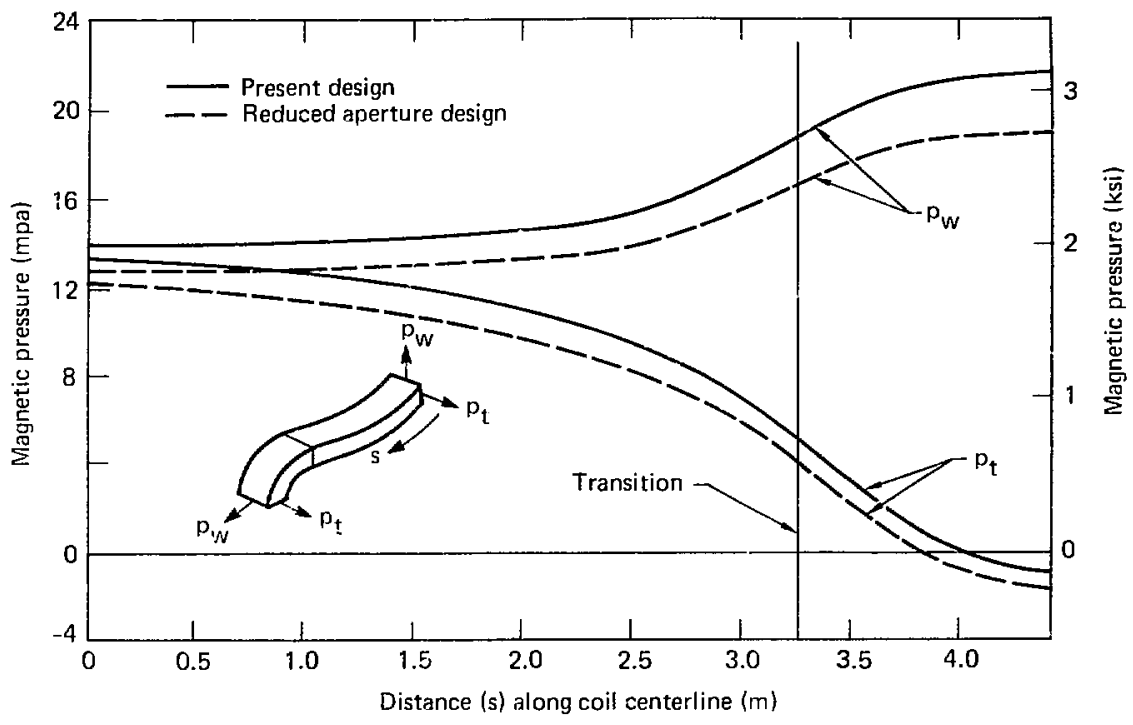

FI(;. 17. MFTF magnet. Average magnetic pressure-EFFI calculation prior to redistribution.

calculated using an EFFI computer program mode] and the load redistribution extracted from integra! coil/structure finite element modeis. ${ }^{35}$ The inalysis models built by General Dynamics/Convair used sik rod elements to represent the coil pack. Transverse coil pack members with appropriate pack modulus properties transfer:ed the applied loads to the structural case. ${ }^{83}$ The finite element model is illustrated in Fig. 18.

Another way to illustrate the EFFl-generated loads in Fig. 17 is to use a coil sketch with applied load vectors, as Fig. 19 shows. These loads do not account for the effects of the structural case. ${ }^{39}$ Due to the compliance of the supporting case and the motion of the coil pack with respect to the coil jacket. the electromagnetic pressure exerted on the surrounding material is lessened in the smali radius region. ${ }^{40}$ This effect can be seen by comparing Fig. 20 with Fig. 19.

The superconduetor and copper bus lead-outs penetrate the coil jacket and structural case at the helium vapor exit pipe in the manner shown earlier in Fig. 15 and with the applied loads from Fig. 21. The lead support structure has been designed to withstand the maximum expected electromagnetic loads. ${ }^{41}$ The geometry selected for the lead-out path allows coil pick motion to occur without jeopardizing the lead-out assembly, as deatt with in more detuil luter in this report.

\section{COIL WINDING TIGHTNESS}

As Fig. 14 shows, the MFTF coil pack is made up of alternate layers of supereonductor and NEMA G-11 insulation. The tightness of the wound coil influences the superionductor pack motion and pressure load redistribution. The degree of pack tightness is quantitatively described as the statkheight buildup per layer of conductor ubove the sum of the individual component heights. This phenomenon is the result of surface features of the superconductor and NEM G-11 which prevent continuous surlace-to-surface contact.

When fictitious, perfectly flat surfaces are considered in analyses, the early reduced compressive stiffness shown in Fig. 13 is interpreted as an initial per-layer "gap." As a result, reference to the word 

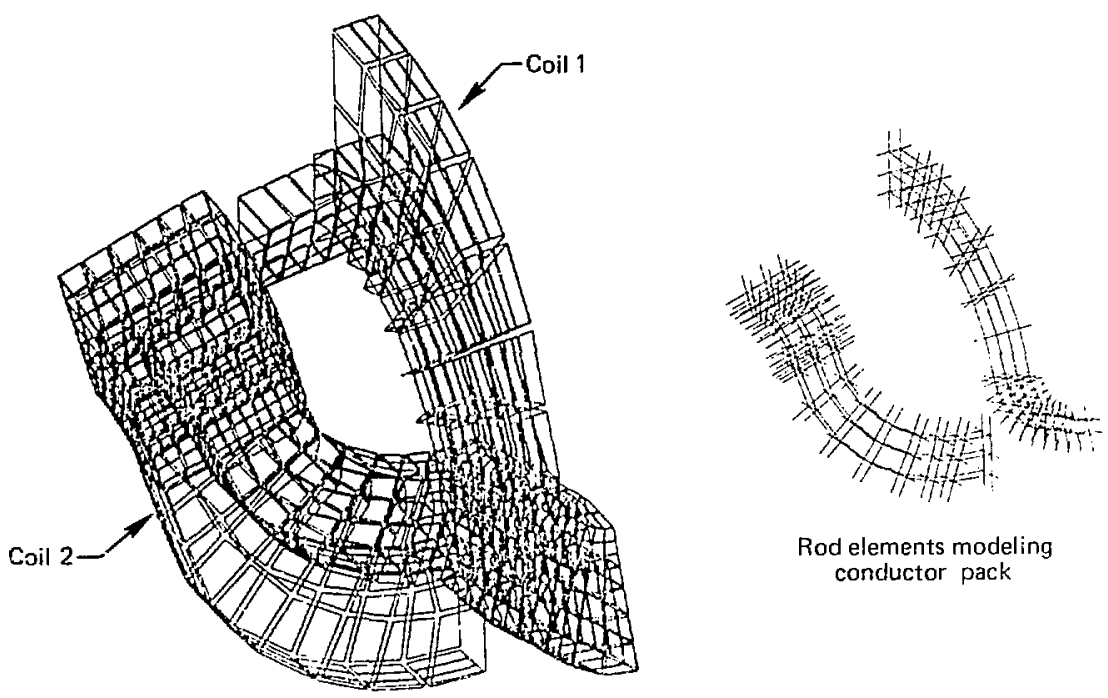

Rod elements modeling conductor pack

Complete model - plate elements

FIG. 18. MFTF-refined nodel.

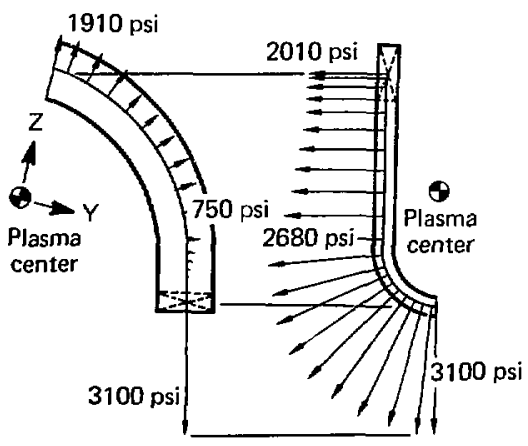

FIG. 19. MFTF electromagnetic loads at 2-T central field. "gap" in the context of coil winding has come to represent his analog of a surface contatet phenomenon.

Several methods were employed to maintain the tightness of the MFTF coil pack. The superconductor was continuously held at a tension of $600 \mathrm{lb}$ during coil winding. Small-radius clamps helped retain superconductor pretension. and side climps closed interturn gaps on the large radius of the coils. The clamping. tensioning. and compaction measuring techniques are described in the MFTF coil winding specificaton. The actual winding tightness. achieved with the tensiuning and clamping scheme described above, was found from stack height measurements to be from 0 to 5 mils per conductor.

An intermediate effect of this pretensioning is the distortion or possible buckling of the jacketed coil during transfer to the structural case subassembly. An early analysis indicited that a notential problem existed and that further investigation wis needed. ${ }^{42}$ Interference between the jacketed coil 


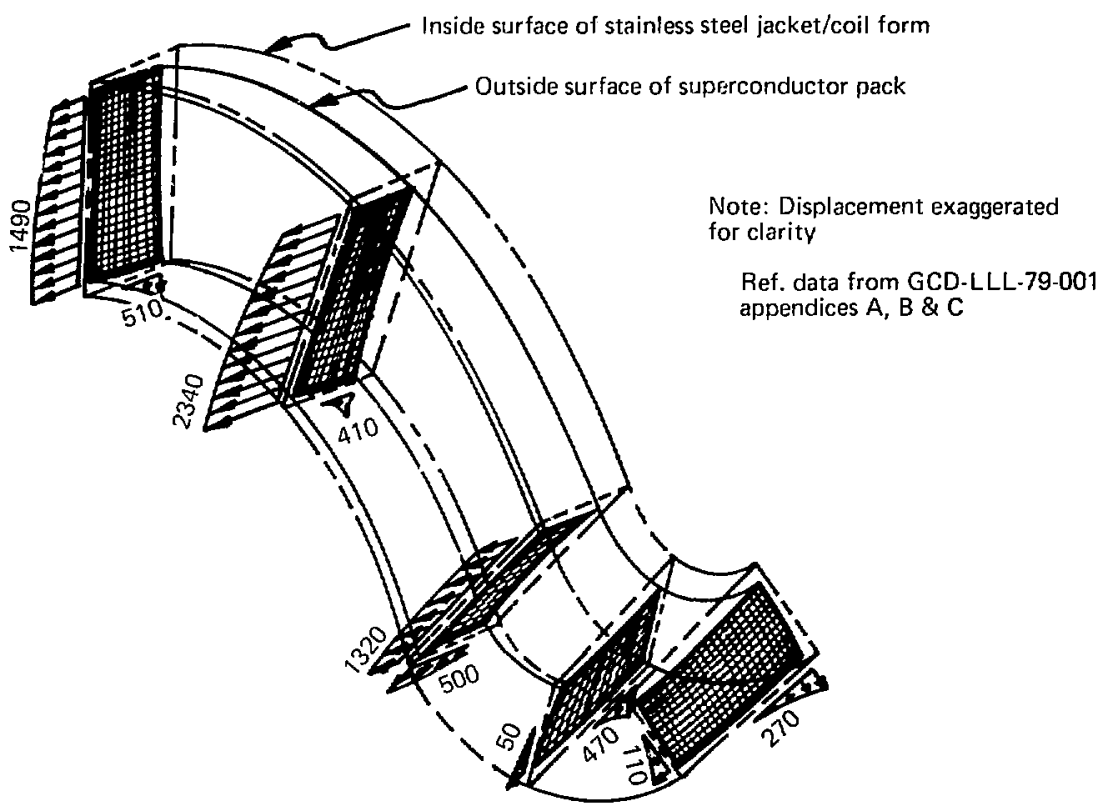

FIG. 21. MFTF average redistributed magnetic pressure (psi).

and the structural case due to coil distortion would renult in ansembly delitys and possibly the dexign and labriation of additional hardware.

A comprehensive buckling analysis wals baler performed by General Dynatmics/Convair which took into account a conservaltive $50 \%$ relaxation of the winding pretension. ${ }^{+3}$ This analysis predicted that the jacketer coil would not buckle when the coil-form adapter strongback was removed. The analyses also prediated a displacement of about 0.9 in. at the large-radius symmetry plane which is within the allowable range for structural case assembly.

These. as well as earlier analyses. were very conservative and highly dependent on an accurate prediction of superconductor pretensile load retention. A program of strain measurement was undertaken to experinentally determine actual winding load on the coil form. Permanent strain gauges. meant to be read during magnel operation. were read during coil winding. Additional temporary coil-form strain gauges were applied to complement the permanent installations. ${ }^{+1}$ All of these gauges were also read during coil demounting and transfer. Preliminary results from these efforts confirmed the conservative nature of the analytical assumptions.

\section{SUPERCONDUCTOR STRESS AND STRAIN}

The analytical prediction of superconductor stress and strain in the MFTF magnet evolved from early hand antalyses to sophisticated finite element analyses and parametric studies. Hand calculations were performed using simplifying assumptions such as no relative motion of conductors with respect to other conductors and the supporting case. ${ }^{45}$ or of uniform stress or solenoid-like behavior. ${ }^{24}$ When a relationship between superconductor winding tightness and strain was shown, ${ }^{44}$ tests were initiated to determine the actual stress-strain response 


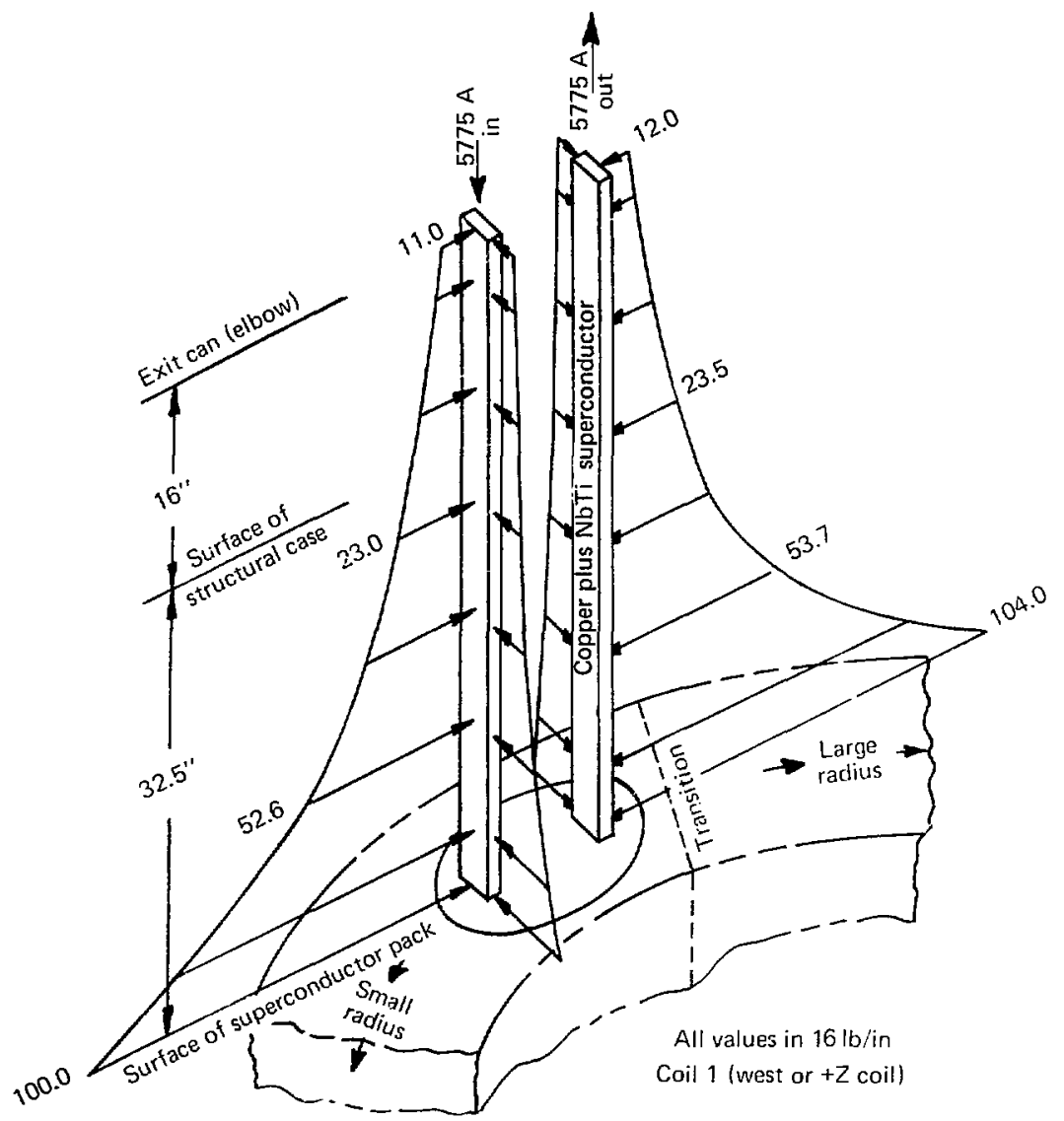

FIG. 21. Flectromagnetic forces on MIFTl superconductor leads.

of the wound coil pack for inclusion in analytical models.

The stress anilysis of the MFTF mannet structural case ${ }^{10.46}$ led to improved methods of predicting the effects of calse deflection on superconductor strain. ${ }^{\text {th }}$ This early work. bowever. did not address the effects of winding tightness and coilpack motion which tend to redistribute stresses across the pack. als Fig. 22 shows.
The effects of winding tightness on conductor stress and strain were investigated by General Dynamics Convair. ${ }^{4}$ A paramelric study was conducted to measure the degree of coupling between coil-pack modulus and conductor stress. Lising three dillerent simulated coil-pack moduli to address winding gaps of 0.5 and 10 mils per conduc. tor. it was found that although the coil motion increised with larger gap sire. superconductor stress 
Superconductor stress ( $\mathrm{ksi}$ )

05510,52025

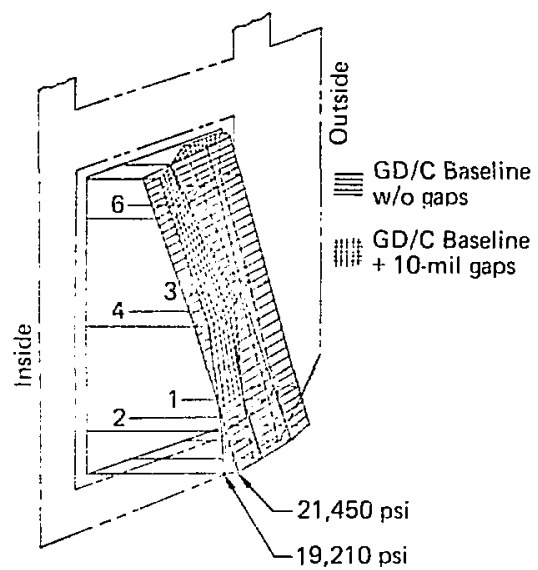

FIG. 22. MHF superconductor stress distribution.

tended to redistribute itself with a slight reduction in the peak from a value of $22 \mathrm{ksi}$ with no gaps to about $19 \mathrm{ksi}$ with 10 -mil gaps. Figure 22 graphically illustrates the thange in superconductor stress distribution.

The analyses have indicated a new conductor stress of about $22 \mathrm{ksi}$ when the nugnet is at its maxintum operating current of $5775 \mathrm{~A}$. Due to nonlanear superconductor behavior and hysteresis, the superconductor strain can reach a peak of $0.25 \%$ during the first energizing. This number is reached by neglecting any radial support of the coil pack in the small radius. However. of this $0.25 \%, 0.15 \%$ is nonreversible permanent set and $0.10 \%$ is clastic strain with little variation in the hysteresis loop for subsequent load unload cycles.

The wrapped superconductor and reinforced joint assemblies were successfully pulled in liquid helium to about three times the expected axial load levels. Of greater concern was the possible reduction in the critical-current value of the superconductor and degradation of the residual resistivity ratio of the copper stabilizer due to static und cyclical straining.

A comparison of MFTF operating strains with current literature on strain effects revealed no meusurable degradation of the critical-current value for a peak strain of $0.25 \%$ or for repeated sirainings to the same level, even to the point of fatigue failure of the specimen. A $3 \%$ reduction in the copper stabilizer residual resistivity ratio was predicted for a single strain of $0.25 \%$. However, no further degradation could be found for subsequent cyclical struining to $0.10 \%$. 48

\section{COIL PACK MOTION}

Superconductor motion was considered when designing the internal components of the coil patck such as lead-outs, joint and ramp designs. slip planes, helium-bubble plenum details. and various lillers and supports. The motion of the M1:TF coil pack with respect to the jacket and structural case was predicted by postprocessing linite element conputcr sutput provided by General Dynamies; Comair ${ }^{22.47}$ The diagram in Fig. 23 depiets the coil pack with exaggerated displacenents to emphasis the directions of motion. Displacement value will vary due to aetual ats-uound conditions.

The slip plane previously discusied allows the magnet to salely accommodate several lintes the coil motion that is anticipated. An analysis of the design requirements of the slip plane depieted in Fig. It showed that at cosflicient of friction of 0.9 or less would prevent dimage to the slotted NEVA $(j-11$ interlayer insulation. This was because 95\% of the conductor motion occurs before $40 \%$ of the peak magnetic ficld is reached and when electromagnetic loads are relatively stnall. Tests of sever al slip-plane designs showed two sheets of 0.007 -in.-thick Mylar to be more than adequate, with a coefficient of friction of 0.17 or less at eryogenic temperatures.

Conductor stress and motion analysts revealed that a reduction in normal load on the slip plane in the small radius and a more favorable mechanicat environment for conductor lead-outs and coil diagnostics would occur if radial motion in the small radius was allowed. In the small radius region. General Dynamics/Convair analyses indicated at tendency of the conductor pack 10 selr-support or lightly bear on the jacket wall if radial motion was not heavily restrained. As a result. the radial inside surface of the coil jacket in the small radius was designed to include a layer of highly compliant felt padding in addition to the Mylar-on-Mylar slip plane. This reduced or eliminated damaging radial loads in the end regions where internul anomalies 


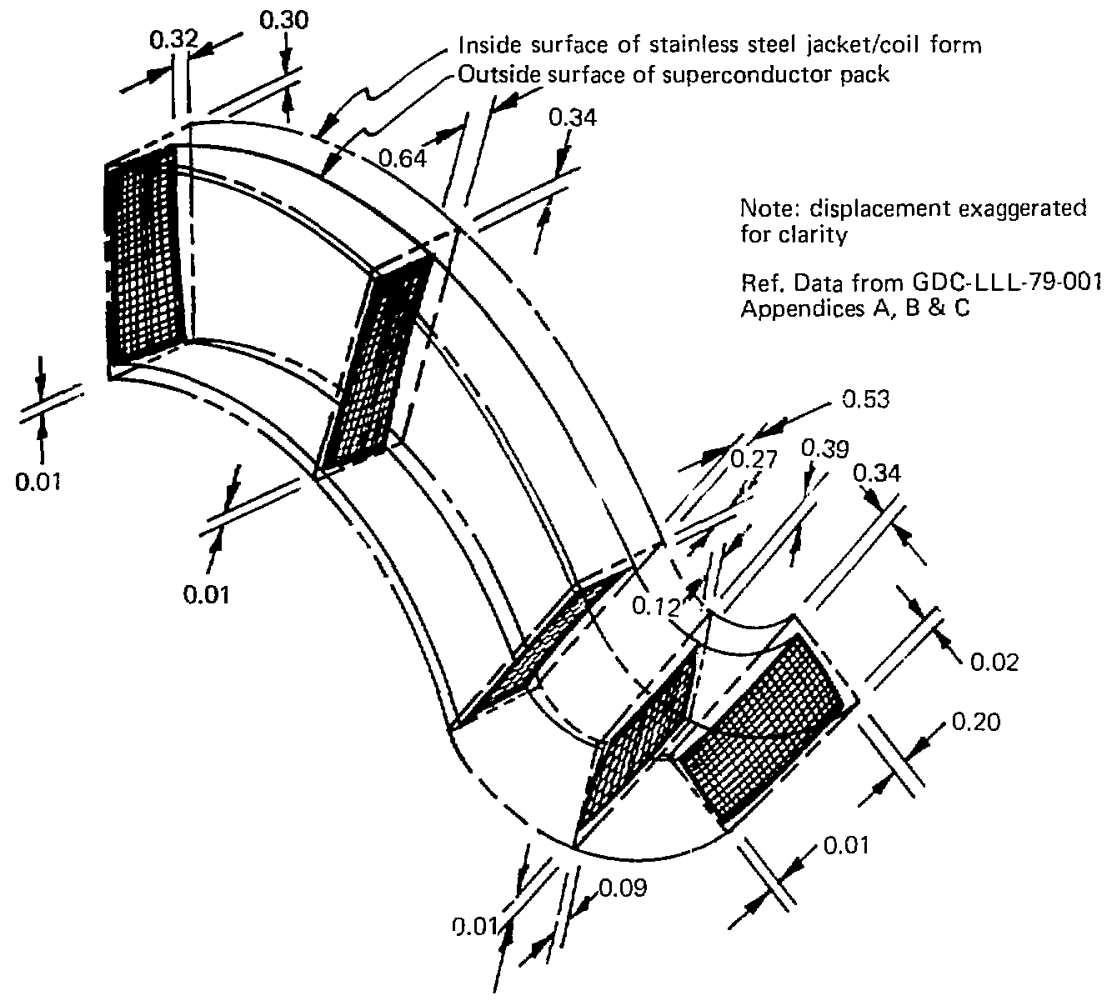

FIG. 23. MFTF average superconductor pazk motien (inches).

such as lead-outs and permanent clanes must be instalicd.

Predicted coil motion also impacted the design of penetrations in the NEMA $\mathrm{J}-11$ sheets where the superconductor must ramp up from one layer to the next. The possibility of a short circuit due to relative motion of adjacent layers was eliminated by surrounding the conductor penctrations with NEMA G-11 blocks. This arrangement salely allows over $3 / 8$ in. of relative interlayer motion, 30 to 40 times the amount that is predicted by idealized analyses. Large excursions could occur if layers were to seize rather than slip. Even though this is highly unlikely, the esnservative penetration design allows for these movements.

Seneral other details of coil internal design were influenced by predicted coil notion. Superconductor strain-gauge leads were routed and strainrelieved to allow for motion of the gatuged region. Interturn button insulation was glued to a woven string and slots in the interlayer sheets were made too small for the butlo.?s to pass through. in order to mechanically trap the buttons if they are scoured off of the superionductor. Coil leitd-outs were positioned to allow coil pack motion to occur without mechani ally loading the lead assemblits. 
Glut blocks on the outer edge of the interlayer insulation provide a flat machined surface for slipplane motion.

The MFTF coil pack mechanical behavior may best be summarized by two statements: Much effort was put ints winding light coils to minimize the coil pack motion that was predicted by analyses. Given the directions and relative magnitudes of the expected motion, coil internal details were designed to allow for several times the anticipated loads and motion without compromising magnel performance. 


\section{SECTION 4 \\ COIL WINDING}

\section{INTRODUCTION}

This section describes the basic criteria used in the winding of the MFTF yin-yang magnets. It also covers the equipment, special tooling, and materials necessary for the winding ind enclosure of the coil in a 0.5 -in.-thick stainless-steel jacket.

\section{COIL GEOMETRY}

The yin-yang magnet consists of two C-shaped coils that are enclosed in a structural case and attached roughly in the shape of a ball. Figure 24 depicts the geometry of one coil and Table 8 lists coil dimensions.

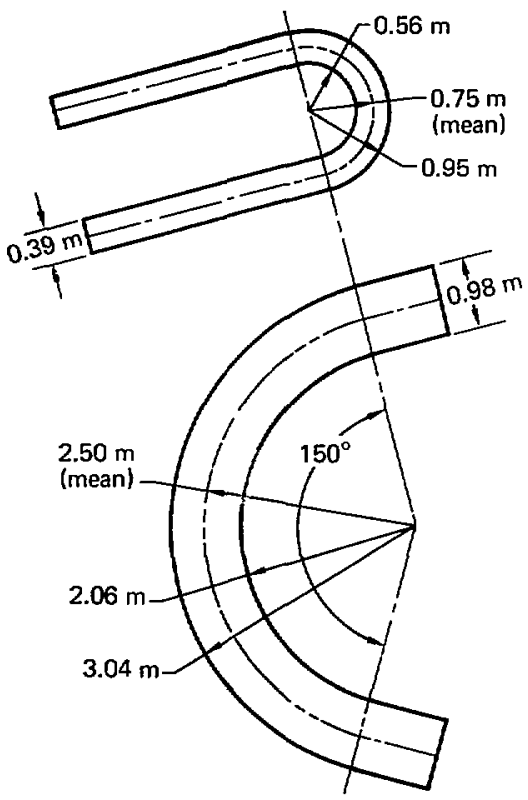

FIG. 24. MFTF coil geometry outline.
TABLE 8. C-coil dimensions.

\begin{tabular}{lcc}
\hline & \multicolumn{2}{c}{ Value } \\
\cline { 2 - 3 } Parumeter & Mleters & Inches \\
\hline Major radius & & \\
Minor radius & 2.50 & 98.45 \\
Cruss section & 0.75 & 29.53 \\
Height & & \\
Width & 0.98 & 38.58 \\
\hline
\end{tabular}

The coil is wound in pancake construction with superconducting conductor. There are 58 lavers of 24 turns giving a tolal of 1,392 conductor turns.

The lotal length of superconductor used in each coil is $25,000 \mathrm{~m}(82,000 \mathrm{ft})$. A grand total of $50,000 \mathrm{~m}(164,000 \mathrm{ft}$ or $31 \mathrm{mi})$ of superconductor is required to wind the pair of coils.

\section{COIL WINDING EQUIPMENT}

Before the MFTF coils could be wound it was necessary to design and develop the equipment required. The initial concepts provided by A. R. Harvey were based on experience winding the baseball coils and other similar coils. These concepts were pursued by R. C. Ling, R. E. Hinkle, and EG\&G designers. The winding machine, reel support, conductor spools, button dispenser, and cold-welding process were the first to be developed.

\section{MFTF Coil Winding Machine}

The coil winder design was started in August 1976 and the initial design specification ${ }^{+9}$ was released in September 1976. Constructed by Teledyne Readco, York, PA, the winder in Fig. 25 was delivered to LLNL in September 1977.

The coil winder was designed with maximum versatility to allow for future changes in the coil geometry. It is capable of winding a two-axis coil with a miljor radius from $60 \mathrm{in} .(1.5 \mathrm{~m}) 10130 \mathrm{in}$. $(3.3 \mathrm{~m})$ with $360^{\circ}$ of rotation. The minor radits can vary from 12 in. $(0.3 \mathrm{~m})$ to 60 in. $(1.5 \mathrm{~m})$.

The design characteristics ${ }^{50}$ of the coil winder are given in Tible 9. 


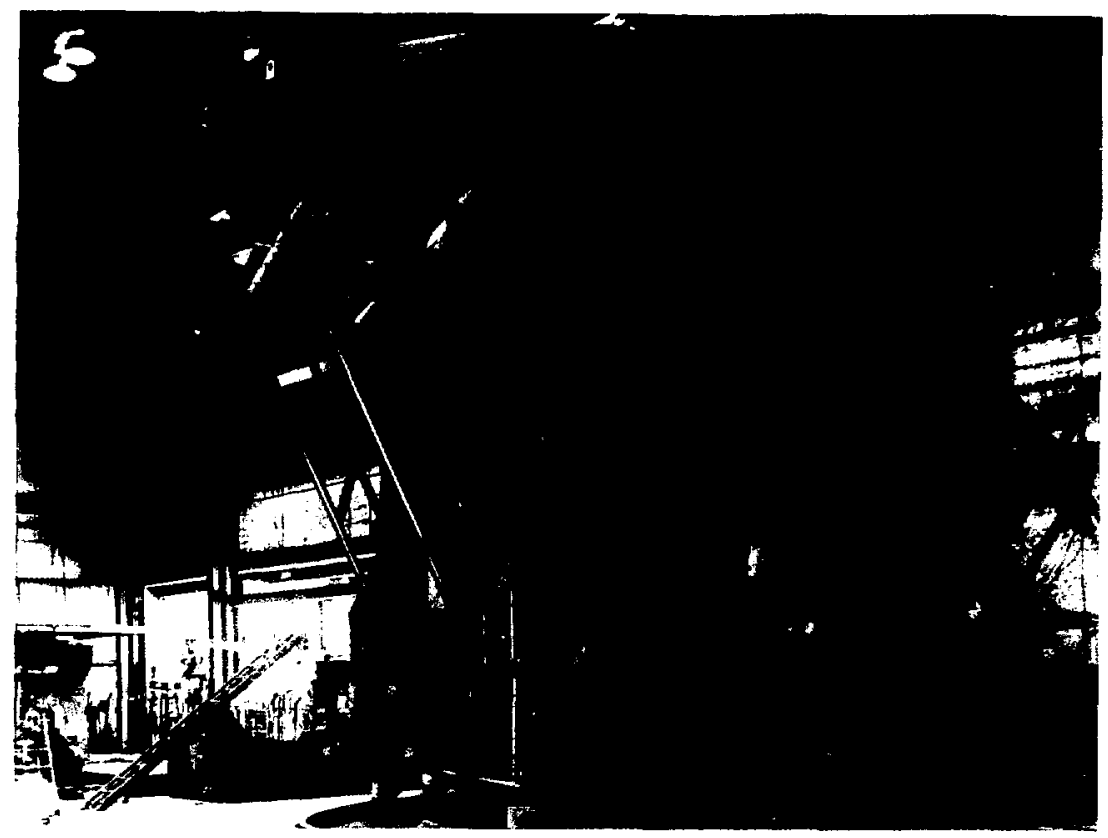

FIG. 25. MFTF coll winding machine.

\section{Reel Support}

The reel support (Fig. 26) wis designed by EG\&G designers under the direction of R. C. Ling 5 l and fabricated by Hopper Manufacturing, Bitkersfield, CA.

The reel support provides two basic functions. One is to support the 11-ft reel of superconsuctor during winding. The other is to provide constant 1ension for the conductor between 50 and 1,000 lb. A counter-balanced weight system is coupled to a torque motor with a center sending device that applies more or less torque to the reel to keep it batianced with the weights. This system was tested with a dynamoneter and strain gauges and found to be accurate within $\pm 50 \mathrm{lb}$. The entire upper ussembly that supports the reel is floated on air bearings to provide a friction-free motion, and is capable of being elevated and pivoted to keep the conductor in an ideal winding position.

Other design characteristics ${ }^{52}$ for the reel sapport are given in ithle 10.

\section{Button Dispenser}

The button dispenser was initially designed and developed by the LLNL coil shop to apply the interturn insulation buttons to the MFTF test coil. h was redesigned by EG\&G for MFTF winding and later modified by the winding technicians.

The dispenser (Fig. 27) was designed to apply the interturn insulation (buttons) to the conductor's side continuously while the conductor is being wound onlo the coil forn. The basic principle is to apply one drop of Loctite 414 super glue to each button, rotate the button, and hold it tightly agiinst the conductor for a second while the glue sets. Loctite $\$ 414$ was selected after extensive testing. 5.3

\section{Cold Welder}

Figure 28 shows the cold-welding process adupted for the MFTF conductor after use on the MFTF test coil. ${ }^{54}$ Purchased from the Heintz division of the Kelsey Hayes Co., Philadephia, PA, the 
TABLE 9. MrTF magnet winder characteristics.

\begin{tabular}{|c|c|}
\hline Paramcter & Value \\
\hline Design load, lb & $172 \times 10^{3}$ \\
\hline Design toryuc. in.-1b & $6 \times 10^{6}$ \\
\hline \multicolumn{2}{|l|}{ Operating torquc: } \\
\hline No logd, in.-1b & $5.2 \times 10^{6}$ \\
\hline Full load, in.-lin & $5.1 \times 10^{6}$ \\
\hline \multicolumn{2}{|l|}{ Hotation: } \\
\hline $\begin{array}{l}C W \text { and } C C W \text {, both } \\
\text { azimuth and elevation axcs }\end{array}$ & Continuous \\
\hline \multicolumn{2}{|l|}{ Drike spexd: } \\
\hline Arimuth axis, max., rpmı & 0.75 \\
\hline Eletation axis. rpm & 0.20 \\
\hline Opersting temperature, ${ }^{\circ} \mathrm{F}$ & 32 to 110 \\
\hline Design lift, yr & 5 \\
\hline Survital scismic load. $g$ & 0.25 \\
\hline \multicolumn{2}{|c|}{ ['oncr: $480 \mathrm{v}, 3$ phase, fo $\mathrm{Hz}, 150 \mathrm{kw}$ : } \\
\hline Elevalion drive. A & 150 \\
\hline Aximulh drive, A & 100 \\
\hline \multicolumn{2}{|l|}{ Dimensions: } \\
\hline \multicolumn{2}{|l|}{ Height: } \\
\hline No load, it & 23.17 \\
\hline With load, It & 30 \\
\hline \multicolumn{2}{|l|}{ Diameter: } \\
\hline Service platform. It & 32 \\
\hline Bast, ft & $\mathbf{2 t}$ \\
\hline \multicolumn{2}{|l|}{ Wejght: } \\
\hline To load, lb & $351) \times 10^{3}$ \\
\hline With load. it & $522 \times 10^{3}$ \\
\hline
\end{tabular}

welder hydraulically precses the two ends of conductor together, causing a cold flow and molecular bonding of the copper. The Nb-Ti strands do not bond, but do intermesh. The resulting joint is stronger than copper, but not as strong as the conposite.

\section{TOOLING}

Auxiliary tooling encompassed three major areas, adaptors for mounting the coil to the winder. elamping systems to maintain conductor tightness. and the iniscellaneous tooling required for coil finishing. Where possible, initial designs and concepts were fabricated and tried during the construction of the MFTF test coil.

\section{Adaptors}

The need for two adaptors was apparent from the onset of the design: one for holding the coil form
T:ABI.l: 10. Reel support characteristics.

\begin{tabular}{|c|c|}
\hline Parameter & Value \\
\hline Design load, lb & 12,000 \\
\hline Design tension, !b & 600 \\
\hline Verlicle trayed, ff & 4.5 \\
\hline Verticle specd, in. ' $\mathrm{min}^{-1}$ & 3.6 \\
\hline Pivot travel, deg & \pm 7.2 \\
\hline Pivot speed, deg $\cdot \min ^{-1}$ & 2.4 \\
\hline Recl drive: bidirectional & $\begin{array}{l}\text { Continutous-duty } \\
\text { ae torque motor }\end{array}$ \\
\hline Operating temperature, ${ }^{\circ} \mathrm{F}$ & $32+10$ \\
\hline Operating humidity, \% & 12 to 95 \\
\hline Operuting tife, yr & 5 \\
\hline Seismic loud, a & 0.25 \\
\hline \multicolumn{2}{|l|}{ Dimensions: } \\
\hline 1.ength, ft & w \\
\hline Width, ft & 10 \\
\hline Height, it & 30 \\
\hline Weight: without reel, It & 21.000 \\
\hline \multicolumn{2}{|l|}{ Recl size: } \\
\hline o.d., it & 11.17 \\
\hline Width, it & 2.33 \\
\hline Hub diameter, ft & 111.5 \\
\hline $\begin{array}{l}\text { Hecl weight: with } \\
9.0(\text { It of supercunductor, th }\end{array}$ & 11.5100 \\
\hline
\end{tabular}

while winding and one for mounting the coil-form adiptor to the coil winder. Figure 25 shows the covilform-lo-coil-winder adaptor in place on the winder. This was designed at LLNL in conjunction with Teledyne Readcos during the winder construction.

The coil-mounting adaptor was designed by EG\& $G^{j 6}$ and constructed by FMC Corporation. San Jose, $\mathrm{CA}$. along with the toil form. The design was to support a dead weight of 60 tons and a winding torque of $5,000 \mathrm{ft}-\mathrm{lb}$ with a salety factor of 2.5. It had to be easily removable so that mininum strain would be placed on the finished coil during disassembly.

\section{Clamping Systems}

The need for quick-acing movable clamps for winding, and permanently fixed clamps for holding a layer after winding, was evident from experience with the baseball coil and the MFTF test coil.

The clamps were reduced to two types, end clamps $5^{57}$ and side clamps. . $^{5.59}$ Four end tlamps, slown in Fig. 29, are mounted on each end of the 


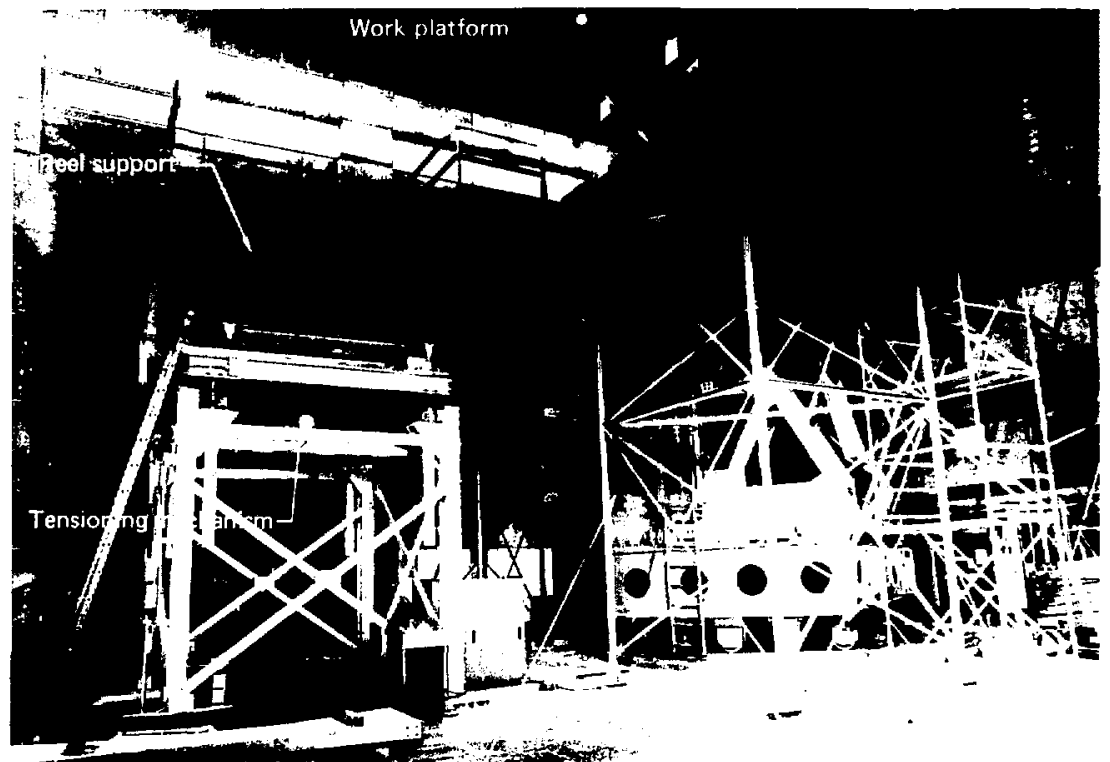

Coil winding machfine

FIG. 26. MFTF reel support.

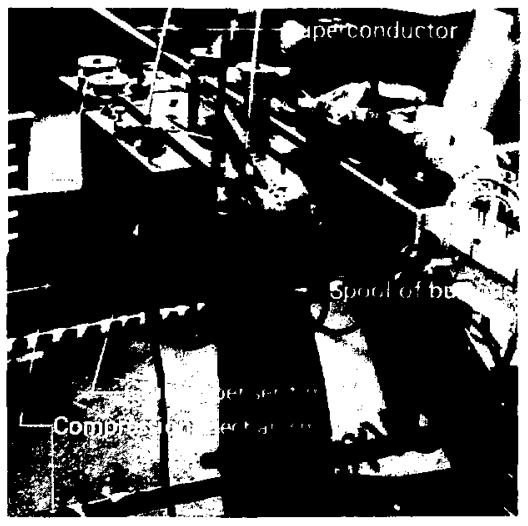

FIG. 27. MFTF winding button dispenser.

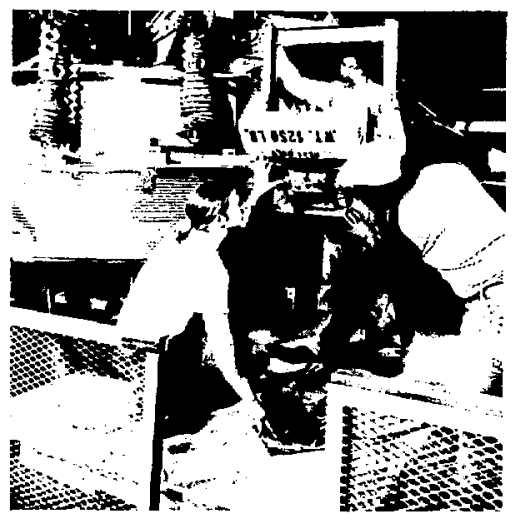

FIG. 28. Cold-welding process. 


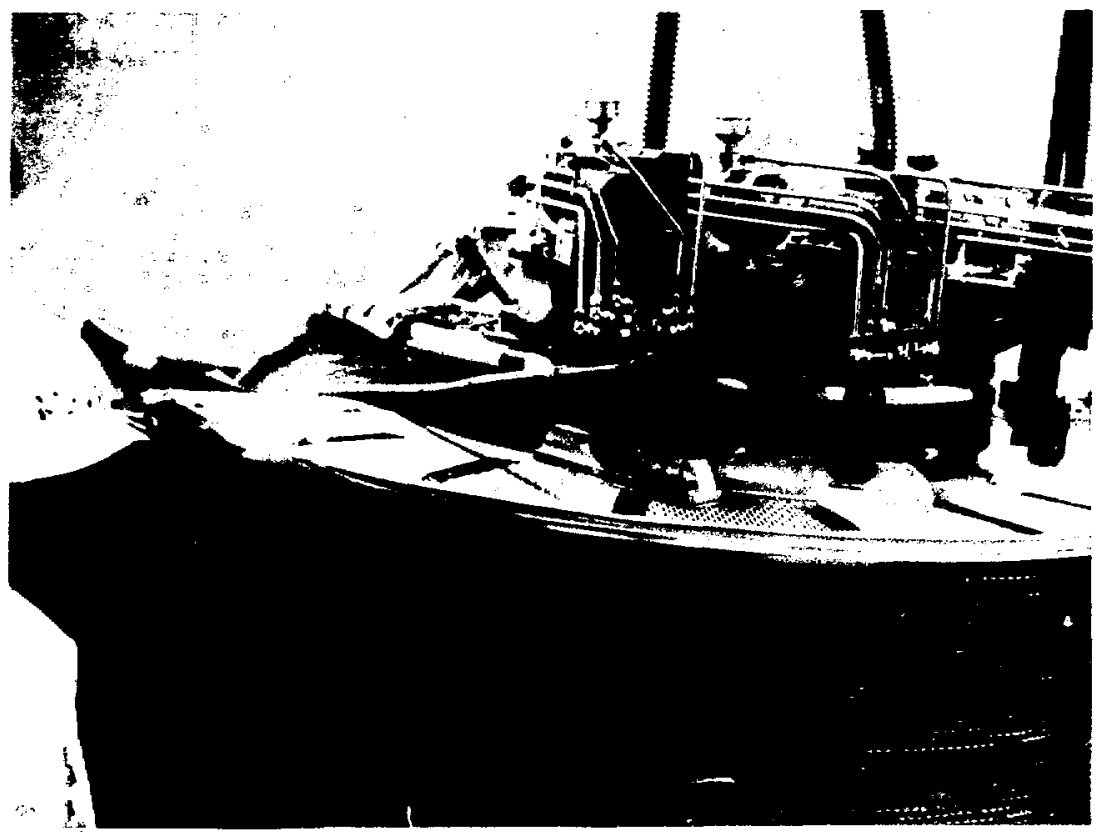

FIG. 29. End winding clamps.

coil-mounting adapter. Each clamp is pneumatically operated and capable of being swung out of the way. Each exerts an axial downward thrust of 1,500 to 2,500 lb.60

There are five sets of side clamps (see Fig. 30) on each side of the large radius of the coil form. They use a scew thread with a quick aeting spring detent to produce fast lateral movement and telescope for verticle movement. The side clamps are designed to exert a lateral force of $500 \mathrm{lb}^{61}$ to hold each turn in position during the winding. Upon completion of the layer. the clamps are reset to hold the first turn of the next layer. To hold the previous layer in place fixed clamps were required.

The lower clumps shown in Fig. 31 were designed und constructed by EG\&G to support the sides of the windings. They are stack able I-in.-thick plates capable of exerting $500 \mathrm{lb}$ of force in two places by the use of set serews.

Permanent end clanps in Fig. 32 were designed ${ }^{62}$ :o replace the end winding clamps. They are 1/2-in.-Lhick, 316L stainless-steel plates, held in place by 1/2-in.-diam bolts on the outside and by 3/8-in.-diam bolts on the inside. The unside bolts are part of the weld-backing bar. The entire system of bolts is torqued to $40 \mathrm{ft}$-lb each to replace the accumulated $6.000 \mathrm{lb}$ of end-clamping force.

Tooling tables were designed and constructed by EG\&G to provide : stible support for the tower clamps and side elamps. This can be seen in Fig. 30.

Miscellaneous tooling covers items that have been developed by the winding technicians and LLNL design team. The major inem is the routing fixture (Fig. 33). it is constructed from tho sets of linear ball bushings and shafts hatat are mounted to the coil form to support an air-operated router. ${ }^{63}$ The prime purpose of this tool is to machine a smouth surface on tbe side of the NEMA G-1! fitler blocks. This machined surlace is further sanded to become a smooth load-bearing surface that transmits the electromignet forces to the slip plane and subseguently to the structural sted ciase. 


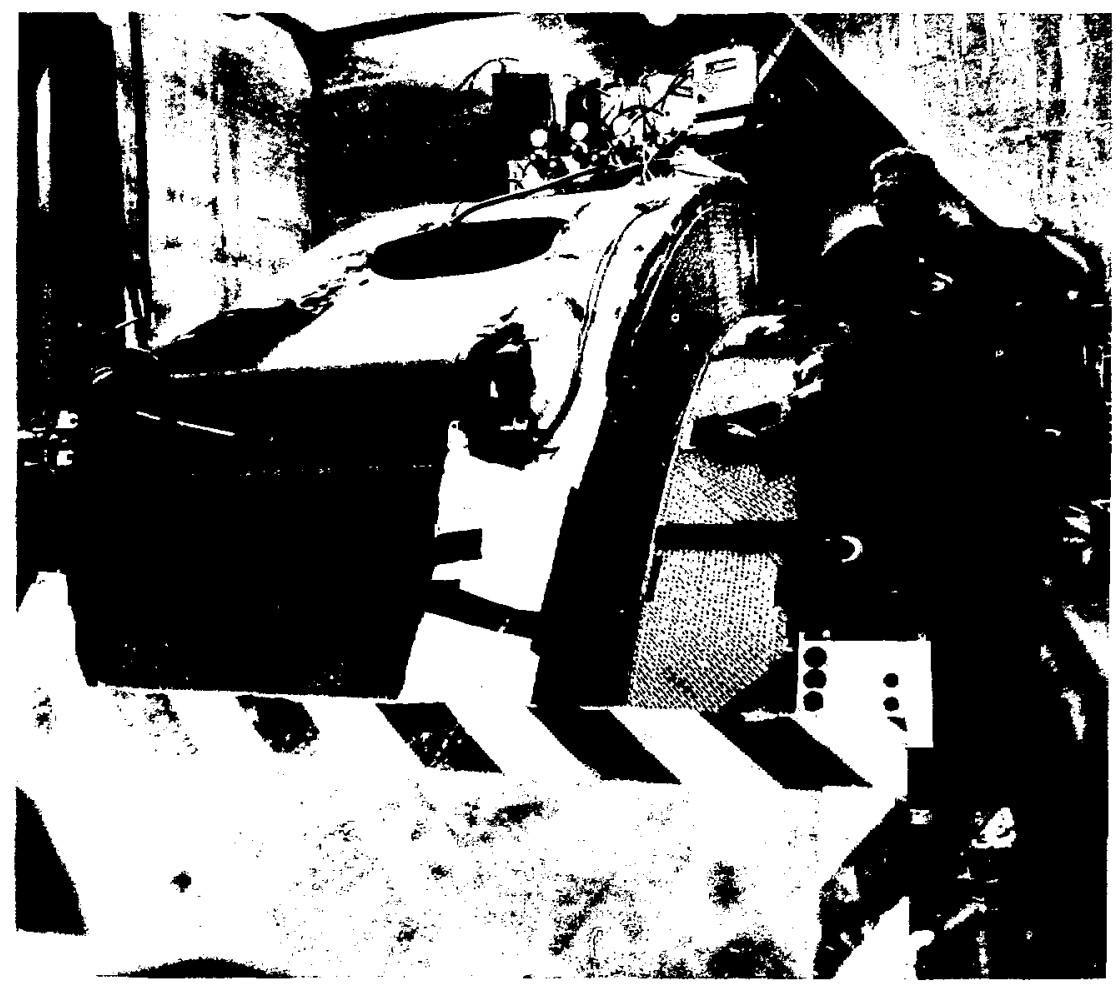

FIG. 30. Side winding clamps.

\section{INSL IATION}

The insulation materials have been successfully used in previous coils. No new or unusual materials have been needed to meet the MFTF magnet insubating reguirements in Table 11.

TABLE II. MFTF magnet voltages.

\begin{tabular}{lc}
\hline Uagnet area & Voliage \\
\hline Ciround plane, V/ds, & 1000 \\
I.ayer-tu-layer, V(de) & 17.3 \\
Jurn-to-turn, V(de) & 0.7 \\
\hline
\end{tabular}

The biggest insulation problem is to prevent arcing in gastous helium as predicted by the Paschen curve in Fig. 34 for helium at $20^{\circ} \mathrm{C}$ and l atm.

\section{Interturn Insulation (Buttons)}

The design of the interturn insulation was taken from the Baseball II coil with improvements. The insulation must be capable of bending in two directions to conform to the cuil geonetry: it must alsu leave space for the liquid helium to circulate. The button approuch that was developed for the Baseball II eoil depended upon the glue hond to keep the buttons spaced along the conductor. The improved version (Fig. 35) added a Dacron string attached to the buttons for spacing. 


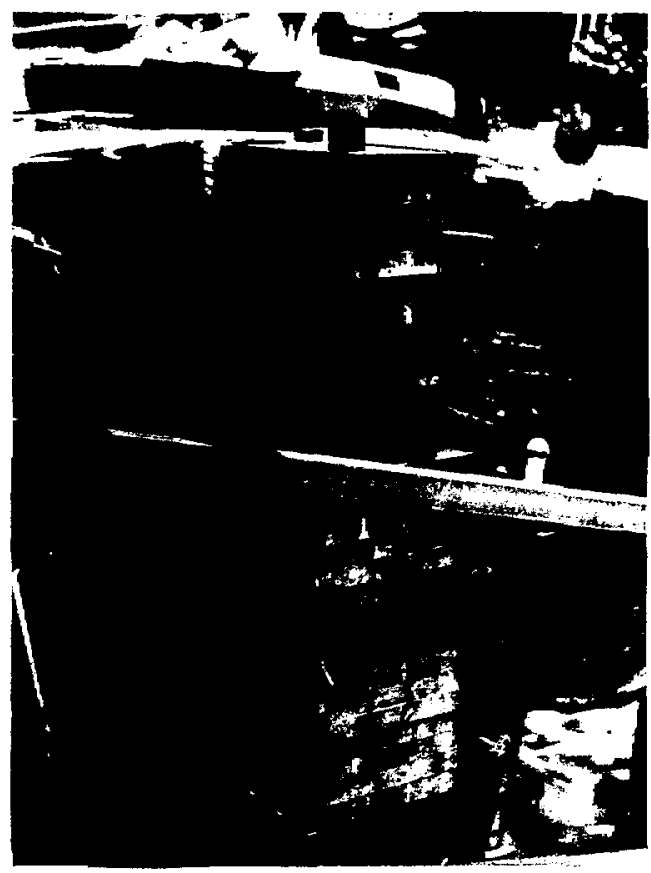

FIG. 3I. Tower clamps.

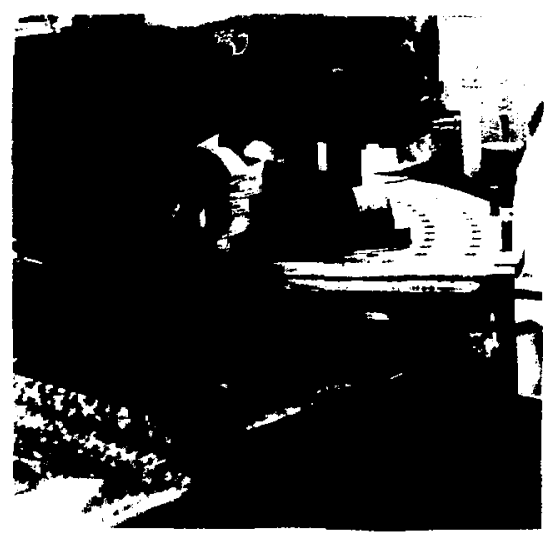

FIG. 32. Permanent end clamps.
The bution is an octagonally shaped 0.040-in.thick piece of NI:M: C C-11 with a groove in the center. Since the breakdown voltage ${ }^{6+t}$ on the NEMA $\mathrm{G}-11$ is $700 \mathrm{x} \cdot \mathrm{mil}^{-3}$ at room temperature the interturn insulation requirements were easily met.

Because of poor vender ferformance LLNL was fored to undertake the job of designing the machine to produce the buttons at the rate of at least 1.500 ft iday. R. Leber (MFED) was responsible for the success of this task. The MFTF winding technicians now produce the interturn buttons on three machines in aceoruanee with the manulacturing process as outlined:

Sheet Material. Sheel material of NEMA G-11 is procured by LLNL and surfaced to maintain a uniform 0.040 in. with a 0.002-in. Mattness.

Strips. The sheets are semt to a second vendor to be sheared into strips 0.437 -in. wide. A grouve 


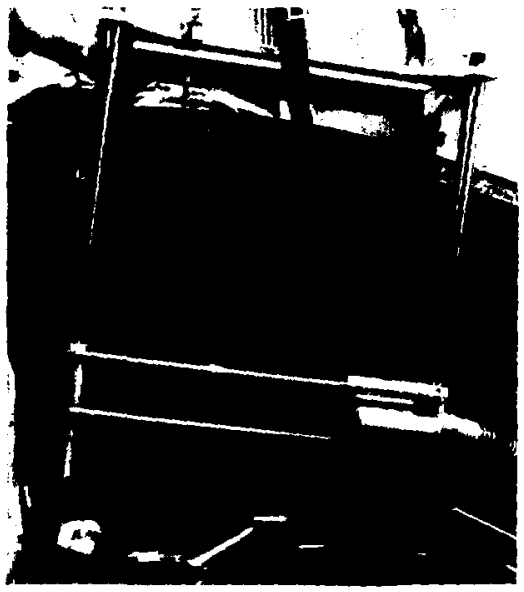

FIC. 33. Router guide assembly.

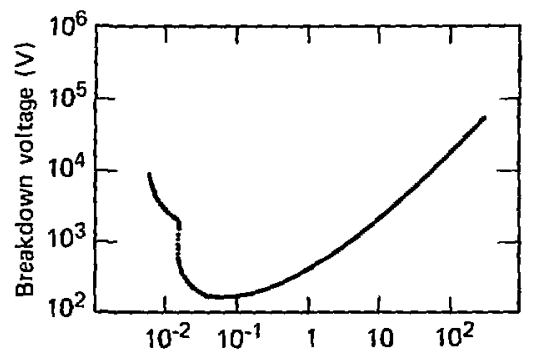

Pressure spacing praduct (bar.mm)

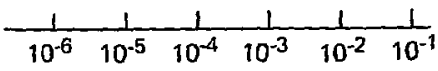

Density spacing product $\left(\mathrm{gm} \cdot \mathrm{cm}^{-3} \cdot \mathrm{mm}\right)$

Notes:

1. Dim. tol. \pm 0.015 except as noted.

2. Cement items 1 to 2 with LLL approved adhesive.

3. Mat"l for item 1 to have surface sanded to thickness tol. shown. Edge finish to be clean sheared or punched.

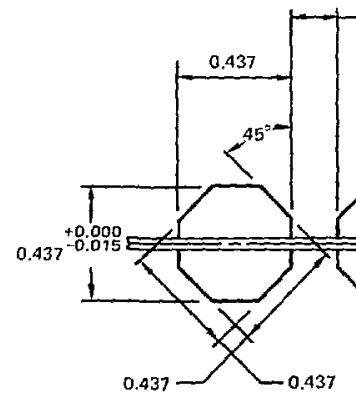

All dimensions typica! and in inches

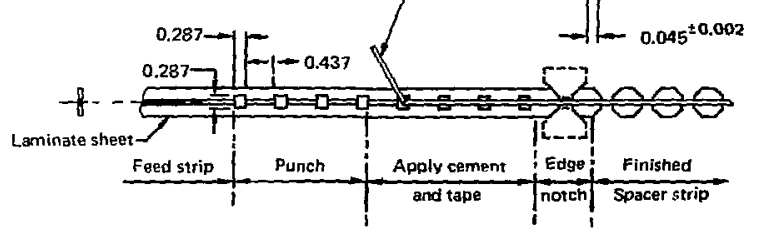

Suggested method of production

FIG. 35. MX coil interturn space strip. 
0.050-in, wide and 0.025 -in. deep is milled in the exact center of each strip, and the strips are sent to LLNL.

Square Punching. The strips are inspected for thickness and groove depth and then run through the machine in Fig. 36 to punch a square hole in an evenly spaced pattern.

Applying the String. The punched strips are fed into the string machine (Fig. 37) which feeds Dacron stririg into the milled groove and applies a single drop of Loctite 414 glus 33 to the joint. This newly formed ribbon of punched strips is wound onto a plastic spool.

Button Punching. The square-punched ribbon is run through a second punching operation which removes the remainder of the square hole and chamfers the edges of the remaining center piece. What remains is an octagonal-shaped button glued to the string. This is respooled onto a $400-\mathrm{ft}$ capacity spool with a ribbon of Mylar between each layer of buttons to prevent them from twisting. Figure 38 shows the bution punch with some loose buttons being refastened to the string.

\section{Interlayer Insulation}

The interlayer insulation (Fig. 30) is fibricated in 36-in.-wide by 48-in.-long sheets 1/16-in. thick. LLNL drawing No. AAA78-110166 depiets the geometry of the perforations. Nominally the material is punched with a $3 / 16$-in. wide $\times 1.5$-in. long slot spaced 3/16-in. apart.

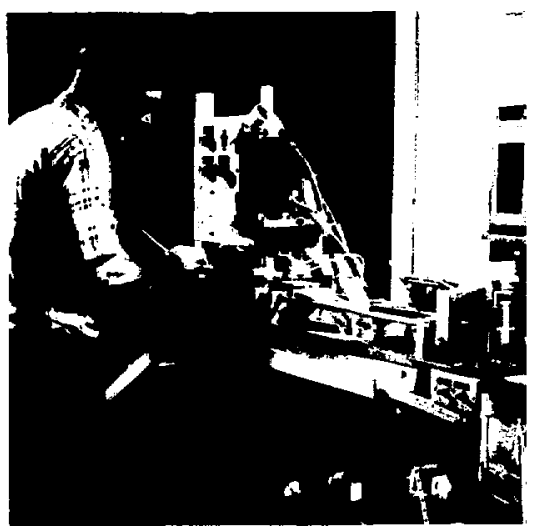

FIC. 36. Square-punching machine.
These sheets are sand blasted at LLNL and then cut to fit the coil form in such a manner that the slots are $45^{\circ}$ off the vertical centerline of the conductor.

\section{Ground Plane Insulation}

The material selected for the ground plane insulation is Kapton. lt wis selected because of its excellent breakdown voltages of $3,600 \mathrm{~V} \cdot \mathrm{mit}^{-1}$ at room temperalure. which increatses to 10,800 $\mathrm{V} \cdot m i^{-1}$ at $-195^{\circ} \mathrm{C}^{\text {t.5 }} \mathrm{Table} 12$ shows the mechanical properties of Kapton.

The Katon is applied to the coil form in 2and 4-in.-wide strips (see Fig. 39). Each strip is bonded with $3 \mathrm{M} * 714$ glate and placed so it overlaps the previous one by $50 \%$. A second liner is placed over the lirst in the same manner with the overlapping being $50 \%$. This process is continued for live layers to produce a type of baffled pathway that is at least 2-in. long for protcction from arcing to ground.

Kapton exhibits an additional characteristic of being able to withstand $400^{\circ} \mathrm{C}$ which gives additional protection from damage during closurc welding.

\section{Plenum Chamber}

When the magnet is operating the liquid helium coolant has bubbles of gals for whicli a path of escale must be provided. To accommodate the gas bubbles, 3 in. of space was left between the last tayer of conductor and the coil jacket. It is this space that is referred lo as the plenum chamber.

The 3-in. space has to be filled with a porous material that is sapable of transnitting loads from the conductor pack to the jacket. The material selected was the interlayer insulating material previously described. The orientation of the perforations was studicd to determine an optimum path for the bubbles. The selected scheme was to bond four shects together with the perforations in line. These then were bonded to four sheets of similar construction except that the perforations were rotaled $45-90^{\circ}$. This scheme of four slieets one way and then four the other $u$ ax continued until the entire space wats filled.

\section{Slip Plane}

The conductor motion analysis"2 shows that the conductor is going to compress until all the winding gaps are closed and then move out towards 


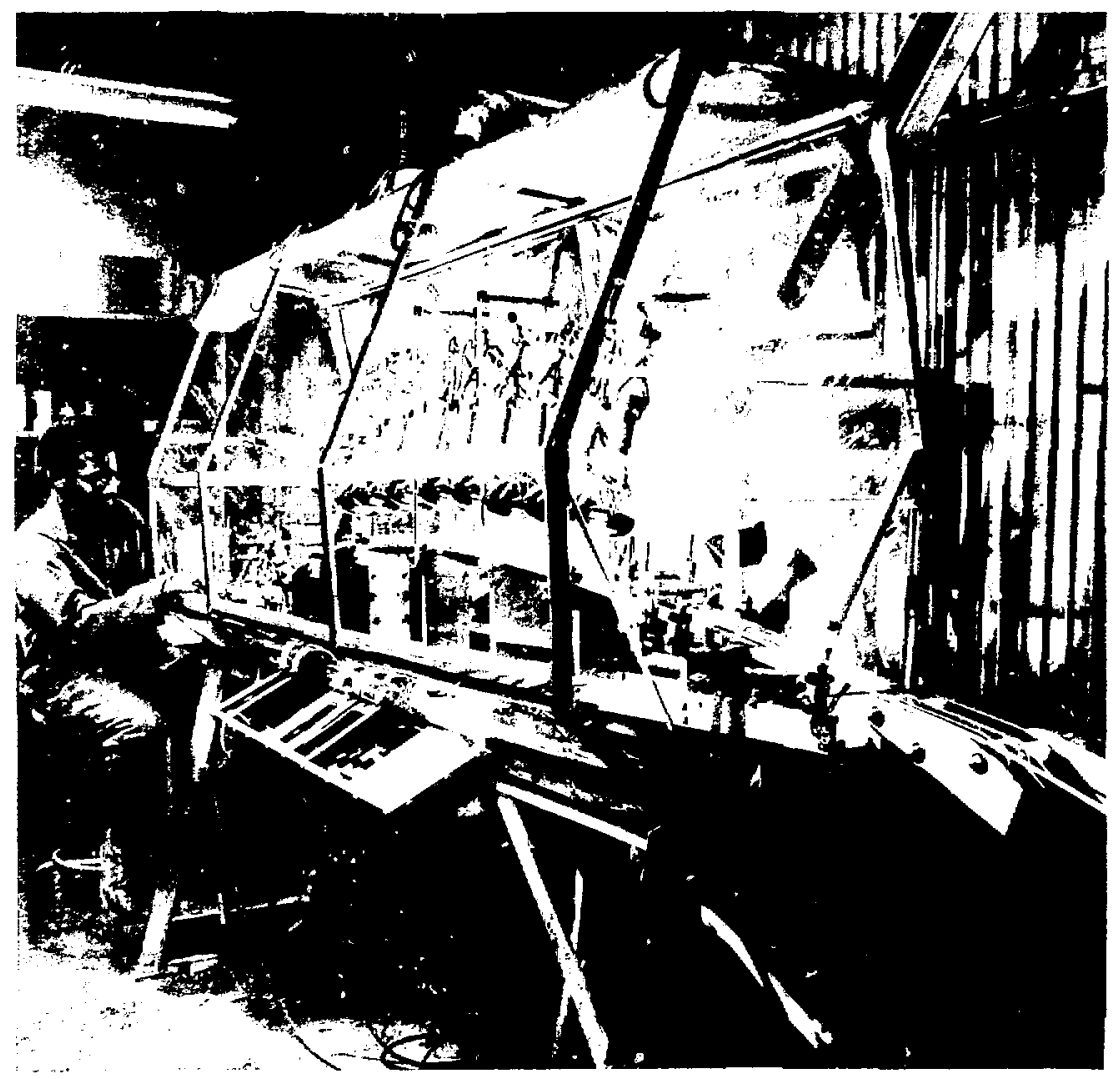

FIG. 37. String-application machine.

the 1/2-in. jacket. To accommodate this motion a slip plane has been provided to reduce the coefficient of friction and provide a sacrificial layer of material if local deformations are excessive.

Sanples were produced that duplicated the edge construction of the NEMA G-11 glue blocks and tested in a special fixiure at both room and liquid nitrogen temperature. They were placed against sample slip planes and loaded with a controlled foree while a measured foree was applied to start the materials slipping. Table 13 is a summary of the lest results,
The Mylar-un-Mylar system was selected because it did not exhibit stick-slip behavior and avoided the uncertainties of the addition of the moly-disulfide power into the system.

\section{Glue Blocks and Filler Blocks}

The material seleeted to fill the inside of the coil from the conductor to the slip plane is NEMA G-1I.

Glue Blocks. The glue blocks (Fig. 33) are fabricated with 1/2-in.-wide $\times 1 / 32$-in.-thick $\times 40$ in.-long strips of NEMA G-11. Euch strip is 
bonded, on a curved form, to the next strip using Epoxy 815 and versimide hardner. These strips are built up to approximately 0.45 -in. thick.

The inside edges of the completed blocks are chamfered approximately $1 / 8$-in. wide by $1 / 8$-in. deep, and grooves are cut every inch to provide cooling along the surface of the conductor.

Once a glue block is bonded to the interlayer insulation it will provide $500 \mathrm{lb}-\mathrm{in} \mathrm{-}^{-1}$ of support, in shear, to hold the liner light against the coil form. Once these perniment side clamps are instialled they can hold the conductor in place and the Tower clamps are removed.

Filler Blocks. The filler blocks are of a similar design except they are machined to lit the outside of the conductor pack at the smill radius. Tbey provide a solid filler between the conductor and the jacket.

Felt Filler. To provide for the conductor pack motion previously discussed, it is necessiary to allow

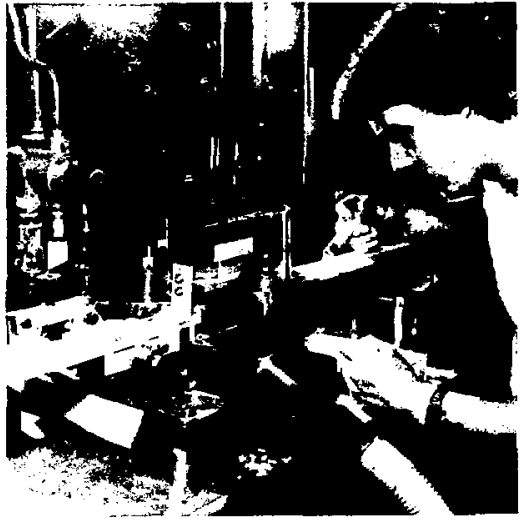

FIG. 38. Button-making machine.

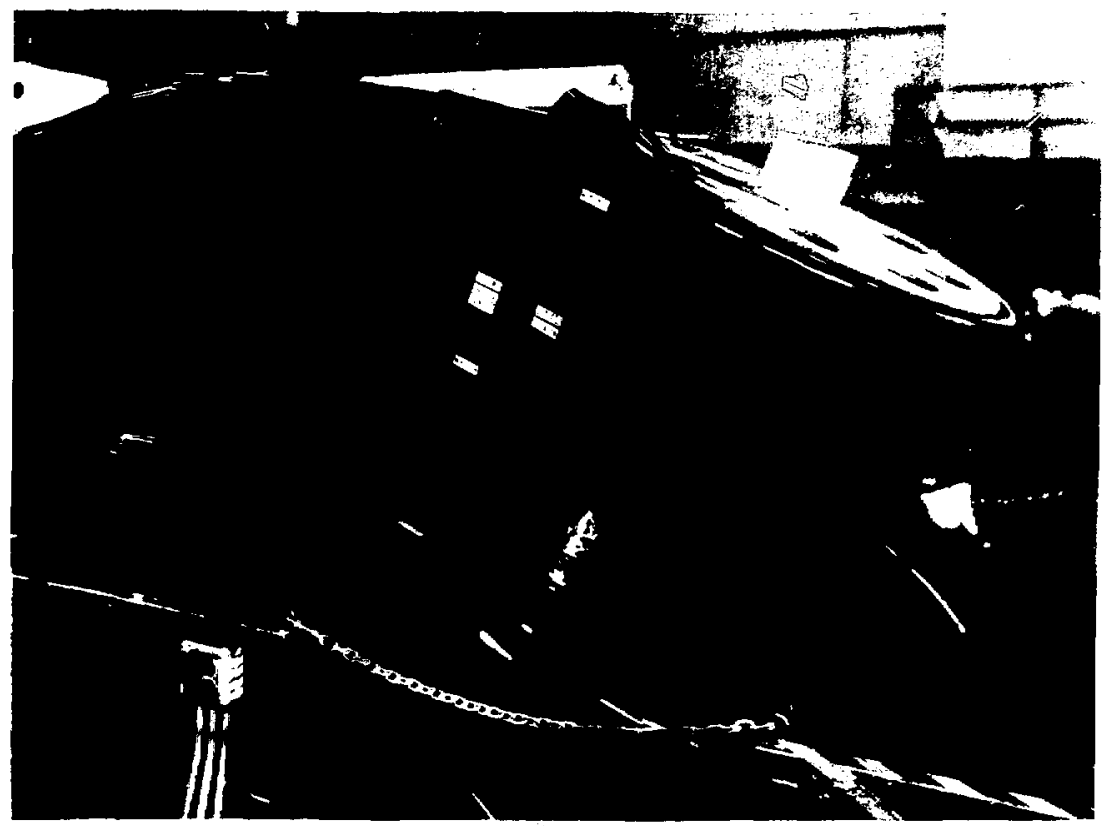

FIC;. 39. Coil form No. 1 ground plane installation. 
TABLE 12. Properties of Kapton-type H. ${ }^{75}$

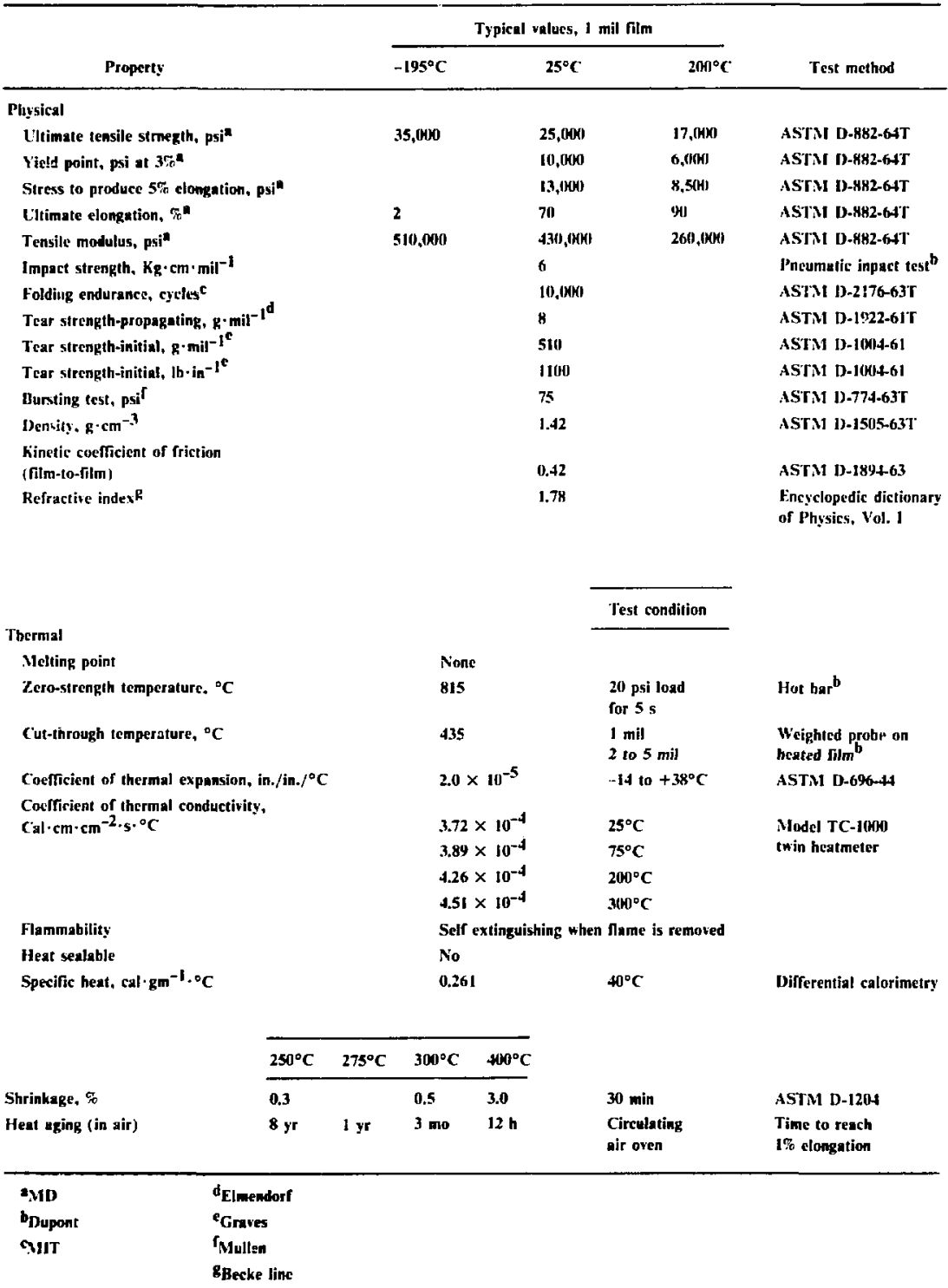


TABLE 13. Coefficient of static friction test summary.

\begin{tabular}{lll}
\hline Material & $\begin{array}{c}\text { Room } \\
\text { temperature }\end{array}$ & $\begin{array}{c}\text { LN } \\
\text { temperature }\end{array}$ \\
\hline G-11 on G-11 & 0.3 to 0.35 & 0.3 to 0.35 \\
N1ylar/moly/Nyylar & 0.13 to 0.16 & 0.13 to $0.16^{\mathrm{a}}$ \\
Wylar-on-N1ylar & 0.13 to 0.16 & 0.13 to 0.16 \\
\hline
\end{tabular}

${ }^{a}$ Cotfficient of sliding friction dropped to 0.99 with moly cuating.

the conductor at the small radius to move radially outward. This molion is permilted by plating $3 / 8$ in. of felt beiween the Kapton and the filler blocks. The felt will compress allowing the conductor to displace at aut 0.120 in ?2

\section{Filler Material}

Upon completion of the coil winding the coil is built up with the glue blocks, slip plane, Kapton and NEMA G-11 sheats. The jacket, 1/2-in.-thick 316L stainiess steel, is fitted to the extcrior of the toil pack. Nominally there is 1/4-in. of clearance. This volume is filled with Epon 815 with chopped fibers and versimide hardener. Figure 40 shows the top filler on the end of the first coil. When this filler is ered the jacket is welded into nlace. The nller

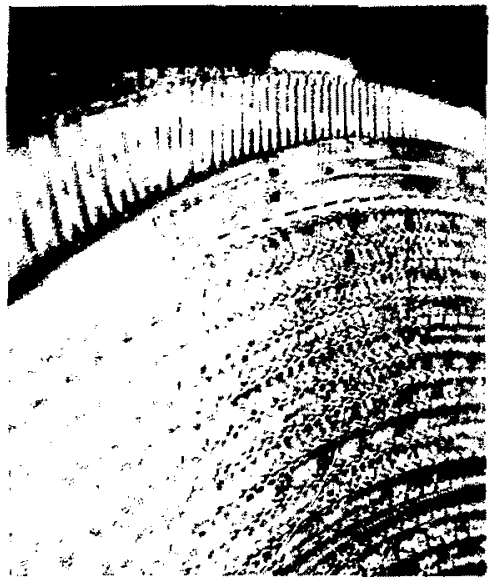

FIC. 40. External joint. provides a light load transmiting media to the jacket from the conductor pack.

A washer test was made using the Epon 815 and glass-fiber compound $A$ barge steel washer was imbedded into a sample of the material and then thermal cycled 10 times in liquid nitrogen. No cracking was observed from expansion and contraction. Compression tests were made in the LLNL Test Laboratery using the same composition. The results were 10,000 psi to fajlure in compression, correspondiag to a safety factor of 4 compared to the 2500-psi maximum load predicted by analysis, to

\section{WINDING TECHNIQUES}

Prior to the commencement of winding the first MFTF coil a practice coil form was built and 10,000 $\mathrm{ft}$ of $1 / 2$-in.-square copper vire was wound 10 debug the winding equipment and tooling. From this effort a detailed winding procedure ${ }^{25}$ was prepared which is a living document that is maintained by the engineer in charge of winding.

The lirsl MFTF coil winding was starled in February 1979 and completed six months later, September 1979. This ineluded unwinding the first sis layers, delays due to slivers in the conduetor wrapping process, and several weeks of delay due to conductor shortages. Winding rates of four lavers per week were achieved during the last part of winding when the material logistics were corrected.

\section{CONDUCTOR JOINING}

Joining two pieces of $\mathrm{Nb}$ - $\mathrm{Ti}$ superconductor together has been a subject of extensive study over the past years. Several methods were tested including soft soldering, silver soldering. and cold welding. As mentioned eartier, the cold welding process was the nos satisfatory one. It wats used sucessfully for the MFTF test coil although the joint is not as strong as the parent material. It was decided to increase the cold-weld strengh and redundancy by adding additional stabilizing copper to the sides of the core. ${ }^{67}$ The result of this change was a machined join tray into which the core is soldered after it has been cold velded. Figure 40 shows an external joint completed in the first coil.

The joint is made by stripping bick and remov. ing a section of the copper stabilizer, and then cold welding the ends of the core lugether. The soldwelded joint is then soldered into the copper joim 
tray that provides the mechanical strength ats well as the electrical patly to assure that there is continuity even if the cold weld were to break. Exkensive tensile testing has been donet to verify the design concept. The joined conductor is sronger than the parent material, even when no cold weld was made in the core.

A detailed optrating procedured's as well als detailed check list have been prepared for joints. The linished coil hats a total of 5 s joint. Twenty-six are internal joints (ilgann the coil form) and 26 are ckernal joints as shome in rig. 40.

\section{CIRRENT I.EADS}

I wo carrelat leats are teguired to hook the coil to the externat power stapply. Both leads have been designed" 1 (n) mees the "orst ease conditions; i.t...

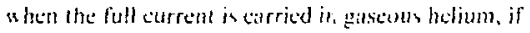
the superconductor geess normat.

\section{Internal lead}

The lead that comnect the end of the first liyer and tracto sertically atcons all is lavers all the center of the umail ratius and along the tup of lager 58 and finally out the heliun exhast port is ealled the inernat lead. This lead is comprated of three masife pieces of copper or bus bars.

\section{External Lead}

The esternat lead in the one that carnes the end of the lase turn of the las bater on through the heliam enatud port. It 10o inconstrueted of a heavy picec of copper bas bar.

The joining of the esnductor to the buse, is dene in a bimilar mamer as the joint tray exatept there is no cold weld.

The copper bus bars inave cooling channels for free heliam flose and a niece of Nb-Ti superconducting core is soldered into al grove along the sides. The superconductor is continuous except for two places a here joining the buses made it impractical. The joining of the copper bus bars was done using Handy and Harman "Easy Flow" silver solder, It hats a niclting itmperalure of $1160^{\circ} \mathrm{F}$. The superconductor was seft soldered in the growes with a $50-50$ soft solder afier the silver-solder joints were made.

Figure 41 shows the current-lead instillation for coil No. 1. LL.NL drawings AAA79-107723, AAA79-107724 and AAA79-10774: describe the bus bars in detail. Drawing AAA79-107727 shows the assembly of the lead buses.

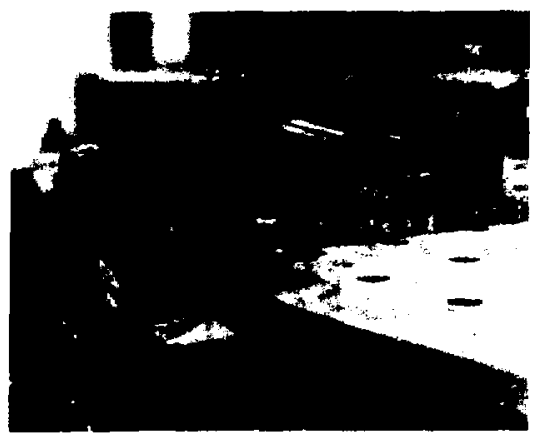

FIG. 4l. Current lead installation for coil No. 1.

The leads ane brought out through the heliun exhaust port. Analysist shous a magnetic atiraction betswerr the leads. They are separated by 2.5 in.-thick NFMA G-11 dividers that have been glued together. The divider is locked into place in the exhatust tube by means of welded guides. The leads are boled to the divider in such a fashion that the bolts do not go through and are separated by a minimum 2-in. space.

\section{COIL CLOSURE}

Figure 42 shows a typical cross section of the coil at the large radius. The closure is done sequentially starting at the small radius ends and progressing lowards the conter.

The general sequence of events in closing the coil are as lollow's:

a. install all the NEMA G-1] glue blucks,

b. rout the glue block surface,

c. install the weld backing bars,

d. install the slip plane,

e. instali the plenum chamber,

f. complete the ground-plane Kapton insulation,

25. fill the remaining volume to within !/4-in. of the jacket with soljd NEMA G-11 material.

$h$ fill the remaining $1 / 4-i n$. with fiber-filled Epon 815,

i. install the jacket section and tack weld in place, and

j. continue the process working from the coil end: to the center. 


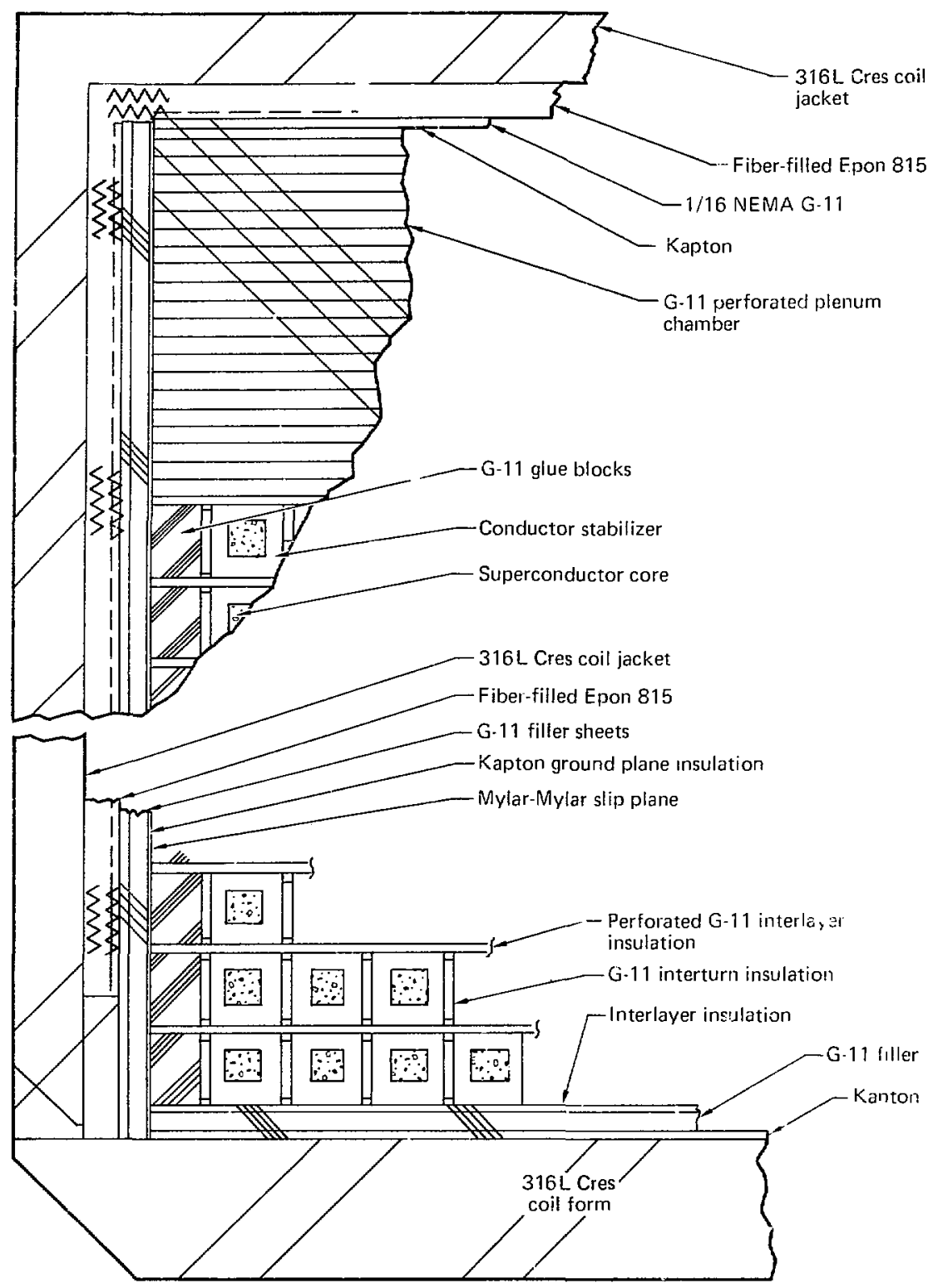

FIG. 42. Large radius-typical cross section. 


\section{INSTRUMENTATION}

Sirain gauges have been installed on the corl form prior to winding as part of the General Dynamice Instrumentation Plan. ${ }^{70}$ Additional strain gages were installed on conductors at liyer 2 and 26 to monitor the conductor motions and strains. ${ }^{47}$

Oner strain gauges were added to the underside of the coil form to monitor the coil form strains during winding. Voltige taps $5^{71}$ "Were installed at part of the coil closure 10 monitor the vollages at various layers of the coil during aperation. Additional voltize laps have been added wo the eurrent leads for similar reasons.

\section{QUALJTY ASSURANCE}

The basic Quality Assurance program for winding is described tia the Magnet Sysiem Qualoty Assuratee P'an (M-078-1)(-01). This plan deseribes s?.e wpe of records to mainiatin als well as responsibilizies of indivaduals.

The detailed Qualu! Assuranee reyuiremens for the winding of the cojls ance given as part of the test of the MlTF Coil winding Procedure (MEL78-001432). This defines the respensibilutes as well as the forms used to report the mealsurements and inspections marle during the uinding operation.
Several inspections are routinely made at the completion of winding a layer:

a. visual inspection for debris, flatness, and any protruding insulation;

h. electritul resistance and Hi-Pol measurements lo detect any shorting or debris that may exist:

c. " winding gap measurements at four points, measuring the stack height and width: and

('. joint inspection tor cleanline:ss.

All ancmalies are corrected before continuing io wind the next layer.

Check lists are used for each joint to assure that no detiil is overlooked in the process. Each step of the procedise is signed of by the operator, and the linal tiat is sued by the shift supervisor.

Onerating, vocedures are specified for each oper tion. These are referenced in the coil winding procedure and all are available on the winding platform.

Shift log bonks and photographic records are mainatined to re ord problems and progress. Each shill supervisur completes a new page each shift.

All of the data is reviewed daily by the engineer in tharge of winding. Any discrepancies are recorded on a Nonconformance Report which is reviewed by a Materials Review Bourd that decides upon the corrective action or disposition of the discrepincy. 


\section{SECTION 5 \\ THERMAL ANALYSIS}

The cooldown and warmup thermal analyses of the Lawrence Livermore National Laboratory (LiNL) Mirror Fusion Test Facility (MFTF) magnet system included investigation of a broad range of flow rates and supply temperature schedules. At the onset of these studies there were several objectives or design goals: (1) to cool down and warm up the magnet system within three to five days: (2) to yield acceptable levels of thermally induced stresses resulting from transverse and longitudinal temperature differentials: and (3) to yield acceptable stress levels with or without flow imbalances in separate sections of the magnet. All of these analysis objectives were met.

Details of the initial studies are contained in Ref. 72. As the design evolved and the interplay between thermodynamic and structural analysis became better understood, an iteration of the detailed cooldown and warmup analyses was performed. This analysis particularly emphasized longitudinal temperature variations and is con- tained in Ref. 73. This document is a condensation and integration of the results of those two prior studies.

\section{COOLDOWN AND WARMUP BASIC ASSUMPTIONS}

Cooldown and warmup of the MFTF magnet is achieved by means of helium through-llow in two separate, parallel-flow passages: one through the conductor bundle, and the other through the guard vacuum. A mass flow fraction for each of the parallel flows was apportioned on the basis of the relative mass to be cooled or warmed, $19 \%$ of the total flow to the conductor, and $81 \%$ to the guard vacuum. The latter flow split was established early in the program and maintained throughout. Subsequent incorporation of additional mass to the magnet case in the form of stiffeners did not alter this recommendation.

The magnet assembly was modeled numerically (Fig. 43) in terms of successive arrays of block-type

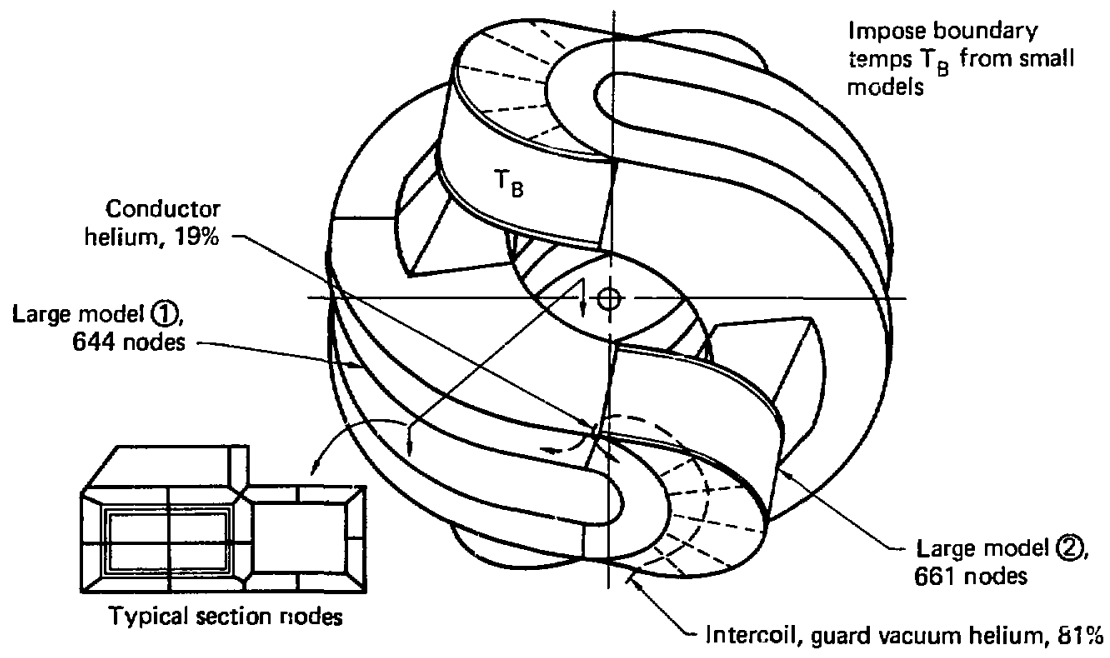

Plan as viewed from below magnet

FIG. 43. Cooldown and warmup analysis large models (1) and (2) address transverse thermul gradients. 
nodes (i.e., rectangular paralleiepipeds) representing elemental masses of conductor region, potting, jacket, case, coil-extension structure, and intercoil structure. The block-type nodes were provided with convective linkages to adjacent helium-flow nodes, which were crdered directionally to appropriately model the helium throughflow. Convective linkages between flow nodes and surfaces of conductor nodes were based on a laminar flow Nusselt number of 4.0, an effective hydraulic diam of $0.131 \mathrm{~cm}$, and a surface area per conductor of $8.17 \mathrm{~cm}^{2} / \mathrm{cm}$. Euch conductor region node contains 348 conduetors.

Guard-vacuum-space helium flow includes flow between the jacket and the case, and between the guard-vacuum baffle and the case. Flow passages of $1 / 8$-in. depth in the jacket cavity and $1 / 4$-in. depth in the baffled cavity cover $50 \%$ of the case inner surface, and a laninar Nusselt number of 4.0 was again assumed. Helium flow passes through the intercoil and coil extension structures prior to entering the guard-vacuum space. For the intercoil and coil exiension surfaces, a turbulent-flow natural-convection Nusselt number was computed:

$$
N_{N u}=0.13(\mathrm{GrPr})^{1 / 3} .
$$

The flow rates employed in the cooldown and warmup analyses, up to $340 \mathrm{~g} / \mathrm{s}$, represented a preliminary value supplied by LLNL. Supply temperatures for flow schedules were assumed to be controlled on the basis of a measured case temperature located at the lower minor radius. Local flow iates contacting each convectively cooled or heated node were apportioned based on ratios of locil-to-total cross-suctional flow area.

Effective properties of the conductor region nodies were computed by an independent analysis, in which mass-weighted average specilic heats were generated as functions of temperature, and series/parallel conductive linkages were resolved into directional thermal conductivities, also as functions of temperature. Appropriate heat and conductivity data for 316 SS, 304 SS, and NEMA G-11 fiberglass epoxy werc obtained from the exit near the topmost location of the coil jackel. These several flow paths and splits were simulated in both large and small analysis models. Figure 44 shuws a worst-case flow-rate schedule where $340 \mathrm{~g} / \mathrm{s}$ of helium enters the magnet during the time that return temperature is $300 \mathrm{~K}$ and varies linearly to
$150 \mathrm{~g} / \mathrm{s}$ with return temperature decreasing to $100 \mathrm{~K}$ and remains at $150 \mathrm{~g} / \mathrm{s}$ for return temperatures decreasing to $4.5 \mathrm{~K}$. The accompanying inlet temperature profile consisted of two steps: $80 \mathrm{~K}$ for return temperature $>100 \mathrm{~K}$ and $4.5 \mathrm{~K}$ for return temperature $<100 \mathrm{~K}$.

Because the external case stiffeners of Large Model 1 do not have a direct convective linkage to the cooldown/warmup helium, it was anticipated that they would sustain the most severe transverse temperature differentials. Large Model 1 was therefore run with the severe cooldown flow schedule of $340 \mathrm{~g} / \mathrm{s}$ and $136 \mathrm{~g} / \mathrm{s}$ at $300 \mathrm{~K}$ return temperature to assess the effects of flow rite on transverse differentials. Large Model 2 was run only with the cooldown flow schedule with $136 \mathrm{~g} / \mathrm{s}$ initial flow rate. The small model was run with these as well as several other cooldown and warmup flow schedules including constant flow rates.

\section{ANALYSIS RESULTS}

Figure 45 shows resulting transverse differcntials and cooldown duration as a function of the flow rate with $300 \mathrm{~K}$ return temperature. This severe flow rate and inlet temperature profile is responsible for the large temperature differentials. Structural analysis of this maximum differential beiween the stiffener, which is not direetly cooled, and the rest of the magnet which is "wetted" by cooldown helium gas, shows that the temperature differential up to $180 \mathrm{~g} / \mathrm{s}$ yields acceptuble stress levels. This corresponds to a minimum cooldown duration of $44 \mathrm{~h}$.

Figure 46 shows the detailed temperature history data during cooldown with an initial flow rate of $136 \mathrm{~g} / \mathrm{s}$ and two-step inlet temperature profiles. These data are for the cross section midway in the major radius section of the magnet where maximum transverse gradients occur. The "wetted" portions of the magnet exhibit temperatures in a narrow band during cooldown. The stiffener, which is not directly cooled, remains warmer than the case temperatures. In this case, the stiffener is about $95 \mathrm{~K}$ warmer (max) than the rest of the magnet and it has been determined that this condition is acceptable by structural analyses.

In contrast, Fig. 47 shows similar transwerse gradicnt temperature histories for the twotemperalure step cooldown with inaximum initial 


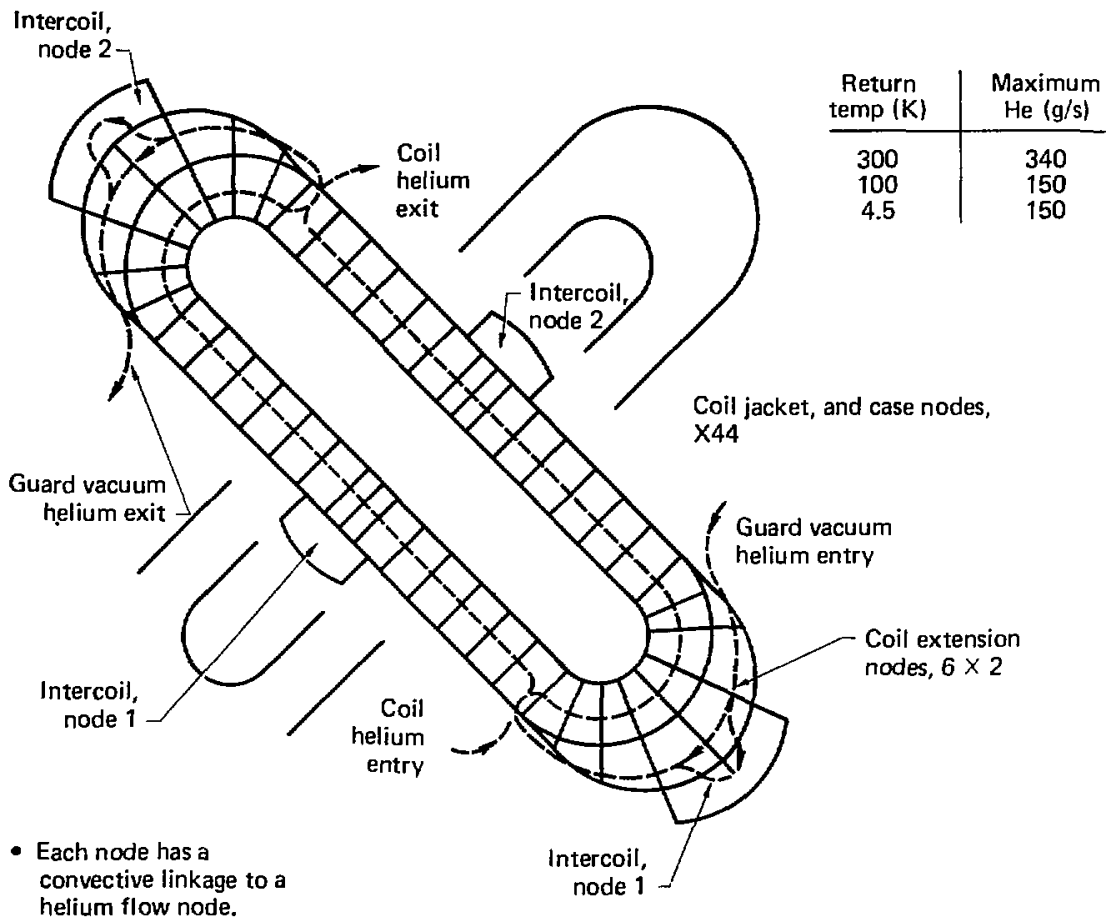

F1G. 44. Cooldown and warmup analysis small model addresses longitudinal thermal gradients and cooldown/warmup durations.

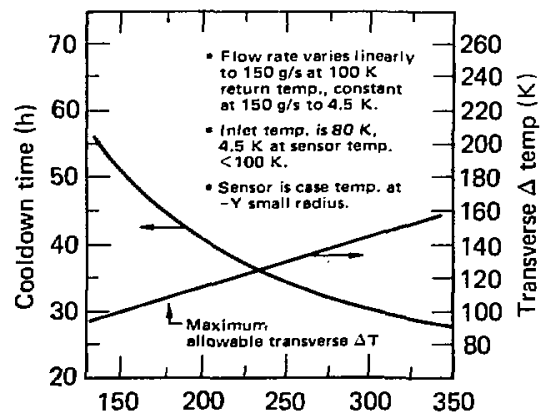

Flow rate at $300 \mathrm{~K}$ return temperature $(\mathrm{g} / \mathrm{s})$

FIG. 45. Cooldown Aow rate at $300 \mathrm{~K}$ return temperature must not exceed $180 \mathrm{~g} / \mathrm{s}$ for allowable transwerse gradient. תow rate of $340 \mathrm{~g} / \mathrm{s}$. The wide and increasing departure of the stiffener temperature from the more uniformly cooling case temperatures is evident and is so large as to be unicceptable structurally. This is a symptom of the extremely rapid cooldown with this high flow rate.

Figure 48 shows the corresponding $340 \mathrm{~g}$. (high flow) longitudinal temperature gradients induced in the lower leg of the yin or yang mignet from the coolant inlet to the exit region. Duration into the cooldown is the tinie parameter. These data are from the literature. The latter dala were employed in the cooldown/warmup model for the magnet jacket, case, and potting material, respectively. Data for oxygen-free high-conductivity (OFHC) copper was taken from Ref. 74. Reference 75 was employed for helium properties, and NEMA G-1I epoxy properties were taken from Ref. 76 . 


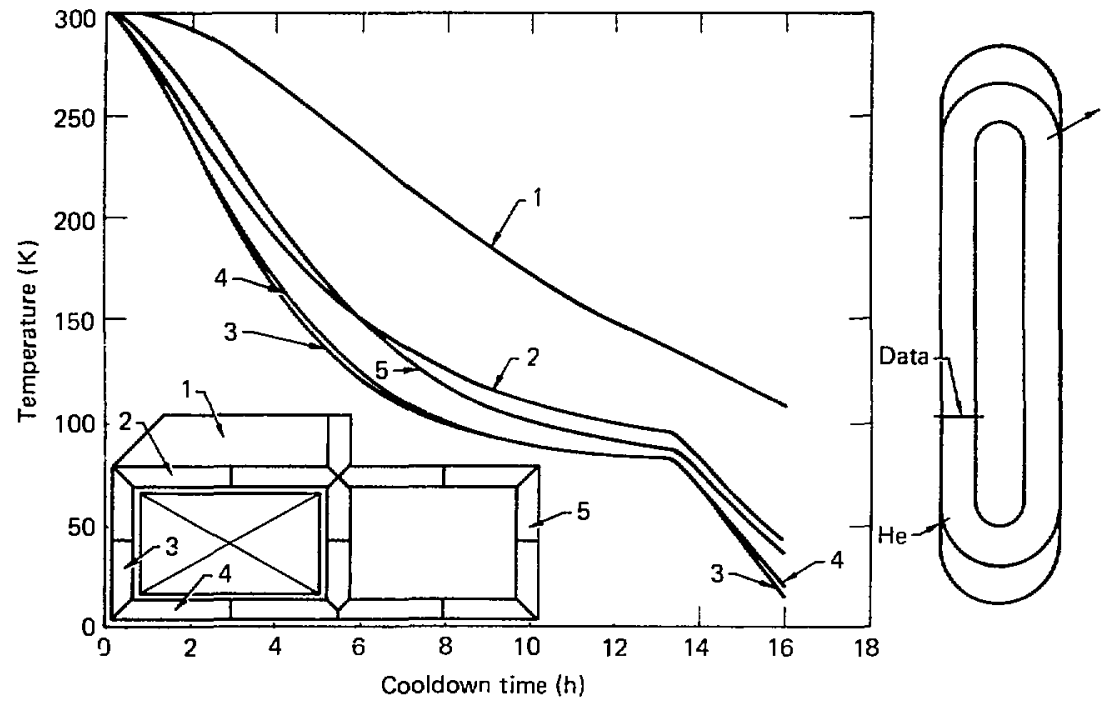

FIG, 46. Cooldown initial flow rate of $1.36 \mathrm{~g} / \mathrm{s}$ results in acceptable transverse gradients.

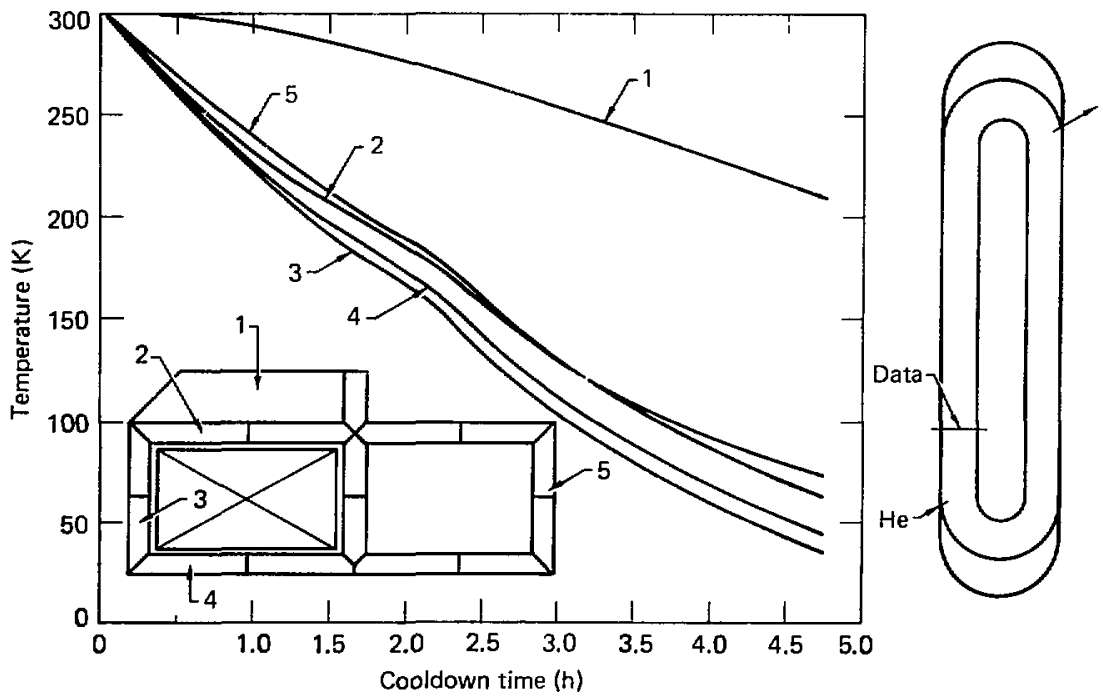

FIG. 47. Maximum cooldown flow rate $(340 \mathrm{~g} / \mathrm{s})$ causes severe transverse temperature gradients. 


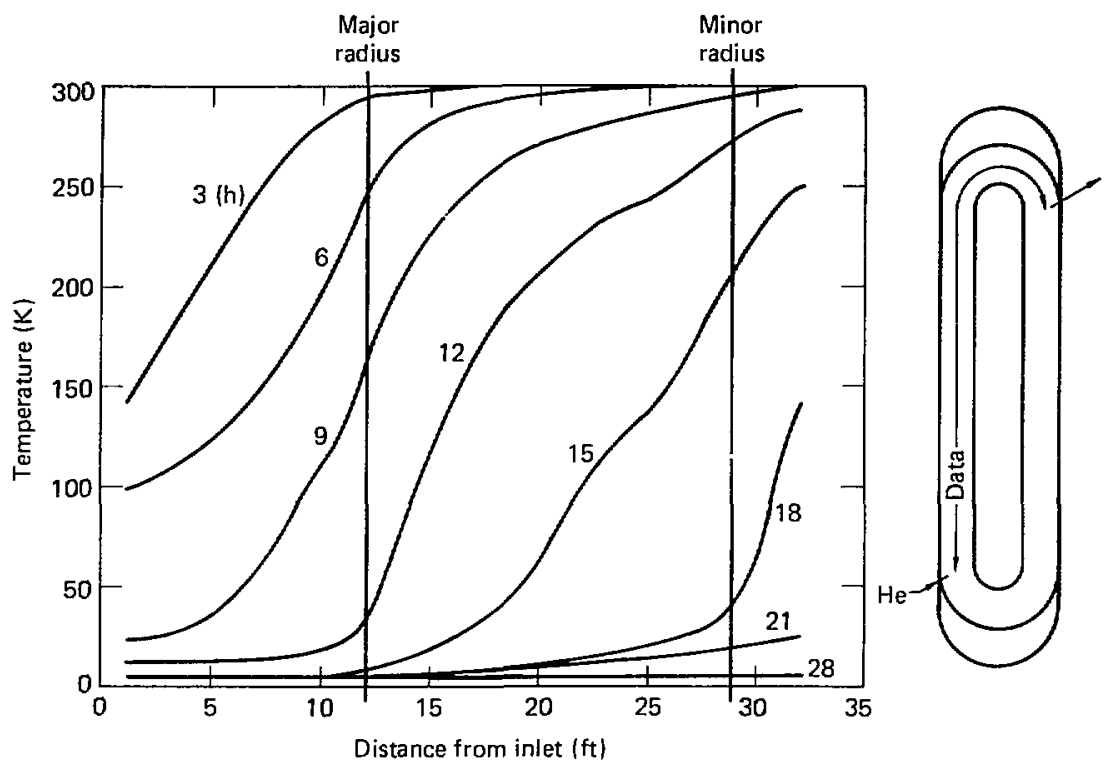

FIG. 48 . Cooldown is 28 h with $340 \mathrm{~g} / \mathrm{s}$ initial now rate.

Properties of $30+\mathrm{L}$ and 316 SS were obtained from Refs. 77 and 78 .

\section{COOLDOWN AND WARMUP ANALYSIS MODELS}

The cooldown and warmup thermal analysis models were formulated for an improved. unpublished version of the Convair thermal analyzer computer program: the original version is documented in Ref.79. There are two program modifications affecting the analyses of this report: (i) provision for accepting "block-lype" node representation, and (2) optional explicit, forwardmarching solution of the heat balance equations. The batter option was employed in cooldown/ warmup analysis. All analysis runs were executed on the National Magnet Fusion Energy Computer Center (NMFECC) at LLNi.

Two major models were used during the course of the magnet thermal analysis. $\wedge$ threedimensional model (shown schematically in Fig. 43) was developed primarily to examine transverse gradients: this model also produced longitudinal gradients. This model was so large it was deemed cionomic:al to break it down into two models: Large Mudel 1 ( $64+$ nodes) in the major radius zone of the malnet. and Large Model 2 (661 nodes) in the minor radius. coil-extension zone of the magnet. For the large model. the cross section was nodalized in block-nude form. as shown in the cross section in Fig. 43. so thitt transverse temperature differentials across the magnet cross section could be predicted.

A smaller. essentially one-dimensional model of a total sin or sang magnet (Fig. 44) provided longitudinal temperature distributions and boundary conditions to initiate and drive the large models of Fig. 43. All the transverse nodalization of the large models were collapsed mathematically into one transierse node at each station along the magnet resultine in $4+$ longitudinally-arrayed nodes around the entire magnet. This model, having much fewer nodes. (totil of 119), in addition to providing the boundary conditions for the large model, provided an economical solution for longitudinal gradients. cooldown durations, and thermal effects of the unbilanced flow split into the two legs of the milgnet. 
Figures 43 and 44 show the guard-vacuum helium ( $81 \%$ of the total), entering the lower coil extension. flowing through it, and then entering the guard-vacuum cavities which surround the coil jacket. While flowing through the coil extension, $57 \%$ of the guard-vacuum helium is diverted by relative hole sizes into and out of the intercoil structhire to condition its mass. At the top of the magnet the guard-vacuum helium similarly flows through the upper coil extension before exiting the magnet. The coil helium (19\% of the total) enters the magnet ir:ar the low point and flows up each leg of the winding to join at the top outlet. Magnet cooldown was analysed using the small model with transverse nodes collapsed into a single node: thus at any station along the magnet, the node represents a weighted average temperature. With rapid cooldown in $28 \mathrm{~h}$. very large longitudinal gradients and bottom-to-top differentials occurring at about $12 \mathrm{~h}(\mathrm{AT}=275 \mathrm{~K})$ are evident. Because the longitudinal temperature differential could be driven to such a large value, effort was thereafter concentrated on reducing the longitudinal differential.

Since longitudinal differential was known to be less a function of flow rate than of severity of inlet temperature schedule, a mitigated four-step inlet temperature profile for cooldown was selected. Figure 49 shows the schedule, the cooldown dura" tion. and the boltom-to-lop longirudinal temperature differential as functions of constunt flow

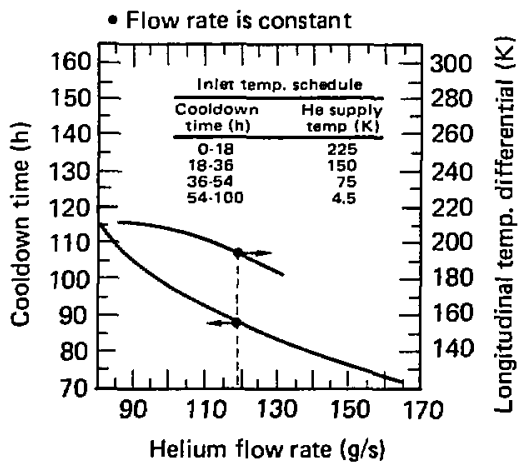

FIG. 49. Longitudinal temperature differences are acceptable for 3.6- to 5-day cooldown durations. rates. The data confirms the longitudinal temperature differential to be relatively insensitive to flow rate and to decrease with higher flow rates.

The structural analysis was performed for a $119 \mathrm{~g} / \mathrm{s}$ flow rate that corresponds to a $195 \mathrm{~K}$ longitudinal temperature difference and cooldown in $88 \mathrm{~h}$ and was certified as acceptable with moderate stresses. The longitudinal-temperature differentials can be accepted for 3.6- to 5-day cooldown durations with the four-step inlet tenperature schedule. Figure 50 shows the corresponding detailed magnet longitudinal-temperature profiles from bottom-to-top with cooldown time as a parameter. The acceptable maximum longitudinal differential of $195 \mathrm{~K}$ occurs at about $63 \mathrm{~h}$ into the cooldown.

Figure 51 shows warmup time and magnet longitudinal-temperature differential as functions of constant warmup flow rate. Warmup is considered to be completed as an accesible condition at $285 \mathrm{~K}$. Again, the four-step inlet temperature schedule was used and is defined in the figtre. Because of the less effective use of the heat capacity of the helium by this warming profile relative to that of the cooling profile, this figure shows that the warmup is slower than the cooldown. The maximum longitudinal differentials are milder (and, again relatively insensitive to flow rate) and the transve: se gradients would also be milder. The figure shows warmup can be achieved in $122 \mathrm{~h}$ (approximately 5 days) with a constant flow rate of $150 \mathrm{~g} / \mathrm{s}$. All of these mild longitudinal-temperature differentials during warmup have been deemed acceptable structurally by comparison to the larger differentials of cooldown.

Figure 52 shows the magnet temperatures versus distance from the conditioning flow inlet during warmup with $150 \mathrm{~g} / \mathrm{s}$ flow and the four-step inlet temperature schedule. Time into the warmup is shown as the parameter. The maximum differential of $120 \mathrm{~K}$ occurs about $65 \mathrm{~h}$ into the warmup.

The effects on transverse gradients and longitudinal-temperature differentials of the yin or yang magnet, or between the two magnets. may be assessed structurally. The temperature data could be taken in detail from Refs. 89 and 90 . However. the gradients in the two legs of a magnet or between magnets are essentially independent one to the other, depending only on the different flow rates in those individual paths. Therefore, Figs. 45.49. and 51 indicate the differences in temperature gradient and differentials for different flow rates 


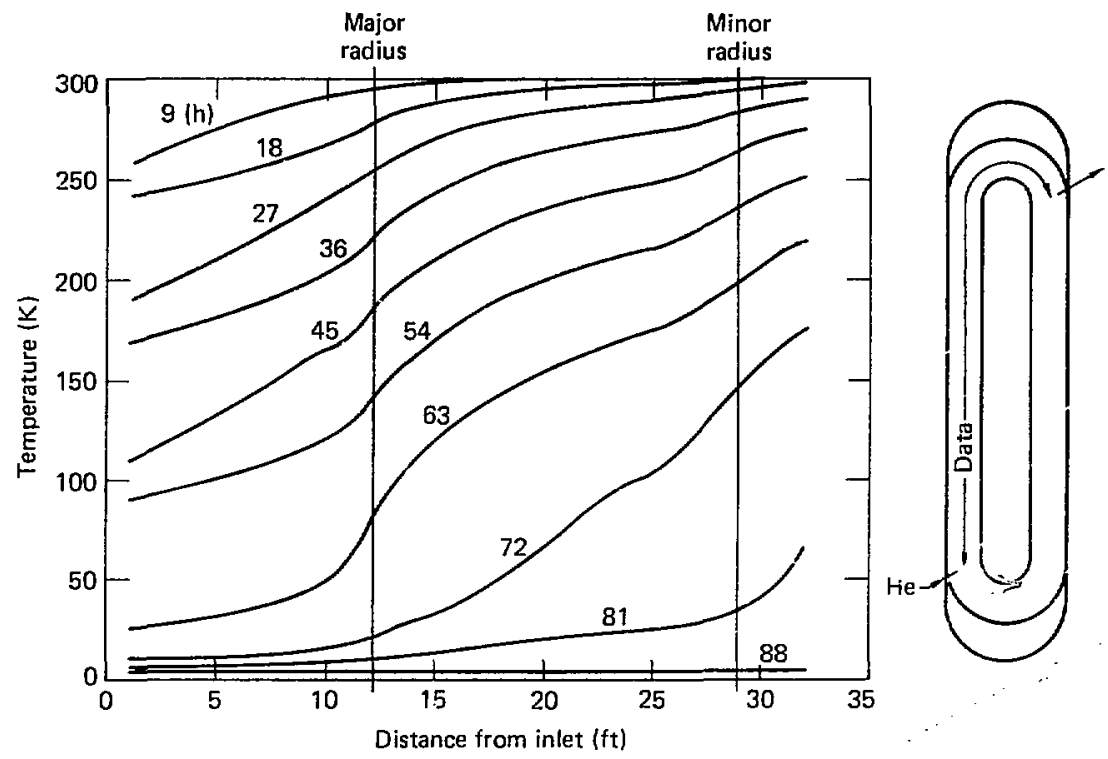

FIG. 50. Longitudinal temperature gradients for $119 \mathrm{~g} / \mathrm{s}$ flow rate with 4-st: $;$ cooldown inlet temperature schedule were structurally evaluated to be acceptable.

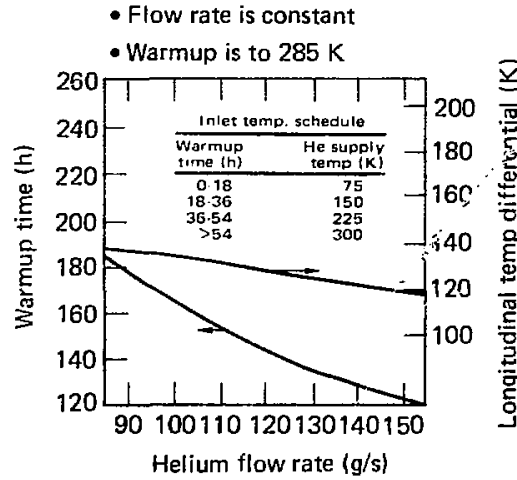

FIG. 51. Warmup in 3 to 5 days yields mild longitudinal gradients. (unbjianced llow splits) into the different portions of the magnet system. Structural analysis for a sutere flow imbalance in the separate legs of a single magnet in which the helium flow rate in one leg was 40 r. greater than that in the other leg results in mild and acceptuble stresses.

\section{CONCLUSIONS AND RECOMMENDATIONS}

1. Cooldown analyses employing the large model (Fig. 43) yielded detailed temperature xcursion and transverse temperature differential data. Resulting thermai stress: $: \mathrm{s}$ are acceptable to a maximum how rate of $180 \mathrm{~g} / \mathrm{s}$ at $80 \mathrm{~K}$ inlet and $300 \mathrm{~K}$ return temperutures. Resulting cooldown time is $44 \mathrm{~h}$.

2. Longitudinal temperature differences employing the simall model (Fig. H4) have been structurally certified acceptable at a $119 \mathrm{~g} / \mathrm{s}$ flow rate 


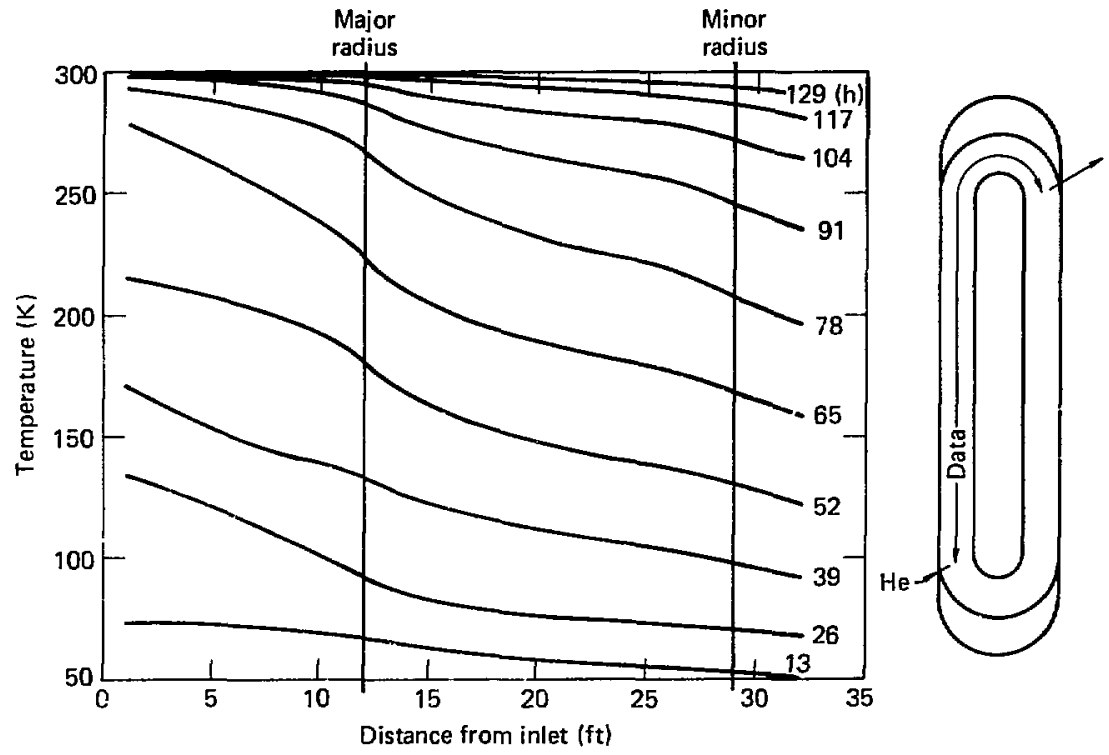

FIG. 52. Warmup to accessible conditions is achieved in 5 days with $150 \mathrm{~g} / \mathrm{s}$ now rate and 4-step inlet temperature.

with the four-step inlet temperature profile achieving conldown in $88 \mathrm{~h}$. Reduction of fongitudinal gradients with higher flow rates also implies ateceptwhility for higher flow rates.

3. Will the follosing four-step inlet temperalure sehedule:

$\begin{array}{cc}\begin{array}{c}\text { Coldown } \\ \text { time (h) }\end{array} & \begin{array}{c}\text { Helium supply } \\ \text { tenperiture (K) }\end{array} \\ 01018 & 225 \\ \text { j8 to } 36 & 150 \\ 36 \text { to } 54 & 75 \\ >54 & 4.5\end{array}$

Totil !lou rattes to $119 \mathrm{~g} / \mathrm{s}$ and cooldown in 3.6 to 5 Jais accommodate stress constraints and are acceptable.

4. Warmup with the following lour-step supply lemperature management schedule:

\begin{tabular}{|c|c|}
\hline $\begin{array}{l}\text { Wirmup } \\
\text { lime (h) }\end{array}$ & $\begin{array}{l}\text { Helium supply } \\
\text { tempersture (K) }\end{array}$ \\
\hline 01018 & 75 \\
\hline 181036 & 150 \\
\hline 36 to 54 & 225 \\
\hline$>54$ & 300 \\
\hline
\end{tabular}

Total flow rite of $150 \mathrm{~g} / \mathrm{s}$ yields mild and accepable temperature gradients. Warmup time to $285 \mathrm{~K}$ is $122 \mathrm{~h}$ (approximately 5 dilys).

5 Since magnet gradients are inlluenced more by reduced severity of inlel lemperallure schedule than by fow ratc, gradually decreasing (increasingly) or fincr step-wist decreasing (incriasing) helium supply temperitures could permil even higher flow rales and faster conldown (warmup). If decmed expedient these options would require further study and thermodynamic/structural anily sis certificition. 


\section{SECTION 6 \\ CRYOGENIC SYSTEM}

The cryogenic system for the MFTF magnet provides liquid helium to the magnet coils to maintain a superconducting stale. Several interfaces and effects must be accounted for in the magnet system design to achieve this condition. Moreover. the magnet system must be able to survive numerous rapid discharge cycles without detrimental effects. These topics are reviewed in the following text.

\section{INTERFACES}

The magnet will be supplied with liquid heiium through dedicated lines running between the vacuum vessel ports and the magnet. As illustrated in Fig. 53, each magnel coil has separate supply and return lines.

The magnet assembly wi!l be supported by two hanger and five stabilizer struts. Heat conduction in these struts is minimized by liquid nitrogen-cooled barriers.

Liquid nitlogen-cooled heat shields will completely envelope the magnets for thermal radiation protection. Figure 54 shows these shields. with additional water-cooled shiclds in critical areas, to protect the niarogen shiclds from beam and plasma heating.

Another interface with the magnet in the carrent leads penetrating the vatuum vessel wall. where the lead temperature must make a 5 to $300 \mathrm{~K}$ transition. Also, the temperature and stiain sernsors on the magnet will be a source of hedt Iransfer to the liyuid helium.

\section{LIQUID HELIUM SYSTEM}

The piping system for supplying liyuid helium to the magnet is illustrated in Fig. 55 . Each magnet coil has dedicated supply and return lines and valves except at the helium Dewar penetrations. Flon through the magnet is by natural convection with liquid entering the bottom of the magnet. splitting at the bottom of each coil, llowing up each half coil and rejoining before exiting out at the top. The principal reason that the yin-yang pair is oriented at $45^{\circ}$ is so the helium will how in this manner.
Important to the thermal control of the magnet is atn adequate circulation of LHe. Forced pumping is not practical. so natural circulation wits chosent. because it has been satisfactory in smaller magnet systems. A computer model of the LHe naturat circulation was developed to estimate steady-state
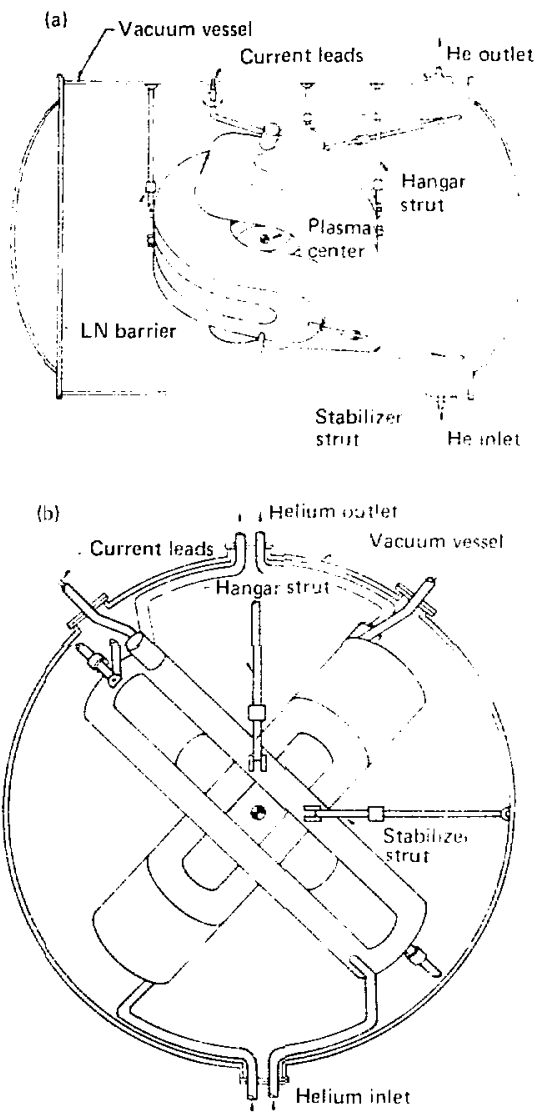

FIG. 53. Schemutic of magnets in the vacuum ressel showing LHe lines, support struts. and current leads. 


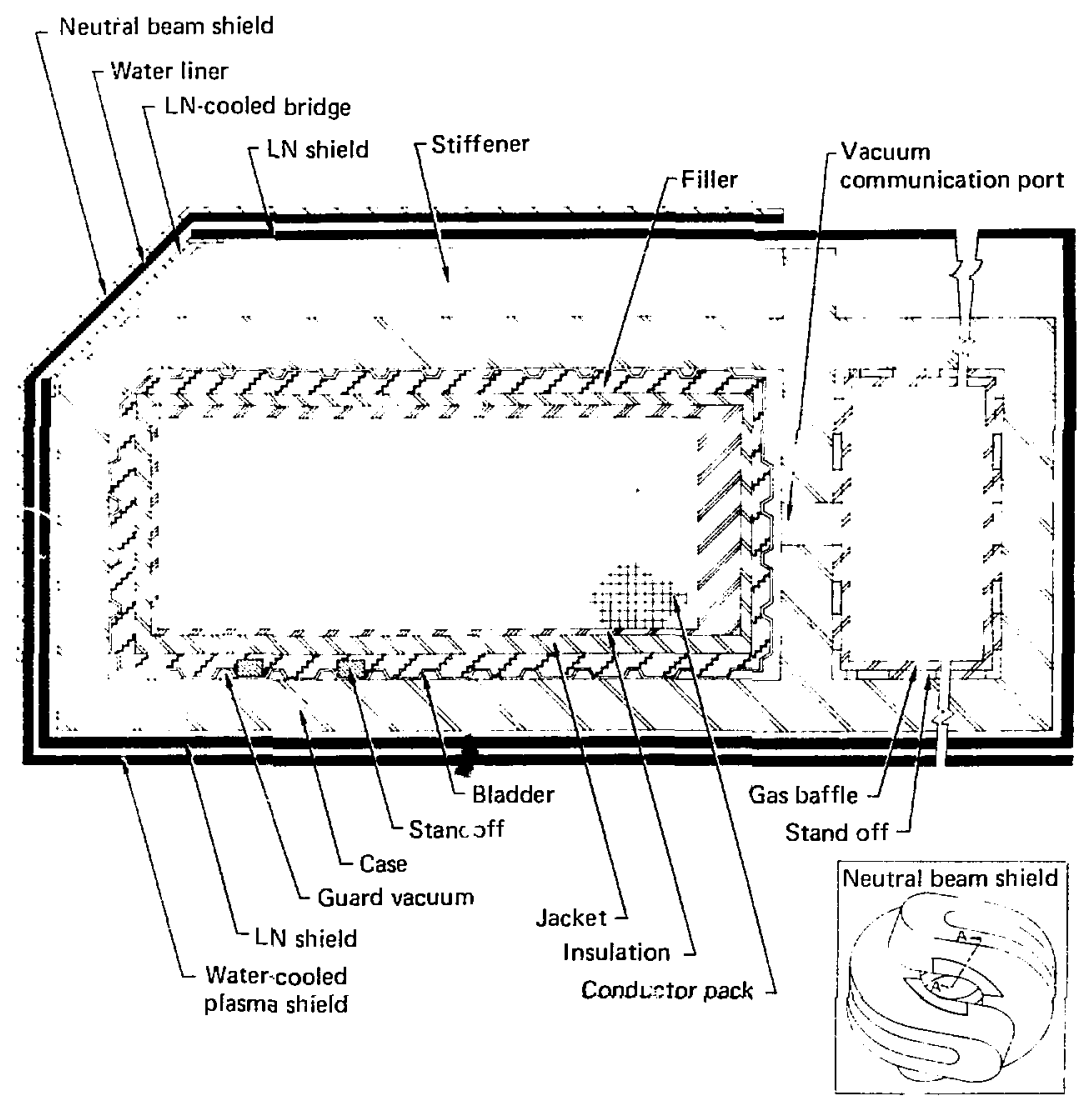

FIG. 54. Sectional ("A-A") view of tie magnet showing its construction and thermal shields.

mass livu rate and vapor quility. Also, a sensiaivity stud! "as made to delermine which paran eters have the greatest influence and to estimate the range of uncertainty for LHe flow rate.

The principal requirement of the L He system is to muintain quality with less than 10 vol\% vaf or in the magnet. Heat-transfer analyses indicate that signilicantly higher vapor qualities would probably reduct crgustabilaly.

The conductor pack and magnet shape do not immediately lend thenselves to a simple flowmodeling approach. Therefore, three approaches to modeling the magnet were considered: (1) the Blasius friction equation. (2) Darcy`s porous media equation. and (3) a three-dimensional orifice model. In selecting an appropriate method, estimates of hydraulic diam, flow tortuosity, porosity, permeability. friction factor, and effective orifice dimensions were made, and the three approaches were compared by means of their respective pressure drops. The porous media approach resulted in the smallest pressure drop, the Blasius approach yielded a pressure drop 10 tinles greater. and the orifict; approach gave a pressure drop that 


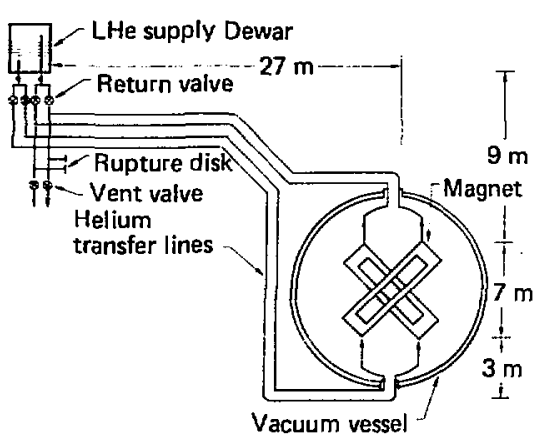

FIG. 55. Schematic of the piping systems for supplying LHe to the magnets.

was 1000 times greater. We rejected the orifice assumption as unreilistic, and chose the Blasius friction method over the porous media approach because it was more conservative. Thus, the magnet pressure ioss $\triangle P$ was estimated with a modified Blasius friction equation in the following form:

$$
\Delta P=\mathrm{R}_{\mathrm{m}} \eta \mathrm{d}_{\mathrm{h}} \mathrm{M}^{2} / 2 \tau \mathrm{A}_{\mathrm{p}}^{2} \phi^{2} .
$$

Flow in the magnet is expected to be laminar by the Reynolds number definition, so that the friction factor ( $f$ ) is given as:

$$
f=64 \mu \Lambda_{\Gamma} \phi / \eta M d_{h} .
$$

Pressure losses in the piping system were simply modeled using loss coefficients for bends. valves, entrance-exit regions, and other effects. These were calculated as functions of the friction factor $f$. The effect of two-phase flow was also included by using the Lockhart and Martenelli correlation: flow in the piping system was assumed turbulent.

Helium flow rates were estimated by an iterative computing method. Using an assigned heat load for selected flow model elements and an assumed tlow rate, helium properties were determined by each element node using NBS data. The resulting pressure imbalance in the flow circuit due to cumulative contributions of friction, monentliat, and gravity was computed. The flow rate was readjusted and the calculations repeated until the pressure imbalance was acceptably small. This procedure provided a means for determining the effect of heat load on flow rate (Fig. 56a). Also, vapor quality was determined and appears as a function of heat load in Fig. Sób.

Because the modeling procedure entails some uncertainties, we were interested in how sensitive the results were to changes in certain variables. Tablc l4 shows the maximum expected range in these flow parameters, and Table 15 shows our estimate for the total LHe-system heat input. The results of the sensitivity study are reflected in Figs. $56 a$ and $56 \mathrm{~b}$ by the uncertainty range curves.

The effects of two-phase flow are significant for helium nass qualities as low as only $1 \%$ and flows near $300 \mathrm{~g} / \mathrm{s}$. Surprisingly. the static head inside the LHe Dewar is the most significant parimeter affecting mass flow rate because of the relativcly low fluid-flow resistance of LHe. Also, pipe friction is far more influential on flow than either magnet friction or heat input.

On the basis of this calculation we selected a pipe with a 6 -in. $(15-\mathrm{cm})$ inside diameter for the LHe supply and return lines. This pipe size and our estimated system heat load of $510 \mathrm{~W}$ yields an equilibrium tnass flow rate of approximately $750 \mathrm{~g} / \mathrm{s}$. Vapor quality at the top of the magnet is less than 5 vol\% (0.7\% by mass), and it is less than $25 \mathrm{vol}^{\%}$ at the top of the return line. These results imply that an adequilte safety margin has been - provided in the thermal control of the magnet.

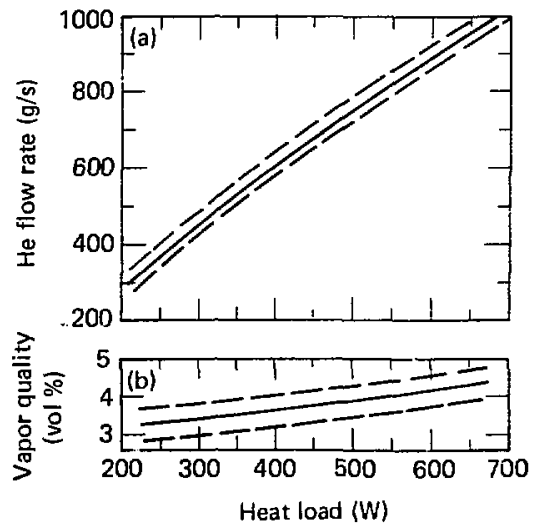

FIG. 56. Steady-state LHe natural circulation through the magnets. 
TABLE 14. Lncertainty range of flow parameters.

\begin{tabular}{|c|c|}
\hline Parameter & Range \\
\hline Friction factor, 5 & 0.014 to 0.018 \\
\hline Tortuosity factor, $\eta$ & 1.5 to 2.0 \\
\hline Porosity, s & 0.30 to 0.35 \\
\hline L.He Jewar head, m & 0.5 to 1.41 \\
\hline Hydraulic diumeter $\left(d_{h}\right), \mathrm{cm}$ & 0.15 to $1 . .35$ \\
\hline Piping heat leakage, w & 3) to 80 \\
\hline I.tngth of piping. $m$ & 80 to 100 \\
\hline
\end{tabular}

TABLE 15. Liqquid-helium-system heat sources.

\begin{tabular}{lc}
\hline \multicolumn{1}{c}{ Parameter } & $\begin{array}{c}\text { Heat input, } \\
\text { W }\end{array}$ \\
\hline W. shietu radiation & 160 \\
LN shield conduction & 90 \\
Wilgnet hianter rods & 60 \\
Conductor joints & 45 \\
Instrumentation teads & 70 \\
Hedium duels & 85 \\
Tutal & 5101 \\
Curt nt leads, nax. tent rate & $1.6 \mathrm{~g} / \mathrm{s}$ \\
\hline
\end{tabular}

$\therefore$ plentum space is included at the top and bottom of each coil inear the supply and out let ports, as illustrated in Fig. 57. These plenums are 6-cm thick and constructed of $6.5-\mathrm{mm}$-1hick layers of NEMA G-11 having 5- by $37-\mathrm{mm}$ slots alternately oriented $90^{\circ}$ to each other. They provide a $50 \%$ bearing surface for the conductor and a 0.5 porosity for helium flow. Both plenums distribute flow entering and leaving the coil. and the top plenum also provides a space for vapor to flow outside the coil so the conductor vill always be liquid-cooled.

$A$ detail of the helium outlet from the conductor pack is shown in Fig. 58. Current leads contained in these ducts are wrapped with Kapton to prevent voliage breakdown to the conductor pack and surrounding structure. The supply duet at the bottom of each coil is identical except for the $u b-$ sence of the current leads.

Outermost turns of the conductor in the outside flat areas in the large-radius regions of each coil are supported by beveled NEMA G-1 $l$ backing blocks. These blocks support magnetic pressures of nearly $20 \mathrm{Mla}$ (2900 psi) and are beveled, as illustrated in Fig. 59, so that vapor can migrate upwards through the channels to the plenum.

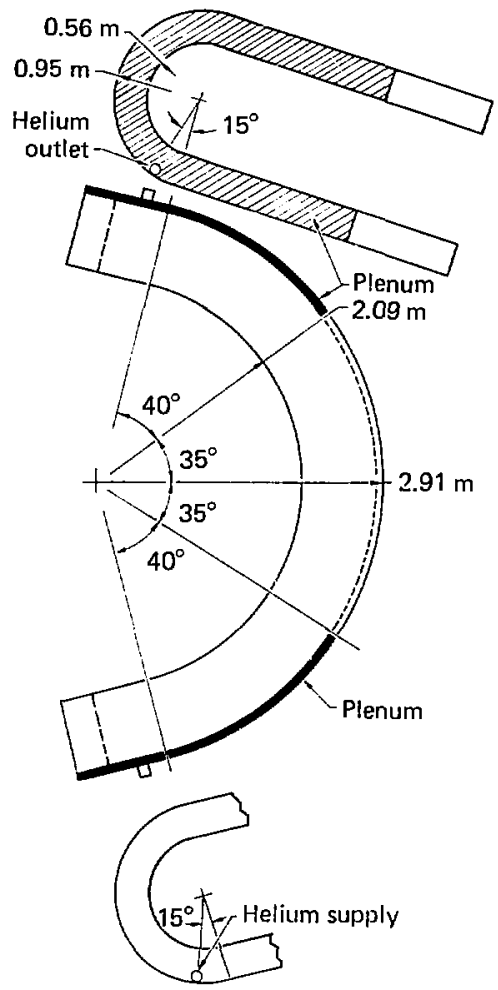

FIG. 57. Jacket around coil showing dimensions and locations of helium plenums.

\section{CRYOSTABILITY}

The MFTF superconductor is cryostable from experimental and analytical studies. The High Field Test Facility (HFTF) at LLNL has demonstrated the conductor will recover if driven to a normal state in a horizontal solenoid configuration at the MFTF peak field and current conditions. Convair/ General Dynamics and General Atomic made analytical studies of conductor cryostability and concluded there is sufficient heat transfer for the conductor to recover in the peak field and current condition.

A comparison of calculated surface heat flux on the conductor when in a normal condition to experimentally measured heat Mux is shown in Fig. 60. 


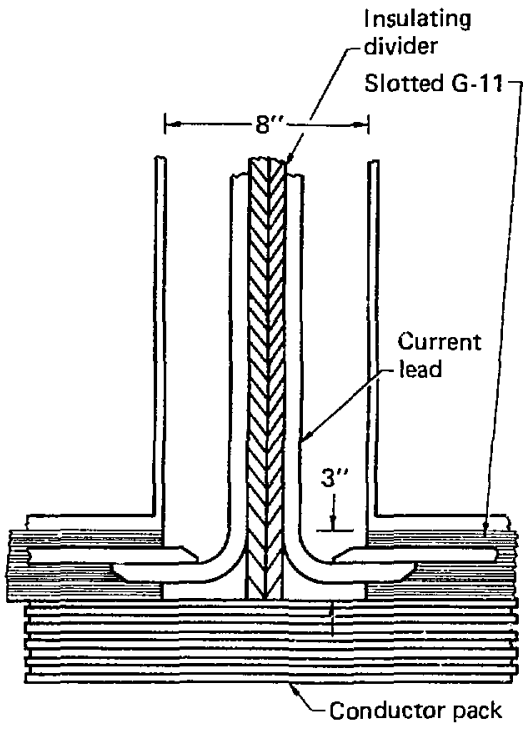

FIG. 58. Helium outlet for magnet.

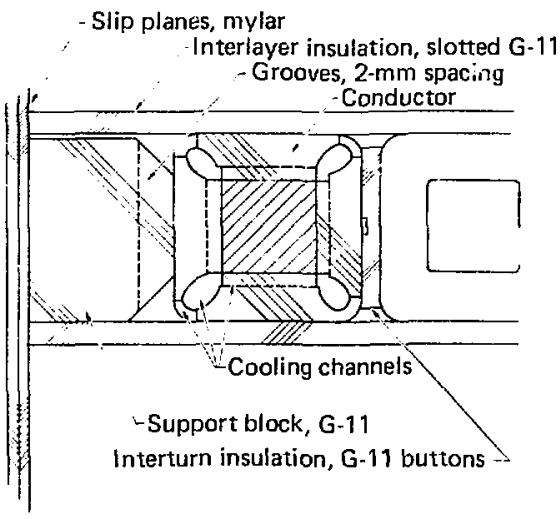

FIC. 59. Conductor and support iJlocks in outside Iayer of large-radius region of magnet coil showing channels for helium now.

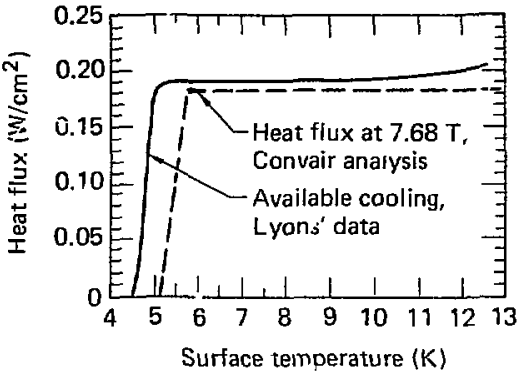

FIG. 60. Conductor heat nux.

The available cooling exceeds the surface heat flux by approximately $5 \%$. resulting in a small margin for uncertainties or haws. Moreover, a calculation by Convair of the effect of solder flaws on cryostability indicated that a worst case had practically no effect. (A worst-case solder flaw is detined as no more than 27 flaws of $40 \%$ contict or less per $1.5 \mathrm{~m}$ of conductor, or less than 13 naws per $7 \mathrm{~cm}$, or less than 8 consecutive flaws on one sidc.)

Plenums and flow channels are provided in the magnet to inhibit vapor accumulation, as described in tbe foregoing section, anu thus help assure cryostability.

\section{CURRENT LEADS}

A pair of copper bus conduciors with superconductors will carry current from the valuan: vessel watl to each magnet. These conductors will normally be in liquid helium. but they are designed to be superconducting in vapor tlow. If the liquid level in ihe current lead pipes should be depressed. the leads will be cooled by cold-end conduction and by controlled vapor flow. A heit transtor analysis of these leads has provided a design that should guarantee cryostability for all operating conditions. By using 2.5- by $7.5-\mathrm{cm}$ (1- by 3 -in.) OFHC copper conduetors having a residual resistivity atio greater than 150, a $\mathrm{Nb}_{3} \mathrm{Sn}$ superconductor with a $0.4-\underline{g}$, s vapor flow per lead. the vapor-cooled length operating at $6.000 \mathrm{~A}$ can be over $4 \mathrm{~m}$, which is more than sufficient. A section view of these conductors is shown in Fig. 61.

The portion of tbe leads penerating the vacuum vessel wall will have a temperature transition from approxinutely $5 \mathrm{~K}$ in the ctrrent lead 


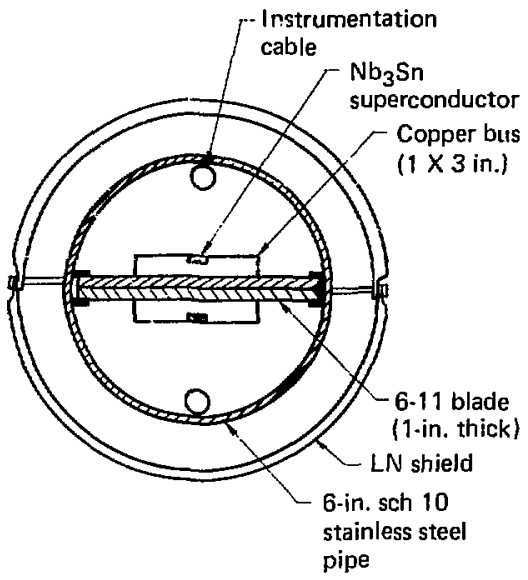

FIG. 61. Helium-cooled current bus.

pipe to $300 \mathrm{~K}$ outside the vessel. They are designed to use near-optimum helium flow and to have a sufficient amount of thermal mass for safe operation by using concentric copper and stainless steel tubes. The lcads will be constructed of approximately 60 copper tubes 0.25 -in. o.d $(6.35 \mathrm{~mm})$ by 0.025 -in. wall $(9.65 \mathrm{~mm})$ by 60 -in. long $(1.5 \mathrm{~m})$. Each copper tube is encased in an 0.31 -in.-o.d. $(8 \mathrm{~mm})$ stainless steel tube. This design gives a mass ratio of stainless stcel to copper of about $2: 1$ and should permit approximately $20 \mathrm{~min}$ of adiabatic operation at $6000 \mathrm{~A}$ before a fasi discharge of the magnets must be initiated.

The cffect of the stainless steet on the lead electrical resistance is small as can be shown by analysis. Equating joule heating in the lead to convective cooling gives an expression for the trad length in the following form:

$$
r=\frac{\operatorname{mseA}_{\mathrm{c}} \frac{A_{\mathrm{S}}}{A_{\mathrm{c}}} \frac{\bar{\rho}_{\mathrm{C}}}{\bar{\rho}_{\mathrm{S}}}+1}{\mathrm{I}^{2} \bar{\rho}_{\mathrm{C}}}
$$

where $m$ is the helium mass flow rate, $\Delta e$ is the helium enthalpy change. $I$ is the lead current, $A_{c}$ and $A_{5}$ are copper and stainless steel cross-section areas and $p$ is the electrical resistivity integral over the dimensionless length $x / c$.

$$
\bar{\rho}=\int_{0}^{1} \rho \mathrm{d}\left(\frac{\mathrm{x}}{\ell}\right) .
$$

Flow circuitry for these leads is stown in Fig. 62. A by-pass open-close valve is included to maintain flow in the event of a failure of the flowcontrol valve. Heliuı flow will ordinarily be regulated proportional to lead current with a controller using the lead voltage drop as the input signal. A $2.5-\mathrm{cm}$ vent line will be connected to the helium duct, as shown in Fig. 62, to prevent the liquid level from being depressed too far.

\section{QUENCH}

In the event of a quench, the magnet will automatically be put into a last-dump mode by a quench detection conputer. Voltage taps on the coil bundle and current leads will be used to detect normal conduction zones. The contained energy will be dissipated in an external discharge resistor that will be sized to limit both voltage and maximum conductor temperature.

A conservative method for estimating the maximum conductor temperature $\mathrm{T}$, in time $\tau$ with current $I$ and resistance $R$, is to compute an adiabutic temperature rise of each element. including the mass $\mathrm{m}_{i}$. length $\mathrm{L}$, and hcat capacity $\mathrm{c}_{\mathrm{j}}$.

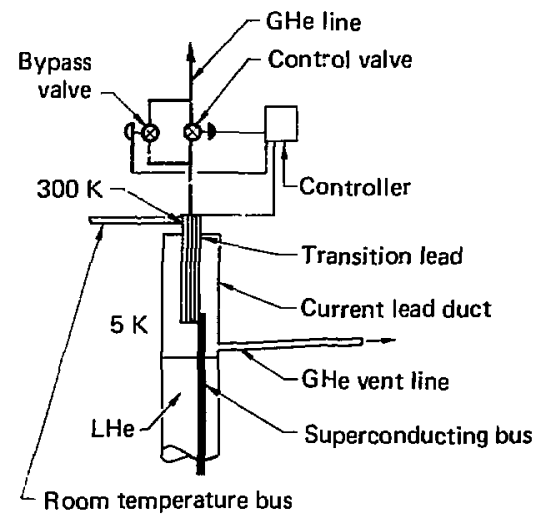

FIG. 62. Transition lead. 


$$
\because \quad \mathrm{Rd}_{\tau}=\sum_{\mathrm{i}} \operatorname{Lm}_{\mathrm{i}} \int_{\mathrm{T}_{0}}^{\mathrm{T}_{\max }} \mathrm{c}_{\mathrm{i}} \mathrm{dT} .
$$

Instantaneous thermal communication between the conductor and adjoining materials is assumed. The participating materials are the superconductor. copper, interlayer and interturn insulation. and heliun? gas.

The current history is defined according to the delay time $r_{\text {d. }}$.

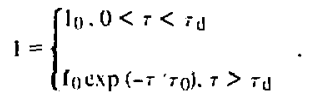

Since $R$ can be expressed in terms of resistance length and area. $\rho \mathrm{L} / \Lambda$. Eq. (5) can be restated in the following form:

$$
\frac{\mathrm{I}_{0}^{2} T_{0}}{\mathrm{~A}}\left(\frac{\tau_{\mathrm{d}}}{\tau_{0}}+\frac{1}{2}\right)=\sum_{i} \mathrm{~m}_{\mathrm{i}} \int_{\mathrm{T}_{0}}^{\mathrm{T}_{\mathrm{milt}}}\left(\mathrm{c}_{\mathrm{i}} / \mu\right) \mathrm{dT} .
$$

Solution of Eq. (8) yields the maximum temperature as a function of delay until a discharge is initiated. This decay constant corresponds to a peak voltage of $1000 \mathrm{~V}$ across a $0.17-9$ quench resistor. with a 12-H inductanee in the magnet (i.e.. $\tau_{0}=$ $\left.H_{1}\right) V_{\text {max }}$ ). Copper properties assumed in Fq. (8) are those of OFHC copper hiving at residual resistivity ratio equal to 150 and a 7.76-T magnetic field.

Figure 63 shows that a maximum temperature of $200 \mathrm{~K}$ is reached if a 10-s delay in initiating discharge is allowed. l.onger decay tine constants (i.e.. lower quench voltages) result in higher temperatures. This temperature is considered permissible since it is a conservative estiniale and is limiled to a small region of the coil where both initial transition to normal conduction and peak field could occur. A $200 \mathrm{~K}$ temperature rise from $5 \mathrm{~K}$ should result in less than $0.1 \%$ thermal expansion of the conductor. Also. $10 \mathrm{~s}$ is adequate time to initiate a discharge with an automatic quench detecting system.

Magnet structural materials can also develop resistive heating during a fast discharge by a transformuer coupling effect between the magnel coil and surrounding structure. Because of its properties, a copper guard-vacuum bladder would show the greatest temperature increase from this source. Assuming adiabatic conditions. resistive and sensible heating of the copper can be equated.

For a 1392:1 turn ratio, a peak coil voltage (V) of $1000 \mathrm{~V}$. and a current-decay time constant (ro) of $69 \mathrm{~s}$, the temperature (T) can be found by Eq. (9).

$$
\frac{0.26 \tau_{0}}{V_{L_{-6}^{2}}^{\frac{2}{3}}}=\int_{T_{0}}^{T_{\text {maas }}} a \mathrm{dT} \text {. }
$$

where $L_{\mathbb{C}}$ is the effective length and $\rho$ is the product of resistivity and specific heat.

Solution of this equation vields a maximum temperature of $5 \mathrm{~K}$ for the copper hladder: it is much tess for a stainless steel bladder.

A similar analysis of the stainless-stecl wise vields a temperature of $10 \mathrm{~K}$. Total energy disuipalion in the case. bladder and coil jacket is approsimately $6 \mathrm{MJ}$, or less than $1.5 \mathrm{~s}$ of the energ! contained by the magnet before discharge.

Heat transfer to the helium oceurs at a much slower rate than the inductive healing and has no eflect on conductor stability because ans appreciahle amount of vapor is formed long after the current has decayed to a low value.

Rupture dises in the vent lines will linit vapar pressures during a quench to approvimately so pui The gaseous helium recovery sistem wan secept up to $16.000 \mathrm{~g}$ /s. which will be adequants.

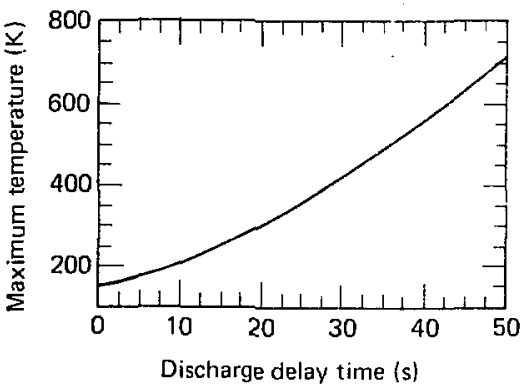

FIG. 63. Maximum conductor temperature during a quench. 


\section{REGENERATION}

All liquid helium coolex surfaces of the magnet sistem must be warmed periodically to more than $15 \mathrm{k}$ for boil-olf of condensed hydrogen. This is to be accomplished by radiating heat to the magnet catse and piping from the nitrogen shields. However. the shields must first be filled with a warm gas and the magnet must be discharged. Helium vapor gencration in the ragnet system will be used to depress the liquid helium level to the bottom of the vacuum vessel and pump liquid into the storage system. After regeneration, the nitrogen and helium systems will be returned to their normal states as soon as possible. 


\section{SECTION 7 \\ POWER SUPPLY SYSTEM}

The power supply system for the yin-yang superconducting magnet provides controlled power and protection in case of quench or other potentially destructive conditions. Principal requirements for the power supply system are: provide a controlled current of 0-6000 A in each coil with an offset of up to $1200 \mathrm{~A}$ between coil currents; provide a means to energize and deenergize the magnet within $\mathbf{4}$ hours; provide detection of quench or other abnormal condition in the magnet; and deenergize the magnet, either in a slow or zapid mode, upon detection of an abnormal condition. Two identical power circuits are used for each of the superconducting coils (Fig. 64). Control and coordination of the two power circuits and detection of an abnormal condition in the power supply system or the magnet is done locally in the power supply and magnet protection controller.

\section{SYSTEM DESCRIPTION}

The power circuit for teach coil consists of a 0 $12 \mathrm{~V}, 0-6000 \mathrm{~A}(\mathrm{dc})$ power supply for energizing the coil and maintaining the current during steady state, a 0.0015 -ohm resistor in parallel with a pneumatic controlled switch for slow de-energizing of the coil, and two 6000-A, 750-V(dc) circuit breakers with a center tapped 200-MJ resistor for fast de-energizing of the coil. The dc power supply is a conventional thyristor phase-controlled rectifier with a freewheeling diode path rated for full current. A pneumatic switch is in parallel with the power supply to bypass the supply if its cooling water fails. The slow de-energizing resistor and pneumatic switch arc used to insert resistance in scries with the magnet coil during operator controlled turndown or an equipment failure of a noncritical magnitude. Two fast de-encrgizing de circuit breakers are used to interrupt the current from the power supply and transfer it to the 200-MJ resistor if a critical condition in the magnet is detected, such as a propagating normal zone or overheated current lead. The 200 MJ resistor is a passively cooled resistor of the natural air convection type. It is center tapped with a soft ground to limit the coil voltage to $500 \mathrm{~V}$ or less from ground.

The power supply and magnet protection controller interfaces with the MFTF computer system besides being a complete local system which can operate independently. Its most significant function is to: monitor key signals such as voltage taps in the coils, current lead voltages, helium level and pressure, and failure indicators in the cryogenic system; process the information to determine if an abnormal condition exists and its severity; and then initiate a hold on the curient rise, a slow deenergizing command, or a fast de-energizing command.

An uninterruptable power system is used to ensure operation of the magnet protection components during a power outage. A $120-\mathrm{V}(\mathrm{dc})$ battery supplies control power to the circuit breakers and input power to an inverter which powers the power supply and magnet protection controller. The ac building power is used as a backup in case of inverter failure.

\section{ENERGIZING AND DE-ENERGIZING CHARACTERISTICS}

Figure 65 shows the energizing and slow deenergizing characteristics of the power supply system. With $12 \mathrm{~V}$ from the power supply and an inductance of $12 \mathrm{H}$ in series with the cable resistance of $0.5 \mathrm{~m} \Omega$, the current increases at nearly $1 \mathrm{~A} \cdot \mathrm{s}^{-1}$. Actual energizing characteristics will be slower and will use the full 4 hours allotted. This is to minimize probability of rate-induced normal zones developing in the magnet at high current. With the power supply turned off and with $2 \mathrm{~m} \Omega$ in series with the 12- $\mathrm{H}$ inductance, the magnet current decays completely in 3 hours. A slower rate of decay can be obtained by leaving the power supply on; however, it is not anticipated that this w:"! be needed.

The fast de-energizing characteristic is not shown in the figure. It would be an exponential decay with a time constant of approximately $70 \mathrm{~s}$.

\section{POWER COMPONENTS}

The major power components are the power supplies, pneumatically controlled switches, $1.5-\mathrm{m} \Omega$ resistors, dc circuit breakers, $6 \cdot \mathrm{kA}$ bus, the 200-MJ fast de-energizing resistors, and the battery/inverter 


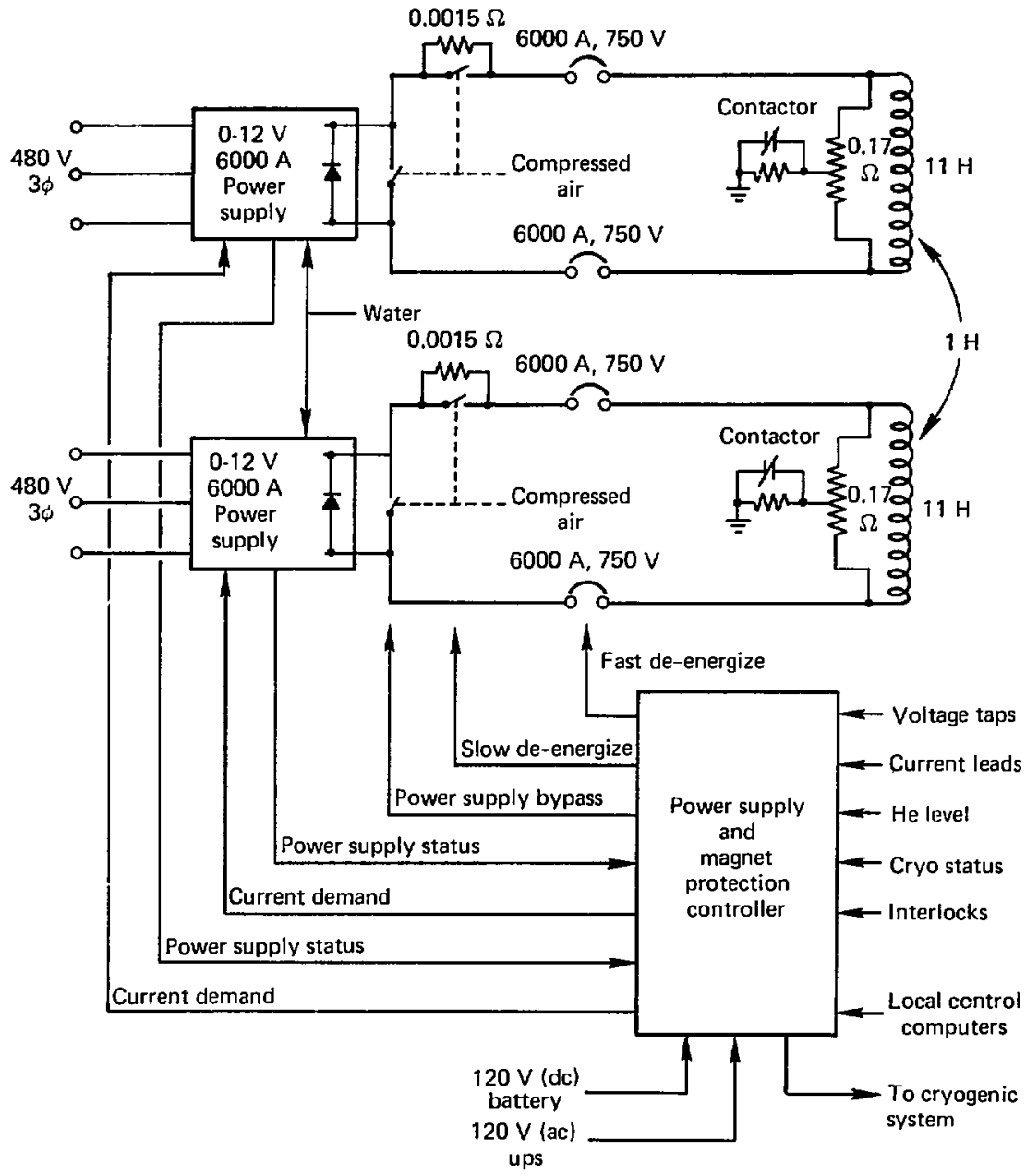

FIG. 64. Magnet power-supply system. 


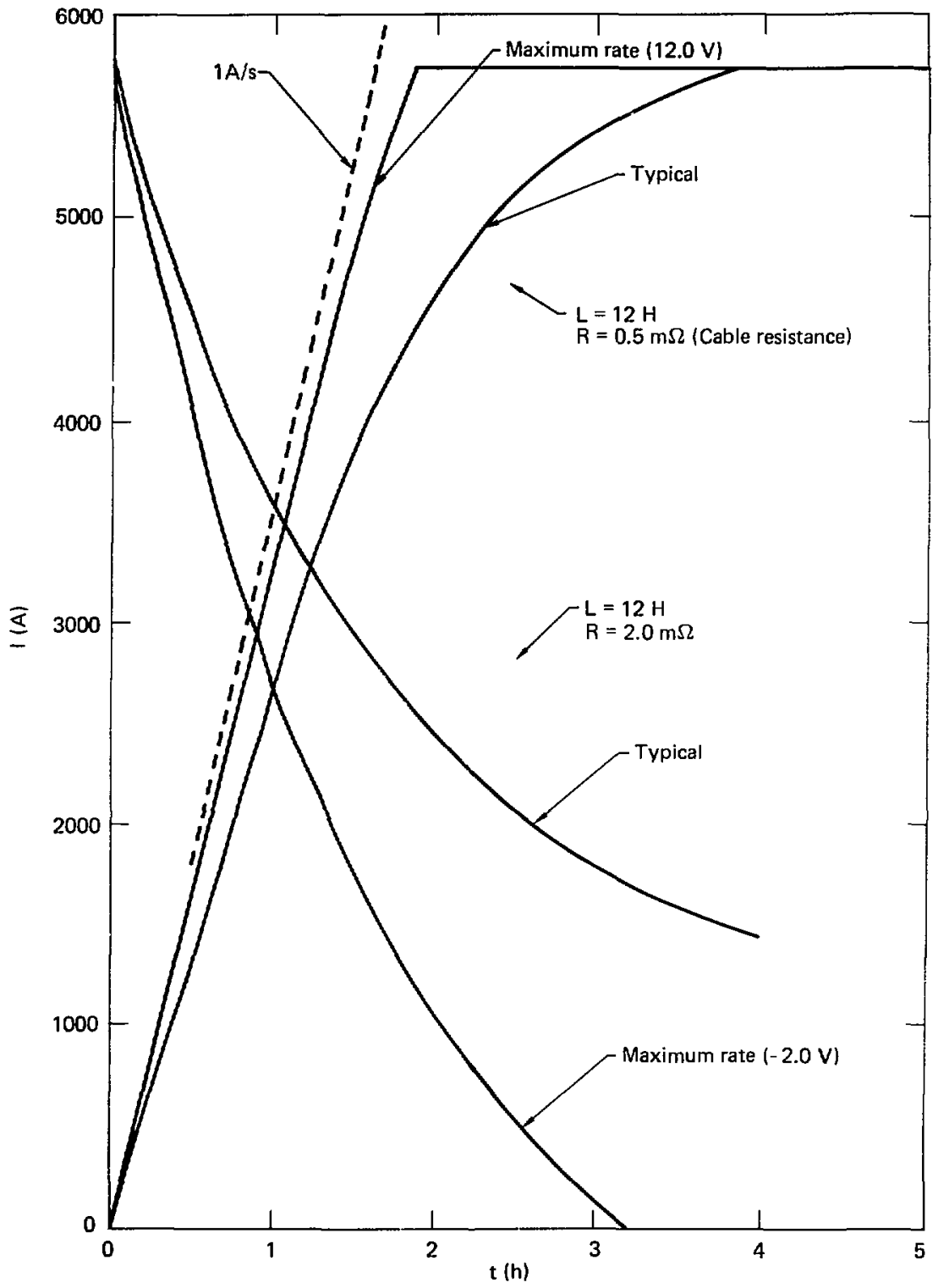

FIG. 65. Energizing and de-energizing characteristics. 
system. With the exception of the fast de-energizing resistors and the 6-kA bus, all the power components are located on the third floor, northeast end of Bldg. 431. The fast-dump resistors are localed on top of the southeast vessel support pillar.

\section{Power Supplies}

Each power supply will be built to EE Department Specifieation LES 22249. The supplies will produce $0-12 \mathrm{~V}, 0-6000 \mathrm{~A}$ with a serites connecled load of $12 \mathrm{H}$ and $0.5-2.0 \mathrm{~m} !$ ? The $0.5 \mathrm{~m} !$ ? is the cable resistance and the $2.0 \mathrm{msl}$ is the cable resistance plus $1.5 \mathrm{~m} \Omega$ of the slow de-energizing resistor. A continuously rated frec-wineting diode path $*$ ill be provided so that the magnet current will not be interrupted if the power supply or the input ac line voltage fails.

The power supply is regurred to produce full output with $480 \mathrm{~V} \pm 5 \%$ input. It will operale continuously at reduced output voltage down $10416 \mathrm{~V}$ and for $0.2 \mathrm{~s}$ down to $330 \mathrm{~V}$. This latter voltige occurs during starting of motors in the cryosystem.

The power supplies will operate either in a locial or remote mode, but locil mode is only for operaition of the power supplies into a dumny load during initial checkout and maintenance. The remote mode is used during operation of the mignet and corresponds to operation of the supplies from the power supply and magnel protection controller. Power supply current and voltage dentands will be four 20-mA analog signals provided from the controller, while digital inputs and outputs of zero and $24 \mathrm{~V}$ will be for on/off, local mode inhibit, and power supply diagnostic indicators. The power supplies will be capable of both current and vollige regulation with automatic crossover, but the magnet will be primarily operated in current regulation with the voltage regulator serving as a voltage limit. The maximum absolute errors are $\pm 60 \mathrm{~A}$ and $\pm 0.5 \mathrm{~V}$ with miximum repeatibility errors of $\pm 30 \mathrm{~A}$ and $\pm 0.5 \mathrm{~V}$.

The power supply output terminals are isolated by $\pm 1000 \mathrm{~V}(\mathrm{dc})$ from the power supply enclosure, ac input terminals. and control ground. This is to prevent a ground fault during the fast de-energizing mode where $\pm 500 \mathrm{~V}$ exist between each rnagnet terminal and ground.

No filtering is required in the power supplies because of the high magnet inductance. $A$ ripple frequency of $350 \mathrm{~Hz}$ or greater was specified with special presautions for minimizing lower frequency harmonics.

\section{Preumatically Controlled Switches}

The switches which parallel the power supply outputs and the $1.5 \mathrm{~m}$ ? slow de-energizing resistors are Square D type DB or equivalent. These switches are capable of continuous operation at $6000 \mathrm{~A}$ and can interrupl $6000 \mathrm{~A}$ up to $20 \mathrm{~V}$. They are mounted in series with the interconnecting bus bars which atr used in the magnet power supply area.

Control of the switches is with at conventional pncumatic control system enploying an air-cylinder operater, a four-way solenoid valve, and a pressure regulator. An asceumulator will be used w ith a check vilve to provide a backup source of air to allow operation with loss of building air. The four-way solenoid value is connected to the swilch using polspropylene tubing to separate the suitch and the comerols by $\pm 1000 \mathrm{~V}(\mathrm{dc})$.

The switches which parallel the power supply outputs are normally open and cloxe atutomatically when commanded by the pouce supply water flow and overtemperature monitors. The switches which patrallel the 1.5-me resistors are mormally closed and open when commanded by the power supply and matanet protection controller. All of the switches hate limit suitches for monitoring by the contruller.

\subsection{Milliohm Resistors}

The 1.5-mer resistors are used for slow deenergiring of the magnet. They are ralted at $5+\mathrm{kW}$ and are naturat-convection air cooled.

\section{dc Cïrcuit Breakers}

Two de circuit breakers per EE Department Specification LES 22250 are used for each magnet coil for redundancy, and will be moumed on open Prames in the power supply areal. They are capable of operating at $6000 \mathrm{~A}(\mathrm{dc})$ continuously and will interrupt up to $300 \mathrm{~kJ}$ of stored energy in the inductance of the cables and the fist discharge resistors. Although rated to operate in a $750-\mathrm{V}(\mathrm{dc})$ circuit. they actually cin operate up to their are voltage of $2200 \mathrm{~V}$.

The control circuit of each circuit breaker will be powered from a 120-V battery. Each breaker will have an undervoltage release which will automatically open the breaker if the control cireuit 
voltage falls below $70 \mathrm{~V}$. The primary means of opening the circuit breakers is the shunt trip coil, which will be controlled from the power supply and magnet protection contruller. Individual driver circuits are used for each breaker. The breaker pusition auxiliary switches are used for monitoring by the controller and also for interonnceting the breakers to ensure opening of all four breakers simultaneously (Fin. 66).

\section{6-kit Cuble Bus}

The cathle bus runs from the power supply area to the magnet lead exit ports are approximately 100ft long. Cable bus will be used which is similat to eable tray but with mainlained spacing between conductors for sufficient cooling 10 allow the cables to be sired as single conductors in free air. The advantages of cable bus over rigid bus are: continuous cable runs wibout needing expansion joints; and redundant personnel safeus due to having insulated cables in an enclosed. grounded duct. Detilis of the cable hus design will he done hy the inanufacturer.

\section{1-M.J Fast-I)ump Resistors}

During a fast de-energized condition. the magnet energy is dissipaled in the fast dump resistorn. The resistors will be passively cooled using natural air convection. The resistors will bave everal parallel paths to provide redundancy.

A cable independent of the 6-kA bus will be used to connect the magnet leads at the top of the vessel to the dump resistors which are located on top of the southeas vessel support pillar. Independent cable is used to emare that the dusp resintors are connected in case of damage to the 6-k $A$ bus. These cables are sled lor short time ratings and will nol operate at $6-k A$ continuously.

\section{Battery and inverter System}

A 120-V. 100-1 h bittery, 25-A charger, and a 2.5-kVA inverter comprise the uninterruptable poner supply system (Fig. 67). The battery is of fead-calcium construction with a translucent jar for high reliability and ease in maintenance. The battery is composed of 20 separate units mounted in a seismic, two step rack. The inverter operates from the battery and supplies poser to the power supply and magnet protection controller. It has an electromechanical transfer switch which transfers the power source from the inverter to the building ac power in case of inverter failure. The estimated mean time between failure for the combined power source is more than $100,000 \mathrm{~h}$. As shown in the figure, several conditions in both the charger and inverter are monitored by the controller.

\section{POWER SUPPI.Y AND MAGNET PROTECTION CONTROLLER}

The power supply and magnet protection controller is a local control system which can operate in conjunction with the MFTF coniputer system or independently. It will be located in the power supply area in the northeast corner of Bldg. 431 .

\section{Functions:}

The controller has a ineans for selecting locas or remote operation using a heylock switch, checking out components prior to application of power to the magnet. monitoring of component failures. and selecting at hoid. slow, or fast de-energizing command. It also communicates to the Local Control Computers in Bldg. 439 through a CAMAC crate. Based on digital commands from the local control computers it provides analog current and voltage deminds to the power supplies, generates the energising trijectory, controls insertion of the 1.5ms! resistors. and controls on off commands to the power supplies.

The most critical controller function is to provide magnet protection. It monitors: voltage tars in the magnet for detection of a normal zone (quench). voltage taps across the current leads for detection of overtemperature, helium levei and pressure in the helium supply Dewar for detection of yuenth or near quench conditions, and failures in the erogenie and acuum systems to anticipate a potenti.l loss in couling of the inagnet. or large heat intlux. Based on the severity of an abnormal condition. the controller selects a hold, slow, or fast dechergis ing command.

\section{Required Features}

Becalls: of the critical nature of magnet protection. the following featurts will be included in the controller The yuench detection and current lead voltage monitoring nill have fully redundant st ste:ns. Stelf-chech ing will be used in low reliability components such as nicrocomputers. Checkout of ke? components prior to operation will be done automatically where possible. Checkout will continue duriag early stiges of energuing the magnet. 


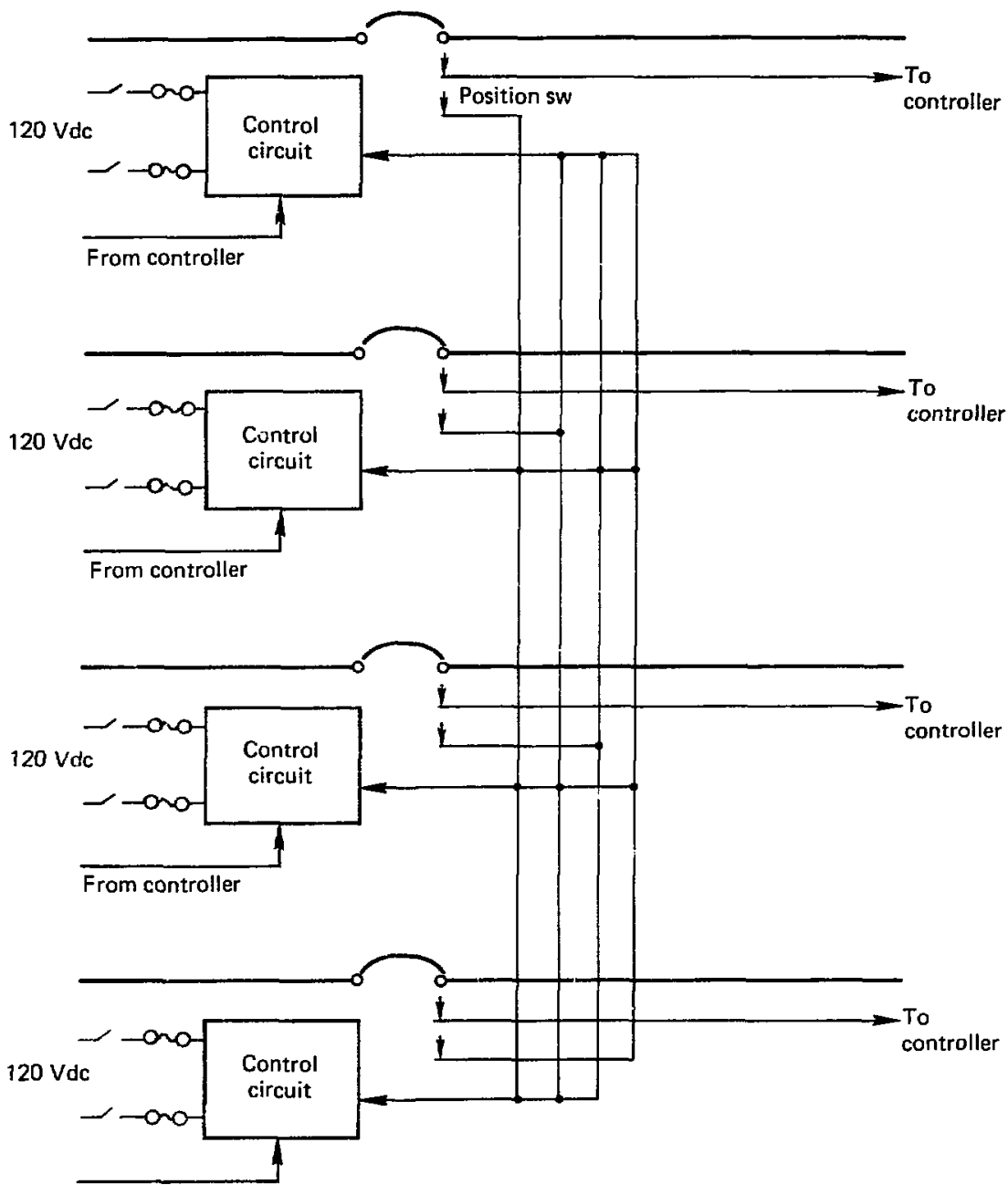

From controller

FIG. 66. Circuit breaker interconnections. 


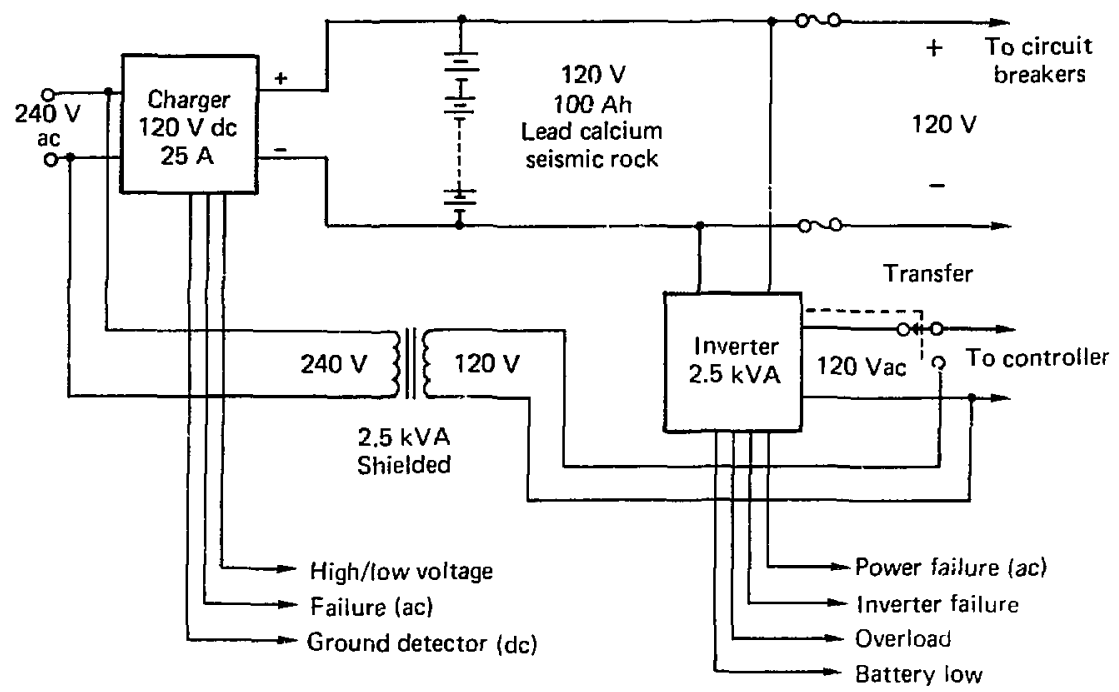

FiG. 67. Battery and inverter system.

\section{De-energize Modes}

As stated carlier, there are three modes of operation if an abnormal condition in the power supply system or the mignet oceur: hold. slow deenergike. and fast de-energize. The hold mode stops the increasc in current during energiring. The slow de-energice mode turns the power supplien ofl and imert 1.5 mQ in series with each magnel coil. The fast de-energise mode opens all four de circuit breakers and sends a signal to the cryogenic system to close the supply villees from the Dewar and open the valhes to the helium recovery system.

Table 16 shous the main failure conditions and the appropriatc attion which will be initiated. The hasis for this table is the failure modes, effects, and cruticality analysis performed by Intermagnetics General Corporation (IGC). ${ }^{80}$ This table also reflects the use of the fast de-energize mode as the last line of protection. This is to minimize disruption to the MFTF operation and to minimize probability of voltage failures in the magnet.

\section{Quench Detection}

Detection of a normal zone in the magnet will be done by monitoring the voltage taps in both coils and by monitoring helium pressure in the helium supply Dewar. Use of the witage tarp enables delection of normal fones as thon a $1 \mathrm{~m}$. identification of their approximate locituon in the coils. and their growth behanior. Lise of the helum pressure enables detedum of normal regions in the coil but not thes location or grow th tharacteristics. It is used to cuscr potential blind pous in the clectricall quench delector. and beciluse it in a completels different lspe of detertin and woulo not have a fault mode in common with the electrical detitor.

Based on lemperiture rise citculation and experimental normal sone propagution fates of approximately $1 \mathrm{~m}$ s the magnet will colter the fast deenergire mode at a normal rone length of approxinaticly $10 \mathrm{~m}$. To detect small stable normal fones and to montor growth rates it is required to detect a normal ronc its small as $1 \mathrm{~m}$. Detection or growth rates is regured to discriminate against fast signals which occur duc to conductor motion and electromagnetic interference.

Detection of a $I-m$ length requires detection of $26 \mathrm{mV}$ of resistive voltage (at $6000 \mathrm{~A}$ ) in the preence of $\pm 12 \mathrm{~V}$ of inductive voltage during energlsing or de-energizing. A well known method for quench delection with a single coil is the balaneed 


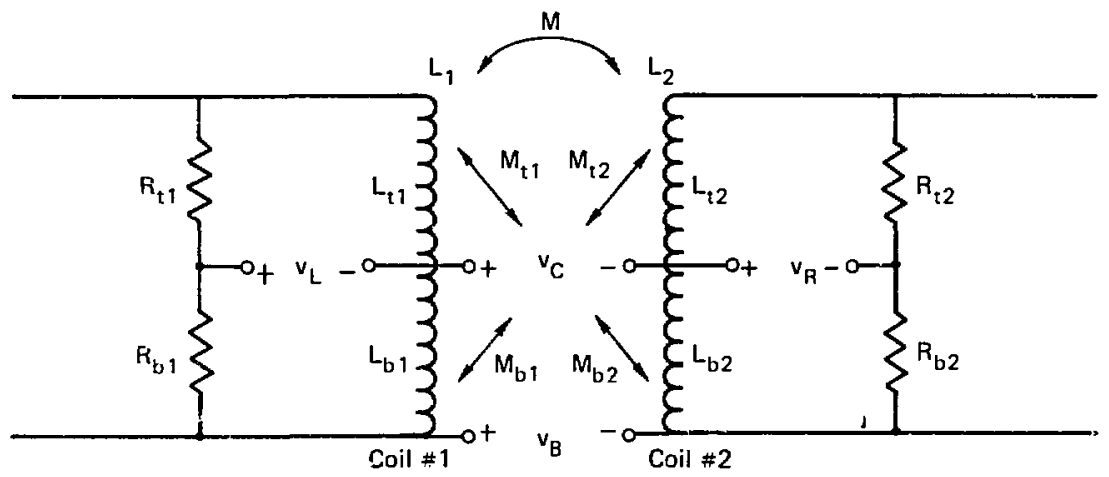

Detector equation: $v_{o}=K_{1}\left(v_{C}-v_{B}\right)+K_{2}\left(v_{L}-v_{R}\right)$

For similar coils:

$$
\left.\begin{array}{l}
L_{t 1}=L_{t 2}=L_{t} \\
L_{b 1}=L_{b 2}=L_{b}
\end{array}\right\} \quad L=L_{t}+L_{b}=L_{1}=L_{2}
$$

$$
K_{1}=\frac{M_{b}}{L_{b}}\left(\frac{1-\frac{L_{b} M}{L_{b}}}{1-\frac{M_{t}}{L}-\frac{L_{b}}{L}}\right) \quad K_{2}=\frac{1-\frac{M_{b}}{L_{b}}}{1-\frac{M_{t}}{L}-\frac{L_{b}}{L}}
$$

For MFTF: $L_{t}=5.79 H$

$$
\left.\begin{array}{l}
L_{t}=5.79 H \\
L_{b}=5.32 H
\end{array}\right\} \quad L=11.11 H
$$

MG. 68. Quench dett - tion method. 
TABLE action."

16. Failure conditions and appropriate

\begin{tabular}{|c|c|c|c|}
\hline \multirow[b]{2}{*}{ Combition } & \multicolumn{3}{|c|}{ Appropriate action } \\
\hline & Fast & Slow & Hold \\
\hline Growing normal zome, $1>10 \mathrm{~m}$ ) & $\mathbf{x}$ & & \\
\hline Stable normal zome $(<10 \mathrm{~m})$ & & $\mathbf{x}$ & \\
\hline Correm legd overkeating & & & \\
\hline Voltage alarm, tevel 1 & & $\mathbf{x}$ & \\
\hline Voltage alarm, Jevel 2 & $\mathbf{x}$ & & \\
\hline Low belimm lenct in Dewar & & $\mathrm{x}$ & \\
\hline High helium pressure in Denar & & & \\
\hline Pressure alarm, level I & & $\mathbf{x}$ & \\
\hline Pressure alarm, letel 2 & $\mathbf{x}$ & & \\
\hline Valve from heliun Dewar closes & & $\mathbf{x}$ & \\
\hline Mlain racoum failure, major & & $\mathbf{x}$ & \\
\hline Guard sacuum failure, major & & $\mathbf{x}$ & \\
\hline LN system faïure & & & $\mathbf{x}$ \\
\hline Hetiom refrigeration failurc & & & $\mathrm{x}$ \\
\hline .Hagnes-pratectiun sontroller failure ${ }^{b}$ & & $\mathbf{x}$ & \\
\hline MIFTF computer failure & & & $\mathbf{x}$ \\
\hline de poner suppty failure & & $\mathbf{x}$ & \\
\hline Battery charger failuret & & $\mathbf{x}$ & \\
\hline Interter failure & & $\mathbf{x}$ & \\
\hline 12(i-V(ac) pouter failure & & $\mathbf{x}$ & \\
\hline Inverter and I20-V(ac) poner failure & $\mathbf{x}$ & & \\
\hline $120 \mathrm{~V}(2 c)$ to eircuit breaker failure & $\mathbf{x}$ & & \\
\hline
\end{tabular}

Basced on failure modes. effects, and criticality analysis performed hy Iwermagnetics General Corporation.

bQuench detector, currewt-lead voltage alarms, and helium pressure alarm have backup systemb. self-inductance bridge method. Because MFTF has two coils which are coupled together with a ccupling coefficient of approximately 0.1 , and because the karge dimensions of the coil cross-section result in varying coupling depending on voltage tap location, the self-inductance bridge method cannot be used in the conventional manner Based on calculations using the EFFI code, approximately $70 \mathrm{mV}$ result in the bridge due to mutual inductance imbalance. $1 \mathrm{GC}$ in their quench detection and magnet protection study ${ }^{80}$ proposed using current rate indicators to compensate for the mutual inductance imbalance.

An analysis done by LLNL resulted in a quench detection method which successfully compensates for mutual inductance imbalance without requiring current rale sensors. ${ }^{81.82}$ Two voltages between coils are used in addition to the selfinductance bridges to form a detector equation (Fig. 68). The gains $K_{1}$ and $K_{2}$ are functions of the partial mutual and seff induciances in the two coils.

\section{HARDWARE IMIPLENIENT TTION}

Detailed design of the hardware for the power supply and magnel protection controller has not been completed. One implementation was described in the IGC study. ${ }^{80}$ The selected design uses a programmable controller with an analog backup for quench detertion and current leas monitoring. 


\section{SECTION 8 \\ STRUCTURAL ANALYSIS}

\section{INTRODUCTION}

$A$ baseline structural analysis was performed in support of the preparation of the MFTF design drawings. This analysis demonstrated the basic structural integrity of the MFTF structure using the best available loads and milterial data. Subsequent to the completion of the MFTF design, additional anilyses were performed. These refined the finite element analysis in the critical stress region, and interpreted the finite element results in light of the latest material properties and actual structural effeets such as stress concent rations. Also investigated were the potential effects of assumed structural faults in critical magnet structure. These analysis tisks are summarized in scparate sections. The following discussion summarizes the structural requirements analysis methods and results from the baseline struclural analysis documented in Ref. 10.

\section{STRUCTURAL REQUIREMENTS}

\section{Materials}

The structural case material for the MFTF magnet is 304LN CRES steel with a nitrugen content of $0.14 \%$ (minimum). The weld metal is E316L. The coil-jacket plate material is 316 CRES steel as is the jacket weld metal. Design stresses for the MFTF case and weldmients were based on anticipated yield strengths of $120 \mathrm{ksi}$ at $4 \mathrm{~K}$ and on the expectation of adequale fracture toughness and naw growth rates. The preliminary plate and weld mechanical properties were obtained from the National Bureau of Standards (NBS) for use in the case design (Tuble 17), along with properties for the other structural miterials in the magnet.

\section{Factors of Safety}

The basic requirement imposed on the magnet case structure was that there should be a factor of safety of 1.5 on an anticipated $120-\mathrm{ksi}$ yield strength for the operating magnetic and thermal louds. The factors of safety on the remainder of the magnet structure are consistent with the ASME code as in Tuble 18.

\section{Design Load Conditions}

The MFTF magnet must withstand both operating and fault conditions. Design loading conditions include cooldown, warmup, and normal operating conditions. operating and fault magnetic conditions, and seismic inertia conditions In addition to these conditions, the magnet is also designed to a $2.0 \mathrm{~g}$ handling condition.

TABLE 17. Structural material mechanical properties.

\begin{tabular}{|c|c|c|c|c|c|c|}
\hline Materiai & Usage & $\underset{K}{\text { Temp, }}$ & $\begin{array}{l}\text { Ultimate } \\
\text { strengtk, } \\
\text { ksi }\end{array}$ & $\begin{array}{c}\text { Yicld } \\
\text { strength, } \\
\text { ksi }\end{array}$ & $\begin{array}{l}\text { Elastic } \\
\text { modulus, } \\
10^{6} \text { psi }\end{array}$ & Source \\
\hline $304 \mathrm{~L}$ & Support struts & $\begin{array}{l}\text { RT } \\
4.5\end{array}$ & $\begin{array}{l}100 \\
245\end{array}$ & $\begin{array}{l}40 \\
70\end{array}$ & $\begin{array}{l}28.5 \\
29.5\end{array}$ & LLL \\
\hline 30HLN & $\begin{array}{l}\text { Mugnet case and } \\
\text { intercoil }\end{array}$ & 4.5 & 244.6 & $111.8^{a}$ & 29.7 & NBS \\
\hline E316L $\begin{aligned} \Delta F e & =4.5 \\
د F e & =9.2\end{aligned}$ & Case reld metal & $\begin{array}{l}4.5 \\
4.5\end{array}$ & $\begin{array}{l}193 \\
187\end{array}$ & $\begin{array}{l}116^{a} \\
128^{\mathrm{a}}\end{array}$ & $\begin{array}{l}31.9 \\
31.9\end{array}$ & NBS \\
\hline $316 \mathrm{~L}$ & Jacket & $\begin{array}{l}\text { RT } \\
4.5\end{array}$ & $\begin{array}{r}80 \\
200\end{array}$ & $\begin{array}{l}40 \\
80\end{array}$ & $\begin{array}{l}29.5 \\
31.9\end{array}$ & \\
\hline $\begin{array}{l}\text { EPON 828/Norsumid } 125 \\
\text { with chopped glass Fher }\end{array}$ & Conduclor shimming & 20 & -14700 & - & - & $\begin{array}{l}\text { GDC EMS } \\
0-0096-51\end{array}$ \\
\hline $\begin{array}{l}\text { CPR Upjohn } \\
\text { Polycast 1009-78 }\end{array}$ & Jacket-to-case & $\mathbf{R T}$ & -13250 & - & 0.387 & Mfgr Data \\
\hline A286 & Support bolts & RT & 140 & 95 & 29.1 & AMS 5737H \\
\hline
\end{tabular}

$9120 \mathrm{ksi}$ was used for design pending determination of final allowables. 
TABLE 18. Magnet structural safety factors.

\begin{tabular}{llcc}
\hline & \multicolumn{2}{c}{ Factor of safety } \\
\cline { 2 - 3 } $\begin{array}{c}\text { Siructure } \\
\text { or condition }\end{array}$ & $\begin{array}{c}\text { Yield } \\
\text { strength }\end{array}$ & $\begin{array}{c}\text { Ultimate } \\
\text { strength }\end{array}$ & Factor \\
\hline Cuse, jacket, intercoil & 1.5 & - & 4.0 \\
Support structure & 1.5 & $3.0^{\mathrm{a}, \mathrm{b}}$ & 4.0 \\
Shields, shield supports & 1.5 & $3.0^{\mathrm{a}}$ & - \\
Seismic safety factor & 1.25 & $2.5^{\mathfrak{c}}$ & - \\
\hline
\end{tabular}

"Based an ASME codes requirements.

b'itimate strungth safely factor is $\mathbf{2 . 0}$ in welds.

ASME codes allow an increase in allowable working stress for stismic conditions of 120 \%.

Magnet loads were determined for both normal operating (both coils $100 \%$ energized) and fault conditions (one coil $100 \%$ energized. one coil inoperative). The case plate nagnetic pressures for the more critical nornal operating condition are shown in Fig. 69. Also defined were the ground accelerations for the seismic inertia conditions. Magnet accelerations and support system loads are a function of both magnet system and fusion chamber and were determined by a dynamic analysis. Magnet case loads for seismic condition were calculated by General Dynamics Corp. (GDC) based on assumed $1.0 \mathrm{~g}$ verlical and $0.75 \mathrm{~g}$ horizontal accelerations. Thermal loads in the magnet due to longitudinal and transverse thermal gradients during cooldown were calculated using finite element structural analyses thermal distribution.

\section{ANALYSIS METHODS}

The st ress analysis of the MFTF magnet and its suppert sys: $\rightarrow$ is based on data from three separatte finite ele, int analyses: a large 7000-degree-offreedom GDSAP analysis of one-quarter of the magnet, detailed MSC/NASTRAN models of typical case cross-sections, and a simple beanelement model of the eomplete magnet and its sup. ports. The large GDSAP model determined the overall stresses and deflections for the magnetic loads, quench pressure loads, and the normal operating $4.5 \mathrm{~K}$ temperature condition. MSC/NASTRAN models were used to refine the local case hending stresses for the magnetic load conditions, and a GDSAP beam element model was used to determine the overall magnet loads for the unsymmetric seismic and cooldown thermal conditions. These models are discussed below and are documented in Ref. 10.

The 7000-degree-of-freedom plate model of the MFTF magnet is shown in Fig. 70, representing one quarter of each magnet and the interconnecting load-block struclure.

The coil jacket, case structure, and intercoil structure are represented by iinear-strain thin-plate elements, which simulate the axi:ll and bending stiffnesses of the plate structure. The conductors are represented by six continuous rod elements that represent the lumped axial stiffness of the pack. These elements are connected to the surrounding case and jacket structure by other rod elements that sinulate the transverse stiffness of the conductor pack including the conductor, insuliation, and effective gaps.

The louding conditions for the GDSAP plate model are all quarter symmetric. Magnetic loads for both the normal and fault conditions were calculated for an idealized $(5 \times 12)$ conductor grid used in an EFFI analysis. The loads on the EFFI grid were lumped together at the GDSAP conductor nodes and applied to the finite element model. Loads for the normal operating condition atssume $100 \%$ operating current in both magnets, while loads for the EFFI fault condition are bitsed on $100 \%$ eurrent in one magnet and no current in the other. A quench pressure condition consisted of a uniform 700 psi bursting pressure applied to the calse plates surrounding the conductor pack. The normal operating $4.5 \mathrm{~K}$ temperature cor dition was analyzed to determine the residual stresses in the magnet caused by the differences in thernal contraction belween the case and the conductor.

The output from this analysis consisted of the overall stresses and defection in the magnet conductors. jacket, and case. However, the element mesh in this model was too coarse to provide a detailed definition of the local bending stress distributions in the magnet case plates. Therefore, a detailed MSC, NASTRAN model of the cist cross section was created to refine the vverall GDSAP analysis results. This NASTRAN model refined the local case bending stresses as illustrated in Fig. 71 and documented in Ref. 10.

The NASTRAN model was used to analyze three typical sections in the magnet's major radius. Models of the case at $O=24^{\circ} .48^{\circ}$, and $72^{\circ}$ were 

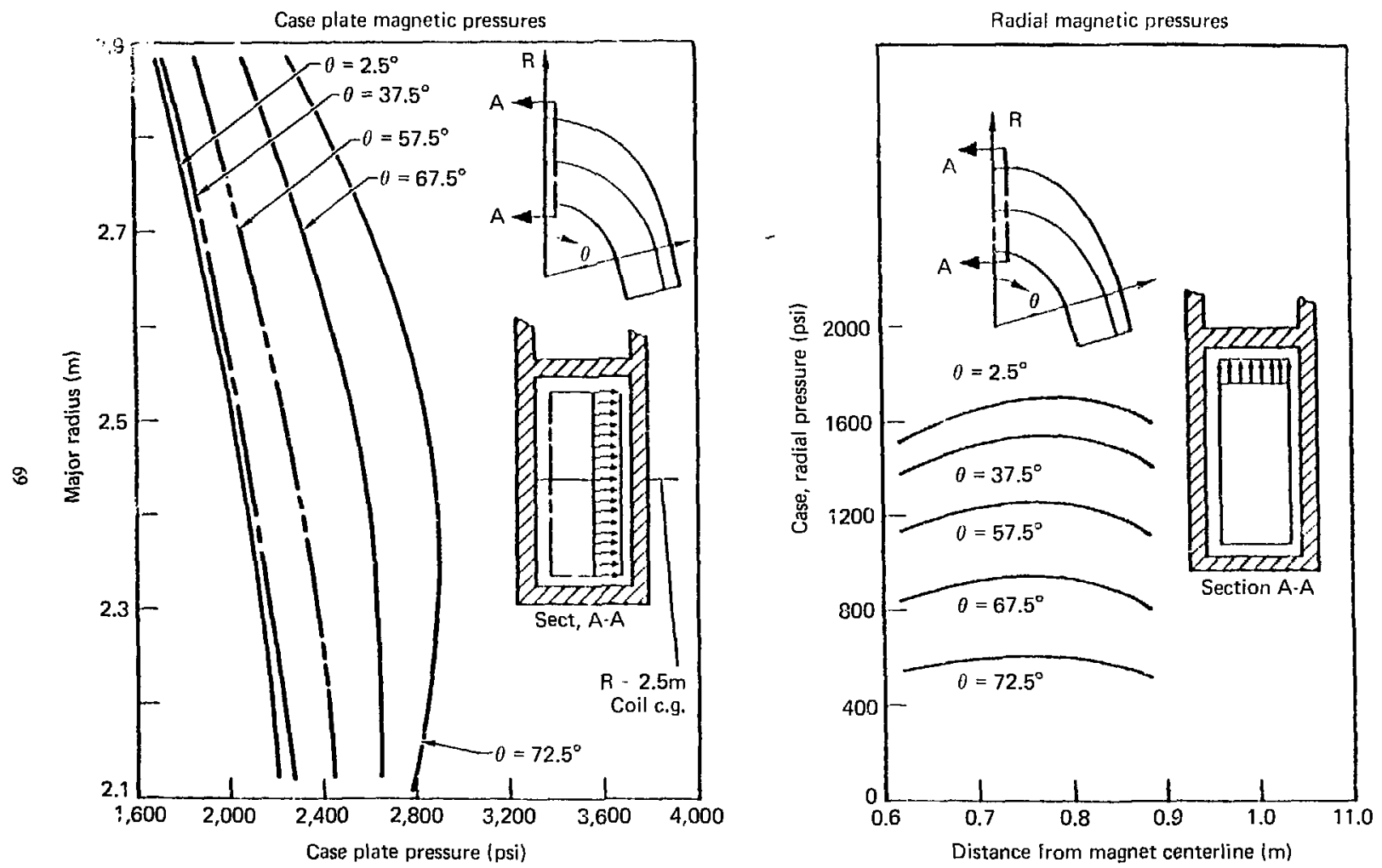

FiG. 69. The conductor pack excrts high pressures on the magnci case. 


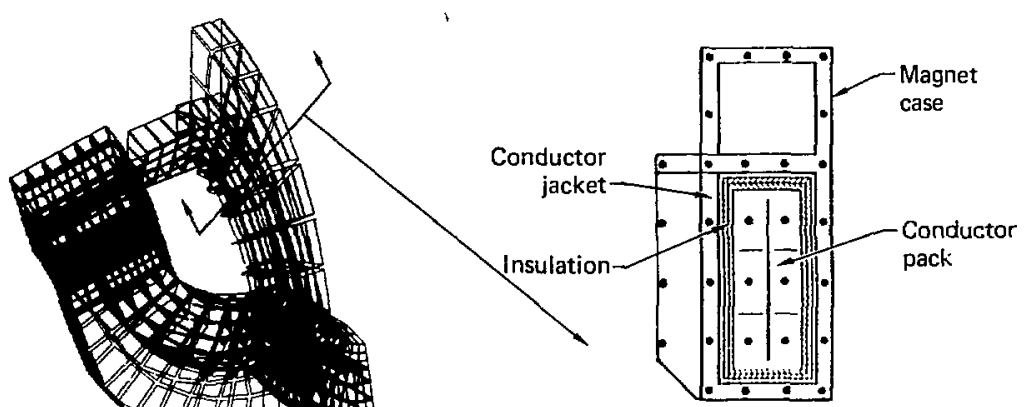

(a) Typical node arrangement
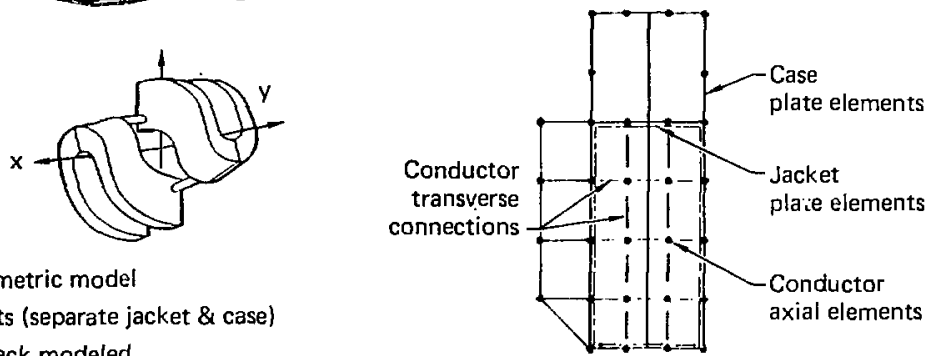

- Quarter symmetric model

- Plate elements (separate jacket \& case)

- Conductor pack modeled

- Reflects current geometry and stiffness

(b) Typical model cross section

FIG. 70. The GDSAP finite element model accurately represents the MFTF structure.

created with the only differences between the models being the thickness of the side plate stiffener, the depth $h$ of the guard-vacuum section of the case, and the applied loads.

The magnetic loads are applied directly to the NASTRAN model case plates as distributed pressure loads, shown in Fig. 69. Additional pressure loads were applied to the NASTRAN model to simulate the effective radial pressures created by the axial stresses existing in the curved crossover plates. These pressures were calculated from the longitudinal stresses obtained from the GDSAP analysis. By assuming that a longitudinal stress $f_{L}$ in the curved plate with radius $R$ and thickness $t$ would create an effective radial (normal to the plate) pressure $P=f_{L} t / R$ in addition to the pressure loading, forced displacements were applied to the NASTRAN model to ensure deflection compatibility with the overall GDSAP analysis.
The GDSA P be:am element model illustrated in Fig. 72 was ereated to determine the overall magnet and support bads for the unsymmetric iriertia and thermal condition and is also documented in Ref. 10. Because the ineritia and thermal stresses were expected to be small, the simple heam element model was considered adequate to confirm that the seismic and cooldown conditions were not critical. The model grid points, which are shown in Fig. 72. are locited at the centroid of the conductor pack. The mass and axial stiffness of the coil are represented by rod elements connected to the model grid and the axial and bending stiffnesses of the magnet case are represented by beam elements whose centroids are offset from the conductor thermal conditions. The cooldown thermal conditions addresses temperature gradients due to three symmetric and three unsymmetric helium flow distributions during cooldown. Temperature distributions for these 
Effective pressures induce by curvature and longitudinal stresses.
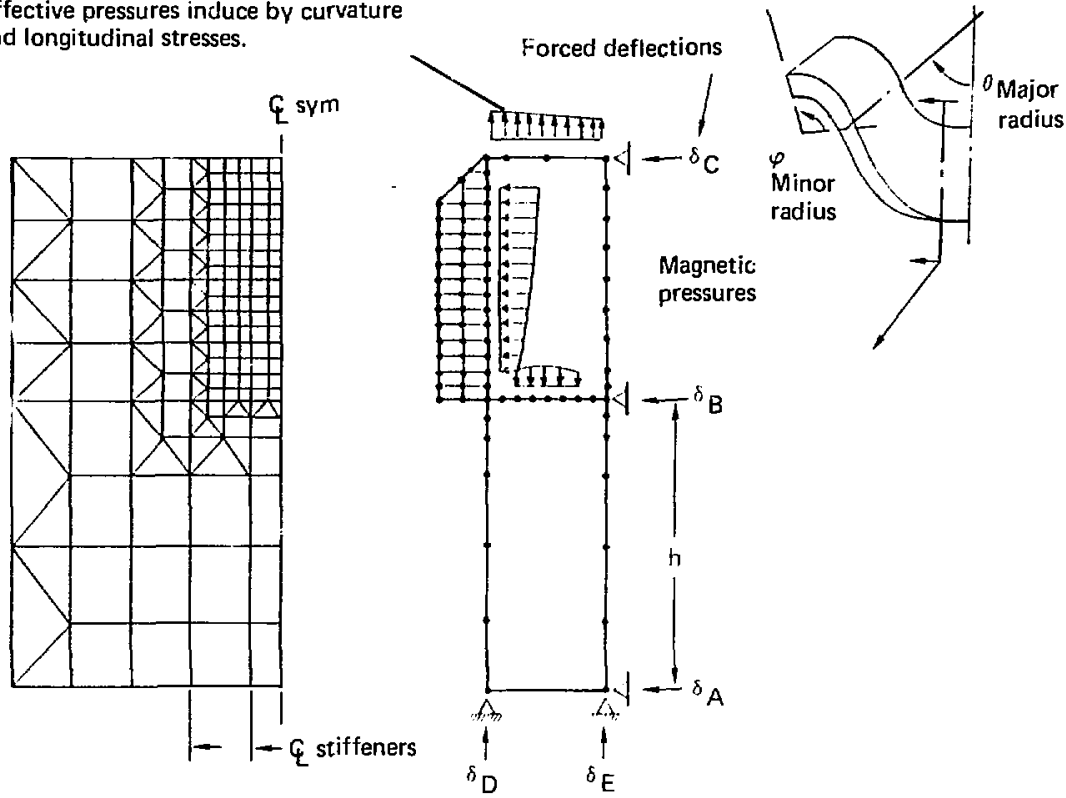

FIG. 7I. The NASTRAN finite element model refines the case bending moments.

various flow distributions are documented in Rıf. 72.

\section{ANALYSIS RESULTS}

\section{Case Stress Analysis}

The case stress analysis can be broken into two categories: the analysis of the major radius, and the analysis of the minor radius. In the major radius, the primary in-plane (membrane) stresses are caused by the C-clamp action of the magnet. The secondary bending moments are caused primarily by redistribution of the magnetic pressure loads applied to the side plates as shown in Fig. 73. In the minor radius, the in-plane stresses are caused primarily by the spreading or opening up action of the major radius lobes. The secondary bending moments are caused by redistribution of the seven million pound intercoil load and by the effects of the high in-plane stresses acting in the curved minor radius plates, also shown in Fig. 73.

\section{Major Radius Analysis}

The critical in-plane stresses in the major rudius case plates were determined entirely by the GDSAP plate model finite element analysis. The plate secondary bending moments were determined by the same analysis but were also refined by the Nastran analysis of typical case cross scctions. In the center crossover plate where the Nastran and GDSAP moments differed because of the manner in which the magnetic pressures were applied. the structure was analyzed for the worst combination of moment and in-plane loads. Fig. 74 shows the combined primary and secondary stresses at several locations in the case. All principal stresses were less than $80 \mathrm{ksi}$.

Peak stresses in the magnet case during cooldown are caused by the temperature gradients between the ease side plates and the external stiffeners. The curvature produced in the stiffener by the temperature gradients causes high bending stresses in the case plate adjacent to the stiffener as 

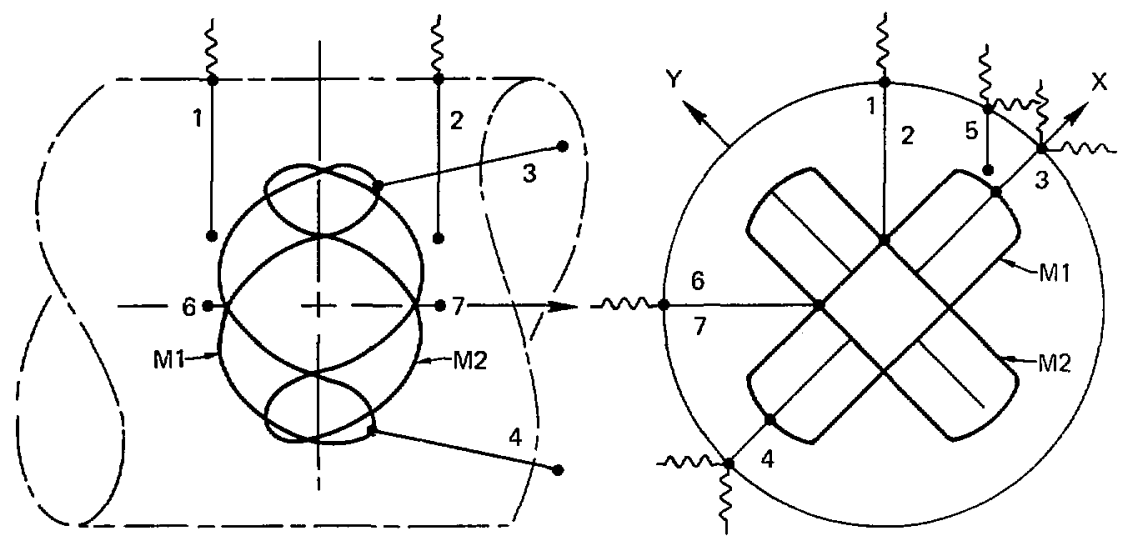

FIG. 72. GDSAP beam element model determines overall magnet stresses for seismic and cooldown thermal conditions.

- Redistribution of applied loads

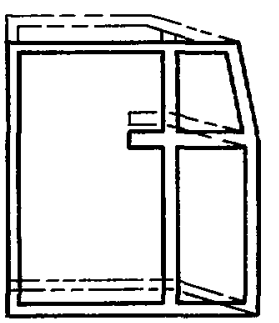

$\left\{\begin{array}{c}\text { Intercoil load } \\ \left(\mathrm{P} \approx 6.5 \times 10^{6} \mathrm{lb}\right)\end{array}\right.$
- Geometry changes that cause effective pressure loads
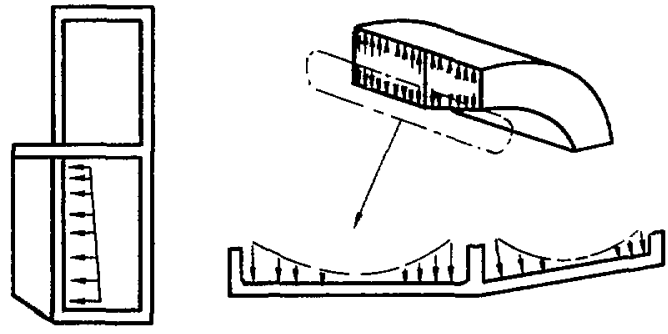

FIG. 73. Critical case stresses are caused by secondary bending moments. 


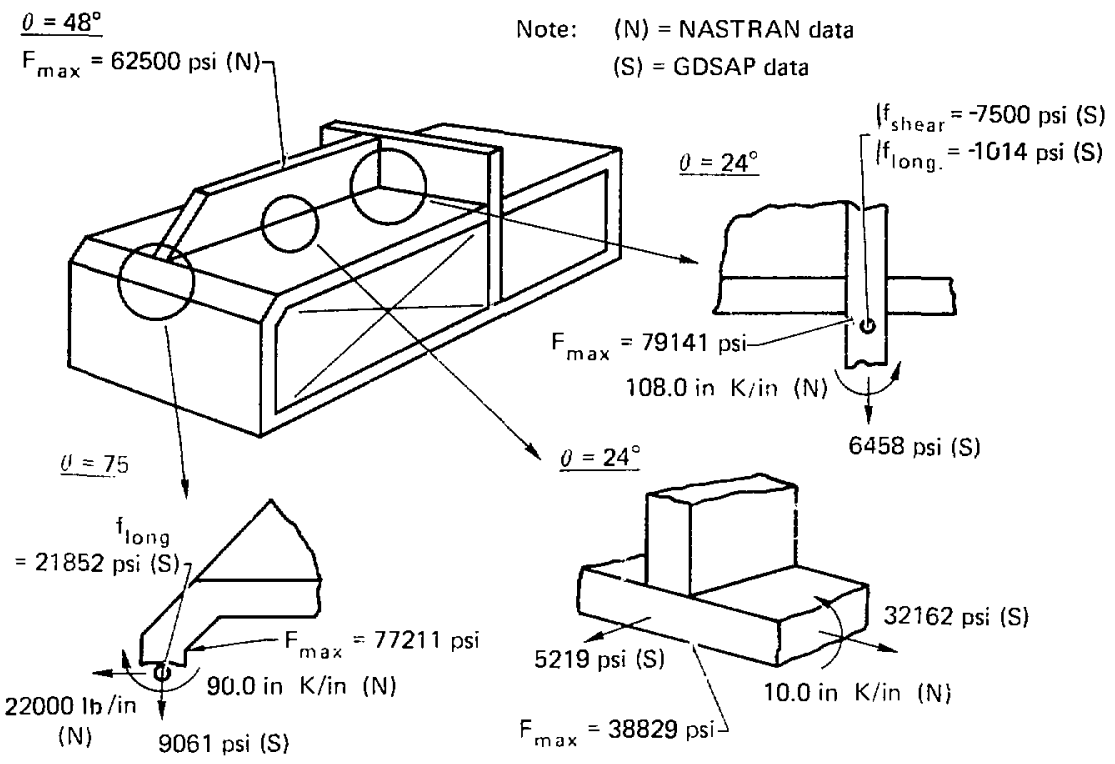

F1C. 74. The major radius stresses are less than $80 \mathrm{ksi}$.

Shom nn in Fig. 75. However, these stresses do not ex. ceed the yield strength of the strueture at the temperat ure at which the stress oceurs. The case stresses ciaused by the longit udinal thermal gridients did not exceed $12 \mathrm{ksi}$.

\section{Minor Radius Analysis}

The strensen in the minor radius are determined primatrily by the GDSAP plate model. Membrane it resses are caused by the opening up of the minor radius due to magnetic loads, but $4.5 \mathrm{~K}$ operating thermal loads subtract slightly from these stresses. The secondars bending moments are due lo redistribution of the intercoil load and to erfec:ive pressures eaused by the case plate curvature as shown in Fig. 73.

Figure 76 shows the si resses at several locition. in the case minor radius. The stresses were taken directly from the finite element analysis except for the secondary moments in the chamferred surface of the inner case plates. The secondary bending moment in that location was modified to account for inaccuracies in the finite element analysis caused by the comblath strain triangular elements used in that portion of the model. The peak principal stresses predicted hy the froseline andlysis exceeded the intended 80-ksi dosign stress hy 2 to $66^{\prime}$ in hoth the inner and celiter crossover platen as shown ir; Fig. 76. Howeser, at ewaluation of several known inadeyuacies in the GDSAP analysis indicated that the predieled stresses would be redered hy a refined inalysis of this area. The analysis refinement lask

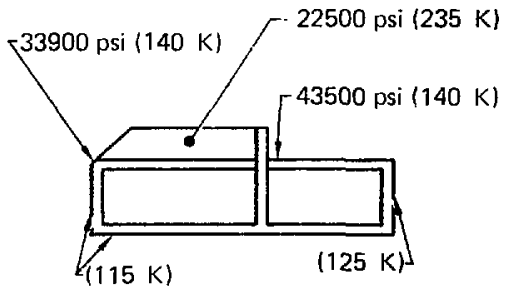

1F](;. 75. Cooldown temperature gradients create signilicant stresses. 

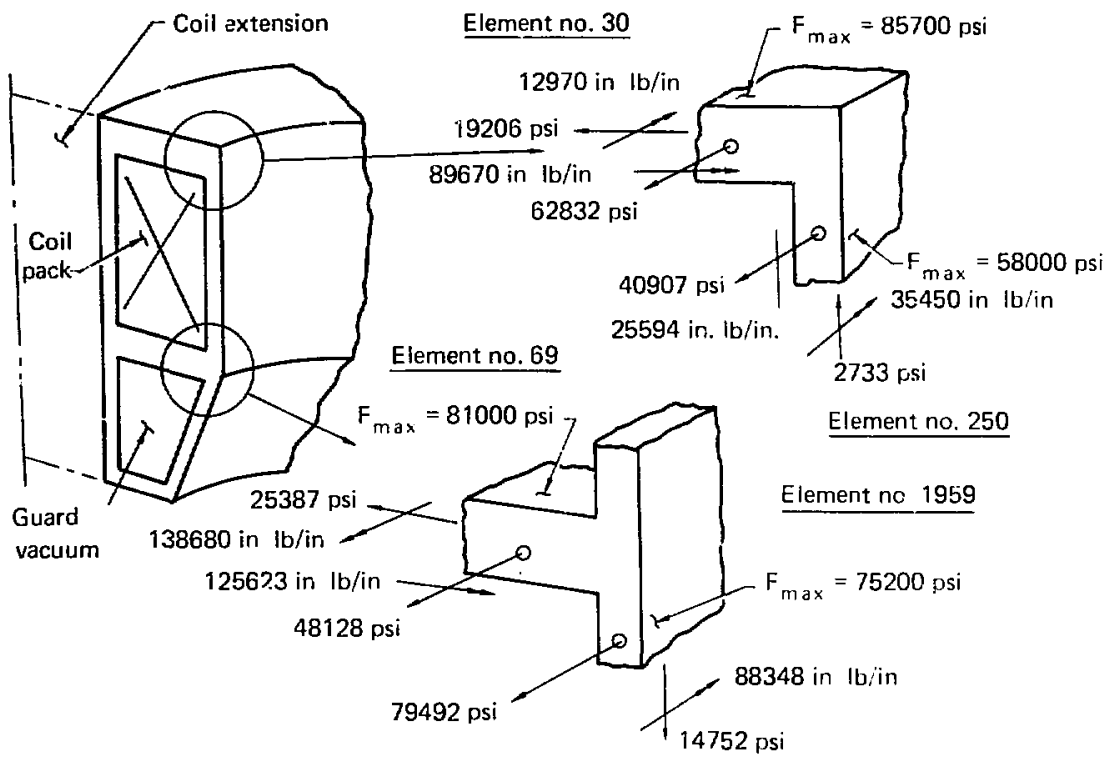

FIG. 76. The peak magnet stresses occur in the minor radius.

was accomplished and is discussed in at stparate secton of this report. and documeited in Ref. 8.3.

\section{Intercoil Struciure Analysis}

The intercoil strueture conncits the major lote of one magnet with the minor radius of the other magnet. The primary stresses in the inicrcoil structure are caused by the normal operating mignetic loads that create a seven million pound compression load in the intercoil member. Additional low stresses are produced in the intercoil structuit by thermal and inertia condations.

Design loads for this structure wers obtained from the large GDSAP platt model and from the smaller GDSAP bean model. Figure 77 shows the membranc stresses in the intercoil structure for the normal operating condition. Stresses for the normal operating thermal condition are less than $500 \mathrm{psi}$ everywhere except in the inner plate near the major radius iobe where the values are shown in Fig. 77 . Overall intercoil louds dae to cooldown and incrtia

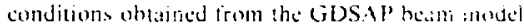

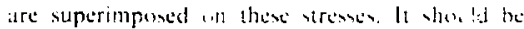
noted that the atrenes snould be multipied be 125 wiscoum for the differente hetwen the $2.5-1 n$.

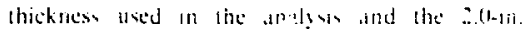
thickners elsed in the linat derent.

\section{Support Structure Analysis}

The support structure consist of two support rods (1.2) that support the werght of the manet and fise stabilier rod (3-7) thatl reket horlannt.s seismic louds as show in fig. 78. The struts and the lugs alluching the struts to the magnet were analy ged bs hand to the loads shown an Table fly. Ales shown in Tiable 19 are the margin of alea for various components in eath support strat. The margins of sufety are hatsed on the follow ing expres. sion:

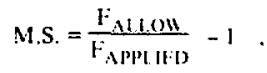



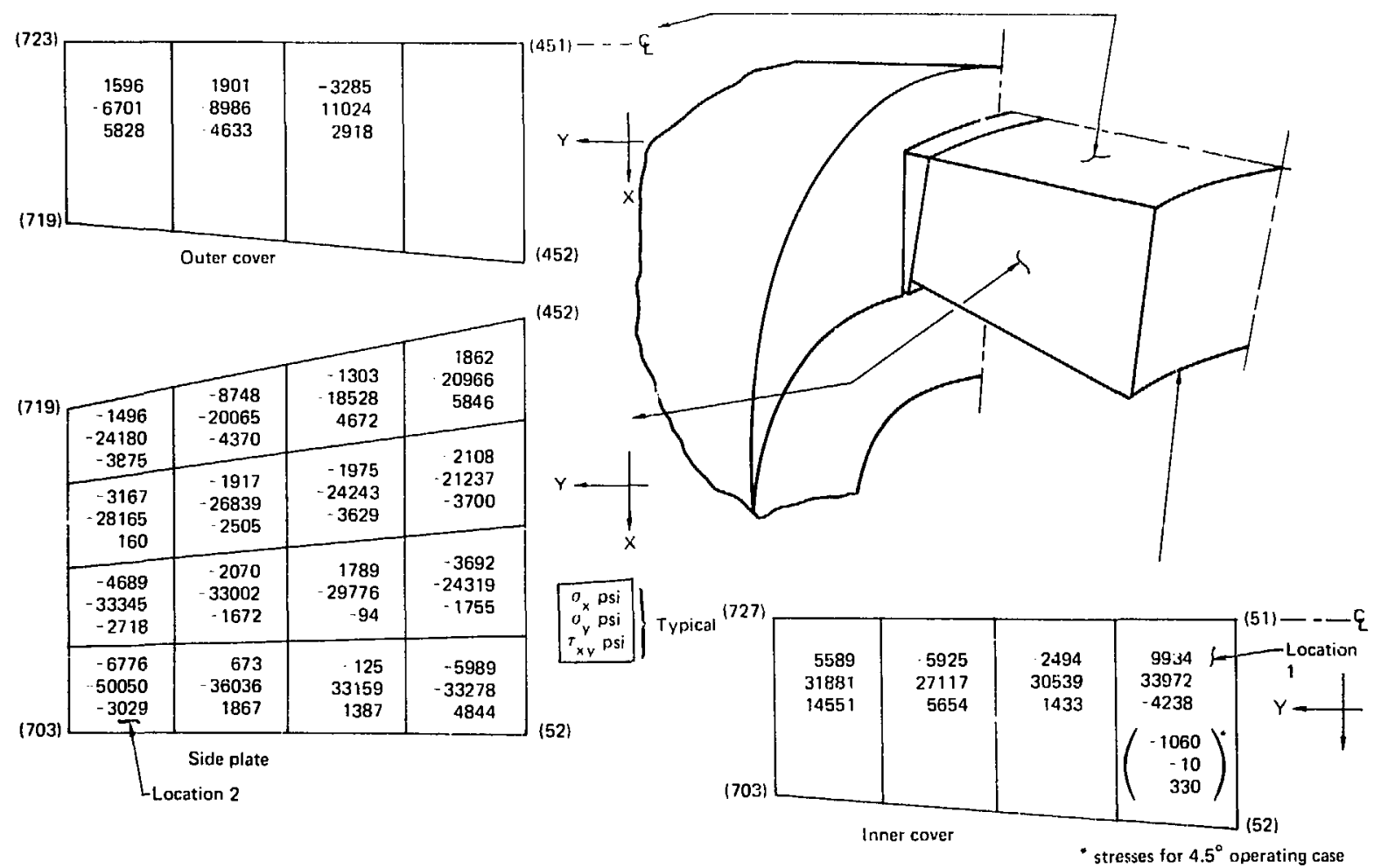

FIG. 77. The stresses in the intercoil structure are acceptable. 
TABI.E 19. Support struts have adcquate margins of safet?.

\begin{tabular}{|c|c|c|c|c|c|c|c|c|}
\hline $\begin{array}{l}\text { Red } \\
\text { No. }\end{array}$ & $\operatorname{loni}_{\text {lead }}^{1.2{ }^{a}} 1$ & $\begin{array}{l}\text { Design } \\
\text { !oad }\end{array}$ & $\begin{array}{l}\text { Strut } \\
\text { tension }\end{array}$ & $\begin{array}{c}\text { Strut } \\
\text { compression }\end{array}$ & $\begin{array}{l}\text { Bearing } \\
\text { capacil! }\end{array}$ & $\begin{array}{l}\text { Strut } \\
\text { end lupg }\end{array}$ & $\begin{array}{l}\text { Clevis } \\
\text { pin }\end{array}$ & $\begin{array}{l}\text { Ctersin } \\
\text { lugg }\end{array}$ \\
\hline \multirow[t]{2}{*}{1} & $+6,67$ & $\perp H(H)$ & & & & & & \\
\hline & - & -.379 & $+11,0(x)$ & +0.95 & +0.15 & +11.111 & $-0.2 x$ & +11.52 \\
\hline \multirow[t]{2}{*}{2} & +724 & +800 & & & & & & \\
\hline & -368 & -.375 & & & & & & \\
\hline \multirow[t]{2}{*}{3} & +518 & +5211 & & & & & & \\
\hline & -237 & -275 & +0.68 & +1. thd & +0.17 & +0.34 & +11.94 & -11.15 \\
\hline \multirow[t]{2}{*}{4} & +424 & +520 & & & & & & \\
\hline & $-26,3$ & -275 & & & & & & \\
\hline \multirow[t]{2}{*}{5} & +310 & +.375 & +1.3 .3 & +0.95 & +11.12 & $+11 . .3 .3$ & +0.76 & - 11.15 \\
\hline & -18.3 & & & & & & & \\
\hline 6 & +359 & +520 & +0.68 & +11.39 & -0.17 & -10.74 & -0.04 & -0115 \\
\hline \multirow[t]{2}{*}{7} & +242 & +5211 & & & & & & \\
\hline & -5115 & & & & & & & \\
\hline
\end{tabular}

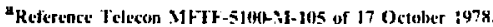

where

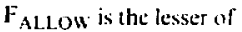

$\left(F_{t}: 3\right) \times 1.2=F_{t u}, 2.5$ and

$\left(F_{1,} / 1.5\right) \times 1.2=F_{13} 1.25$

The lugs were checked for tersion and shear bearing falluren using an industry-wide stundard lug analysis documented in Lockheed Stress Memo No. 1. Bolts were checked for shear and bending failures. The struts tbemselses were checked for tonson and for beam column compression loads. In compression, an initial bou of $1 \mathrm{in}$. was assumed in all rods.

\section{FRACTURE ANALYSIS}

A fracture analysis was performed in support of the MFTF design to confirm the selection of 304LN for the structural case material and to demonstrate adequate life at the 80-ksi design stress level.

A linear elastic fracture analysis of the 304 LN plate and $316 \mathrm{~L}$ weld filler was documented in Ref. 10. The analysis was based primarily on fracture loughness and flan grou th rate data ohtained from NBS. Whert data was not available. the analysis used malertal propertas entumdied trom datil for similar materlals oblaned trom literature: sources. The atnalysis wate performed using the

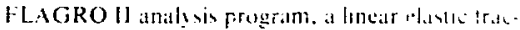
ture nechanies progeram descloped hy Rochuell In. ternational Corporatuon

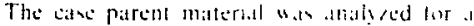
typual surface haw (0.150-1n long $\times 0.00^{-5}$-in deepl and for a Is pical corner flum $(0.050 \times 0.0501$ at the

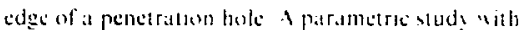

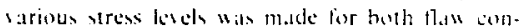
ligurattom using NBS metlertal data and the FLAGRO II analus program. The andish andieated that the requared four desien lises could be ohtamed with is stess lest of 9ohy in the hask

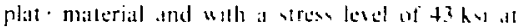
t:pis:al penctration.

The 316L weld material "as analsed for

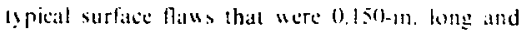
0.075-in. deep. Howerer. during the bavelints

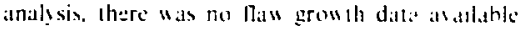
for this malerial. As it was fell that the charisteresties of E:310 filler would he sers similar wo those of 316L., the antalysis "ils performed using E.310 filler baw-growth datil. All analys using 304LN fan-growth data was also performed, resulting in design life stress of $90 \mathrm{ksi}$ with 304LN 17aw-growh dala ind $100 \mathrm{ksi}$ with E310 dalta. 


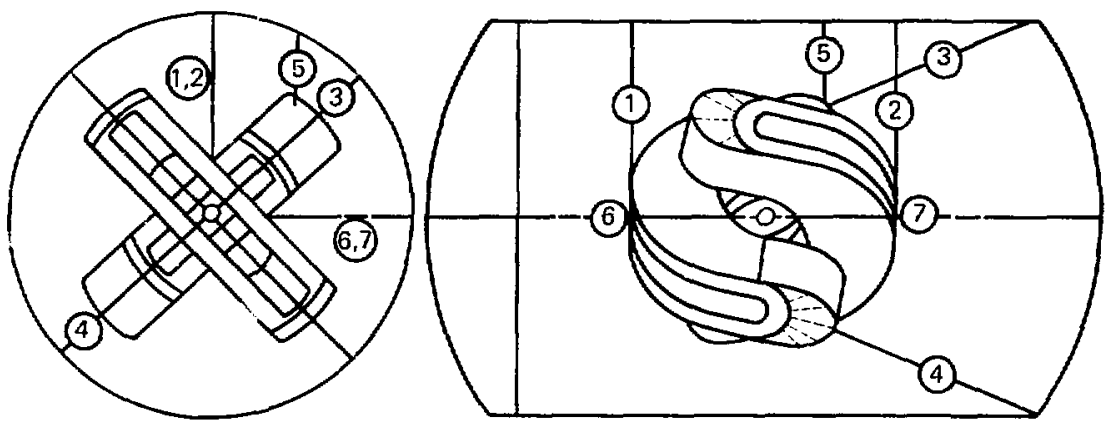

FIG, 78. JlFry supports are designed for magnetic, thermal, and seismic loads. (Rod Vos, 1 and 2 are support rods. Yos. 3-7 are stabilizer rods.)

\section{CONCLISIONS}

The MFTH haseline anahsis comfrrmed the basce structural incenrity of magnel. and that the support system met ASME factor of safety eriteria. Cooldown thermal itresses "ere acceptable for the cooldow to time of 3.6 days which mel design oljectuses. Fracture analyses showed aceptable matnel iife at the desgn stress letel of so ksi. Analysis shoued that stress icels in the magnet were within the 80-ksi design limil eler! where except for several lowations in the minor radius where peak stresses reitched $\$ 6 \mathrm{ksi}$. A subsequent retinement of the finite analyis which is discussed elsewhere in this report and is documented in Ref. 83 reduced the calculated peak stress levels to less than $80 \mathrm{ksi}$. 


\section{SECTION 9 \\ STRUCTURAL FINITE ELEMENT ANALYSIS REFINEMENT}

\section{SUMMARY}

The baseline structural anilysis of the MFTF magnet confirmed the structural integrity of the magnet. However, the peak stresses at several locations in the magnet mirror radius exceeded the allowable design limits of $80 \mathrm{ksi}$ by 2 to $6 \%$. These stresses were duternined by a GDSAP finite eletnent analysis and are documented in Ref. 10. It was recognized at tie completion of the baseline analysis that a refined anilysis of the critical stress region using the NASTRAN program would probably reduce the calculated peak stresses. Therefore, a revised finite element analysis of the MFTF magnet was conducled and documented in
Ref. 83. This analysis incorporated a refined mesh, updated material thicknesses and a NASTRAN plate element that accounts for the out of plane shear flexibility not represented in the GDSAP analysis.

\section{MODEL DESCRIPTION}

For this antilysis the case, jacket, and int_icoil struclure were modeled by isoparametric, quadrilateril, plate tements (Fig 79). The conductor pack was modeled by "lumping" the stiffness of the individual conductor strands into six squivalent. continuous, axial rod elements. Rod elenrents in the

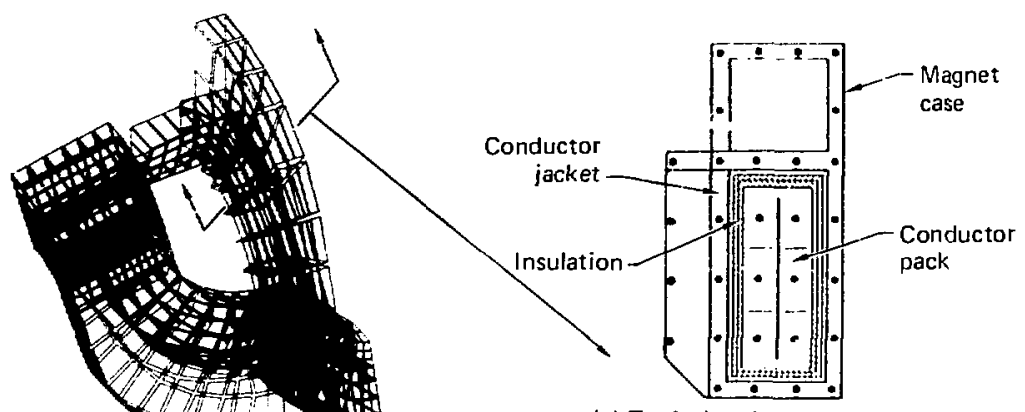

(a) Typical node arrangement
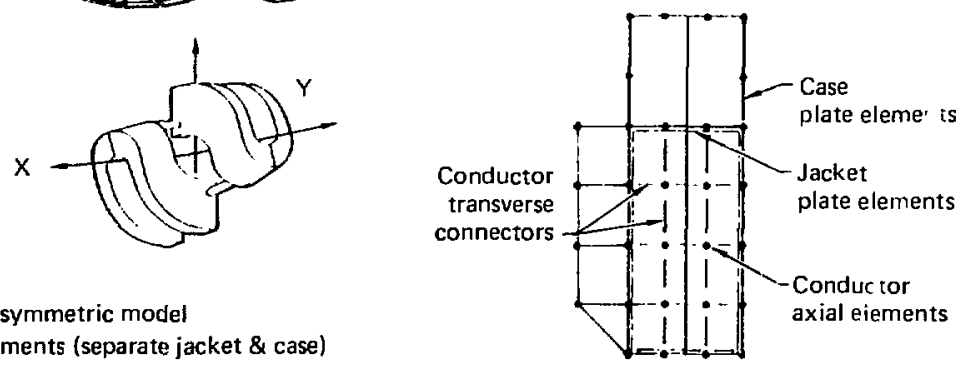

- Plate elements (separate jacket \& case)

- Soriductor pack modeled

- Refiects current geometry and stiffness

(b) Typical model cross section

FIG. 79. Finite element model-typical cross section. 


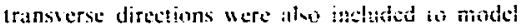
the consuctor pack stifluess in those directions (Fig. 80).

The loading sonditions analyad included - hose loads dae to sictromienetic fores, the residual thermal loads after cooldow in $+K$, the internal pressure load resuhing from a yeanch, and the critical combination o! nom mal operating clectromanencic loads and residual thermal cooldown hads. The eleciromangete had distribution wate determined by L.L.S. and was proportioned atecording to the nodes of the conduetor pack.

The seructural analysis wats accomplished in (wo seps. First. the balueline analysis (Ref. 79). using the CDS IP finite element program, identified those arean where pealk strenses exceded the k0-ksi allowahle stren lesel. This allowable stress level account for a idewor of safters of 1.5 an sield strongth $1120 \mathrm{k}$ if for the 304I Xe material. Regions of critical stress were found in the inner and intermediate crossover plates in the minor radius sestion.

The nodel refinements included: increasing the number of elements in the minir radius region. shanging the case plate thickness from 3.00 in. 10 $3.20 \mathrm{in}$. (to account for the actual thickitess of the receiv cel cisse material), and modeling the offset of the mid-surfaces at the transition from 3.2n-in. to 5.00 -ili. crosisover plate (at the Iransition from mijor to minur radius) (Figs 81 and 82 ). Also, in additiun to a GDSAP anilysis, the model was analysed using the NASTRAN linite element program. NASTRAN aceounts for transwerse shear stiffness in plites and also utilizes some higher order elements. The refined model has fewer triangular tlements than the batseline model and no highly distortes upuadrilateral elements.
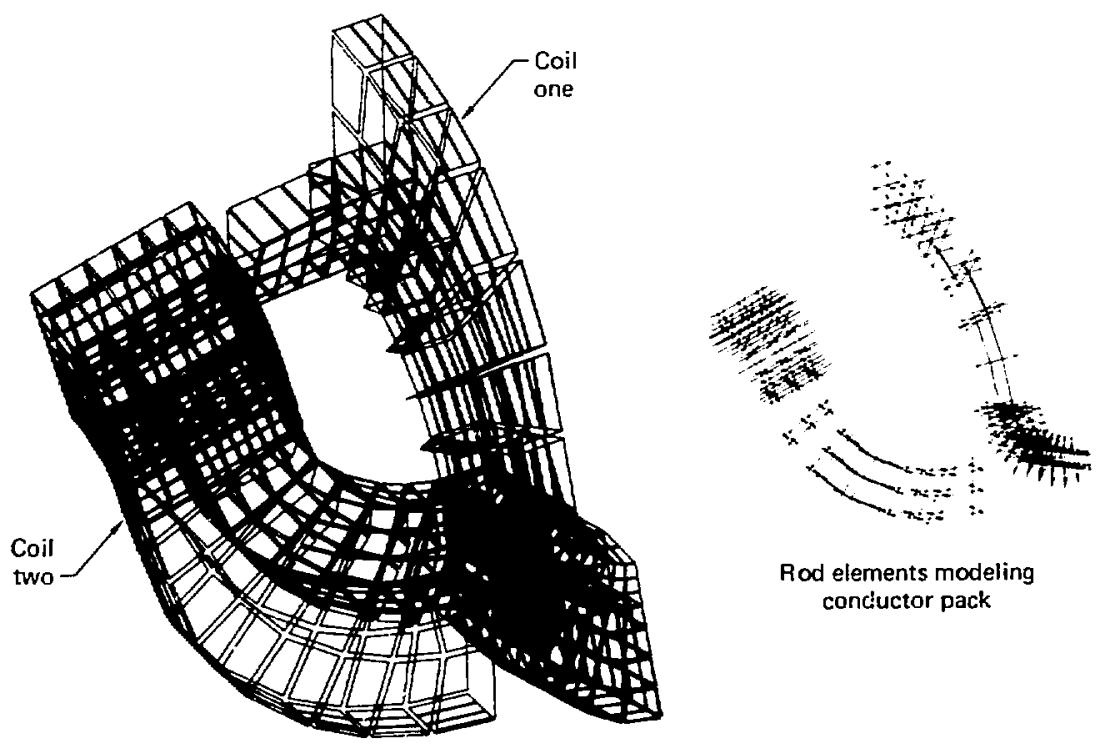

Rod elements modeling conciuctor pack

Complete model - plate clements

FIG, \$). Refined finite element model-cuse structure and conductor pack. 


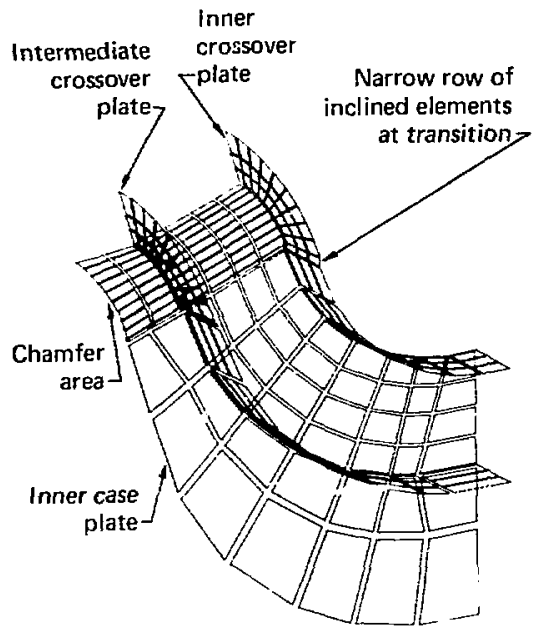

FIC. 81. Kefined model accounts for nonalignment of ncutral surfaces at transition from 3.2-in.-thick plate to 5.0-in.-thick plate.

\section{ANALYSIS RESULTS}

The maximum principal stresses predicted in the critical regions of the minor radius showed reductions of $3 \%$ to $8 \%$ for NASTRAN and $0 \%$ to $7 \%$ for GDSAP from those predicted by the bascline model. The largest stresses occurred with electromianetic loading applied by itself.

For this loading the NASTRAN anilysis found the peak principal stress of $81.5 \mathrm{ksi}$ occurring it $45^{\circ}$ from the axis of stmmetry in the inner crossover plate of the munor radius (Fig. 83). This was the only lucition shouing a stres larger than the 80-ksi allowable stress lew for the NASTRAN analysis. The GDSAP andysis found siresses athere $80 \mathrm{ksi}$ over a $25^{\circ}$ span with a !neak stresh of $83.4 \mathrm{k}$ si (Fig. 83). These stresses represint reductions of :'? by NASTRAN and $5 \%$ b! GDSAP from the previously predicted peak principal atren of siski. GDSAP stresses also exceded the $80 \mathrm{ksi}$ ind slightly tor the intermediate crosisoser plate onsi a $10^{\circ}$ spat at the anis of symetrs whth a peak stresw of $81.5 \mathrm{ksi}$ (Fig. 94). NASTRAN prodicted all itrusses below $80 \mathrm{ksi}$ in thas areal.

\section{Neighbering elements in tension}
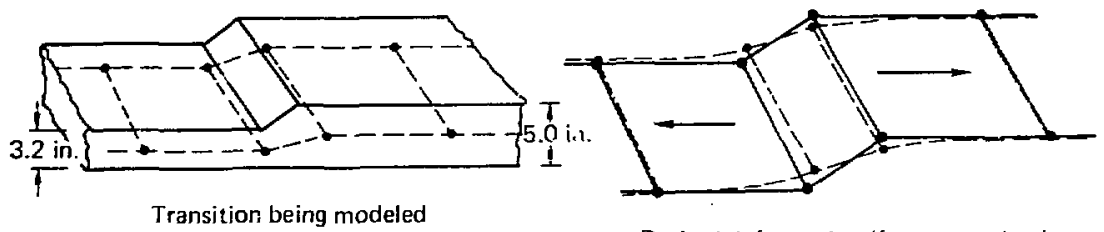

Desired deformation if unconstrained
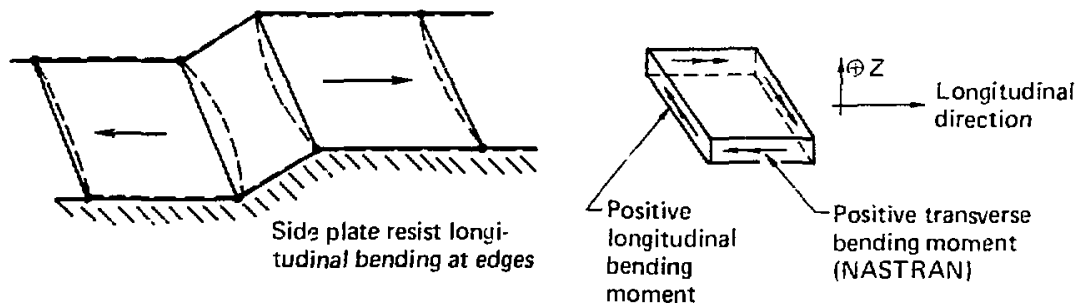

Actual deformations which induce transverse bending moments due to side plate constraints

HJ. \$2. Schemutic of behuvior at Iransition from 3.2-in. to 5.(1-iil. crossuy er plate. 


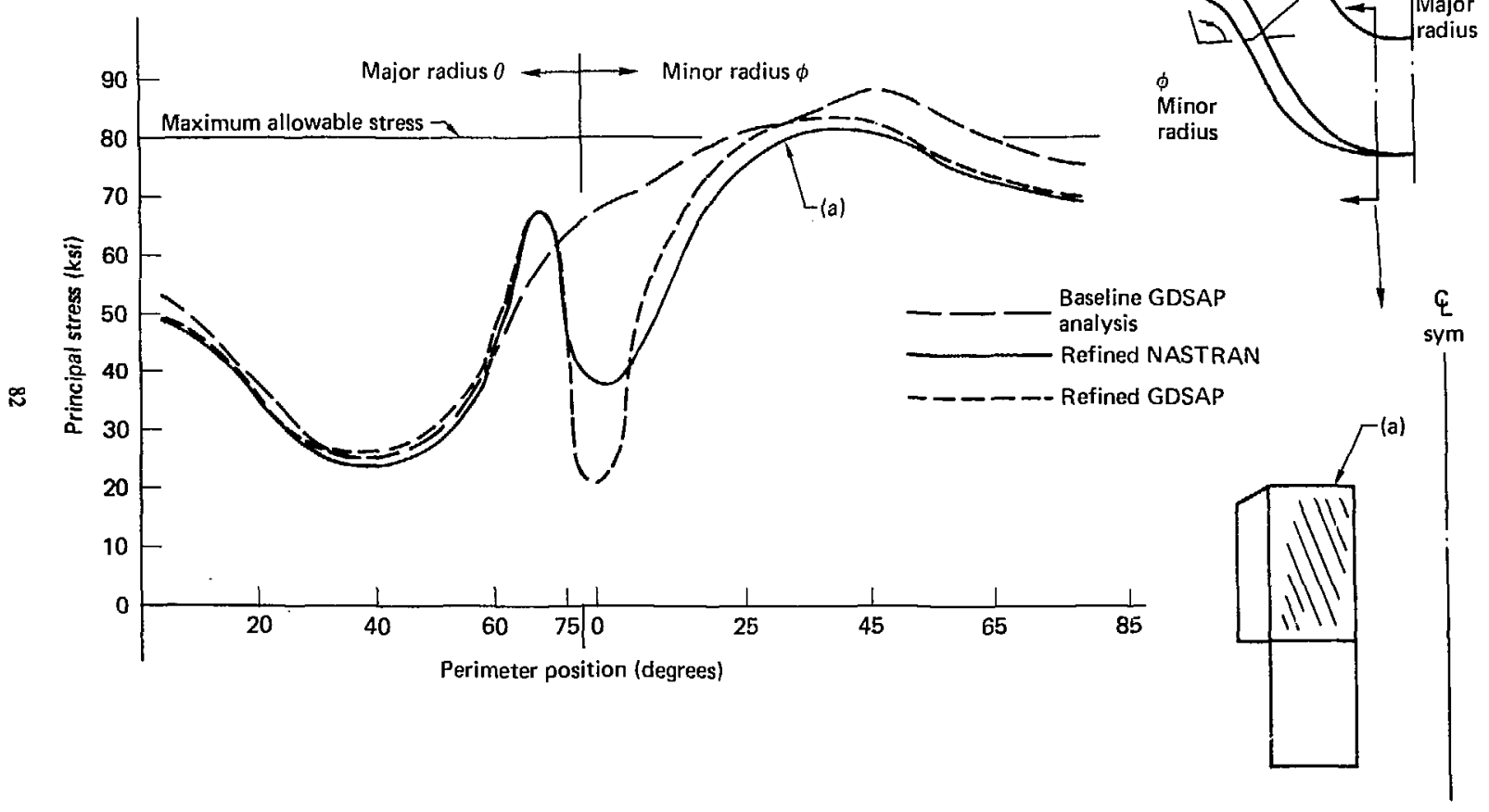

FIG. 83. Principal stress distribution-inner crossover plate-electrontagnetic load only. 


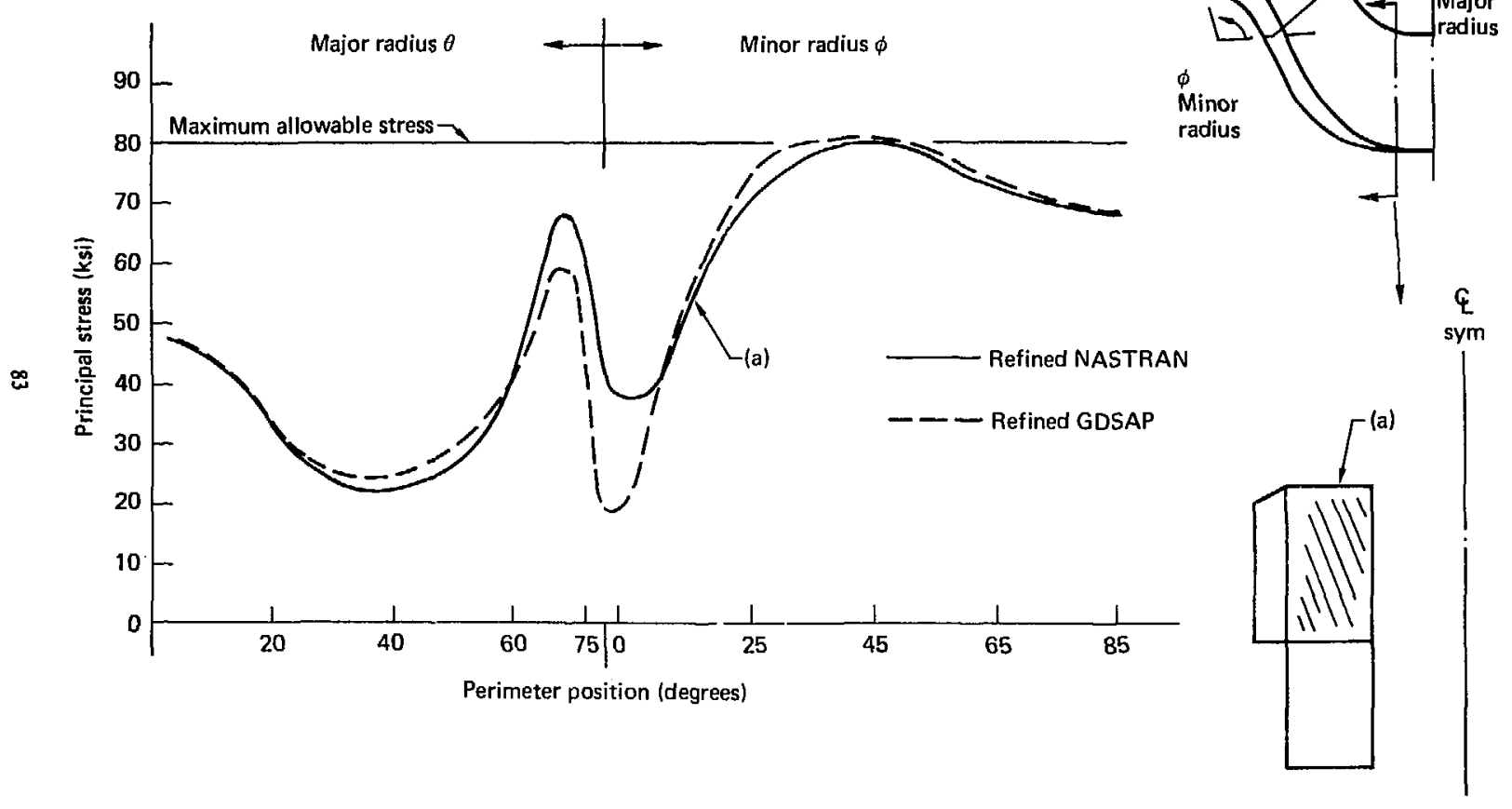

FIG. 84. Principal stress distribution-inner crossover plate-combined electromagnetic and residual thermal loads. 
When the residual thermal loads due to the cooldoun from room temperature to $4.5 \mathrm{~K}$ operating temperature are superimposed on the electromatenetic loads. a slight reducion of stresses is obta ned (Figs. 85 and 86). It is important to nete for this loat combination that NASTRAN showed all stresses in the magnet to be below the $80-k$ si devinn allowable stress level. GDSAP predicted a peak principal stress of $81 . \overline{\mathrm{ks}} \mathrm{k}$, with a span of $10^{\circ}$ in the inner crossover plate at stresses over $80 \mathrm{ksi}$ (17ig. 85). The intermediale crossover plate, for this load combination, slowed a peak principal stress of $80,6 \mathrm{ksi}$ at the axis of symmetry (Fig. 86).

Discontinuities are evident in the stress distributions predicted with the refined model at the tran-ition from 3.20 in.- to 5.00-in.-thick crossover plats material. These discontinuities had not shown up in the baseline analysis. The caluse of the discontinuities wats that the refined model atcounted for the offset of the mi isurfaces at the transition from 3.20 -in. to $5.00-\mathrm{in}$. plate material. This offset, induces both longitudinal and transverse bending moments as is shown schematically in Fig. 82. These discontinuities, which are discussed in more detail in Ref. 83, were found to not have any critical effect on the stresses.

\section{CONCLUSIONS}

The refined finite element analysis verified the structural integrity of the MFTF magnet system with a factor of safety of 1.5 on yield stress for the 304LN calse material. This verification is based on the NASTRAN finite element program for the worst compatible load case (normal operating condition) of electromagnetic plus residual thermal loading. 


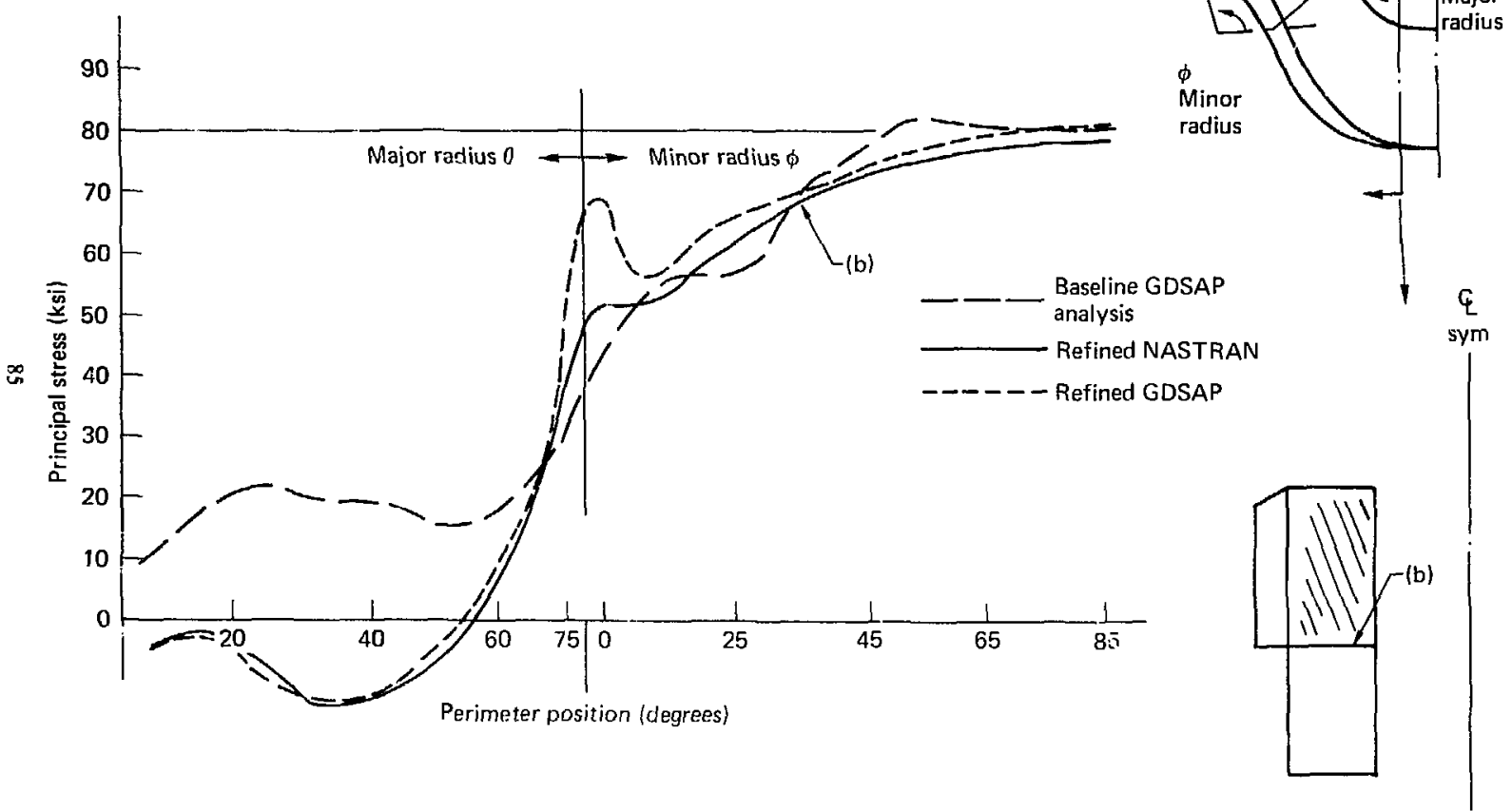

Jil6. 85. Principal stress distribution on intermediate crossover plate--clectronagnetic load only. 


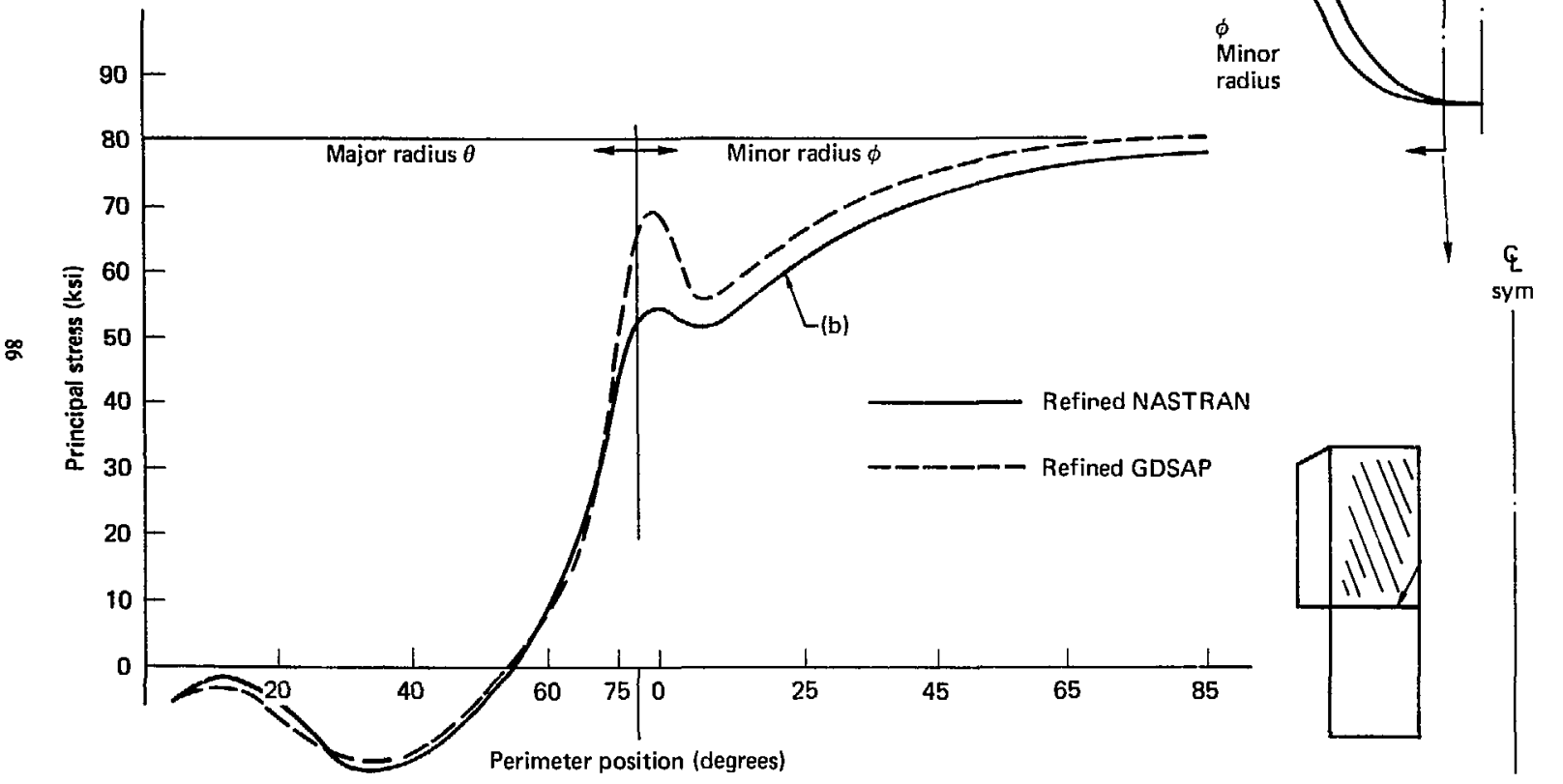

FIG. 86. Principal stress distribution on intermediate crossover plate-combined electromagnetic and residual thermal loads. 


\section{SECTION 10 \\ STRUCTURAL CASE FAULT ANALYSIS}

\section{INTRODUCTION}

A case fault analysis documented in Ref. 84 was performed to assess the criticality of selected failures in the magnet case, jacket and intercoil structure. The locations of the five failures selected for analysis were determined on the basis of the manufucturing processes, structural geometry and lowal stress levels at these locations and, ultimately, on the possible consequences of the failures. Since this task followed the program to confirm the struetural integrity of the MFTF magnet case, jacket and shield systen (Ref. 10), every effort was mide to utilize analysis methods and tools developed earlier. The large. 7000-degree-of-freedom GDSAP model developed during that program was used extensively throughout this analysis task to determine the overall slresses and deflections in the vicinity of assumed faults. Sub.: analyses, hand analyses were used to delermine the stresses normal to the approuching fault front. Using this stress data a Mode I linear elastic fracture analysis was performed to quantify the criticality of each fault.

\section{ANALYSIS METHODS}

A common methodology was used to analyze each of the five selected faulis. The analysis used ine 7000-degree-of-freedom GDSAP model to determine the overall changes in stresses and deflections caused by the assumed faults. Data from this analysis was then used to determine the local stresses normal to the fault front and a simple Mode 1 linear elastic fracture analysis quantified the criticality of the faults.

The 7000-degrec-of-freedom finitc element model used in the fault analysis is basically the same as the model used in the original MFTF analysis and documented in Ref. 10. However, several minor changes that are documented in Ref. 84 were made to the model prior to the start of the fault analysis. The fauls were simulated in the GDSAP anilysis by additional risdes coincidental to existing nodes in the baseline finite element model and chunging fault boundary plate connectivities. No attempl was made to refine the finite element mesh adjacent to the fault boundaries subsequent to the analysis. Model deflection data was used to calculate the local stresses normal to the assumed fiult frorit.

A simple Mode I fracture analysis was performed using the stresses calculated from the fanite element data to determine the criticility of the fault. The fracture anlalysis used the stres intensity solutions for a finite crack in an infinite platte and for at 0.5 -in. edge crack in an infinite plate wapproximate the stress intensities resuling from the fatuls. The expressiens for the stress intensitien in these citses are:

$$
\begin{aligned}
& \mathrm{K}_{1}=\sigma \sqrt{\pi i} \text { linite crack in infinulc } \\
& \text { plate (ReT. } 85 \text { ) } \\
& \mathrm{K}_{\mathrm{I}}=1.1215 \sigma \sqrt{\pi \mathrm{a}} \text { 0.5. . cuge track } 111 \mathrm{H} \text { - } \\
& \text { finite plate (Rof R5) }
\end{aligned}
$$

where $\sigma=$ nominal stress, normal to fitult, and

$$
a=\text { half-crack lenglh. }
$$

The stress intensities resulting lrom the analy is were compared to the plane-strain fritcure toughness $\left(\mathrm{K}_{10}\right)$ dala used in lhe original $\mathrm{Ml} / \mathrm{Tl}$ fraclure analysis. This data is shown in Table 20.

\section{ANALYSIS RESULTS}

A total of five fault conditoms were innilyed during this seludy. Isometric skethes, selection rationale. and analysis results are sunmarised below for each of the following faults:

1. Minor radius intermediate 3- w5 5-in. plate intersection in the chamfer region at center line of symmetry.

2. Conductor pack jacket elosk-out weid in the major-to-minor radius transition.

3. Intereoil member shear transfer weld, bot. tom closure plate to side plate torner weld.

4. The 3-in. close-oul weld at the center int of symmetry in the minor radius at the hottom of the 9 section.

5. The 3- 10 5-in. transition butt weld joint at the major to minor radius transition on the conductor case top plute.

Fault rumbe: 1 is shown in Fig. 87 alone with the rationale for selecting it for analyss. In the finte 
TABIF. 20. lault fracture analyses were based on preliminary material data used during the MFTF design.

\begin{tabular}{|c|c|c|c|c|}
\hline \multirow[b]{2}{*}{ V1:rterial } & \multicolumn{4}{|c|}{ Cauce-material fracture-snalysis properties } \\
\hline & Temp. & $F_{1 \mathrm{y}}$ & $\frac{K_{I C \cdot}}{k s i \text { vin. }}$ & $\begin{array}{l}\text { da/dn } \\
\text { Bon gronth rate. } \\
\text { win./cycle }\end{array}$ \\
\hline $31+41 .>111.12 \div ; 1^{3}$ & 4.5 & $111 . k$ & 2113 & $1.015+\times 10^{-4}\left(\Delta k p^{3.50}\right.$ \\
\hline \multicolumn{5}{|l|}{ t.31fal. weld filler } \\
\hline J1e $\quad 4.5^{3}$ & 4.5 & 116 & :11 & Not w ailuthle \\
\hline il. $9.2^{i 1}$ & 4.5 & $12 \mathrm{k}$ & y5 & Nint utailatile \\
\hline 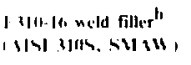 & 4.2 & 1211 & 1116 & $4.9 k \times 11^{-8}(\Delta K)^{5.15}$ \\
\hline
\end{tabular}

dement . . sink conseident grid points were in-

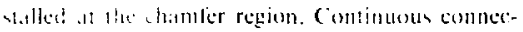

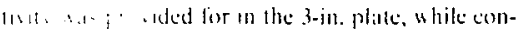

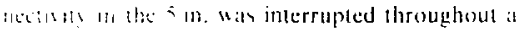
$\because$ at. (appromimatels $6.82 \mathrm{jin.}$.

Nulu, of the 5-in,-plate deflection datat instev that lie sress field normal to the approwhome latule frome is approximately $25,880 \mathrm{psi}$. newhelug bending. Assuming an infinite plate with at finite crsik.

$$
k_{1}=2 \pi x_{11}, \overline{6.82 \pi} \mathrm{psi} \sqrt{\mathrm{int}} .
$$

B.w! "nd the baseline analysis reported $K_{I C}$ b.lute lin ! 316 weld filler $(\mathrm{JFe}=9.2)$ al $4.5^{\circ} \mathrm{K}$ or 95 hui $\overrightarrow{11 . . . ~ a ~ c o m p a r i s o n ~ o f ~ c a l c u l a t e d ~ a n d ~ c r i t i c a l ~}$ ters intensits values indicates that this fault would continue to propagate under static loading until a lomer iress field is encountered or it crack arrest mechanmisn is encuuntered. However, current NBS usting prediets a minimum fracture toughness in the weld metal of $140 \mathrm{ksi} \sqrt{\mathrm{in}}$. Based un this data, the issumed fault would not propagate under static hiading hut would continute to grow under cyclic lerads until failure.

Fault number 2 and its selected rationale are shown in Fig. 88. For the analysis of fault number 2. coincident grid points were installed in the model along the entire 0.5 -in. plate "L" section. J1 was assumed that the transition from 0.5 -in. to 1.0 -in. jacket plating would act as a crack arrest mechanism. Continuily was provided for an all case plating while continuity of the 0.5 -in. jacket plate was interrupted at the plane in question.
Evaluation of the finite element analysis results indicates that the peik tension stress normal to the asstimed fituft ociurs all the bottom of the "L" sec(i.)n where the stress is 40,200 psi. This stress resuits in a Mode 1 strem intensity of:

$$
k_{1}=50 \mathrm{ksi} / \mathrm{in}
$$

Because this stress intensily is less than the predicted $K_{K}$. For the 316 plate malerial, this fault sould not propagate statically. The lasult would propigate to bailure under cyclic loalding. But, the analysin indicates that a total failure of the jacket plate would have little effect on the overall structural case stresses.

Fault number 3 is illustrated in Fig. 89. For the analysis of this fault, the finite element model was modified by instilling coincident grid points along the intercoil member fault corner. The plate connectovity was altered so there could be no load transfer hetween the boltom and side plate locally atong the fault perimeter.

The analysis results indicate very linle redistribution of stress as a result of the assumed failure. Because the stresses were primarily compression, however, the failure mode of coneern was not Mode I fracture. The primary concern was the precipitation of an instibility failure in the large plates. However, an updated stability analysis of the intercoil plates with revised boundary conditions to simulate the cracked weld predieted buckling failure stresses in excess of the peak intercoil stresses. Based on this analysis, there were no significant effects due to the assumed fuult. 


\section{Selection rätionale}

- Weld joint

- Complex unbalanced weld-on-weld joint

- Heat sink gradient

\section{- Joint geometry}

- Chamfer region increases welding difficulty but has no significant effect on gross stress distribution

\section{- Stress}

- Plate membrane stresses parallel to this weld joint approach $80 \mathrm{ksi}$

- Principal stresses in the 5 -in.plate approach $80 \mathrm{ksi}$

\section{- Concern}

- Loss of the 5- to 3-inch joint (basically a shear transfer member) may result in excessive case deflection and subsequent ronductor pack crushing

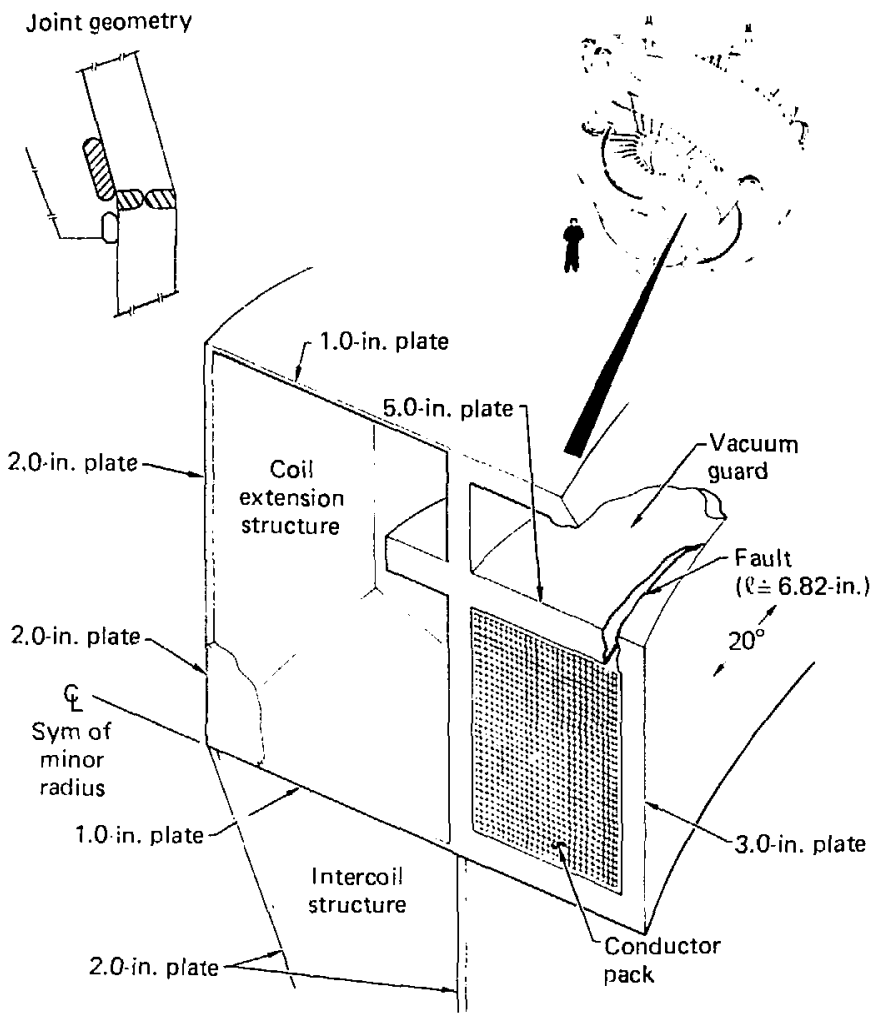

FIC. 87. Fault No. 1: minor radius intermediate 3- to 5-it. plate intersection in the chamfer region at the centerline of symmetry. 


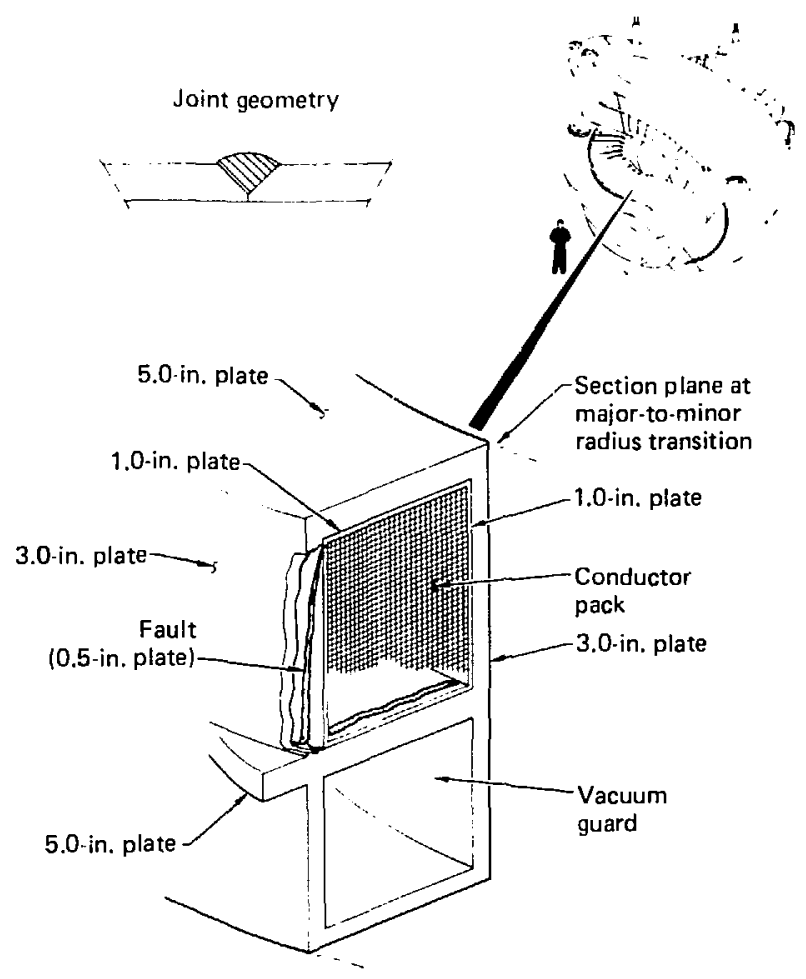

FIG. 88. Fault No. 2: conductor pack jacket close-out weld in the major-to-n nor radius iransition. 


\section{Selection rationale}

\section{- Weld joint}

- Joint geometry - no significant effect

\section{- Stress}

- Compressive only

\section{- Concern}

- Loss of joint may cause intercoil member instability and system catastroph ic failure

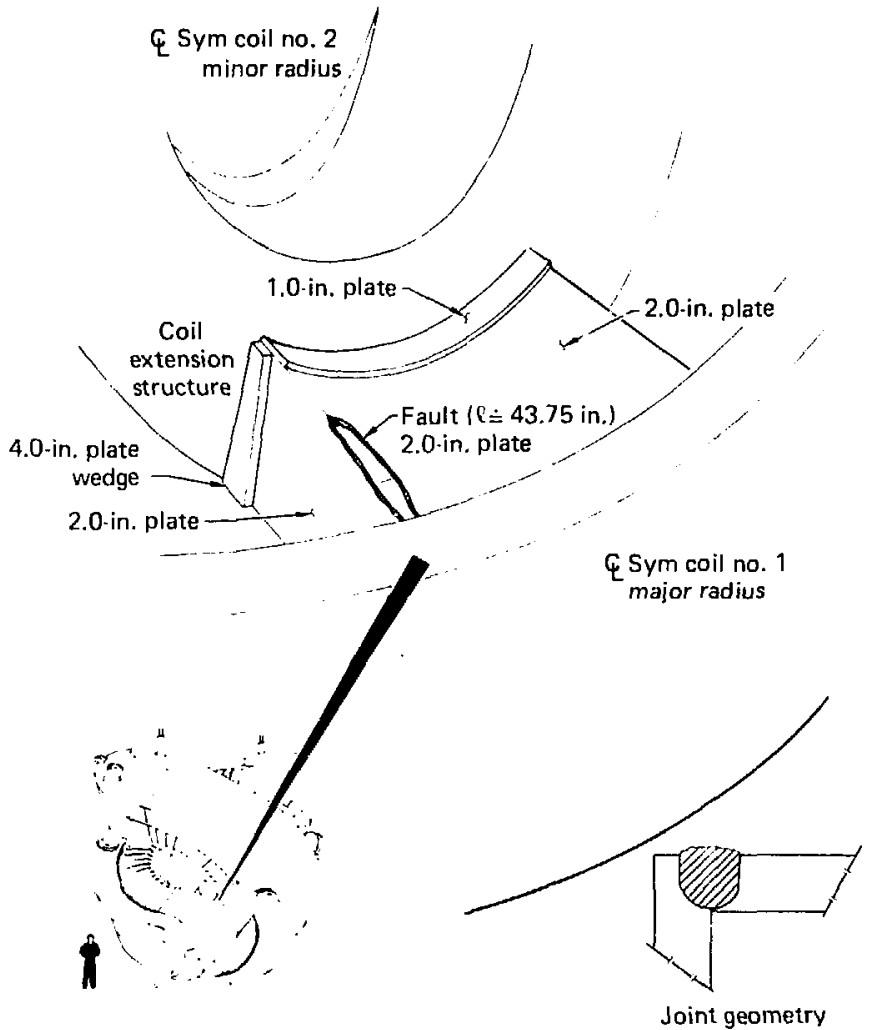

FIG. 89. Fault Nr. 3: intercoil member shear transfer weld, bottom closure plate to side plate corner weld. 
Faul number t, whicl is shom in t-ig. 90, was at . umed to cxtend from the minur radius center line of $y$ mometro through at $20^{\circ}$ are thalf $\mathrm{leng}$ th $=6.82$ ial. Coincedent gad poims were installed in the naseli:at model alonge cxisting fault lire grid points. Comtumity of the 3- to 5-in.-plate joint $u_{\text {ald }}$ inlerrupied by redelining coistng ( 21 AD element sted rism connectumis.

Deflectuon data near the approaching lasult Iront wat extrateded from the compater output for

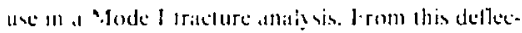
uen ditlat the lixial plate membrane seress wals del r mitked on be approwmattel: 5.667 psi. 1.rom lt. plaver mathancs theors, for an infinte plates linite celles erach.

$$
k_{1}=5067 \sqrt{6.82 \pi}=20.23 \mathrm{kis} \sqrt{\text { in. }}
$$

This trem indicitle that although this crack is not caltavtrophic, it will continuc to propagate under incluc losdding until failure or a critck arrest mechanivm is ciecountered.

fault number 5 was the most critical of the fitec failure that "were analyed. The fiuth. which is besn in fig. 91, catused a signifieant reduction in the overill bending strength of the mignet calse in the minor radius and at resulting increase in stress.
The tinite element results indicated a signalicant increase in stresses approathed 99,300 pi. Al thi,

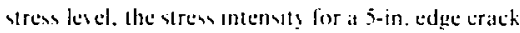
in an infirite plate in:

$$
K_{\mathrm{I}}=1.22 \times 99300 \sqrt{2.5} \pi=.340 \mathrm{k} \times \mathrm{vin} .
$$

This $K_{1}$ reflects a catastrophlac lialure when compared to the critical stres intemilice for $3+1 . N$ and 316l. Welds.

\section{CONCLLSIONS}

Results of this study are summariced in Table 2l. Of the live eonditions analued, one is considered to have uructurally catust rophic efliets: calas!rophic meaning these fatuls would be reflected by sudden and violent changes in the geometry of the structure. The fitule considered stucturally catastrophic (Mode I analysing wa taula Ne. 5 (the 3- 10 5-in. transition but weld joint at llac major-tominor radius tritusition on the conductor cast top plit().

Fitult number t, the 3-in.-plate close-out weld at the center line of symmetry in the minor radius at the bothom of the 9 section, is considered to be

\begin{tabular}{|c|c|c|c|}
\hline Fault & Fault description & Calculated & Discussion \\
\hline 1 & $\begin{array}{l}\text { Minor iadius intermediate } 3 \text { - to 5-in.-plate intersection } \\
\text { in the chamfer region at the center line of symnetry }\end{array}$ & $120 \mathrm{ksi} \sqrt{\mathrm{in}}$ & $\begin{array}{l}\text { K, ceguals KIC. Faull nill be self propugating. } \\
\text { Catastrophic failure assumed." }\end{array}$ \\
\hline 2 & $\begin{array}{l}\text { Conductor path jactiut cluse-trut Held in the mujor-to- } \\
\text { minor radius Irassition }\end{array}$ & So) $k s \mathbf{j} \sqrt{i n}$. & $\begin{array}{l}\text { K, lawer than K KC. Fault will propagate under } \\
\text { cyclic loading. Overall system integrity not } \\
\text { șgnificanly affecterl. }\end{array}$ \\
\hline 3 & $\begin{array}{l}\text { Intercoil member shear transfer neld, botioni closurt" } \\
\text { plate to side plate corner иeld }\end{array}$ & M.S. $=1.17$ & $\begin{array}{l}\text { M.S. calculated assuming cumpressive-yiald } \\
\text { ullowablc of } 12 \text { ksi. }\end{array}$ \\
\hline 4 & $\begin{array}{l}3 \text {-in.-plate cluse-out weld at the center line of symmetrs } \\
\text { in the ninor radjus at the bottom of the } 9 \text { section }\end{array}$ & $26 \mathrm{ksi} \sqrt{\mathrm{in}}$ & $\begin{array}{l}K_{\mathbf{I}} \text { lower than } K_{I C} \text {. Fault will propugate under } \\
\text { cyclic logding. }\end{array}$ \\
\hline 5 & $\begin{array}{l}\text { 3- to 5-in.-transilion butt weld joint at the niajor to minor } \\
\text { radius transition on the conductor case ta }: \text { plate }\end{array}$ & $441 \mathrm{ksi} \sqrt{\mathrm{in} .}$ & $\begin{array}{l}K_{1} \text { ljigher than } K_{1 C} \text {. Fault nill be selr- } \\
\text { propagating. Catastrophic failure }\lrcorner \text { ssumed. }\end{array}$ \\
\hline
\end{tabular}

TABLE 21. Case fault analysis summary. 


\section{Selection rationale}

- Weld joint

- Close-out weld; increases weld inspection difficulty

- Joint geometry

- Not significant

- Stress

- Moderate plate longitudinal membrane stress

\section{- Concern}

- Decreased weld inspectability increases probability of potentially critical flaw existing. Joint failure and subsequent redistribution of stresses may result in excessive deflections and conductor pack crushing

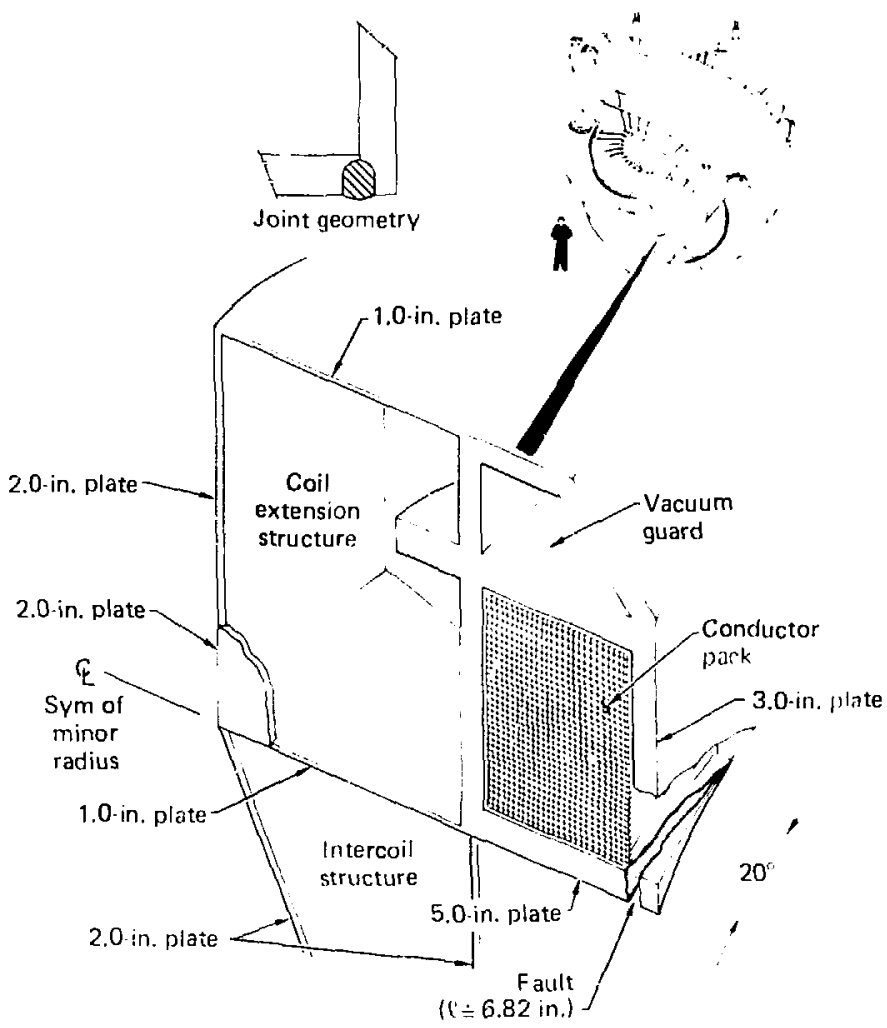

FIG. 90. Faut No. 4: 3-in. plate close-gut weld at the centerline of symmetrs in the minor radius at the button of the 9 section. 


\section{Selection rationale}

\section{-Weld joint}

- One sided butt joint (unbalanced)

- Weld bead reinforcement $\left(K_{T}\right)$

- Heat sink gradient

\section{- Joint geometry}

- 3- to 5-inch plate transition produces local stress raiser

\section{-Stress}

- Plate membrane stresses normal to this joint appr. ach $60 \mathrm{ksi}$

- Transverse secondary bending moments approach 95 in. - kips/in.

\section{- Concern}

- Joint failure causes a significant reduction in magnet section modules resulting in redistribution of stresses and possible system catastrophic failure

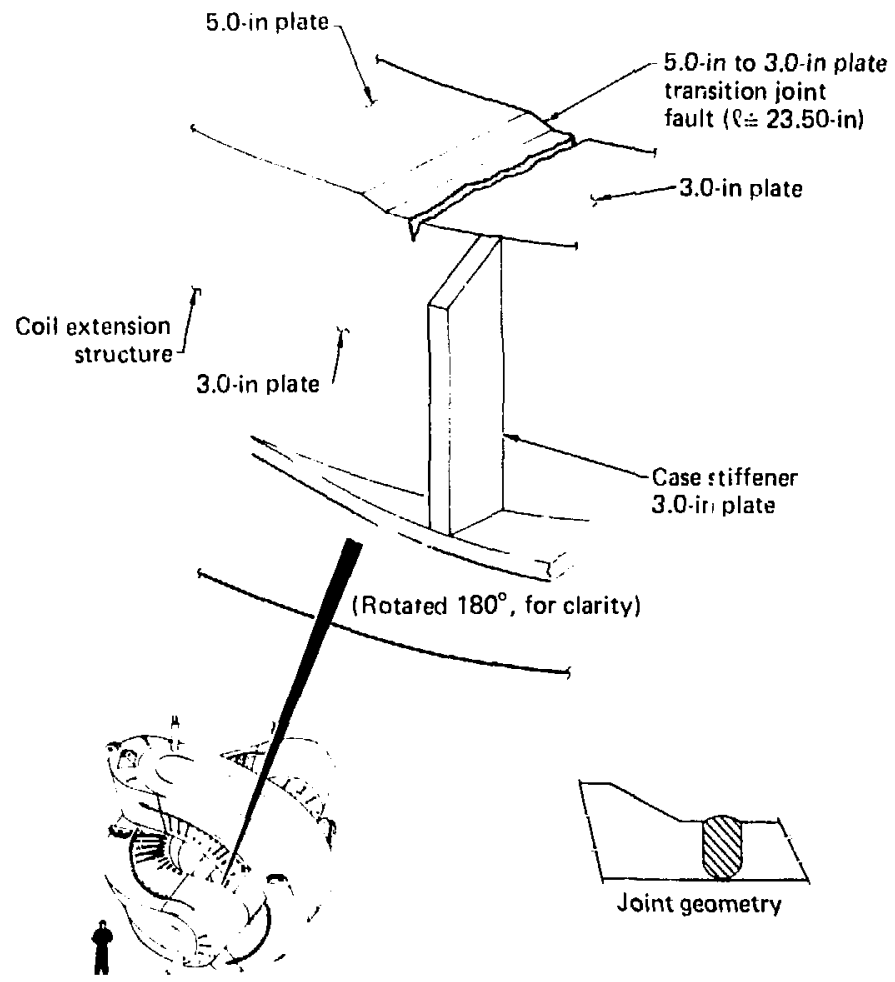

FIG. 91. Fault No. 5: mujor-to-minor radius transition, 3-in. to s-in. bult-weld joint on the conductor case top plate. 
potentially catastrophic: i.e., the calculated stress intensity factors are lower than the critical stress intensity factor but under cyclic loading this faull will continue to propagate until repaired or a suitable crack arrest mechanism is cncountered.

Fult number 1, the 3- to 5-in.-plate intersection in the chamfer region of the minor radius, is potentially catastrophic. elen with updated NBS fracture toughness data. At the calculated $K_{1}$ of 120 $\mathrm{ksi} \sqrt{\mathrm{in}}$., the stress intensity is less than the $K_{\mathrm{lC}}$ of $140 \mathrm{ksi} \sqrt{\mathrm{in}}$. measured for the 316l. weld. This indicates thas the fault would not fail immediately but would continute to grow under cyclic load until fatilure. 


\section{SECTION 11 \\ STRUCTURAL METALLURGY}

\section{INTRODUCTION}

Following the Baseball II magnet experience Nitronic 40 was first selected for the MFTF magnet structure. However. plate of sufficient size was unavailable, and welding across major stress planes was necessary. Accordingly, an effort was made to develop a weld procedure using Inconel 625: a nickel-base alloy, which, it was hoped, could match the parent metal strength and toughness. Because poor fracture toughness of both the Inconel 625 weld and the Nitronic 40 bise metal precluded design stresses above $80 \mathrm{ksi}$, it was decided to abandon the this approatch and use a tougher and less expensive austenitic stainless steel, $304 \mathrm{LN}$, with at ferrite-free 316L weld metal. In this section the experience with both base-metal systems are described.

\section{INITIAL WELD DEVELOPMENT}

Initial weld development programs were oriented toward development of procedures to join Nitronic-40 stainless steel for the case structural muterial, whose nominal composition is $\mathrm{Fe}-21 \% \mathrm{Cr}$ $6 \% \mathrm{Ni}-9 \% \mathrm{Mn}$ (Refs. 87-90). Fusion-welding of thick sections of this alloy (thicker than 1/4-in.) had been greatly hampered by the inability to develop a weld filler metal that matched both the base metal's high yield strength $(\geqslant 180 \mathrm{ksi})$ and moderate fracturetoughness $(\approx 75 \mathrm{ksi} \sqrt{\mathrm{in}}$.) at $4 \mathrm{~K}$ (Refs. 87-90). The filler metals selected for evaluation were a modified Nitronic 40, with nominal composition $\mathrm{Fe}-20 \% \mathrm{Cr}$ $7 \% \mathrm{Ni}-9.5 \% \mathrm{Mn}$, and a nickel-base alloy, known as "Alloy 625," with nominal compositions $\mathrm{Ni}$ $22 \% \mathrm{Cr}-9 \% \mathrm{Mo}-3.5 \% \mathrm{Cb}-3.5 \%$ Fe. The latter material was selected on the basis of its known good $77 \mathrm{~K}$ ductility as a weld filler-metal for joining both stainless steels and nickel-base alloys (Ref. 91). Welding processes evaluated were shielded-metal arc (SMA), gas-metal arc (GMA), gis-tungsten arc (GTA), and submerged arc (SA). All four processes were evaluated using the Alloy 625 filler, while modified Nitronic filler was used with the GMA and GTA processes.

\section{MODIFIED NITRONIC-40 FILLER METAL}

Details of welding are presented in Ref. 92 and summarized in Table 22 of this report [see information labulated for welds No. 1 (GMA) and No. 2 (GTA)]. Weld-metal chemical compositions were typical for this material (Table 23). Weld-metal Charpy V-notch impact tests performed at $77 \mathrm{~K}$ were used as a screening tool to avoid extensive and expensive $4 \mathrm{~K}$ testing of many specimens. Results of $77 \mathrm{~K}$ charpy impact tests are presented in Table 24. Average energy absorption values were $17.5 \mathrm{ft}-\mathrm{lb}$ for the GTA weld and $27.0 \mathrm{ft}-\mathrm{lb}$ for the GMA weld, as compared with typical annealed-base metal values of 60-70 ft-lb at $77 \mathrm{~K}$ (Ref. 90). Microscopic examination of both welds showed the usual duplex austenite-ferrite microstructure with ferrite contents of $4.5 \%$ for the GMA weld and $8 \%$ for the GTA weld. The disappointing $77 \mathrm{~K}$ Charpy V-notch impact performance confirms the SMA results presented at the Octoher 1977 Vail Workshop on Structural Materials for Low Temperature Service, (Ref. 90), and further work on evaluation of modified Nitronic-40 weld metal was discontinued in favor of increased efforts on the Alloy 625 weld metal.

\section{ALLOY 625 WELD METAL}

Details of weld manufacture and resulting chemical composition, microstructure, and mechanisal-property performance are discussed in detail in Refs. 93 and 94 and summarized in Tables 22 through 26 of this report (see information tabulated for welds Nos. 3-6 for the SMA, GTA, GMA, and SA welds, respectively). Welds were made in 2-in.-thick Nitronic- 40 plate, heavilyrestrained by welding the free edges of the plates to a 4 to 6 -in.-thick steel plate, to simulate the high degree of restraint that would be imposed on weldments in the actual case structure. Chemical compositions were usual for Alloy 625 weldments (Table 23). Welds were evaluated for soundness by radiography, which revealed no unacceptable 
TABLE 22. Welds made in the multiprocess study.

\begin{tabular}{|c|c|c|c|c|c|c|c|c|c|c|c|}
\hline \multirow[b]{2}{*}{$\begin{array}{l}\text { Wold } \\
\text { No. }\end{array}$} & \multirow[b]{2}{*}{ Process } & \multirow[b]{2}{*}{$\begin{array}{l}\text { Flux or } \\
\text { shielding gass }\end{array}$} & \multirow[b]{2}{*}{ Filler } & \multicolumn{4}{|c|}{ Electrode } & \multicolumn{3}{|c|}{ Weld joint } & \multirow[b]{2}{*}{$\begin{array}{l}\text { Base } \\
\text { metal }\end{array}$} \\
\hline & & & & $\begin{array}{l}\text { Diam } \\
\text { (in.) }\end{array}$ & Supplier & Heat No. & Lot No. & Type & Origin & Position & \\
\hline $\begin{array}{r}1 \\
2 \\
3 \\
4 \\
5 \\
6 \\
8 \\
9 \\
10 \\
11 \\
12 \\
13 \\
17 \\
20 \\
21\end{array}$ & $\begin{array}{l}\text { Gus-metal are } \\
\text { Gas-tungsten are } \\
\text { Shiedted-metal are } \\
\text { Gas-rnagsten are } \\
\text { Gas-metal arc } \\
\text { Submerged arc } \\
\text { Gas-metal wre } \\
\text { Submerged arc } \\
\text { Flux-cored are } \\
\text { Electroslag } \\
\text { Electroslag } \\
\text { Electroslag } \\
\text { Pulsed gas-metal are } \\
\text { Pulset gas-metal arc } \\
\text { Electrosing }\end{array}$ & $\begin{array}{l}\text { Argon }+2 \% \mathrm{O}_{2} \\
\text { Helium } \\
\text { Helium } \\
\text { Argon + 2\% O2 } \\
\text { Arcos N82 } \\
\text { Argon + 2\% O2 } \\
\text { Hobart } \mathrm{HS} 300 \\
\text { Arcos N82 } \\
\text { Arcos N82 } \\
\text { Arcos N82 } \\
75 \% \mathrm{He} / 25 \% \text { Ar } \\
75 \% \mathrm{He} / 25 \% \text { Ar } \\
\text { Hobart PT203 }\end{array}$ & $\begin{array}{l}\text { Nitronic } 40 \\
\text { Nitronic } 40 \\
\text { Alloy } 625 \\
\text { Alloy } 625 \\
\text { Alloy } 625 \\
\text { Alloy } 625 \\
316 \mathrm{~L} \\
316 \mathrm{~L} \\
316 \mathrm{LT}-3 \\
\text { Alloy } 625 \\
316 \mathrm{~L} \\
316 \\
2 \mathrm{RM} 69 \\
316 \mathrm{~L} \\
316 \mathrm{~L}\end{array}$ & $\begin{array}{l}0.030 \\
0.030 \\
5 / 32 \\
1 / 8 \\
1 / 16 \\
1 / 16 \\
1 / 16 \\
3 / 32 \\
3 / 32 \\
1 / 16 \\
3 / 32 \\
3 / 32 \\
1 / 16 \\
1.045 \\
3 / 32\end{array}$ & $\begin{array}{l}\text { Armco } \\
\text { Armeo } \\
\text { Inco } \\
\text { Inco } \\
\text { Inco } \\
\text { Inco } \\
\text { Unibraze } \\
\text { Johnson } \\
\text { Stoody } \\
\text { Inco } \\
\text { Inihraze } \\
\text { Unibraze } \\
\text { Sandvik } \\
\text { Mckay }\end{array}$ & $\begin{array}{l}91520 \\
91520 \\
\text { NX } 8511 \\
\text { NX } 7478 \\
\text { NX 7478 } \\
\text { IF2-9201047 } \\
17222 \\
0388 \\
\text { NX } 7990 \\
\text { IF2-8311246 } \\
\text { IF2-8311246 } \\
743802 \\
\end{array}$ & 31821 & $\begin{array}{l}\text { Double-V } \\
\text { Double-V } \\
\text { Butt } \\
\text { Butt } \\
\text { Rutt } \\
\text { Butt } \\
\text { Butt } \\
\text { Butt } \\
\text { Butt } \\
\text { Butt } \\
\text { Butt } \\
\text { Butt } \\
\text { Double-V } \\
\text { Double-j } \\
\text { Butt }\end{array}$ & $\begin{array}{l}\text { LLNL } \\
\text { LLNL } \\
\text { LLNL } \\
\text { LLNL } \\
\text { LLNL } \\
\text { LLNL } \\
\text { LLNL } \\
\text { LLNL } \\
\text { LLNL } \\
\text { LLNL } \\
\text { LLNL } \\
\text { L.LNL } \\
\text { CBI-Hsin } \\
\text { FMC San Juse } \\
\text { FMC San Juse }\end{array}$ & $\begin{array}{l}\text { Flat } \\
\text { Flat } \\
\text { Flat } \\
\text { Flat } \\
\text { Flat } \\
\text { Flat } \\
\text { Flat } \\
\text { Flat } \\
\text { Fint } \\
\text { Vertical } \\
\text { Vertical } \\
\text { Vertical } \\
\text { Vertical } \\
\text { Flat } \\
\text { Vertical }\end{array}$ & $\begin{array}{l}\text { Nitromic } 40 \\
\text { Nitromic } 40 \\
\text { Nitramic } 40 \\
\text { Nitromic } 40 \\
\text { Nitranic } 40 \\
\text { Nitronic } 40 \\
304 \mathrm{LN} \\
304 \mathrm{LN} \\
304 \mathrm{LN} \\
304 \mathrm{~L} \\
304 \mathrm{~L} \\
304 \mathrm{IN} \\
304 \mathrm{LN} \\
304 \mathrm{LN} \\
304 \mathrm{LN}\end{array}$ \\
\hline
\end{tabular}

TABLF, 23. Chemical composition of welds made in the multiprocess study ( $w t \%)$.

\begin{tabular}{|c|c|c|c|c|c|c|c|c|c|c|c|c|c|}
\hline $\begin{array}{l}\text { Weld } \\
\text { No. }\end{array}$ & Pincess & C & $\mathbf{M n}$ & $\mathbf{S i}$ & $\mathbf{s}$ & $\mathbf{P}$ & Cr & $\mathbf{N i}$ & Mo & $\mathbf{T i}$ & $\mathrm{Cb}+7 \mathbf{i}$ & $\mathbf{N}_{2}$ & Other \\
\hline 1 & Gas-metal are & 0.017 & 9.52 & 0.14 & 0.007 & 0.012 & 19.93 & 7.17 & & & & & \\
\hline 2 & Gas-lungsten arc & 0.017 & 9.52 & 0.14 & 0.007 & 0.012 & 19.93 & 7.17 & & & & & \\
\hline 3 & ShieIded-metal arc & 0.046 & 0.25 & 0.58 & & & 21.48 & Bal. & 8.85 & 0.16 & 3.60 & 0.05 & Al:0.04, Fe:3.16 \\
\hline 4 & Gas-tungsten are & 0.05 & 0.09 & 0.28 & 0.002 & 0.010 & 22.13 & 61.68 & 8.87 & 0.22 & 3.33 & 0.08 & $\begin{array}{l}B: 0.001, F e: 3.06, \\
d 1: 0.28\end{array}$ \\
\hline 5 & Gas-metal are & 0.02 & 0.24 & 0.14 & 0.004 & 01.012 & 21.90 & 60.34 & 9.56 & 0.27 & 3.39 & 0.04 & Fe:3.91, $N 1: 0.21$ \\
\hline 6 & Submerged arc & 0.02 & 0.24 & 0.14 & 0.004 & 0.012 & 21.90 & 60.34 & 9.56 & 0.27 & 3.39 & 0.05 & $B: 0.001$ \\
\hline 11 & Electroslay, & 0.115 & 0.411 & 0.30 & & & 20.91 & 48.41 & 6.80 & 0.15 & 20 & 0.08 & At:0.15, Fe: 19.50 \\
\hline 12 & Electrosing & 0.030 & 1.711 & 0.48 & & & 18.70 & 12.711 & 2.11 & & & & \\
\hline 13 & Electrosiag & 0.015 & 4.61 & 0.17 & (I.. $\mathrm{H} 17$ & 0.1010 & 24.76 & 71.48 & 2.14 & & & & \\
\hline 17 & P'ulsed gas-metal are & & & & & & & & & & & & \\
\hline 20 & Pulsud gas-metal are & & & & & & & & & & & & \\
\hline
\end{tabular}


TABLE 24. Charpy V-notch impact performance at $77 \mathrm{~K}$ at welds made in the multiprocess study.

\begin{tabular}{|c|c|c|c|c|c|c|c|}
\hline \multirow{2}{*}{$\begin{array}{l}\text { Weld } \\
\text { No. }\end{array}$} & \multirow[b]{2}{*}{ Pracess } & \multicolumn{2}{|c|}{ Ferrite numher } & \multicolumn{2}{|c|}{ Energy ahsorbed } & \multicolumn{2}{|c|}{ Latcral expansion } \\
\hline & & Yender & LLL. & Areragc. ${ }^{\mathrm{a}}$ if lb & Range, in-lh & Average ${ }^{a}$, mils & Range, mils' \\
\hline 1 & Gas-metal are & & 4.5 & 17.5 & $16.5-[8.5$ & 6.0 & $4.0-8.0$ \\
\hline 2 & Gas-1ungsten arc & & 8.0 & 27.7 & $24.5-31.0$ & 12.5 & $12.0-13.0$ \\
\hline 3 & Shiclded-metal arc & & & 37.0 & $37.0-37.0$ & 31.2 & $29.5-32.8$ \\
\hline 4 & Gas-tungsten arc & & & 45.3 & $43.0-46.0$ & 41.4 & $36.7-46.8$ \\
\hline 5 & Gas-metal arc & & & & & & \\
\hline 6 & Submerged arc & & & 70.6 & $19.5-21.5$ & 18.9 & $12.8-24.6$ \\
\hline 8 & Gos-metal arc & & 5.5 & 26.8 & $23.1-30.0$ & 19.5 & $16.6-23.4$ \\
\hline 9 & Submerged are & & 5.5 & 26.9 & $21.5-31.0$ & 13.9 & $10.8-18.4$ \\
\hline 14 & Flux-cored arc & & 13.0 & 14.1 & $9.8-17.9$ & 8.7 & $4.6-11.6$ \\
\hline 11 & Electroslag & & & B8.0 & $71.0-111.0$ & 57.3 & $51.0-66.4$ \\
\hline 12 & Electroslag & & & 95.4 & $80.2-110.5$ & 75.2 & $62.6-75.4$ \\
\hline 13 & Elcetrosiag & & & 103.9 & 45.0 - 111.0 & 50.8 & $44.0-57.5$ \\
\hline 17 & Pulsed gas-metal arc & 0 & & 68.2 & $63.0-79.0$ & 55.0 & $49.0-63.0$ \\
\hline 20 & Putsed gas-metal arc & & 8.5 & 35.9 & $3: 0-42.5$ & 22.1 & $19.0-28.6$ \\
\hline 21 & Electroslag & & 5.0 & 34.9 & $28.0-41.5$ & 30.4 & $24.2-38.0$ \\
\hline
\end{tabular}

Average of 3 to 5 specimens.

$b_{1}$ mil $=0.001$ in.

TABLE 25. $4 \mathrm{~K}$ tensile and fracture-toughness properties of welds made in multiprocess study.

\begin{tabular}{|c|c|c|c|c|c|c|}
\hline $\begin{array}{l}\text { Weld } \\
\text { No. }\end{array}$ & Process & $\begin{array}{c}\text { Ultimate } \\
\text { strength, } \\
\text { ksi }\end{array}$ & $\begin{array}{l}\text { Y'ield } \\
\text { strength, } \\
\text { isi }\end{array}$ & $\begin{array}{c}\text { Elongation, } \\
\text { of }\end{array}$ & $\begin{array}{c}\text { Reduction } \\
\text { in arca, } \\
x\end{array}$ & 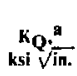 \\
\hline 3 & Shielded-metal arc & $18.3 .0^{b}$ & 127.0 & 30.7 & 25.0 & 122.8 \\
\hline 4 & Gas-tungsten arc & $173.3^{b}$ & 134.8 & 18.0 & 15.0 & 121.3 \\
\hline 5 & Giss-metal arc & $157.7^{b}$ & 121.0 & 22.7 & 26.7 & 136.0 \\
\hline 9 & Submerged are & $157.9^{b}$ & 97.2 & 60.0 & 39.0 & 101.0 \\
\hline 11 & EJectroslug & $507.1^{b}$ & 82.6 & 11.0 & 14.0 & \\
\hline 12 & Electroslag & $204.3^{b}$ & 74.7 & 39.9 & 26.2 & 146.0 \\
\hline 13 & Electrosisg & $200.1^{c}$ & 65.1 & & & \\
\hline 20 & Puised gas-metal arc & $200.5^{h}$ & 118.3 & 48.0 & 38.5 & \\
\hline \multirow[t]{3}{*}{21} & Electrosiag & $170.1^{b}$ & 96.2 & 35.0 & 20.4 & \\
\hline & & $193.7^{\mathrm{C}}$ & 85,8 & 35.0 & 27.9 & \\
\hline & & $183.5^{d}$ & 75.6 & 30.5 & 26.4 & \\
\hline
\end{tabular}

$\mathbf{a}_{\mathbf{Q}}$ is an invalid, nowcenservative, measigre of fracture-toughness duc to inalcquate specimen thickness or improper test procedure.

bL-Longitudiand, parnllel to wefd axis.

ELT -Lang transverse, acress weld axis.

ST-Short trawverse, through weld axis. 
TABLE 26. $4 \mathrm{~K}$ mechanical properties of 2 -in.-thick Nitronic 40 plate used in the alloy 625 welding study.

\begin{tabular}{|c|c|c|c|c|c|c|}
\hline & \multirow{2}{*}{$\begin{array}{l}\text { tittimatc } \\
\text { tensile } \\
\text { strength, } \\
\text { psi }\end{array}$} & \multirow{2}{*}{$\begin{array}{l}0.250 \text { offset } \\
\text { yield } \\
\text { strength, } \\
\text { ksi }\end{array}$} & \multirow{2}{*}{$\begin{array}{c}\text { Elongation } \\
\text { in } 1 \text { in., } \\
\%\end{array}$} & \multirow{2}{*}{$\begin{array}{c}\text { Reduction } \\
\text { in arca, } \\
\text { r }\end{array}$} & \multicolumn{2}{|c|}{ Fraclure-toughticss } \\
\hline & & & & & $\begin{array}{c}\text { I.ongitudinal, } \\
K_{Q}\end{array}$ & $\begin{array}{l}\text { Transwerse. } \\
\text { ksi } \sqrt{\mathrm{m}} .\end{array}$ \\
\hline & 245 & 198 & 22 & 35 & 138 & 135 \\
\hline & 251 & 195 & 26 & 30 & 130 & 136 \\
\hline & 245 & 196 & 20 & 25 & 131 & 132 \\
\hline Average & 247.0 & 194.3 & 22.7 & 31.0 & 133.11 & 1.31 .0 \\
\hline
\end{tabular}

${ }^{2} K_{Q}$ is a nonconscrvative value or fraclure-toughness, i.e. $K_{Q}>K_{I C}$, the minimum-vulue or "plane-strain fracture-toughness," culsed hy the spccimen thickness of $0.5 \mathrm{in}$. heing less than that required to ensure attainment of plane-strain cunditions at the crack-tip during testing.

defects, and by room temperature side-bend testing, which places the entire thickness of a slice cut through the weld in tension. Side-bend specimens cut from SMA, GTA, and SA welds were bent around a $2 t(t=$ specimen thickness) radius mandrel to an angle of $180^{\circ}$ without any evidence of fitilure. However, the GMA side-bend specimens failed at a bend angle of about $30^{\circ}$. Both microscopic examination and chemical analysis of the failed GMA bend-test specimens failed to reveal any cause for this poor performance. Post-weld heat-treatment (PWHT) of another GMA bend specimen at $2150^{\circ} \mathrm{F}$ for $1 \mathrm{~h}$, followed by testing as described above, resulted in this specimen passing the sidebend test. This indicated that the cause of premature failure of the as-welded GMA specimens was associated with the presence of a metallurgicalphase formed during solidification and/or during cooling to room temperature after welding, and that this phase could be removed or rendered innocuous by a high-temperature PWHT. However, such a PWHT is not practical during assembly of the massive case sections, and is certainly not a practical treatment on the case close-out welds once the magnet was sealed inside the care.

Low temperature evaluation of the Alloy 625 weldments consisted of $77 \mathrm{~K}$ Charpy $V$-notch impact tests (Table 24) and $4 \mathrm{~K}$ tensile and fracturetoughness tests (Table 25). Notches in the charpy specimens and cracks in the fracture-toughness specimens were oriented so that the cracks propagated from the top to the botiom of the weld metal. Average Charpy $V$-notch test energy absorption values were $37 \mathrm{ft}-\mathrm{lb}$ for the SMA weld, $45.3 \mathrm{ft}$ Ib for the GTA weld, and $20.6 \mathrm{ft}$-lb for the SA weld.
While below the $60 \mathrm{ft}-\mathrm{lb}$ vilue for unwelded Nitronic 40 (Ref. 90), results lor the SMA and GTA welds represented a distincl improvement over $77 \mathrm{~K}$ Charpy V-notch test energy-absorption value, shown by the modified Nitronic 40 weld metal (Table 24).

Tensile test results at $4 \mathrm{~K}$ of the Alloy 625 w eld metals are summarized in Table 25 and of the Nitronic- 40 base metal in Table 26 . All materials exhibited satisfactory values of tensile ductility, with average elongation values for the base metal and SMA. GTA. and GMA weld metals of 22.75. $30.7 \%, 18.0 \%$, and $22.7 \%$. respectively. Average tensile yield strength values of the base metal and SMA. GTA. and G.MA weld-metals were $196.3 \mathrm{ksi}$. $127.0 \mathrm{ksi}$. $138.0 \mathrm{ksi}$. and $121.0 \mathrm{ksi}$. respectively. Scanning electron microscopy examination of the fracture surfaces of representative tensile specimens showed no signs of brittle failure. with all fracture surfaces exhibiting a ductile fracture appearance.

Fracture-toughness test results of the weld metals are summarized in Table 27 and of the Nitronic-40 base metal in Table 26. While the numerical values are adequate, with average values for the base metal. SMA. GTA, and GMA weldmetals of $132.0 \mathrm{ksi} \sqrt{\text { in. } 122.8 \mathrm{ksi}} \sqrt{\text { in.. }} 121.3 \mathrm{ksi}$ $\sqrt{\mathrm{in}}$. and $\$ 36.0 \mathrm{ksi} \sqrt{\mathrm{in}}$. respectively, further examination of the test specimens and test records give rise to serious doubts ubout the validity of these values for the reasons presented below:

1. While the range of numerical values of the weld metal fracture-toughness for the three weld

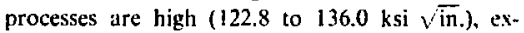
amination of the fracture-toughness test methods 
TABIE 27. Comparison of minimum fracturetoughness specimen thickness required to achieve plane-strain test conditions in Ineoncl 625 weld metal. ${ }^{3}$

\begin{tabular}{|c|c|c|c|c|}
\hline $\begin{array}{l}\text { Weid } \\
\text { prucess }\end{array}$ & ksi $\sqrt{\mathbf{i n} .}$ & ksi & $\begin{array}{l}\text { a, } \mathbf{B}_{\text {calc, }} \\
\text { in. }\end{array}$ & $\begin{array}{c}\text { Bmeas* } \\
\text { in. }\end{array}$ \\
\hline$S M I A$ & 123 & 127 & 2.35 & 0.5 \\
\hline (BIA & 121 & 138 & 1.92 & 0.5 \\
\hline (i,MA & 136 & 121 & 3.16 & $\lceil .5$ \\
\hline llas : metal & 132 & 196 & 1.13 & 0.5 \\
\hline
\end{tabular}

a lirom AST \& l: 399-74, aB $\geqslant 2.5(K / \pi y)^{2}$, where o, $\mathrm{H}$ are the width and thickness of the fracturs-toughness specimen, $K$ the measured value of stress intensity at fracture, and $\sigma y$ the yield strength.

${ }^{b}$ ircrage salues used in calculations.

indicated that the values determined are nonconservative and use of these values for design would result in over-estimation of these weld metals' resistance to brittle fracture. Thesc nonconservative results were obtained because the size of the fracture-toughness samples used were 100 smalt (Table 27 and Ref. 95) to achieve conservative or "plane strain" values. Figure 92 schematically represents the variation of stress intensity factor $\mathbf{K}$, with specimen or component thickness. For conditions of plane strain, where the material thickness is great enough to constrain plastic flow (yielding) in the plane of a crack or other defect, $\mathrm{K}=\mathrm{K}_{\mathrm{IC}}$. For other than conservative or plane strain conditions, $K=K_{\mathbf{Q}}>K_{\mathrm{IC}}$. What had been determined for the

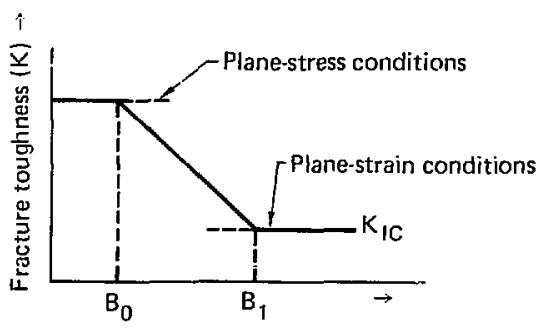

Specimon thickness (B)

FIG. 92. Effect of specimen thickness on fracture toughness.

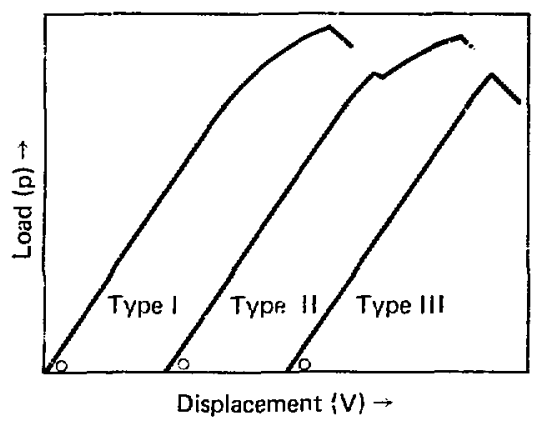

FIG, 93. Types of load displacement traces obfained during fracture toughness testing.

Nitronic 40 base metal and the alloy 625 welds was $\mathrm{K}_{\mathrm{Q}}$.

2. In addition to the nonconservative fracture-toughness values of the various weld metals, examination of fracture-toughness test procedures indicated that the form of fracturetoughness test load/displacement traces indicate that alf the test results exhibited evidence of calastrophic erack propagation. Representative load/displacement curves are shown in Fig. 93. Referring to this figure, either Type 1 or Type 2 behavior is representative of acceptable servicebehavior, i.e.. propagation of a preexistiag flaw requires increasing load. However. Type 3 behavior. where ence a llaw begins to propagate, it continues to do so even with a decreasing load situation, is unacceptable from the standpoint of rational brittlcfracture-resistant design practices.

3. Examination of the $\mathbf{4} \mathbf{K}$ iensile test results shows that the Alloy 625 weld-metal yield strengths. irrespective of weld process used, fall in the range of 117 to $143 \mathrm{ksi}$, or abollt $60-73 \%$ of the base metai value. Design of the magnet ease requires that some of the welds be located in the primary load paths. Under these conditions, $i t$ is good design practice to mateh the base-metal and weld-metal yieldstrengths to prevent localization of load and strain in the weaker weld-metals to avoid over-loading of the weld metal, early development of cracks, and rapid propagation of the small, preexisting flaws expected in any weld. At this time, late June 1978, it 
was recognized by the MFTF magnet project engineer that reconsideration of the selection of the magnet case structure material and the associated welding development efforts was needed. Experts in the associated areas of structural materials for cryogenic service and welding devclopment from within LLNL and from other organizations (National Bureau of Standards at Boulder, General Dynamics/Convair, and the DOE) met at Livermore on June 23, 1979 to reexamine the related issues of selection of the case structural material and associated welding development. The recommendations of this review committce are summarized below and were adopten by the MFTF magnet project engineer for implementation.

By using as a guide the principle of selecting a base metaliweld metal pair with equal $4 \mathrm{~K}$ tensile yjeld sirengths, a base metal $4 \mathrm{~K}$ tensile yield strength not less than 1.5 times the General Dynamics/Convair design stress of $80 \mathrm{ksi}$, and a

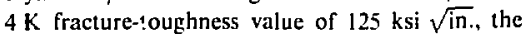
following preliminary recommendations were proposed:

Type 304LN base metal :316L weld metal, or

Type $316 \mathrm{LN}$ base metal $: 316 \mathrm{~L}$ weld metal.

Welds should be made by the GMA process for optimum control of purity, $4 \mathrm{~K}$ fracture-toughness, and ferrite content. Neither of these approaches entails matcrials costs as high as the Nitronic $40: 1 n$ conel 625 approach. The need for resolution of the one open issue, optimization of weld-metal composition 10 prevent weld-metal microlissuring dur. ing production of the restrained, heavy-section welds (up to 3-in. thick) in the actual case, versus limitation of ferrite content to guard against degradation of $4 \mathrm{~K}$ weld-metal fracture-toughness. was recognized.

\section{WELD DEVELOPMENT PROGRAMS PERFORMED IN SUPPORT OF JOINING TYPE-304LN BASE METAL}

Once the choice of type 304LN stainless steel was made, three separate but related welddevelopment programs were begun to provide an initial evaluation of the suitability of the common welding processes, such as SMA, GMA, GTA, SA, FCMA (flux-cored metal arc), and ESW (electroslag welding), for deposition of type 316L stainless steel weld metal. Evaluation of a variety of processes was necessary to ensure the eventual selection of one or more processes that would enable out-of-position (other than flat position) welding to be done, as well as qualify a process, such as SA or ESW, that would enable large quantities of weld metal to be deposited in a short time with a concurrent reduction in welding time and costs (Table 28). With this task essentially completed, and the SMA process selected by Chicago-Bridge and Iron Company ( $\mathrm{CBI}$ ), the successful bidder on the casefabrication contract, two parallel programs were initiated. One of these programs involved qualification of CBI's SMA welding procedures using

TABLE 28. Estimated time required to weld MFTF magnet case assuming $20,000 \mathrm{lb}$ of weld metal deposited.

\begin{tabular}{|c|c|c|c|c|c|c|}
\hline \multirow{2}{*}{$\begin{array}{l}\text { W'ell metal } \\
\text { deposition data }\end{array}$} & \multirow{2}{*}{$\begin{array}{l}\text { Shielded- } \\
\text { metal } \\
\text { arc }\end{array}$} & \multirow{2}{*}{$\begin{array}{l}\text { Gas- } \\
\text { meteI } \\
\text { are }\end{array}$} & \multirow{2}{*}{$\begin{array}{l}\text { Flux } \\
\text { core }\end{array}$} & \multirow{2}{*}{$\begin{array}{l}\text { Submerged } \\
\text { are }\end{array}$} & \multicolumn{2}{|c|}{ Flectroslag } \\
\hline & & & & & (Note a) & (Note b) \\
\hline \multicolumn{7}{|l|}{ Deposition data } \\
\hline $100 \%$ are time. $\mathrm{Jb} / \mathrm{h}$ & 2.5 & 9.0 & 13.0 & 14.5 & 15.0 & 40,0 \\
\hline Est. arc time. : & 20.0 & 30.0 & $\mathbf{4 0 . 0}$ & 50.0 & 95.0 & 95.0 \\
\hline Actual deposition rate, $\mathrm{lb} / \mathrm{h}$ & 0.5 & 2.7 & 5.20 & 7.25 & 14.25 & $\mathbf{3 8 . 0}$ \\
\hline \multicolumn{7}{|l|}{ Welling time } \\
\hline Total hours to weld & 40,000 & $7,407.4$ & $3,846.2$ & $2,758.6$ & 1.403 .5 & 526.3 \\
\hline No. man-hours required & 240 & 44.4 & 23.1 & 16.6 & 8.4 & 3.1 \\
\hline No. man-months required ${ }^{c}$ & 20 & 3.70 & 1.92 & 1.38 & 0.7 & 0.26 \\
\hline
\end{tabular}

\footnotetext{
Per mensured lah rate using a 40-A power supply (max). Not sufficient.

b Attainable with power supply of akequate capacity.

CValues hased on available man-hr/yr $=(8 \mathrm{~h} / \mathrm{d})(5 \mathrm{~d} / \mathrm{wk})(5 \mathrm{wk} / \mathrm{gr})=2000 \mathrm{man}-\mathrm{hr} / \mathrm{gr} / \mathrm{man}$.
} 
E3/GL-15 electrodes, and the other involved development of welding information for use in other areas of magnet fabrication, such as the magnet jacket, and for a backup weld metal should difficulties arise with the weld metal deposited by type E316L-15 electrodes. The status of each of these programs, including results to date, open issues, and ongoing work, is presented below.

\section{Multiprocess Study}

Weids were made by the SMA, GMA, SA, FCMA, and ESW processes in type 304LN stainless steel plate ranging in thickness from $1-3 / 4$ to 3 in. using type $316 \mathrm{~L}$ weld metal in the form appropriate to the welding process. Details of the joint design and welding position are summarized in Table 22. Most of the welds were made at Livermore, but two welds, one GMA and one ESW, were made at FMC (San Jose). The fabrication subcontractor for the magnet case, CBI, supplied a GMA weld using a ferrite-free filler, 2RM69, for evaluation by LLNL. All the welds made at LLNL were made under heavily-restrained conditions, i.e., the plates were first welded to a 4- to 6-in.-thick mildsteel plate to prevent free thermal expansion and contraction of the plates and connecting test weld, thus simulating the situation that exists during assembly of the magnet case.

Those weld-metal chemical compositions determined to date are reported in Table 23. Initial evaluation of welding performance was by room temperature side-bend testing. Fuilures were seen in both specimens from weld No. 8 (GMA process, $316 \mathrm{~L}$, filler) and one of two specimens from weld No. 9 (SA, 316L filler) made at LLNL. Failure in the latter case was associated with an entrappedslag defeet in the tension-side of the sample. Such a defect is associated with incomplete removal of the fused slag during welding, and is not an inherent problem in either the choice of weld filler material or process. However, the two failures in the GMA welds were traced to thin oxide films on the solidifying weld metal, caused by the presence of $2 \% \mathrm{O}_{2}$ in the shielding gas. Oxygen is added to the argon shielding gas to lower the surface tension of the molten stainless steel weld metal and promote flow of the moltun metal to the edge of the weld joint, thus ensuring complete wetting along the entire weld-metal-to-base-meta! interface (Ref. 96). As such, the cause of failure in the GMA samples was associated with the weld process and was considered to be sufficient reason to eliminate conventional GMA welding, which uses Ar- $\mathrm{O}_{2}$ gas mixtures, from further consideration.

Intergranular cracks of lengths insufficient to constitute failure according to Section III of the ASME Boiler and Pressure Vessel Code were seen in side-bend specimens of Weld No. 17 made by CBI (Houston), using the pulsed GMA process, 2RM69 filler and $75 \% \mathrm{He}-25 \%$ Ar shielding gas. Details of evaluation of this weld conducted by both LLNL and CBI (Houston) are contained in Ref5. 97-99. Briefly, many intergranular fissures, with lengths up to $0.008 \mathrm{in}$, were found in the asdeposited weld metal. After side-bend testing, these defects grew to lengths of up to 0.156 -in. While the exact cause of these defects was not determined, the fact that they occurred on a weld metal specially developed for freedom from this type of defect (Ref. 100) and in weld deposits made with a process (GMA) known to be sensitive to both operator and process variables (Ref. 96) causes one to view with concern any use of conventional GMA welds and $2 R M 69$ filler metal for the stringent requirements of $4 \mathrm{~K}$ high-stress service.

Low-temperature mechanical-property evalualtions of all welds included $77 \mathrm{~K}$ Charpy $\mathrm{V}$-notch impact tests, followed by $4 \mathrm{~K}$ tensile and fractiretoughness testing of selected welds. Results are presented in Tables 24 and 25 and discussed balow.

\section{K Charpy V-Notch Impact}

\section{Test Results (Figure 94).}

As a function of weld process, from largest to smallest value of average energy absorption, the results for the Livermore-produced welds were: ESW, SMA, SA, GMA, and FCMA. Using average lateral expansion at the root of the notch as a rating tool, the results for the Livermore-produced welds were: ESW, SMA, GMA, SA, and FCMA. Results are also shown in Fig. 94 for two welds made by FMC (San Jose). Their ESW' weld exhibited much lower impact performance than the two ESW welds made by Livermore, but their pulsed-GMA weld results fell between the SMA and Livermore GMA results. Based on the results of the Livermoreproduced welds, the SMA, SA and ESW welds were selected for evaluation at $4 \mathrm{~K}$. 

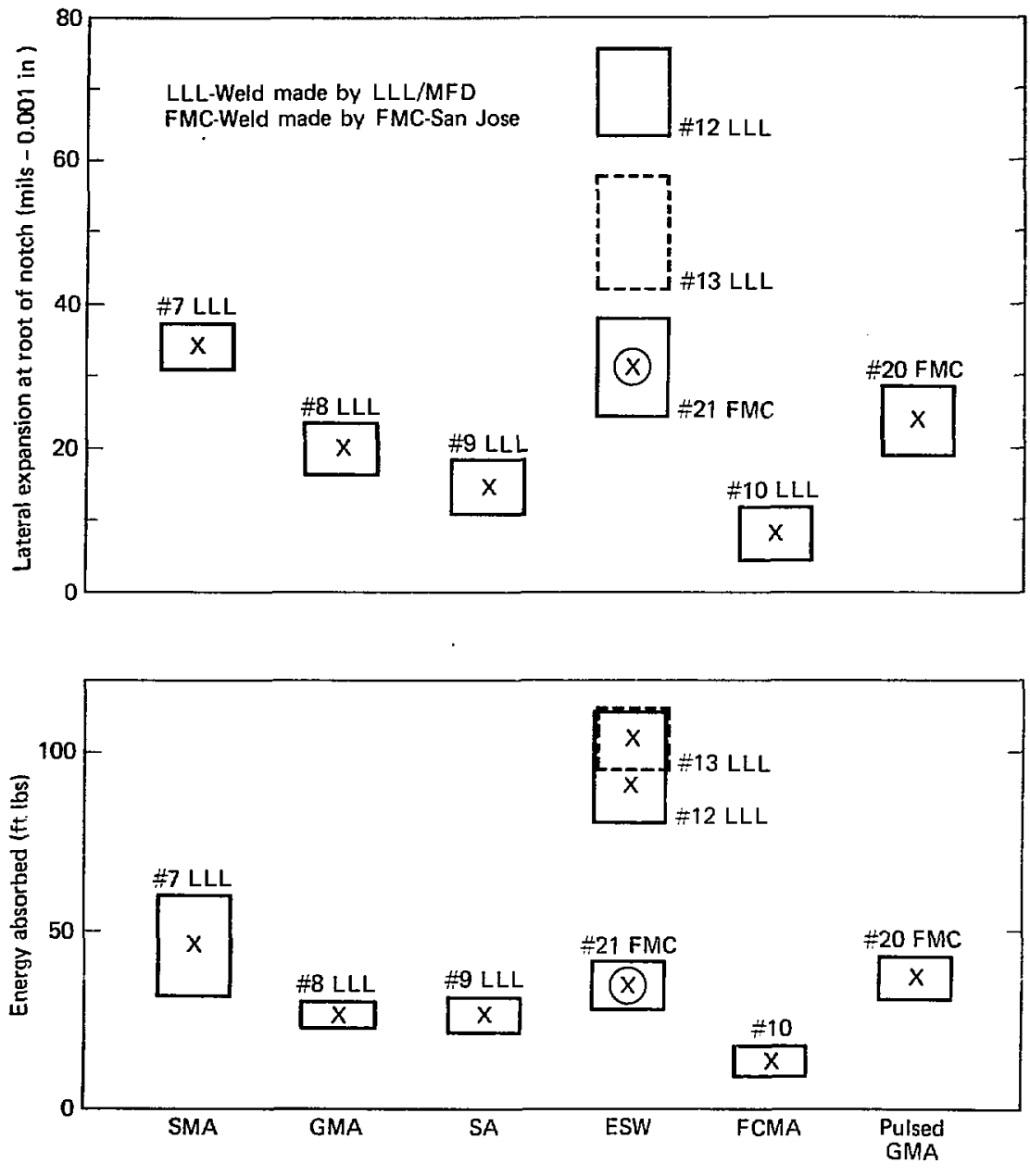

Weld process

FIG. 94. Results of $77 \mathrm{~K}$ Charpy V-notch impact tests on type 316L. weld metal deposited by various welding processes and laboratories. 
$4 K$ Tensile and

Fracture-Toughness Test

Results (Table 25 and Fig. 95)

Table 25 and Fig. 95 give our $4 \mathrm{~K}$ tensile and fracture toughness test results, together with data from other sources (Refs. 101 and 102). Examination of Fig. 95 shows that the SMA weld, No. 7, exhibited a superior combination of yield strength and fracture-loughness relative to both the SA weld, No. 9, and the ESW weld, No. 12. This provided additional support for selection of the SMA process as the primary candidate for Cabrication of the magnet case. Most of the data from Refs. 101 and 102 was generated after testing of welds 7,9 , and 12 was completed. The consistently superior performance of SMA welds shown in Fig. 95 confirms the choice made in the basis of data from the three Livermoreproduced weids.

\section{Evaluation of Weld-Metals \\ Deposited by the SMA \\ Process Using Type \\ E316L-15 Electrodes}

Welds have been made by both Livermore and the CBI corporate welding laboratory, using E316L-15 electrodes supplied by both the TeledyneMcKay Corporution under the trade name
"Kryokay" and by the ARCOS Corporation. Both companies supply product to specification AWS 5.4-75, the industry standard, with an added restriction of a ferrite number (FN) of zero, i.e., an allaustenitic weld metal. All butt welds were made in 3 -in.-thick type $304 \mathrm{LN}$ plates which were heavily restrained by first welding the plates to a 6 -in.-thick strongback (LLNL) or by welding into a rigid restraint fixture (CBI-Houston). These welds are described in Table 29.

Those weld-metal chemical compositions determined to date are reported in Table 30. Initial evaluation of weldment performance was by room temperature side-bend testing. No failures were observed.

Low-temperature mechanical-property evaluations included $77 \mathrm{~K}$ Charpy $\mathrm{V}$-notch impact tests of most welds, followed by $4 \mathrm{~K}$ tensile. fracturetoughness, and fatigue-crack growth testing of selected welds. Results are presented in Tables 31 and 32. The $77 \mathrm{~K}$ Charpy $\mathrm{V}$-notch impact test results are presented in Table 31 and summarized in Fig. 96. On the basis of these results, there was little difference between ARCOS and Teledyne-McKay filler metals, or between welds made in the flat or vertical positions. The $4 \mathrm{~K}$ tensile and fracturetoughness test results are presented in Table 30 and summarized in Fig. 97. Note that the performance

TABLE 29. Shielded-metal-arc welds in type 304LN, using type E316L-15 electrodes.

\begin{tabular}{|c|c|c|c|c|c|c|c|c|c|}
\hline \multirow{2}{*}{$\begin{array}{l}\text { Weld } \\
\text { No. }\end{array}$} & \multirow{2}{*}{$\begin{array}{l}\text { Diam. } \\
\text { (in.) }\end{array}$} & \multicolumn{3}{|c|}{ Electrode } & \multicolumn{3}{|c|}{ Weld joint } & \multicolumn{2}{|c|}{ Ferrite No. by } \\
\hline & & Supplier & Heal No. & Lot No. & Type & Origin & Position & Vendor & LLNL. \\
\hline 7 & $5 / 32$ & Mekiay & 02146 & 2161376 & Butt & LLNI. & Flat & & 1.0 \\
\hline 14 & $3 / 16$ & Mckay & 21333 & 3186938 & Butt & LLNL & Fint & & 1.0 \\
\hline 16 & $3 / 16$ & Arcos & \multicolumn{2}{|c|}{$T-12150-2$} & Flat & LLNL & Flat & 0 & 0 \\
\hline 18 & $\begin{array}{l}5 / 32 \& \\
1 / 8\end{array}$ & MeKay & 386022 & 30186644 & Butt & CB]-Hstn & Vert. & 0 & \\
\hline 19 & $1 / 4$ & Mckay & $N / A$ & $0631-401$ & Butt & LLNL & Flat & & \\
\hline 22 & $\begin{array}{l}5 / 32 \& \\
3 / 16\end{array}$ & Mckay & $N / A$ & $N / A$ & Butt & CBI-Hsta & Flat & & \\
\hline 23 & $1 / 4$ & Arcos & \multicolumn{2}{|c|}{$T-12150-2$} & Butt & CBI-Hstn & Flat & & \\
\hline 24 & $1 / 6$ & Mckay & 386022 & 3086683 & Burt & CBI-Hatn & Vert. & 0.5 & \\
\hline 28 & $5 / 32$ & MeKay & 02146 & 2161376 & Dble-V & LLNL & Vert. & & e \\
\hline 29 & $s / 32$ & Mckay & 16329 & 3178554 & Dble-V & LLNL & Verr. & & 0 \\
\hline 34 & $5 / 32$ & Mckay & 586108 & 2397723 & Burt & LLNL & Flat & 0 & \\
\hline 35 & $5 / 32$ & Mckay & 586108 & 2397723 & Dthe-V & LLNL & Vert. & 0 & \\
\hline 38 & $5 / 32$ & MeKay & 586108 & 2397723 & Butt & CBl-Hsin & Vert. & o & \\
\hline
\end{tabular}




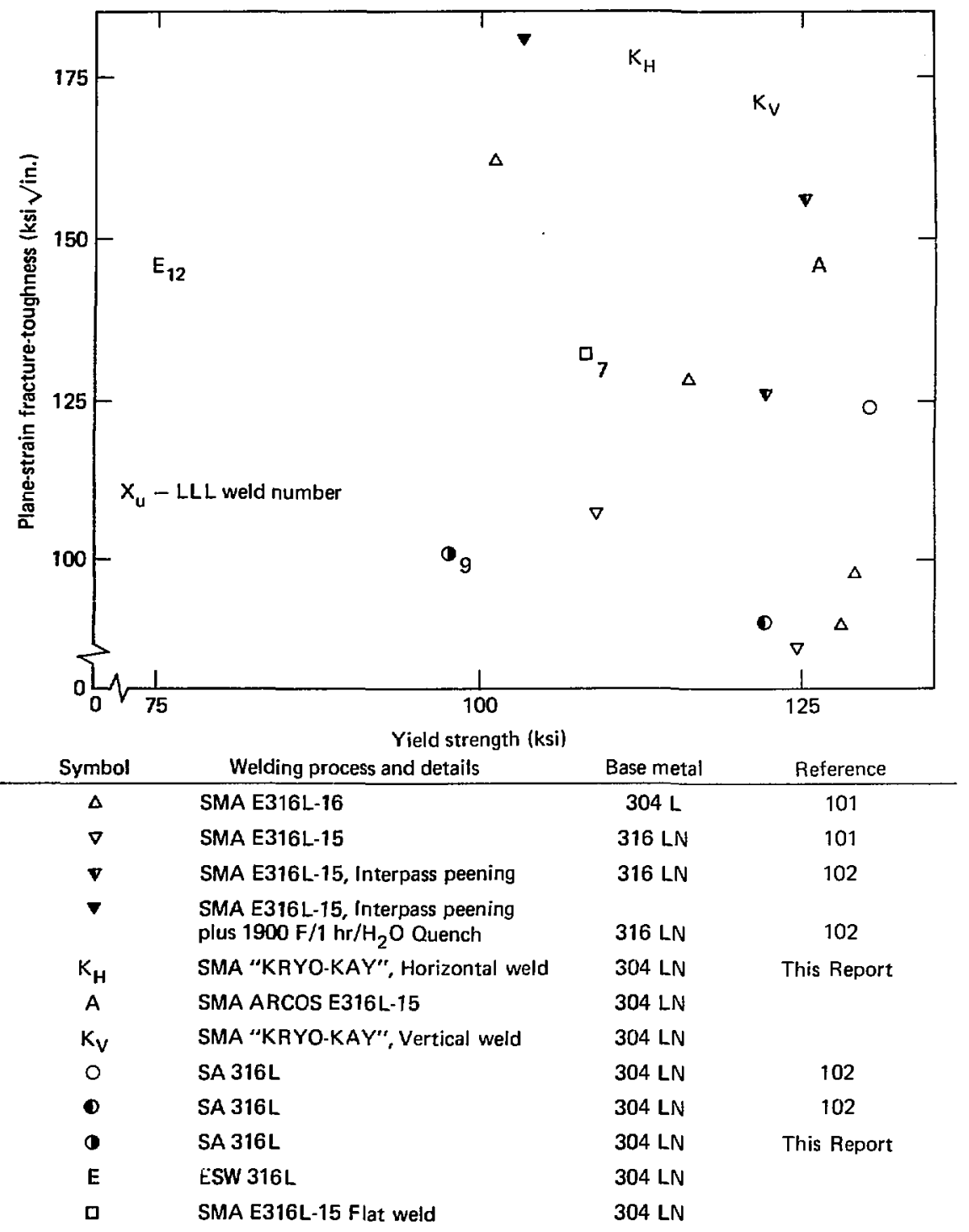

FIG. 95. 4 K plane-strain fracture toughmess as a function of yield stress for type $316 \mathrm{~L}$ weld metal deposited by variows processes. 
TABLE 3. Chemical compositions of shielded metal-are welds made in type 304LN using type E316L-15 electrodes $(w t \%) \cdot *$

\begin{tabular}{|c|c|c|c|c|c|c|c|c|c|c|c|c|c|}
\hline $\begin{array}{l}\text { Weld } \\
\text { No. }\end{array}$ & C & Mn & $\mathbf{S i}$ & $\mathbf{s}$ & $\mathbf{p}$ & $\mathrm{Cr}$ & $\mathbf{N i}$ & $M_{n}$ & $\mathrm{Ti}$ & $C b+T a$ & $\mathrm{Cu}$ & $\mathbf{N}_{2}$ & $v$ \\
\hline 14 & 0.030 & 1.65 & 0.35 & & & 18.0 & 13.2 & 2.25 & & & & & \\
\hline \multirow[t]{2}{*}{16} & 0.033 & 2.44 & 0.36 & 0.007 & 0.032 & 18.20 & 13,81 & 2.14 & & & & 0.056 & \\
\hline & 0.033 & 2.54 & 0.33 & 0.010 & 0.035 & 18.07 & 13,81 & 2.23 & & & & $0.06 \mathrm{~J}$ & \\
\hline 18 & 0.023 & 2.14 & 0.30 & 0.014 & 0.022 & 18.12 & 13,22 & 2.29 & 0.05 & 0.02 & 0.18 & & 0.45 \\
\hline 23 & 0.033 & 2.44 & 0.36 & 0,007 & 0.032 & 18.20 & 13.81 & 2.14 & & & & 0.056 & \\
\hline 24 & 0.025 & 1.94 & 0.28 & 0.012 & 0.021 & 17.80 & 13.00 & 2.22 & 0.06 & 0.02 & 0.22 & & 0.042 \\
\hline 28 & 0.030 & 1.64 & 0.35 & & & I8.0 & 13.2 & 2.25 & & & & & \\
\hline 29 & 0.030 & 1.65 & 0.35 & & & 18.0 & 13.2 & 2.25 & & & & & \\
\hline 34 & 0.036 & 2.18 & 0.22 & 0.012 & 0.018 & 17.84 & 13.58 & 2.10 & & 0.02 & 0.28 & & 0.084 \\
\hline 35 & 0.036 & 2.18 & 0.22 & 0.012 & 0.018 & 13.58 & 13.58 & 2.10 & 0.052 & 0,02 & 0.28 & & 0.084 \\
\hline 38 & 0.036 & 2.18 & 0.22 & 0.012 & 0.018 & 13.58 & 13.58 & 2.10 & 0.052 & 0.02 & 0.28 & & 0.064 \\
\hline
\end{tabular}

As determined on undifuted weld pads deposited in flat position.

of the individual weld metals is independent of both supplier and weld position and falis at the upper end of the scatter-band for all data in type $316 \mathrm{~L}$ weld metals deposited by the SMA process. Examination of the $4 \mathrm{~K}$ tensile ductility data in Table 32 indicated a large variation in both elongation $(5.4 \%$ to $44.0 \%)$ and reduction area $(6.8 \%$ to $33.5 \%)$. Since low values of both of these quantities are indicative of some factor in the weld metal being out of control, metallographic examinations of the welds having both high and low values of these ductility parameters were conducted.

\section{Metallographic Examinations of Weids}

Examinations were performed using standard optical-microscopy techniques, and indicated that low values of elongation and reduction in area appear to be assocjated with the presence of extensive weld-metal defects in or near the plane of fracture. Such defects include microfissures (Refs. 100, 104 $107)$ or small $(0.005-0.030$-in. long) inter-granular cracks that form during solidification of low-ferrite or ferrite-free weld metal (Fig. 98) and such operator-related defects as lack of fusion (Fig. 99) and slag entrapment (Fig. 100), which are caused by less than satisfactory welding practices. A semiquantitative rating of the occurrence of microfissures was made, presented in Table 32, indicates that the presence of appreciable amounts of this type of defect is limited to the vertical welds Nos. 18,28 , and 29 made with Teledyne-McKay "Kryokay" electrodes. As this fact was discovered too late during the fabrication-cycle of the two magnet cases to change to another weld metal, certain remedial steps to limit the occurrence of microfissuring and assess the effect of heavily microfissured welds on the expected performance of simulated case close-out welds were undertaken and are discussed later.

\section{Fatigue-Crack Growth \\ Behavior of Type-316L Weld Metals}

Fatigue-crack growth behavior was evaluated by the National Bureau of Standards and the results are presented in Fig. 101. Note that the behavior of type-316L weld metals are consistent in that the fatigue crack growth (FCG) rates fall with a factor of about 5 of each other and are about a factor of 3 to. 10 less than that of the type-304LN base metal used for fabrication of the magnet cases. An informal report (Ref. 103) prepared by General Dynamics/Convair, using the actual $4 \mathrm{~K}$ mechanical properties of the base metal and welds presented in Fig. 101, demonstrated the structural adequacy of this case at a design stress of $80 \mathrm{ksi}$ at $4 \mathrm{~K}$. 
TABLE 31. Charpy $V$-notch impact performance at $77 \mathrm{~K}$ of shielued-metal arc welds in type 304L $\mathrm{N}$ plate using type E316L-15 electrodes.

\begin{tabular}{|c|c|c|c|c|}
\hline \multirow[b]{2}{*}{ Wet Ne. } & \multicolumn{2}{|c|}{ Energy absorbed } & \multicolumn{2}{|c|}{ lalcral expansion } \\
\hline & Average, $\mathrm{ft}^{-1 b^{2}}$ & Range, It-lb & Average, milsa,b & Range, mils \\
\hline 7 & $\$ 1.7$ & 32,0 to 60.0 & 37.6 & .0 .8 to $37 . ?$ \\
\hline 14 & 33.8 & 29.51038 .11 & 30.11 & 18.5 to 54.0 \\
\hline 16 & 39.4 & 38,0 to 42,0 & 26.0 & 24.0 to 28.5 \\
\hline 18 & 43.7 & 34.0 to 5.3 .01 & 3.5 & 24.0 to $4(1.0)$ \\
\hline 22 & 37.6 & 27.0 to 44.0 & 29.6 & 23.0 I 35.0 \\
\hline 24 & 39.8 & 35.0 to 45.6 & 30.2 & 26.11 in 41.6 \\
\hline 34 & 40.5 & 39.8 to 41.2 & 29.0 & $27,01031.11$ \\
\hline 35 & 40.5 & 39.8 to 41.2 & 29.0 & 27.10 to 31.11 \\
\hline 38 & 46.6 & 39.11 to 56.0 & 30.0 & 28.10 (0 411,11 \\
\hline
\end{tabular}

A Average of 3 to 5 specimens.

$b_{1}$ mit $=0,001$ in.

TABLE 32. $4 \mathrm{~K}$ tensile properties of shielded-metal are welds made in type $304 \mathrm{LN}$ plate using type $\mathrm{E}, 3161, \cdots 15$ electrodes.

\begin{tabular}{|c|c|c|c|c|c|c|c|c|c|c|}
\hline \multirow{3}{*}{$\begin{array}{l}\text { Weld } \\
\text { No. }\end{array}$} & \multirow{3}{*}{$\begin{array}{l}\text { Spec. } \\
\text { orien." }\end{array}$} & \multicolumn{4}{|c|}{ A K teasile properties } & \multirow{3}{*}{$k_{I C}{ }^{b}$} & \multirow{3}{*}{$\begin{array}{l}\text { Occurrence/ } \\
\text { extent of } \\
\text { microfissures }\end{array}$} & \multirow{3}{*}{$\begin{array}{l}\text { Micro- } \\
\text { structure }\end{array}$} & \multirow{2}{*}{\multicolumn{2}{|c|}{ Ferrite $x_{0 .}$ by }} \\
\hline & & \multirow{2}{*}{$\begin{array}{l}\text { Ultimate } \\
\text { strength, } \\
\text { ksi }\end{array}$} & \multirow{2}{*}{$\begin{array}{l}\text { Yíeld } \\
\text { strength, } \\
\text { ksi }\end{array}$} & \multirow{2}{*}{$\begin{array}{c}\text { Elong. } \\
1 \text { in.. } \\
\sigma c\end{array}$} & \multirow{2}{*}{$\begin{array}{l}\text { Heduction } \\
\text { in area. } \\
\text { of }\end{array}$} & & & & & \\
\hline & & & & & & & & & Findor & $\overline{\text { I.I.I. }}$ \\
\hline 7 & $\mathbf{L}$ & 178.2 & 108.0 & & & 132.0 & & Austenite & & 1 \\
\hline & & & & & & & & Ferrite & & \\
\hline 14 & LT & 189.4 & 152.1 & 26.0 & 25.7 & & & Austenite & & 1 \\
\hline & $\mathbf{L}$ & 176.4 & 119.8 & 25.0 & 25.0 & & Few & Ferrite & & \\
\hline & ST & 176.2 & 117.0 & 44.0 & 27.4 & & & & & \\
\hline 16 & $\mathbf{L}$ & 153.5 & 111.1 & 18.0 & 27.5 & & & & & \\
\hline & $\mathbf{S T}$ & 187.4 & 125.7 & 44.0 & 33.5 & $1+6.0$ & Some & Nustenite & 0 & a \\
\hline 18 & $\mathbf{L}$ & 159.4 & 123.8 & 5.4 & 6.4 & 171.11 & Many & Austenite & 0 & II \\
\hline 22 & $\mathbf{L}$ & I83.2 & 112.0 & 36.4 & 28.1 & 18.3 .0 & Some & Austenite & & \\
\hline 23 & $\mathbf{L}$ & 163.6 & 130.7 & 10.0 & 10.9 & & & & & \\
\hline & $\mathbf{L T}$ & 180.7 & 128.5 & 16.0 & 14.5 & & & & 0.5 & \\
\hline & ST & 171.4 & 123.5 & 32.0 & 24.3 & & & & & \\
\hline 28 & $\mathbf{L}$ & 168.7 & 111.9 & 14.5 & 16.2 & & Some & Austenite & & 0 \\
\hline 29 & $\mathbf{L}$ & 184.2 & 145.3 & 9.5 & 10.8 & & Some & Austenite & 1 & 0 \\
\hline 35 & $\mathbf{L}$ & 188.3 & 111.3 & 19.0 & 17.6 & & & & 0 & \\
\hline
\end{tabular}

Sinccinem orientation relative to centerline of weld.

L-Lomiturlons, parstel to weld axis.

LT-Long tranverse, acros weld axis.

ST-Short tranverse, twowgh weld thickness.

Determined by elastic-plastic J-jintegral test. 

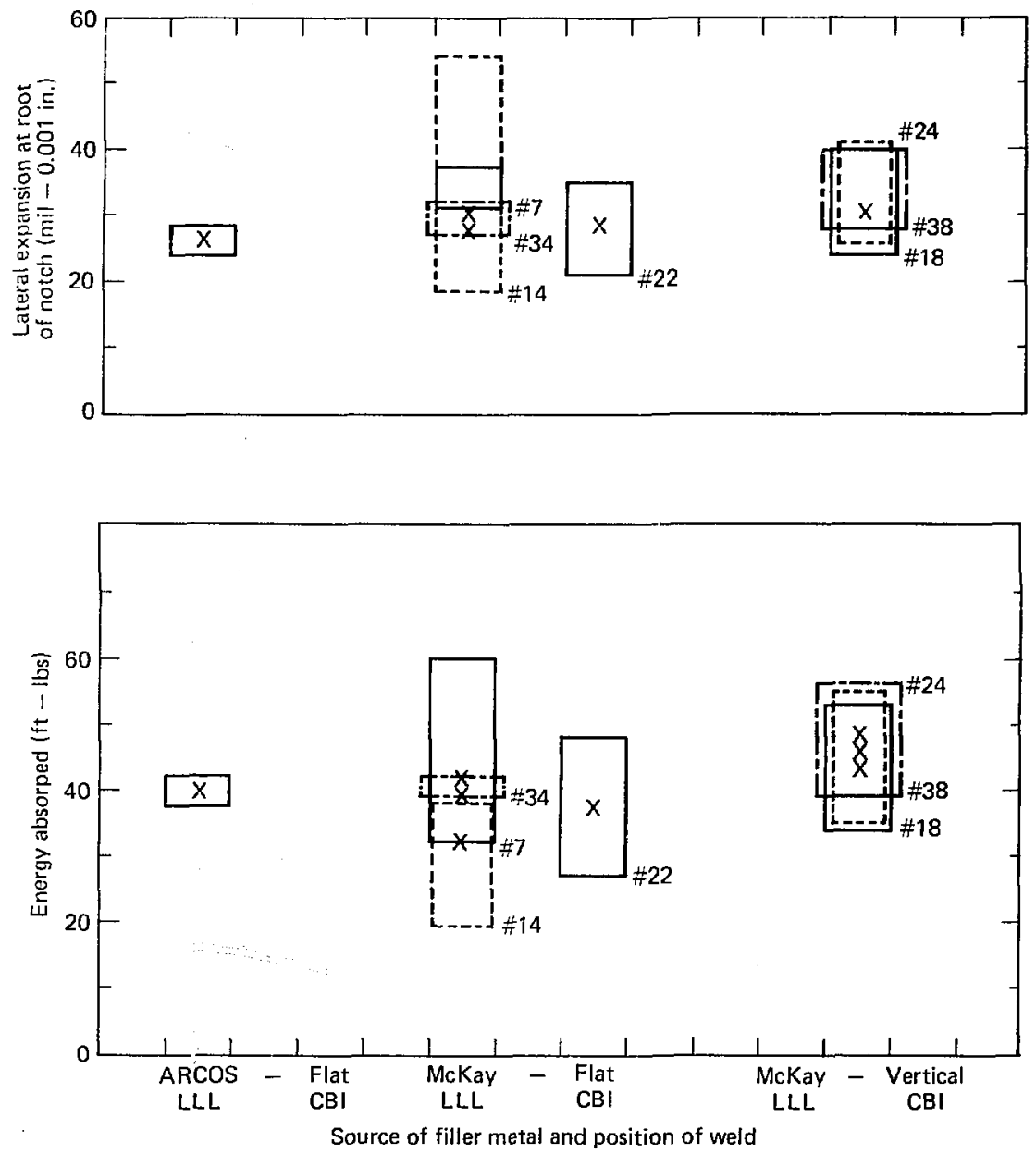

FIG. 96. Results of $77 \mathrm{~K}$ Charpy V-notch impact tests on type 316L-15 weld metals deposited on type 304LN base phate. 


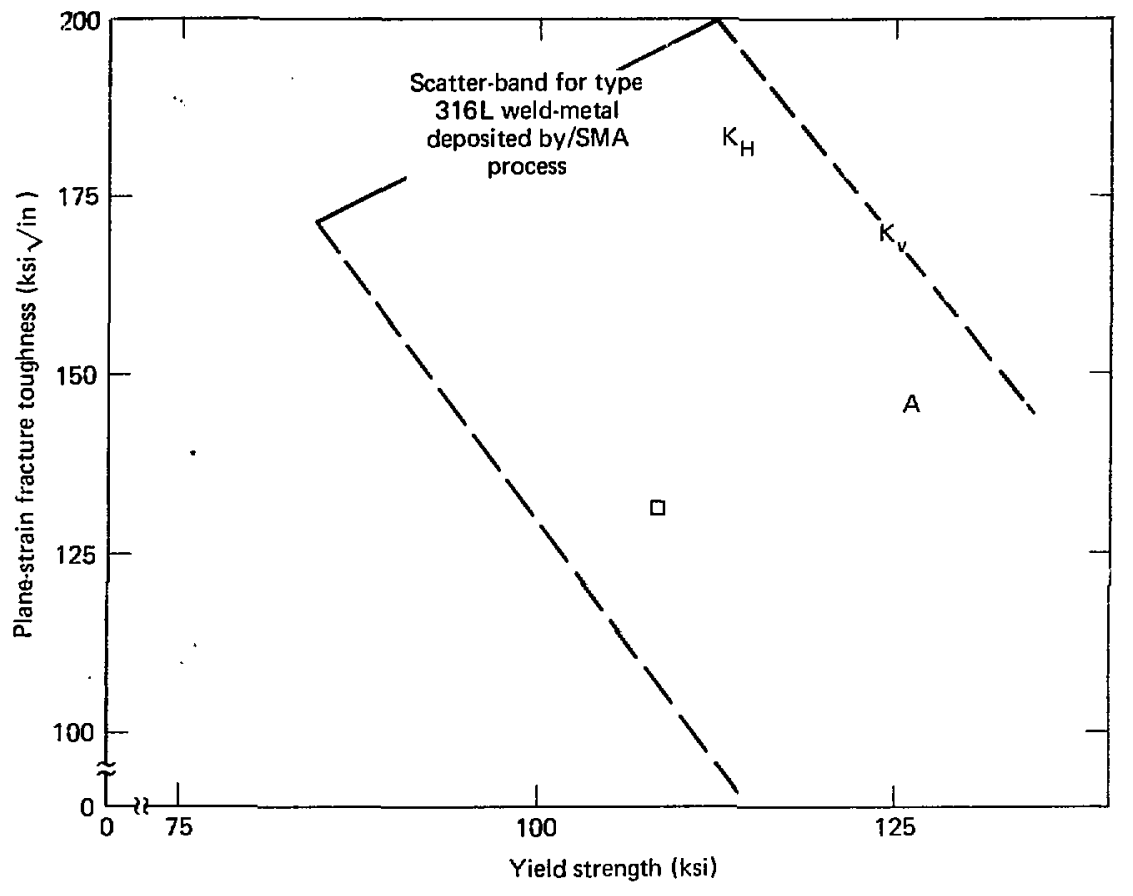

FIG. 97. $4 \mathrm{~K}$ plane-strain fracture toughness as a function of yield strength for type $316 \mathrm{~L}$ weld metal used in fabrication of MFTF. 


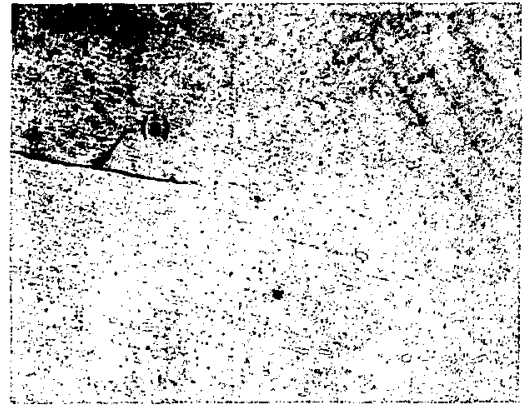

FIG. 98. Microfissure (a) in SMA weld No, 18, A vertical weld made with Kryokay electrodes, magnified 100 times.

\section{EVALUATION OF SHIELDED METAL ARC WELD-METALS DEPOSITED BY OTHER THAN TYPE E316L-15 ELECTRODES}

Details of joint design for these welds are given in 7 able 33. Evaluation of these weld-metals was confined to a limi'ed number of chemical analyses (Table 34), $77 \mathrm{~K}$ Charpy $\mathrm{V}$-notch impact tests (Table 35), and $4 \mathrm{~K}$ tensile tests and metallographic examinations (Table 36). Bricl descriptions of the results reported in Tatbles 34-35 are presented for each weld metal evaluated:

\section{ARCOS 17-15 Cr-Ni}

This wals a lower $\mathrm{Cr}$ higher $\mathrm{Ni}$ modification of type 3!6L, intended to give improved $77 \mathrm{~K}$ impact performance relative to ARCOS' type E316L-15 filler metal. Comparison of $77 \mathrm{~K}$ impact test results for the 17-15 $\mathrm{Cr}-\mathrm{Ni}$ weld metal (Table 35) with the values obtained for ARCOS commercial product (Table 31 and Fig. 96) showed about a $7 \mathrm{ft}-1 \mathrm{~b}$ increase in average energy absorption values and about a 6-nil increase in average lateral expansion values. Results of $4 \mathrm{~K}$ tensile tests (Table 36) showed unsatisfactory behavior in that the ultimate tensiie strength values, when the weld metal was tested in three mutually perpendieular directions, were very slightly greater than the tensile yield strengths. This type of behavior is generally considered indicative of unstable structural behavior, since once yielding commences, the material is in-

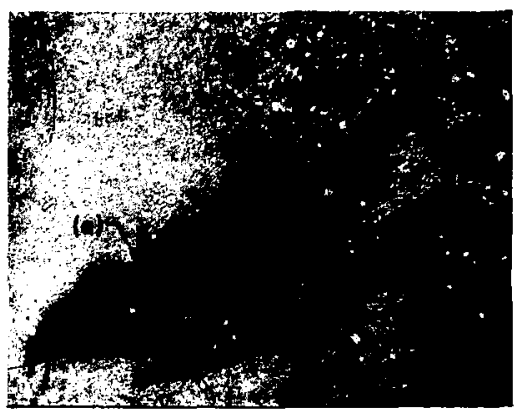

FIG. 99. Lack-of-fusion defect (a) near fusion line (b) in weld No. 52. A Itat-position weld made with Kryokay electrodes, magnified 63 times.

capable of strain hardening to relieve local stress concentrations, and unstable plastic flow will continue at a constant or decreasing load until the occurrence of failure. For this reason, further work on this material was discontinued.

\section{Type 316-16}

This type was evaluated for suitability for joining the inner jacket which surrounds the magnet. Evaluation was limited to a few $4 \mathrm{~K}$ tensile tests and microstructural evaluations (Table 36), which indicated that no evidence of weld-defect formation or undesirable effects on $4 \mathrm{~K}$ tensile properties is expeeted.

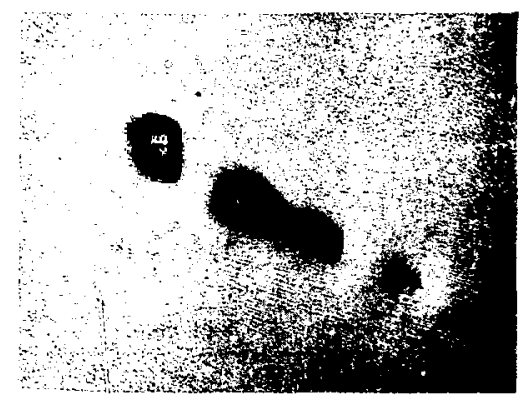

FIG. 100. Slag inclusions in SMA weld No. 52. A vertical weld made with Kryokay electrodes, magnified 63 times. 


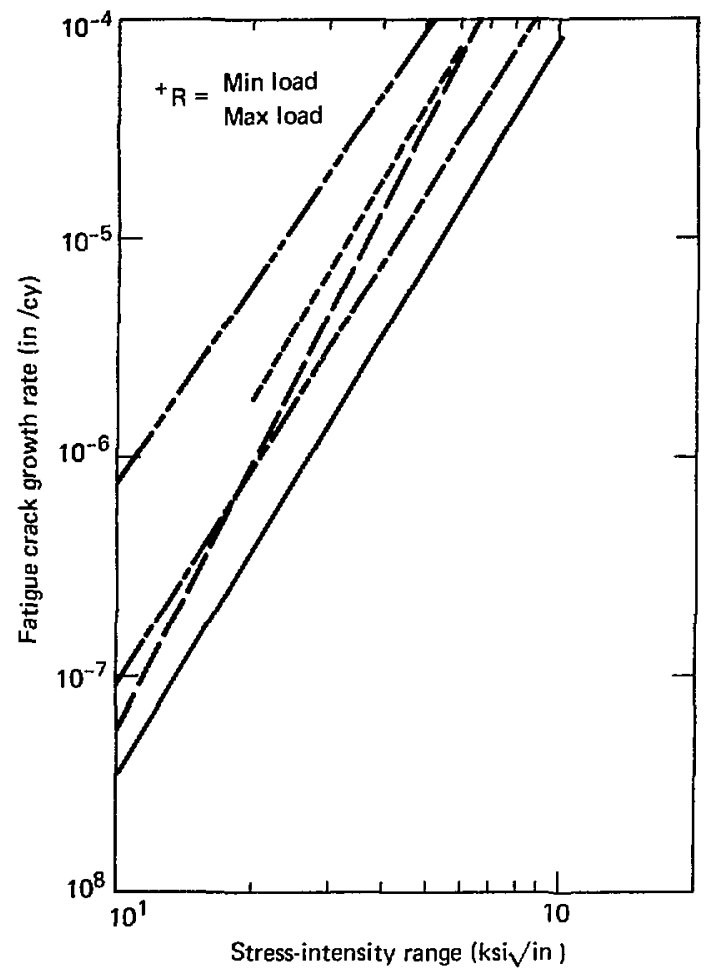

\begin{tabular}{ccccc} 
Symbol & $\begin{array}{c}\text { Product } \\
\text { form }\end{array}$ & $\begin{array}{c}\text { Filler metal } \\
\text { and details }\end{array}$ & $\begin{array}{c}\text { Base } \\
\text { plate }\end{array}$ & $\mathrm{R}^{+}$ \\
\hline 1 & 3-in. weld & Arcos flat weld & $304 \mathrm{LN}$ & +0.1 \\
2 & 3-in. weld & McKay flat weld & $304 \mathrm{LN}$ & +0.1 \\
3 & 3-in. weld & $\begin{array}{c}\text { McKay vertical } \\
\text { weld }\end{array}$ & $340 \mathrm{LN}$ & +0.1 \\
4 & 1-in. weld & $\begin{array}{c}\text { Chemetron flat } \\
\text { weld, 1900 } \mathrm{F}-1 \mathrm{~h}\end{array}$ & $316 \mathrm{LN}$ & +0.1 \\
5 & 3-in. plate & Fan cooled & $304 \mathrm{LN}$ & +0.1 \\
\hline
\end{tabular}

FIG. 101. Liquid-helium fatigue crack growth behavior of the type 316L weld metals deposited by the shieldedmetal arc process using $a-15$ coating- 
TABLE 33. Shielded-metal-arc welds in type 304LN base metal using other than type E316L-15 electrodes.

\begin{tabular}{|c|c|c|c|c|c|c|c|c|c|c|}
\hline \multirow{3}{*}{$\begin{array}{l}\text { Weld } \\
\text { No. }\end{array}$} & \multicolumn{5}{|c|}{ Electrode } & \multirow{2}{*}{\multicolumn{3}{|c|}{ Weld joint }} & \multirow{2}{*}{\multicolumn{2}{|c|}{ Ferrile No. }} \\
\hline & \multirow{2}{*}{$\begin{array}{l}\text { Filler } \\
\text { metal }\end{array}$} & \multirow{2}{*}{$\begin{array}{l}\text { Diam. } \\
\text { (in.) }\end{array}$} & \multirow[b]{2}{*}{ Supplier } & \multirow[b]{2}{*}{ Heat No. } & \multirow[b]{2}{*}{ Lnt No. } & & & & & \\
\hline & & & & & & Type & Origin & Position & Vendor & ILNL \\
\hline I5 & $16-1=$ & $3 / 16$ & McKay & 386022 & 2197476 & Butt & L.J.NL. & Flat & 0 & 0 \\
\hline 25 & $\begin{array}{l}17 / 1 \\
\mathrm{Cr}-\mathrm{Ni}\end{array}$ & $1 / 8$ & $\operatorname{ARCOS}$ & $\mathbf{N} / \mathbf{A}$ & T12984 & Butt & CBl-Hstn & Vert. & i) & $\theta$ \\
\hline 27 & $\begin{array}{l}17 / 15 \\
\mathrm{Cr}-\mathrm{Ni}\end{array}$ & $5 / 32$ & ARCOS & $1345-40-145$ & T12984 & Joble-Y & I.ENI. & Vert. & & 0 \\
\hline 32 & $316-16$ & $5 / 32$ & $\begin{array}{l}\text { Coor.- } \\
\text { Indus. }\end{array}$ & $N / A$ & $N / A$ & Dble-y & LILNL & Vert. & & \\
\hline 33 & $316-16$ & $1 / 8$ & $\begin{array}{l}\text { Coor-: } \\
\text { Indus. }\end{array}$ & $\mathbf{N} / \mathbf{A}$ & $N / A$ & Dhle-V & LLNL & Vert. & & \\
\hline 36 & $3161-16$ & $5 / 32$ & Nemco & 83118 & $N / A$ & Dble-V & LLNI & Vert. & & \\
\hline 37 & Mlod $316 \mathrm{~L}$ & $5 / 32$ & ARCOS & 713243 & $N / A$ & Dblc-Y & ILNL & Vert. & & \\
\hline 26 & $316-16$ & $5 / 32$ & $\begin{array}{l}\text { Conr.- } \\
\text { Indus. }\end{array}$ & $N / A$ & $N / A$ & Dble-Y & LLNL & Vert. & & 1.5 \\
\hline 30 & $\ln 625$ & $1 / K$ & Inco & 1877 & $N / A$ & Dble-V & ILNI. & Vert. & & \\
\hline 31 & In 625 & $5 / 32$ & Inco & $\mathbf{N} / \mathbf{A}$ & $N / A$ & Dhle-V & LLNL & Vert. & & \\
\hline
\end{tabular}

N/A-Dxte not arailable.

TABLE 34. Chemical compositions and ferrite levels of chielded-metal arc welds in type 304LN hase metal using other than type E316L-IS electrodes (wt \%). ${ }^{\mathrm{a}}$

\begin{tabular}{lllllllllllllllll}
\hline $\begin{array}{l}\text { Weld } \\
\text { No. }\end{array}$ & $\mathrm{C}$ & $\mathrm{Mn}$ & $\mathrm{Si}$ & $\mathrm{S}$ & $\mathrm{P}$ & $\mathrm{Cr}$ & $\mathrm{Ni}$ & $\mathrm{Mo}$ & $\mathrm{Ti}$ & $\mathrm{Ch}$ & $\mathrm{T}$ & $\mathrm{Cu}$ & $\mathrm{N} 2$ & v & Vendor & LLNL \\
\hline 25 & 0.041 & 2.80 & 0.30 & 0.04 & 0.025 & 17.57 & 15.85 & 2.01 & 0.016 & 0.06 & 0.13 & 0.017 & 0.159 & 0 & 0 & \\
\hline
\end{tabular}

As determined on undiluted weld pad deposited in flat position.

TABi_E 35. Charpy $V$-notch impact performance at $77 \mathrm{~K}$ of shiclded-metal arc welds in type 304LN base metal using other than type E316L-15 electrodes.

\begin{tabular}{|c|c|c|c|c|}
\hline \multirow[b]{2}{*}{ Held No. } & \multicolumn{2}{|c|}{ Energy absorbed } & \multicolumn{2}{|c|}{ J.wteral expansion } \\
\hline & Average, $\mathrm{ft}^{-1 b^{\mathrm{a}}}$ & Range, ft-lb & Average, mils ${ }^{\mathrm{a}, \mathrm{b}}$ & Kange, wils \\
\hline 25 & 47.3 & 45.11 to 53,0 & 31.4 & 22.6 to 41.5 \\
\hline 27 & 4.9 & 41.0 to 50.11 & 34.9 & 31.0 to 40.0 \\
\hline
\end{tabular}

\footnotetext{
Average of 3 to 5 specimens.
}

$b_{1} \mathrm{mH}=0,001$ in. 
TABLE 36. $4 \mathrm{~K}$ tensile properties and microstructural observations of shielded-metal arc welds in type 304LN base metal using other than type E316L-15 electrodes.

\begin{tabular}{|c|c|c|c|c|c|c|c|}
\hline \multirow[b]{2}{*}{$\begin{array}{l}\text { Weld } \\
\text { No. }\end{array}$} & \multirow[b]{2}{*}{$\begin{array}{l}\text { Spec. } \\
\text { orient. }\end{array}$} & \multicolumn{4}{|c|}{$4 \mathrm{~K}$ tensile properties } & \multirow[b]{2}{*}{$\begin{array}{l}\text { Occurrence } \\
\text { and extent of } \\
\text { microfissures }\end{array}$} & \multirow[b]{2}{*}{$\begin{array}{l}\text { Micro- } \\
\text { siructure }\end{array}$} \\
\hline & & $\begin{array}{l}\text { Ultimate } \\
\text { strempth, } \\
\text { ksi }\end{array}$ & $\begin{array}{l}\text { Yield } \\
\text { stremgth, } \\
\text { ksi }\end{array}$ & $\begin{array}{c}\text { Elongation } \\
\quad 1 \text { in., } \\
\text { \% }\end{array}$ & $\begin{array}{c}\text { Reduction } \\
\text { in area, } \\
\%\end{array}$ & & \\
\hline \multirow[t]{2}{*}{15} & & (b) & (b) & (b) & (b) & & \\
\hline & L. & 136.4 & 132.3 & 11.0 & 19.6 & & \\
\hline \multirow[t]{2}{*}{25} & L.T & 132,3 & 129.8 & 13.5 & 16.2 & & \\
\hline & ST & 94,2 & 94.2 & 56.0 & 38.9 & & \\
\hline 27 & L & 175.0 & 146.1 & 12.5 & 13.7 & Some & Austenite \\
\hline 32 & L & 201.0 & 162.9 & 9.0 & 16.3 & & \\
\hline 33 & L. & 197.3 & 119.4 & 7.0 & 16.1 & & \\
\hline 36 & $\mathbf{L}$ & 202.0 & 129.7 & 20.0 & 16.8 & & \\
\hline \multicolumn{8}{|l|}{37} \\
\hline 26 & L. & 162,1 & 162.1 & 7.0 & 10.9 & liew & Austenite and \\
\hline $3 B$ & & (b) & (b) & (b) & (b) & & ferrite \\
\hline \multirow[t]{2}{*}{31} & I. & 188,9 & 132.3 & 27.0 & 22.4 & Yone & \\
\hline & & & & & & & Austenite \\
\hline $\begin{array}{r}\text { aspe } \\
\text { I. } \\
\text { LI } \\
\text { SI } \\
\text { b }_{\text {Not }}\end{array}$ & $\begin{array}{l}\text { oricniation } \\
\text { udianal, pa } \\
\text { otransvers } \\
t \text { transvers } \\
\text { ble or dete }\end{array}$ & $\begin{array}{l}\text { elative to ce } \\
\text { allel to weld } \\
\text { across rel } \\
\text { through } \\
\text { nined. }\end{array}$ & $\begin{array}{l}\text { line of welt } \\
\text { is. } \\
\text { is. } \\
\text { thickness. }\end{array}$ & & & & \\
\hline
\end{tabular}

\section{Multiprocess Study}

Results of this study represent the first systematic evaluation of a variety of welding processes for the deposition of stainless steel weld metal for $4 \mathrm{~K}$ service. As such, this program was truncated once the magnet case fabricator, CBI, in-' dicated a willingness to use the SMA process for fabrication of the magnet cases. The results contained in Tables 22-24 and summarized in Figs. 9495, although far from complete, support the following very tentative conclusions:

1. Selection of the SMA process, using type E316L-15 electrodes manufactured by TeledyneMcKay and sold under the trade name "Kryokay", was a technically-valid decision at the time the selection was made, December 1978-January 1979. Even though this process exhibits the lowest rate of weldmetal deposition (Table 28), the combination of good $4 \mathrm{~K}$ tensile and fracture-toughness properties exhibited by weld No. 7, made with Teledyne-
McKay E316L-15 electrodes, coupled with the case fabricator's willingness to use this process over other, higher weld metal deposition-rate processes. such as SAW and FCMA for which little or no $4 \mathrm{~K}$ data was availuble at the tine of issuance of the magnet case $R F Q$, reenforces the balsic validity of the selection. Type 316L weld metal depositud by the SMA process was the only process: filler metal combination where anylhing more than fragmentary information on $4 \mathrm{~K}$ properties was in existence in the December 1978 to January 1979 time frame.

2. Use of $\mathrm{O}_{2}$ additions $10 \mathrm{Ar}$ to stabilize the welding arc and/or improve the weld-bead contour during GMA welding of Type 316L or 2RM69 fillers should not be used bicituse of the pronounced tendency towards formation of weld-pass-boundary oxide-films, which reduce low-temperature toughness and promote premalure failures in sidebend testing. Rather, the use of pulsed GMA welding and Ar- $\mathrm{H}_{\mathrm{e}}$ shielding galses should be evaluated. 
3. The following weld-process:filler-metal combinations, although not selected for use, exhibited sufficently satisfactory combinations of mechanical propertics at $77 \mathrm{~K}$ and $4 \mathrm{~K}$ which, when coupled with their known improved weld metal depnsition-rates over those shown in Table 28 for the SMA process, make them candidates for further evaluation for "out-of-position," i.c.. other than nat-position applications:

\begin{tabular}{lll} 
Process & Filler metal & $\begin{array}{c}\text { Shielding gas } \\
\text { or flux }\end{array}$ \\
\hline $\begin{array}{l}\text { Pulsed GMA } \\
\text { Electro-slag }\end{array}$ & $\begin{array}{l}\text { E316L } \\
316 \mathrm{~L}\end{array}$ & $\begin{array}{l}\text { Ar or Ar-He } \\
\text { neutral, such as } \\
\text { Hobart HS-300 }\end{array}$
\end{tabular}

\section{EVALUATION OF SHIELDED- METAL ARC WELDS USING TYPE 316L-15 ELECTRODES}

Results of this investigation indicate that, on the basis of $4 \mathrm{~K}$ tensile, fracture-toughness, and FCG lest results, type $316 \mathrm{~L}$ stainless steel weldmetal deposited with SMA electrodes with a limetitania $(-15)$ coating should be adequate for the intended application. However, the fairly consistent occurrence of reduced $4 \mathrm{~K}$ tensile ductility in vertical welds made with both Teledyne-McKay and $\therefore$ RCOS electrodes, and the occurrence of large numbers of microfissures, slag inclusions, and lack of fusion in these fully-austenitic welds, gives cause for concern regarding the structural integrity of these vertical welds. To determine whether the defect-containing welds might be unsuitable under the anticipated service conditions, while miaintaining fabrication of the magnet cases, several efforts were mounted in parallel:

1. Review of available literature on the effects of mierolissures and other defects on the low-temperature properties of stainless steel weld metals.

2. Manufacture and testing of several large fatigue specimens from highly microfissured stainless steel welds.

3. Evaluation of candidate backup weld metals deposited by the SMA process, should either or both of the above efforts indicate the existence of serious impairment of the fracture-toughness or
1. CG performance of microfissure-containing $316 \mathrm{~L}$. weld metal.

4. Accelerated developinent of ultrasonic test (UT) nondestructive inspection methods to ensure that the critical slose-out welis in the rutagnet cases are free of haws that are large enough to propagate to failure of the welds under design conditions.

Review of the published information on microfissures in stainless steel weld metals (Refs. 104-107, for example) revealed over 100 applicable references on possible mechanisms of microfissuring and how to minimize or eliminate it. Only one (Ref. 107) was found that evaluated the effccts of microfissures on mechunical properties from room temperature to $77 \mathrm{~K}$ in completely austenilic types 316 and 310 stainless stcel weld metals deposited by the SMA process. Their conclusions were that:

a. Microlissures are unlikely to significantly affect the tensile strength or ductility between $77 \mathrm{~K}$ and $300 \mathrm{~K}$ in types 316 or 310 stainless stecl weldmetals if the loss in load-bearinie area due to microfissures is less than 5\%. A bove $5 \%$ loss in loadbearing area, a progressive decrease in tensile ductility with increasing loss in load-bearing arca up to the maximum loss of load-bearing of about $20 \%$ was seen for type 310 weld metal. No data on this effect wus available for type 316 weld metal, since not more than $5 \%$ loss in load-bearing area due to microfissure formation was seen in this material.

b. Higher Charpy V-notch impact energyabsorption values were obtained for fully austenitic weld-metals (types 316 and 310 ) containing microfissures than for microfissure-free deposits of typc-316 wcld metal containing as much as $17 \%$ ferrite. An estimated plane-strain fracturetoughness value for the fully austenitic type-316 weld metal at $77 \mathrm{~K}$ is $150 \mathrm{ksi} \sqrt{\mathrm{in} .}$, which is comparable to a value of $144 \mathrm{ksi} \sqrt{\mathrm{in}}$. at $77 \mathrm{~K}$ for a similar material in which no microfissures were seen (Ref. 101).

Specimens for $4 \mathrm{~K}$ fatigue testing of heavilymicrofissured type-316L weld mctal have been machined and nondestructively examined for location, size, and amount of defects, and are awaiting shipment to Martin-Marietta, Denver Division, for testing under a fatigue-spectrum representative of anticipated case operating conditions. Also the candidate backup SMA welding consumables listed in 
Table 32 have been or are in the process of being manufactured into 2- to 3 -in.-thick restrained welds for evaluation by microscopy, side-bend testing, and $4 \mathrm{~K}$ tensile and fracture-toughness testing. For production quality control a subcontract is being placed with a manufacturer of ultrasonic testing equipment for the purpose of optimizing special UT transducers and constructing a protolype operating UT system for inspection of the case weldments. Reference 108 contains additional details on this activity.

\section{EVALUATION OF SHIELDED- METAL ARC WELD METALS DEPOSITED BY OTHER THAN TYPE E316L-15 ELECTRODES}

The unsatisfactory $4 \mathrm{~K}$ tensile and microfissuring results on the $A R C O S 17-15 \mathrm{Cr}-\mathrm{Ni}$ filler metal has resulted in discontinuance of work on this material. Any additional work on other filler metals will be carried out under the evaluation of candidate backup filler metials task previously described. 


\section{REFERENCES}

1. F. H. Coensgen, W. F. Cummins, B. G. Logan, A. W. Molvik, W. E. Nexsen, T. C. Simonen, B. W. Stallard, and W. C. Turner, Phys. Rev. Lett. 35, 1501 (1975).

2. C. D. Henning et al., "Large Superconducting Baseball Magnet-Part II," in Proc. $87 h$ Intl. Cong. of Refrigeration, Washington, D.C., 1971 (Intl. Inst. of Refrigeration, 1971).

3. G. A. Carlson, B. Arlin, W. L. Barr, B. M. Boghosian, J. L. Erickson, J. H. Fink, G. W. Hamilton, B. G. Logan, J. O. Myall, and W. S. Neff, Jr., Tanden Mirror Reactor with Thermal Barriers, Lawrence Livermore National Laboratory, Rept. UCRL-52836 (1979).

4. D. N. Cornish, J. P. Zbasnik, R. L. Leber, D. G. Hirzel, J. E. Johnston, and A. R. Rosdahl, IEEE Trans. Magn. MAG-15: 530 (1979).

5. D. N. Cornish, D. W. Deis, A. R. Harvey, D. G. Hirzel, J. E. Johnston, R. L. Leber, R. L. Nelson, and J. P. Zbasnik, Development Work on Superconducting Coils for a Large Mirror Fusion Test Facility, Lawrence Livernore National Laboratory, Rept. UCRL-7889I (1977).

6. J. W. Ekin, "Fatigue and Stress Efrects in NbTi and $\mathrm{Nb}_{3} \mathrm{Sn}$ Multililamentary Superconductors," Aduances in Cryogenic Engineering. 24, Plenum Press, New York (1977), p. 306.

7. J. H. Van Sant and R. M. Russ, "MFTF Magnet Thermal Control," Advances in Cryogenies Engineering. 25, Plenum Press, New York (1979).

8. Fluid Flon Data Book (General Electric Co., Schenectady, N.Y., 1977).

9. C. D. Henning and E. N. C. Dalder, "Structural Materials for Fusion Magnets," in Trans. Intl. Conf. on Structural Mechanics in Reactor Techmology, 5th Berlin. 1979. (Commission of the European Com. munities and the Nuclear Regulatory Commission, 1979), vol. N.

10. J. W. Wohlwend, C. D. Poniktera, and S. Dharmarajan, Structural Analysis of the Magnet Sywtem for Mirror Fusion Test Facility (MFTF), General Dynamics/Convair, Rept. CASC-LLL-78-003 (1978).

11. H. 1. Muthenry and R. P. Reed, Nutl. Eng. Design (to be published).

12. F. R. Fickett and R. P. Reed, Materials Siudies for Magnetic Fusion Energy Applications a Low Temperatures-LI, National Bureau of Standards, Rept. NBS-1R-79.1609 (1979).

13. C. E. Witherell, Lawrence Livermore National Laboratory, private communication (1979).

17. E. Adams, E. Gregory, and W. Marancik, in Proc. Imt. Conf. on Magnet Technology, oth, Bratislava, Czechoslorakia, 1977.

15. D. F. Neal, A. C. Barber, A. Woolcock, and J. A. F. Gidley, Acta Metall. 19, 143 (1971).

16. R. M. Scanlan, J. E. Johnston, P. A. Waide, B. A. Zeillin, G. B. Smith, and C. T. Nelson. "Manufacturing and Quality Assurance for the MFTF Superconductor Core," in Proc. Symposium on Engineering Problems of Ftrsion Research, 8th, San Francisco, CA, 1979 (ORNL, IEEE, ANS, and DOE, 1979).

17. D. N. Cornish. D. W. Deis, and J. P. Zbasnik, "Cold-Pressure-Welded Joints in Large Multifilamentary Nb-Ti Superconductors," in Proc. Symposium on Engineering Problems of Fusion Research. 7th. Knoxville. TN, 1977 (ORNL, IEEE, ANS, and DOE, 1977); IEEE Publication No. 77CH1267-4-NPS (1978) p. 1266.

18. J. W. Ekin. A. F. Clark, and J. C. Ho, J. Appl. Phys, 49, 3410 (1978).

19. D. W. Deis, MFTF Superconductor Core, Lawrence Livermore National Laboratory, Spec. MEL77001373-D (1979).

20. Wrap Around Flat Pattern, MFTF Square Conductor, Lawrence Livermore National Laboratory, Dwg. AAA78-105238 (1978).

21. D. W. Deis, MFTF Stabilized Superconductor, Lawrence Livermore National Laboratory, Spec. MEL77-001376-B (1978).

22. J. Horvath, Lawrence Livermore National Laboratory, internal memorandum to J. Van Sant. MF-TRI.I.I (June 26, 1979). Readers outside the Laboratory who desire further information on LLNL internal documents should address their inquiries to the Technical Information Department, Lawrence Livermore National Laboratory, Livermore, Califormia 94550. 
23. H. S. Freynik, Jr., D. R. Roach, D. W. Deis, and D. G. Hirzel, Nickel-Chromium Strain Gauges for Cryogenic Stress Analysis of Superconducting Siructures in High Magnetic Fields, Lawrence Livermore National Laboratory, Rept. UCRL-72726 (1977).

24. R. Hintz, Lavrence Livermore National Laboratory, internal memorandum, MF-TR-1.1.2.6.2 (December 18, 1978).

25. R. E. Hinkle, MFTF Coil Winding Procedure, Lawrence Livermore National Laboratory, Spec. MEL78-001432 (1978).

26. Interturn Spacer Sirip, Superconductor Magnet Development. MX Coils, Lawrence Livermore National Laboraiory, Dwg. AAA76-115794 (1976).

27. Perforaled Sheet, MFTF Magnet System 1.I.2.6.2, Coil Insulation, Lawrence Livermore National Laboratory, Dwg. AAA78-110166 (1978).

28. J. Horvath, Lawrence Livermore National Laboratory, internal m:morandum (January 25, 1979).

29. R. Hinkle, Lawrence Livernore National Laboratory, internal :nemorandum to C. Henning (March 30, 1979).

30. J. Horvath, Lawrence Livermore National Laboratory, internal memorindunt to C. Henning (October 16. 1979).

31. R. Hinkle, Latwrence Livermore National Laboralory, internal memorandum to C. Henning (October 15, 1979).

32. T. B. Miller, D. R. Roach, and H. S. Freynik, Jr., Lawrence Livermore Nalional Laboratory, EMS-7948 (October 22, 1979).

33. R. Hinkle, Lawrence Livermore National Latoratory, internal memorandum to C. Henning (September 10, 1979).

34. D. Deis, Lawrenee Livermore National Laboratory, internal memorandum to R. Hinkle, MF-TR1.1.2.6 (May 18, 1978).

35. R. H. Bulmer, Lawrence Livermore National Laboratory, internal memorandum. MF-EN-1.1 (Februatry 3, 1978).

36. S. J. Sackett, EFFI-A Code for Calculating the Electromagnetic Field, Force, and Inductance in Coil Systems of Arbitrary Geometry, Lawrence Livermore National Laboratory, Rept. UCR L-52402 (1978).

37. S. J. Sackelt, EFFI-User's Mamal, Lawrence Livermore Natonal Laboratory, Rept. UCID-1762I (1977).

38. S. J. Sacketi, Calculation of Electromagnetic Fields and Forces in Coil Systems of Arbitrary Geometry, Lawrence Livermore National Laboratory, Rept. UCRL-77244 (1977).

39. J. Horvath, Lawrence Livermore National Laboratory, internai memorandum to R. Hintz (January 23, 1979).

40. J. Horvath, Lawrence Livermore Nutional Laboratory, internal mamorandum to C. Henning. MF-TR1.1.1.2 (Murch 28, 1979).

41. J. Horvath, Liwsence Livermore National Laboratory, internal memorandum to J. Van Sant, MF.TR1.1.2 (May 7, 1979).

42. Siress Analysis of the Coil Form and Coil Mouming Adapter for Laurence Livermore Laboratory"s Mirror Fusion Test Facility, EG\&G, Rept. SRO-226 (1978).

43. Sinturural Siability Analysis for the Mirror Fusion Test Facility (MFTF) Jacket Assembly, General Dynamics-Convair, Rept. GDC-LLL-79-003 (1979).

44. J. Horvath, Lawrence Livermore National Laboratory, internal memorandum to J. Van Sant (August 30, 1978) and to D. Roach and H. Freynik (November 9, 1978), MF-TR-1.1.1.4.

45. J. Horvath, Lawrence Livermore National Laboratory, internal memorandum to $\mathcal{D}$. Cornish, MX-SR1.1.1 (January 18, 1977).

46. J. Horvath, Lawrence Livermore National Laboratory, internal memorandum to V. Kopytoff (February 16, 1978).

47. R. W. Baldi and D. C. Poniktera, Conductor Stress Analysis for the Mirror Fusion Test Facility (MFTF) Magnet System, Gencral Dynamics/Convair, Rept, GDC-LLL-79-001 (1979). 
48. J. Horvath, Lawrence Livermore National Laboratory, internal memorandum to C. Henning (July 27 , 1979).

49. R. C. Ling, Coil Winder, MX Magnet, Lawrence Livermore National Laboratory, Spec. MEL 76001323 (1976).

50. R. C. Ling, "The Coil Winder for the Magnet of the MFTF," in Proc. Symposium on Engineering Problems of Fusion Research. 7th Knoxville. TN, 1977 (ORNL, IEEE, ANS, and DOE. 1977), p. 728; Lawrence Livermore National Laboratory, Rept, UCRL 79744 (I977).

51. R. C. Ling, MFTF Reel Support, Lawrence Livermore National Laboratory, Spec. MEL 77-001342 (1977).

52. R. C. Ling, Y. Chang, and L. D. Hunt, "Reel Support for Winding the MFTF Magnet," in Proc. Symposium on Engineering Problems of Fusion Research. 7th Knoxville, TN, 1977 (ORNL, IEEE, ANS, and DOE. 1977) p. 733; Lawrence Livermore National Laboratory, Rept. UCRL-79747 (1977).

53. D. Deis, Results on MFTF Test+Coil Tum-to-Turn Insulation, Lawrence Livermore National Laboratory, internal menorandum, MX-SR-6.1.2 (April 15, 1977).

54. D. Cornish, Cold-Pressure-Welded Joints in Large Multifilamenlary Nb-Ti Superconductors, Lawrence Livermore National Laboratory, Rept. UCRL-79723 (1977).

55. Coil Mouming Adapter Support, Teledyne, Dwg. 550-011897 (1977).

56. Coil Mounting Adapter, Lawrence Livermore National Laboratory, Dwg. AAA78-105254 (1978).

57. R. E. Hinkie, End Clamp Design, Lawrence Livermore National Laboratory, internal memorandum, MX-ENOL-4 (October 12, 1976).

58. R. E. Hinkle, Side Clamp Design, Lawrence Livermore Nationai Láboratory, internal memorandum, MX-ENOI-3 (October 8, 1976).

59. R. E. Hinkle, Coil Clamp Assembly. Major Radius, Lawrence Livermore National Laboratory, internal memorandum, MX-EN-6.1.2 (January 28, 1977).

60. Experimentol load derived by winding similar layer on test coil Baseball and MFTF practice cuil.

61. Experimental load required to remove $100 \%$ of the winding gap from a section of the conductor between clamps (10 fect).

62. End Clam, Plate, Lawrence Livermore National Laboratory, Dwg. AAA78-117505 (1978).

63. Rourer Guide Assembly, Lawrence Livermore National Laburatory, Dwg. AAA79-107707 (1979).

64. NEMA Standard (Norember 12, 1970).

65. Kapton polyinide, Type H, film propertics, E.I. DuPont de Nenours and Co., Inc., bulletin H.]D.

66. J. Horvath, MFTF Slip Plane Analysis, Lawrence Livermore National Laboratory, internal mcmorandum (October 16, 1979).

67. R. E. Hinkle, Reinforced Joint Stabilizer Design, Lawrence Livermore National Laboratory, internal memorandum (November 13, 1978).

68. MFTF Superconductor Joining Procedure, Lawrence Livermore Nationill Laboratory, Spec. MEL 78001434 (I979).

69. R. Hintz, Magner Work Shop, Lawrence Livermore National Laboratory, (July 1979).

70. Instrumentation Plan for MFTF, General Dynamics/Convair, Rept. CAS-LLL-78-005 (1979).

71. Instrumentation Installation, Lawrence Livermore National Laboratory, Dwg. AA79-101290 (1979).

72. R. F. O'Neill and D. H. Reimer, Thermodynamic Analysis of the Magner System for Mirror Fusion Test Facility, General Dynamics, Rept. CASD-LLL-78-002 (1978).

73. R. F. O'Neill, MFTF Superconducting Magnet Cooldown and Wamup Revised Thermal Analysis, General Dynamics, Rept. 696-0-T-79-49I (1979).

74. Handbook on Materials for Superconducting Machinery, Battelle Memorial Institute, Rept. MCIC-HB04 (1977), p. 5.1.3-12 (1976).

75. Thermophysical Properties of Helium-4 from 4 to $3000 \mathrm{R}$ with Pressures 10 IS, O60 psia., National Bureau of Standards. Technical Note 622 (1972).

76. M. B. Kasen, Properies of Filamentary-Reinforced Composites at Cryogenic Temperatures, ASTM STP 580 (1975). 
77. 304L Stainless Steel Thermal Conductivity, Ref. 90 (1974) p. 8.1.2-7.

78. R. W, Jennings, Thermophlysical Properties of Selected Materials, General Dynamics/Convair, Rept. 966-3-CHM-66-002 (1966). This Convair internal reference was employed for $316 \mathrm{~L}$ stainless steel thermal conductivity and for 316 and $340 \mathrm{~L}$ stainless steel specific heat. It was also employed for a best estimate of G-10 specifie heat.

79. R. F. O'Neill and E. R. Neuharth, Convair Thermal Analyzer Computer Progran No. P4560, General Dynamics/Convair, Rept. GDC-BTD69-005A (1969).

80. Intermagnetic General Corporation, Quench Detection and Magnets Protection Study, Lawrence Livermore National Laboratory, Rept. UCRL-15097 (1979).

81. E. W. Owen. Currents and Voltages in the MFTF Coils During the Formation of a Normal Zone. Lawrence Livermore National Laboratory, Rept. UCID-184\%) (1980).

82. E. W. Owen, Detection of a Normal Zone in the MFTF Magnets, Lawrence Livernore National Laboratory, Rept. UCID-18309 (1979).

83. K. R. Loss and J. W. Wohlwend, Structural Analysis of the Magnet System for Mirror Fusion Test Facility (MFTF), Addendum I, General Dynamics/Convair, Rept. CASD-LLL-78-003 (Addendum 1) (1979).

84. R. W. Baldi and D. E. Poniktera, Case Fawh Analysis for the Mirror Fusion Test Facility (MFTF) Magnet System, General Dynamics/Convair, Rept. CASD-LLL-79-002 (1979).

85. K. Tada, The Siress Analysis of Cracks Handbook, Del Research Corporation (1973).

86. D. Read and S. Dharmarjjan, Material Property Data, 304LN amd 3/6L Filler. Teletan Record of Conversation between Dr. Read (NBS Boulder) and Dr. Dharmarajan (GDC), internal memorandun , MFTF-T-2000-040 (June 28, 1978).

87. J. M. Wells, W. A. Logsdon, and R. Kossowsky, "Evaluation of Weldments in Austenitic Stainless Steels for Cryogenic Applications," presented at the Inl. Cryogenici Materials Conference, Botder. Colorado, 1977 (Westinghouse Research Laboratory, Scientific paper, 77-9D9-CR YMT-Ps).

88. C. E. Witherell, Welding Inner and Outer $M X$ Magnet Cases, Lawrence Livermore National Laboratory, interdepartmental communication to J. N. Doggett (October 7, 1976).

89. C. E. Witherell, Welding Outer Case for MFTF Magnet, Lawrence Livermore National Laboratory, interdepartmental communication to R. H. Butler (January 18, 1978).

90. R. H. Espey, "Weldability of 21-6-9 Stainless Sted," in Materials Sndies for Magnetic Fusion Energy" Applicarions al Low Temperanures - I" National Bureau of Standards, Rept. NBS-IR 78-884, (1978) pp. 169-177.

91. Joining Humington Alloys, Huntington Alloy Products Division, International Nickel Company, Inc. (1972) pp. 36-39.

92. C. E. Witherell, Lawrence Livermore National Laboratory, intea departmental communication to R. H. Bulmer (February 10, 1978).

93. R. R. Vandervoort and C. E. Witherell, Lawrence Livermore National Laboratory, interdepartmental communication to V. Kopytoff (May 8, 1978).

94. R. R. Vandervoort, "Mechanical Properties of Inconel 625 Welds in 21-6-9 Stainless Stecl at 4 K." Cryogenics, 448 (1979).

95. Siandard Test Method jor Plain-Strain Fracture-Toughmess of Metallic Materials, American Society for Testing Materials, Rept. ASTM-E-399-74 (1974) Sec. 7.1.1.

96. A. B. Crichten, J. R. Crisci, N. A. Freytag, V. Hasken, R. B. Hitchcock, and G. P. Yanok, "Gas-Metal Arc Welding," in Welding Handbook (American Welding Society, 1978) 7th ed., vol. 2, pp. 114-152.

97. C. E. Witherell, Lawrence Livermore National Laboratory, interdepartment communications (February 13, 1979).

98. O. W. Seth, Lawrence Livermore National Laboratory, private communication to E. Dalder (February 9, 1979).

99. O. W. Seth, Lawrence Livermore National Laboratory, private communication to C. E. Witherell (Frhruary 20, 1979). 
100. A. Bachmann and B. L. Lundquist, "Properties of a Fully Austenitic Stainless Steel Welủ Metal for Severe Corrosion Environments," Welding Journal 56, 230 (1977).

101. H. I. McHenry, D. T. Read, and P. A. Steinmeyer, "Evaluation of Stainless Steel Weld Metals at Cryogenic Temperatures," in Materials Studies for Magnetic Fusion Energy Applications at Low Temperature - II National Bureau of Standards, Rept. NBS-IR-79-1609 (1979) pp. 299-312.

102. T. A. Whipple. "Mechanical Properties of Stainless Steel Weldments at Cryogenic Temperatures," presented at the NBS-DOE Workshop on Materials at Low Temperatures, Vail, Colorado, 1979.

103. General Dynanics-Convair, private communication, July 1979.

104. R. J. Castro and J. J. deCadenet, Welding Metallurgy of Stainless and Heat-Resisting Steels, (Cambridge University Press, New York, 1975) pp. 82-134.

105. C. D. Lundin and D. R. Spond, The Ferrite-Fissuring Relationship in Austenitic Stainless Steel Weld Mctals, Welding Rescarch Council, University of Tennessee, Knoxville, TN, Final Report (1975).

106. T. G. Gooch and J. Honeycombe, Microcracking in Fully Austenitic Stainless Steel Weld Metal: Overall Assessment of the Welding Institute Investigation, The Welding Institute, Rept. M/73/73 (1973).

107. J. Honeycombe and T. G. Gooch, The Effect of Microcracks Upon the Mechanical Properties of A ustenitic Stainless Steel Weld Metals, The Welding Institute, Rept. M/69/72 (1972).

108. E. Dalder. private communication to C. D. Henning (December 7, 1979). 